\title{
PASIFIKA TERTIARY STUDENTS' USE OF INFORMATION AND COMMUNICATION TECHNOLOGIES
}

\author{
by \\ Kerese Tuifaktoga Manueli
}

\author{
A thesis \\ submitted to the Victoria University of Wellington \\ in fulfilment of the requirements for the degree of \\ Doctor of Philosophy \\ in Education
}

Victoria University of Wellington

2012 


\section{ABSTRACT}

Information and Communication Technologies (ICT) are pervasive in our daily lives. In New Zealand tertiary education institutions, the adoption of ICT is widespread. Meanwhile, Pasifika students' participation in tertiary education has been increasing. Yet, for this group of students, academic success has been a concern to successive governments, tertiary institutions, and Pasifika peoples. ICT may offer an opportunity to improve Pasifika students' academic achievement.

The study is premised on the belief that positive learning experiences will lead to improved academic outcomes. Consequently, the study explored ways of using ICT to enhance Pasifika students' learning experiences. Adopting an interpretivist approach, the case study investigated the ICT skills and the use of ICT for learning enhancements of a group of Pasifika students at a New Zealand institute of technology. Over a period of eighteen months, data was gathered through talanoa, participant observation, and the researcher's reflective journal. The three method approach enabled data triangulation. Data analysis adhered to the theoretical propositions of the study.

Among the key findings, is the disturbing realization that Pasifika students' ICT skill levels were not at the level assumed by the institution. The main uses of ICT by the Pasifika students in this study were for personal communication and entertainment. The students' use of ICT for educational purposes was limited due to the mismatch of their ICT skills and those required by the institution. Inadvertently, this has further disadvantaged the students' learning experiences.

The study concludes by offering an ICT skills development framework for use with Pasifika students. Moreover, the study proposes a number of recommendations for practice, policy, and further research. 


\title{
ACKNOWLEDGEMENT
}

\author{
Hiạ' rā heta ma hiạ' la fa' \\ (Rotuman proverb)
}

The proverb hia' rā heta ma hia' la fa' was reiterated by my late father, Rev. Aisake Manueli, when I embarked on my undergraduate degree. This proverb is used by Rotumans to challenge one another to complete a given task and not to leave it half done. A literal translation of the proverb is "keep pressing the branch until it breaks" (Inia, 1998, p.31).

I pay homage to my extended family - past and present.

Many people have helped me weave the infinite threads of my thinking towards this momentous milestone. I am indebted to you all and please forgive me if I omit your names. You have been a huge part of my PhD journey. Thank you.

A hearty ua'ua'ạki to my primary supervisor, Associate Professor Kabini Sanga, and my secondary supervisor, Dr Cherie Chu, for your outstanding academic and moral support. You are inspirational academics and visionary leaders. I have learnt and developed immensely under your guidance.

Fa'afetai, malo 'aupito, vinaka vakalevu, ko rabwa, meitaki ma'ata, and thank you to the participants who contributed to this study. I hope that you were enriched as much as I have through our talanoa and I wish you well in your future endeavours.

I must acknowledge the support of the Pacific Leadership Cluster members throughout my PhD journey. I thoroughly enjoyed the experience, support and the words of encouragement.

To my work colleagues - thank you lan Hunter for your support and understanding; Leonie and Michele for your caring words and jokes; Rhys, Todd, Paul, Steve, lan Armstrong, Andrew, Mariki, Nick, John and Anthony for the occasional chats; Terry for the 'keep fit advice' and the brisk walks around the block; Aristotle and Jeff for the networking assistance. 
Faka fetai Aleki for your moral support, sound advice and always available for a talatalanoa. Your calm, sagacious, humorous disposition and 'can do' attitude had always been invigorating when everything seemed impossible. Faieksia.

Noa'ia Saga'itu and Losa for the moral and emotional support. This one is for the Aisake and Maria clan.

Last but not the least, are the three adorable people in my life: Sela, you are everything to me. Words cannot fully express how much your love, support, and persistence had kept me going during this journey. I truly owe you big time. Thank you Doris and Merllissia for being there! Your smart comments, jokes and sometimes irritating behaviour often keep me sane.

Hanis on Gagaja la pärea isa.

$$
\text { In memory of my parents }
$$

Rev. Aisake Manueli and Maria Suamoto 


\section{ATTESTATION OF AUTHORSHIP}

I, Kerese Tuifatoga Manueli, hereby declare that this thesis is my own work and that, to the best of my knowledge and belief, it contains no material previously published or written by another individual (except where explicitly acknowledged), no material which to a substantial extent has been submitted for the award of any other degree or diploma of a university or other higher education institution. 


\section{TABLE OF CONTENTS}

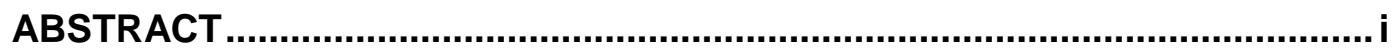

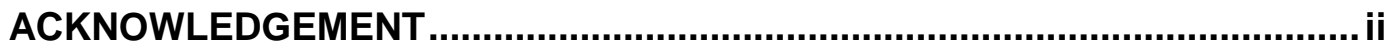

ATTESTATION OF AUTHORSHIP ............................................................ iv

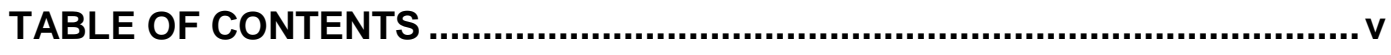

LIST OF FIGURES ................................................................................

LIST OF ACRONYMS ............................................................................. xii

GLOSSARY ........................................................................................... Xiii

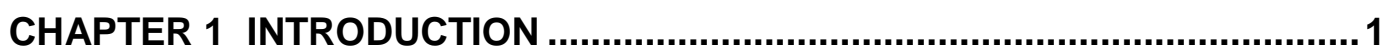

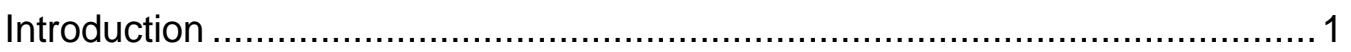

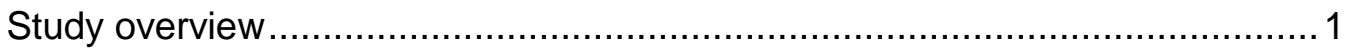

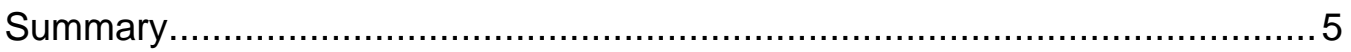

CHAPTER 2 BACKGROUND AND RATIONALE ......................................... 6

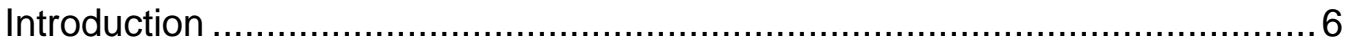

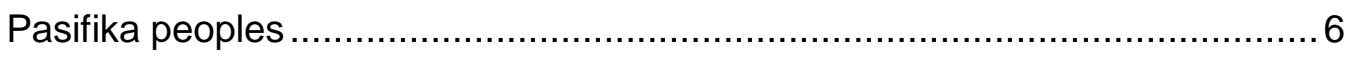

Tertiary Education Participation............................................................. 8

Pasifika Students at WelTec................................................................ 10

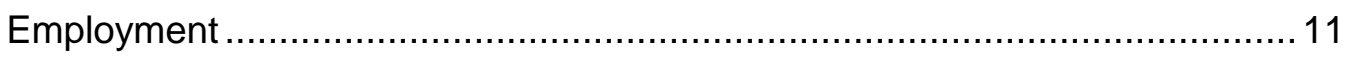

Literacy and Numeracy ....................................................................... 12

Information and Communication Technologies (ICT) .................................. 13

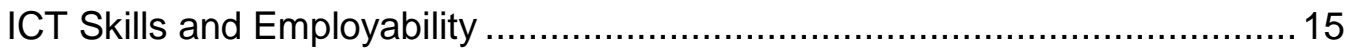

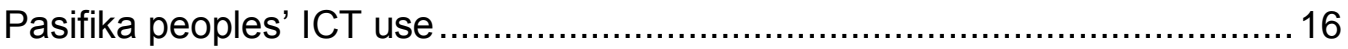

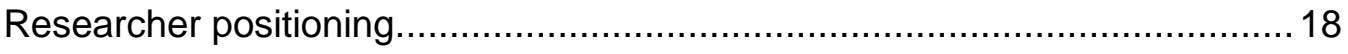

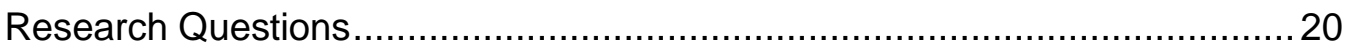

Significance of the research ............................................................. 20

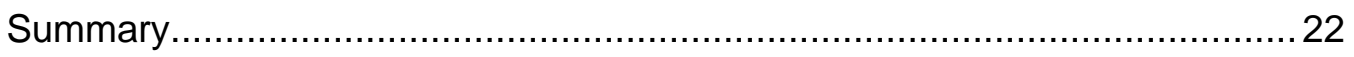

CHAPTER 3 LITERATURE REVIEW ...................................................... 23

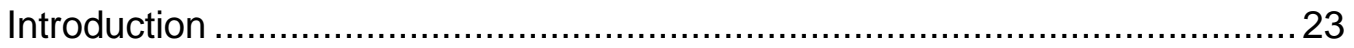

ICT in New Zealand Tertiary Education Sector ...........................................23

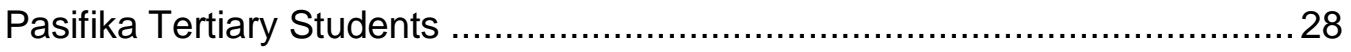

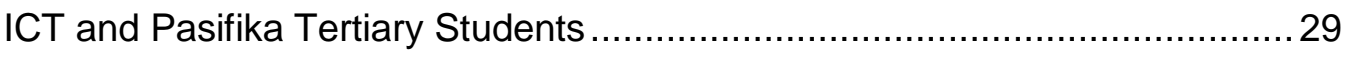

Systems Development Life Cycle (SDLC) ….......................................... 31

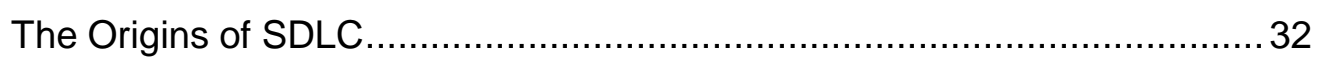

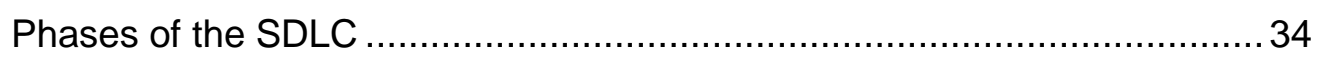

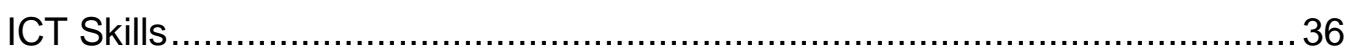

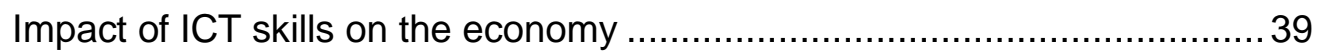

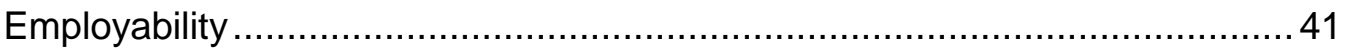




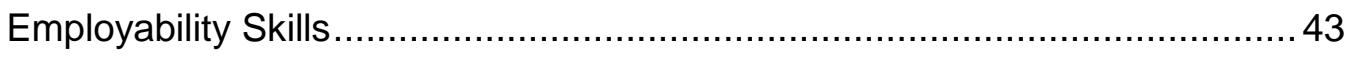

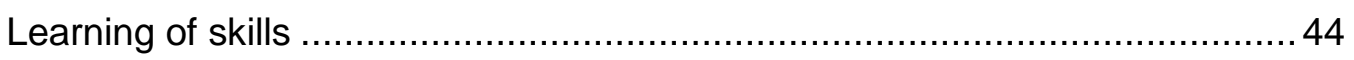

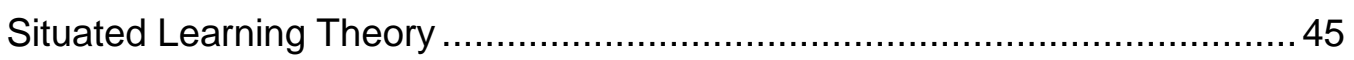

Pasifika Students' Learning Styles ..................................................... 48

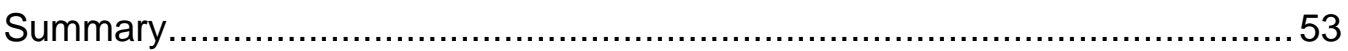

CHAPTER 4 INTERNATIONAL STUDIES ON ICT-SUPPORTED LEARNING 54

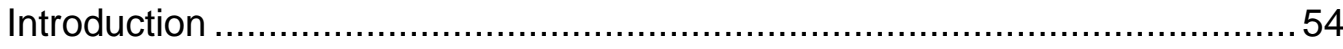

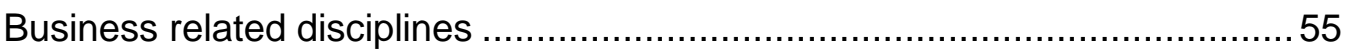

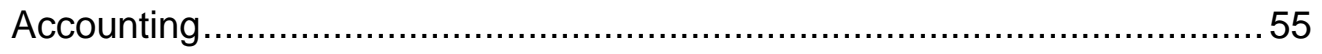

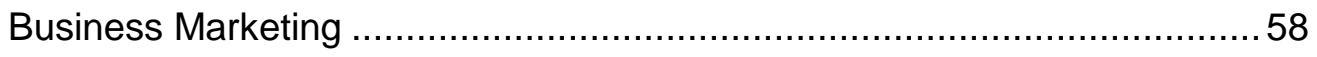

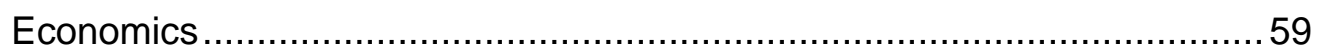

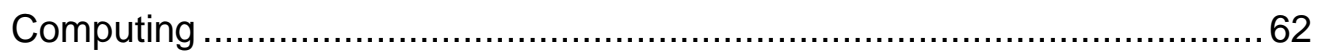

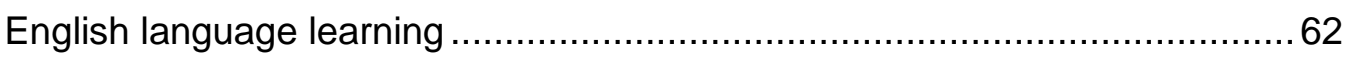

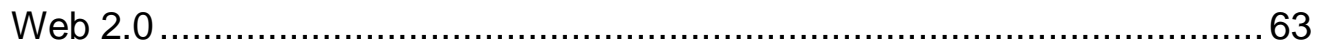

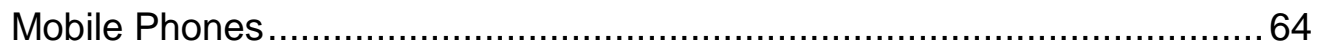

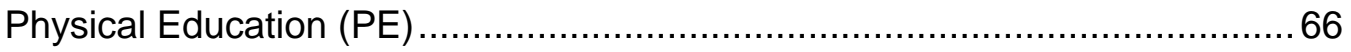

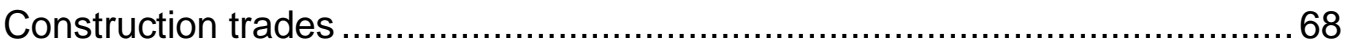

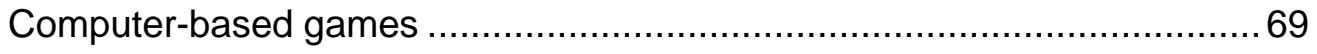

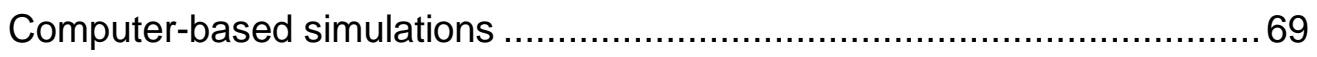

Information Technology (IT) and Computer Science (CS) ........................... 70

Reasons for attrition............................................................................ 71

Factors that influence persistence ….............................................. 72

Computer-based animation...................................................................... 73

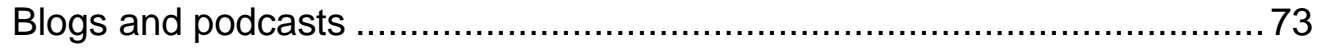

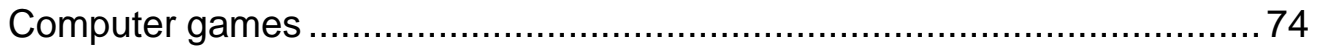

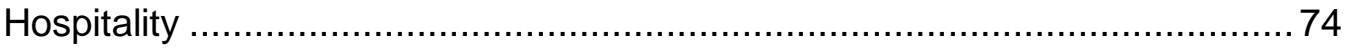

Use of ICT in the Hospitality Industry ............................................... 74

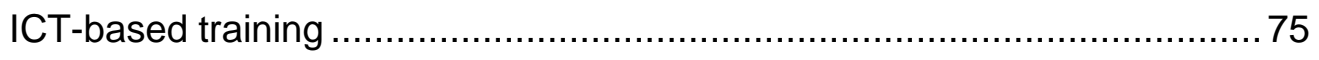

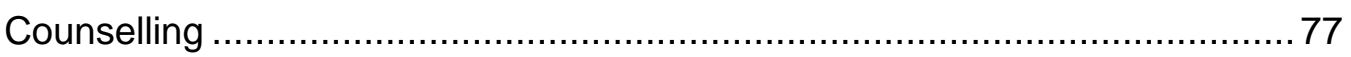

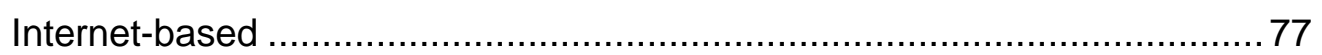

Computer assisted instruction .............................................................. 78

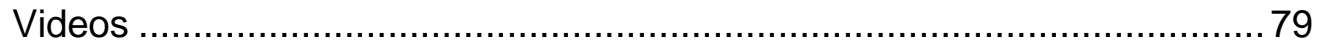

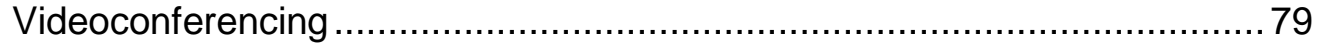

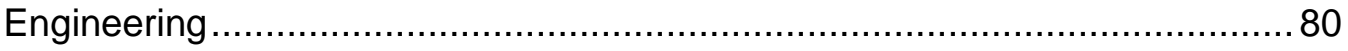

Computer animations, simulations and games........................................ 80

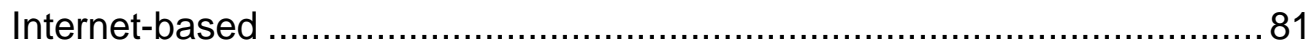

Self-efficacy of first year engineering students ................................... 82

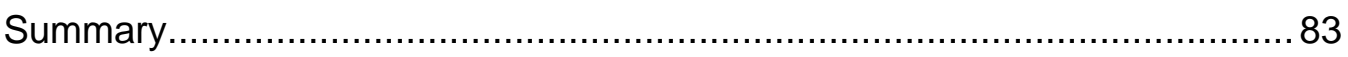




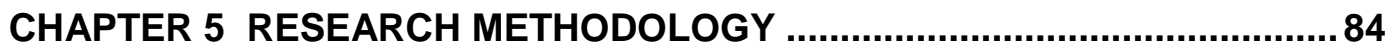

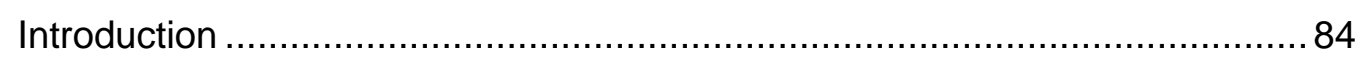

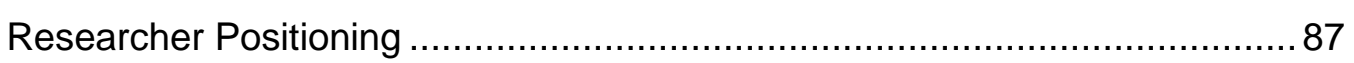

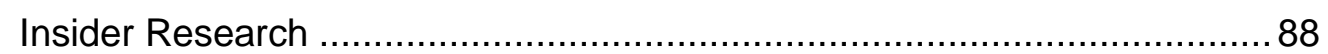

Sometimes an Insider, Sometimes an Outsider ..................................... 89

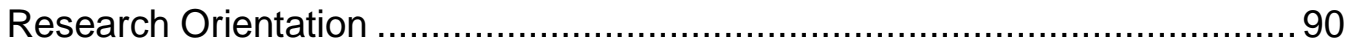

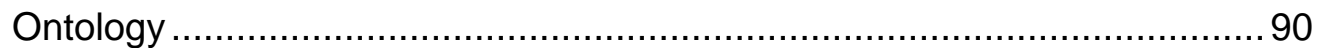

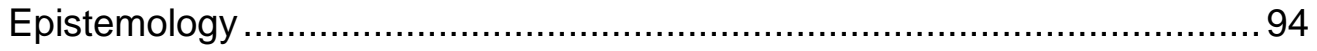

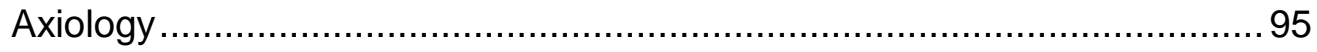

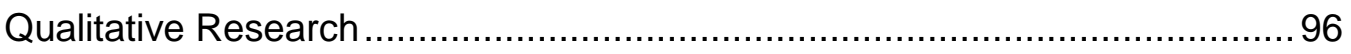

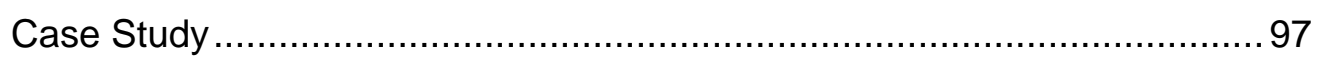

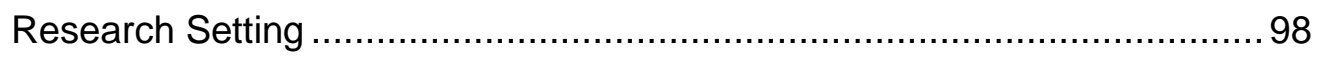

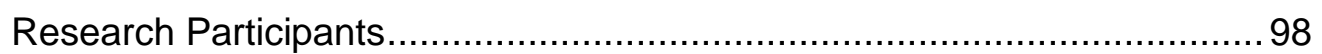

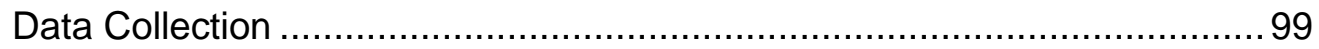

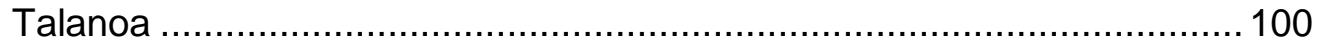

Participant Observation ..................................................................... 107

Researcher's Reflective Journal .................................................... 107

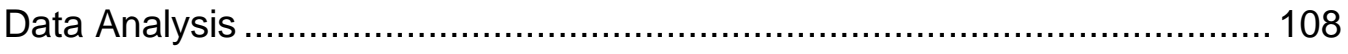

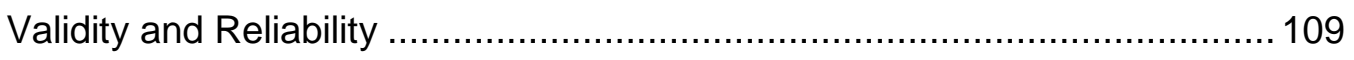

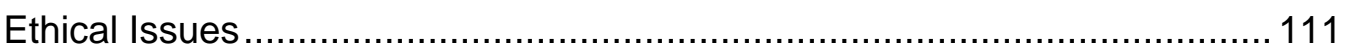

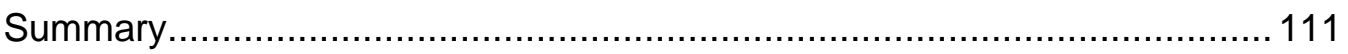

CHAPTER 6 THE FINDINGS ...................................................................112

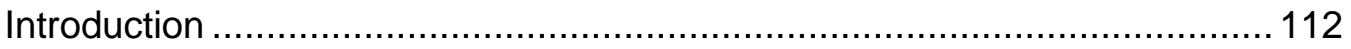

Pasifika Tertiary Students' ICT Skills Development Framework ..................112

Motivations for the Use of the SDLC ...................................................... 113

Phase 1 - Measure Current ICT Skills Level of Participants........................ 114

Unit Standard 2780 (US 2780)............................................................ 117

Unit Standard 2781 (US 2781) ...................................................... 121

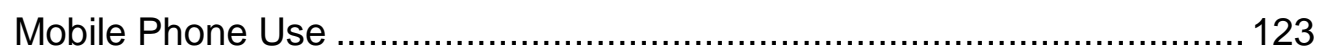

Use of Mobile Phone to Support Learning ......................................... 124

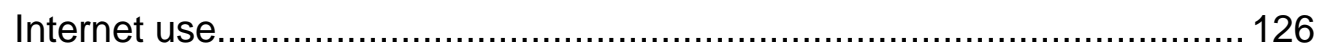

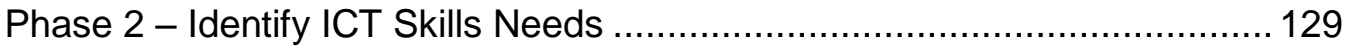

Business Studies ........................................................................... 130

English for Speakers of Other Languages (ESOL) ................................ 131

Exercise Science, Construction Trades, and Hospitality ......................... 132

Counselling \& Alcohol and Drug Studies (CADS) ................................. 132

Information Technology (IT) and Engineering .................................... 133

Phase 3 - Analyse Gaps ............................................................... 133 


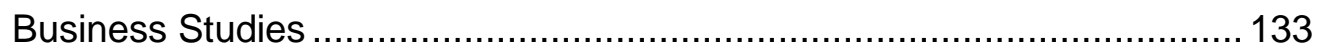

English for Speakers of Other Languages (ESOL) .............................. 135

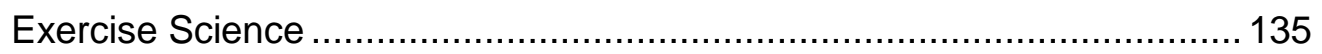

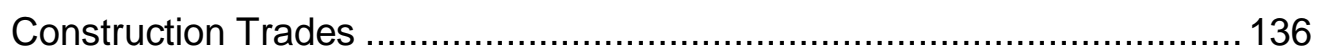

Information Technology (IT) f........................................................ 137

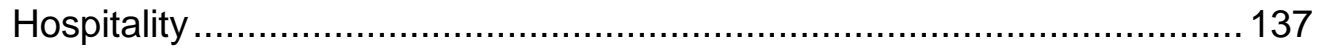

Counselling \& Alcohol and Drug Studies............................................ 138

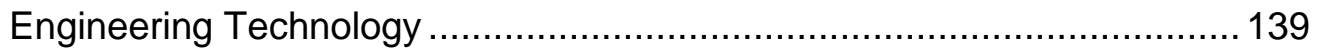

Phase 4 - Developing Strategies to Enhance Participants' ICT skills ........... 139

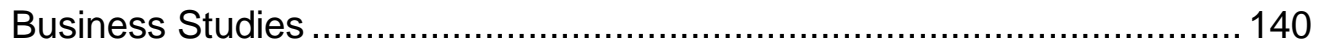

English for Speakers of Other Languages (ESOL) ............................... 142

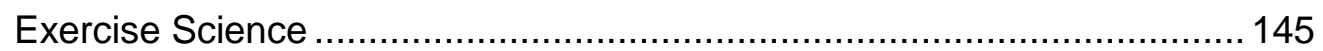

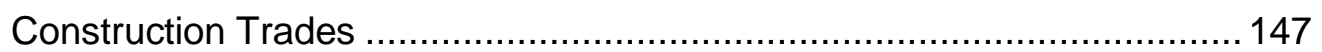

Information Technology (IT) ........................................................... 148

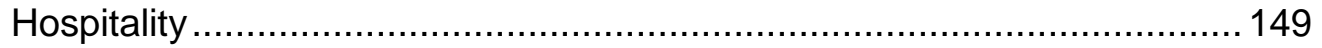

Counselling \& Alcohol and Drug Studies............................................. 149

Phase 5 - Implement Strategies ....................................................... 150

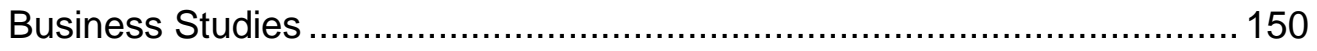

English for Speakers of Other Languages (ESOL) ............................... 153

Exercise Science ........................................................................... 154

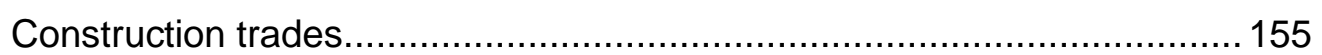

Information Technology (IT) ......................................................... 156

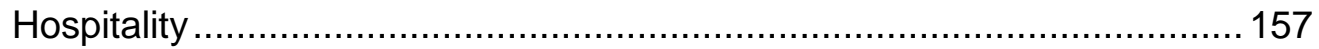

Counselling \& Alcohol and Drug Studies (CADS) ................................. 158

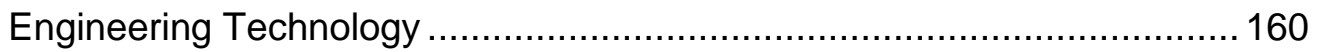

Phase 6 - Monitoring and Evaluation of Strategies .................................. 160

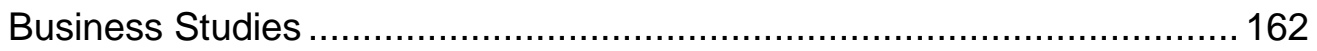

English for Speakers of Other Languages (ESOL) ............................... 163

Exercise Science .............................................................................. 164

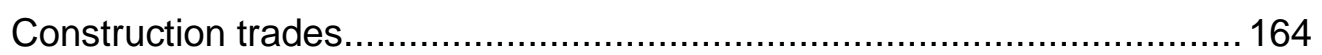

Information Technology (IT) ............................................................ 166

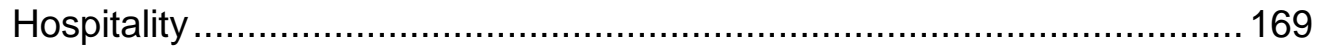

Counselling \& Alcohol and Drug Studies (CADS) ................................ 171

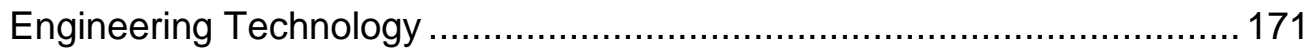

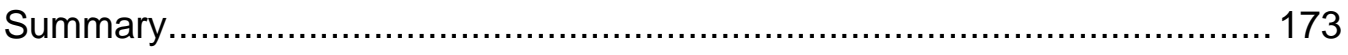

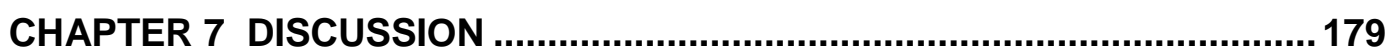

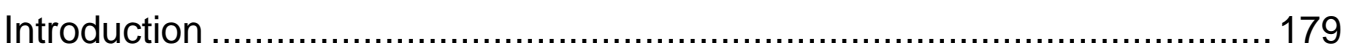

Significance of Talanoa in this study ................................................ 179 
What are some barriers to Pasifika students acquiring ICT Skills? 180

Lack of interest in using ICT

Limited ICT access

Lack of awareness of ICT potentialities. 183

Lack of foundation or basic skills 184

Computer phobia .185

Participants' age 186

Past work experiences. 186

What are some factors that support Pasifika students in acquiring ICT Skills?

Prior learning experience 187

Prior work experience 188

Peer and family network support. 189

Self-efficacy 190

What are some ICT skills that would enhance Pasifika students' learning experience? 191

Business Studies 192

Exercise Science 197

Construction Trades 199

Information Technology (IT) ..................................................... 200

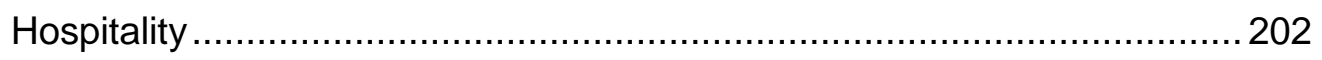

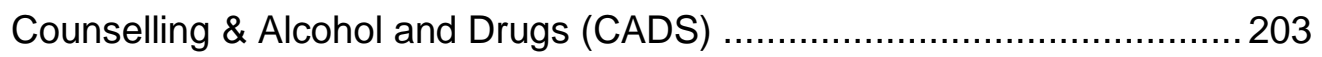

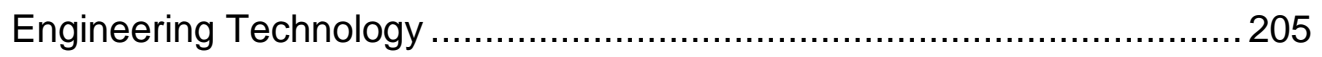

Pasifika Students' ICT Skills Development Framework .............................. 206

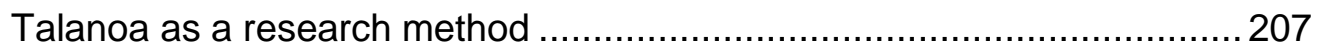

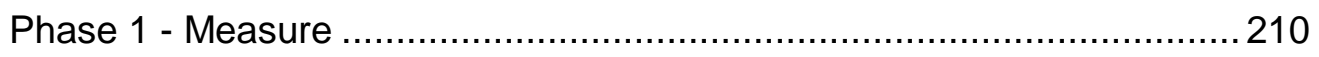

Phase 2 - Identify Needs............................................................... 210

Phase 3 - Analyse Gaps .............................................................. 211

Phase 4 - Develop Strategies ...................................................... 211

Phase 5 - Implement Strategies ....................................................... 211

Phase 6 - Monitor and Evaluate ..........................................................2 212

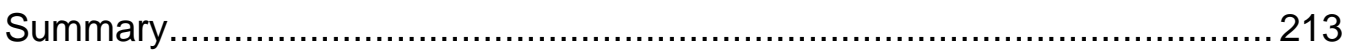

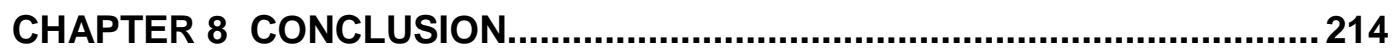

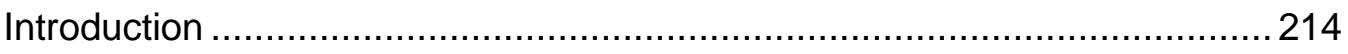

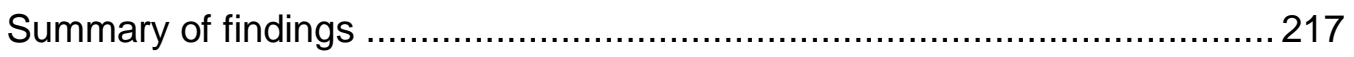

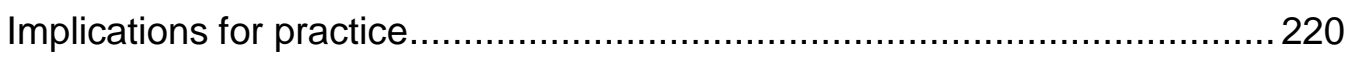

Implications for institutional policy .................................................... 221

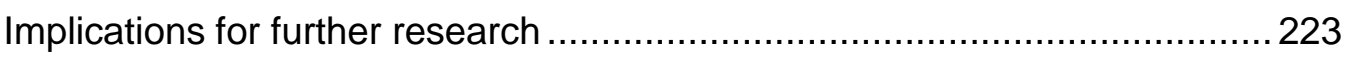




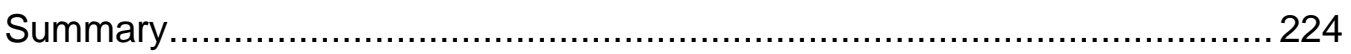

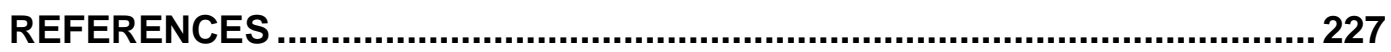

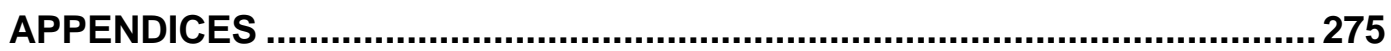

Appendix I - Ethics Approval............................................................. 275

Appendix II - Introductory Letter ........................................................... 276

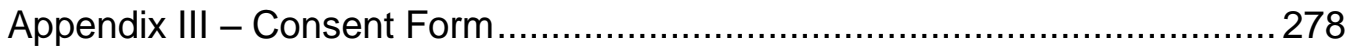

Appendix IV - Participant Observation Template .....................................2279

Appendix V - Template for Reflective Journal.......................................280 


\section{LIST OF FIGURES}

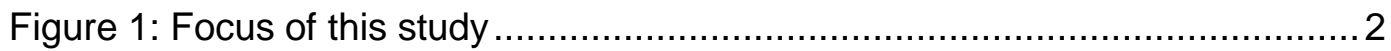

Figure 2: Pasifika students' ICT skills development framework .......................... 4

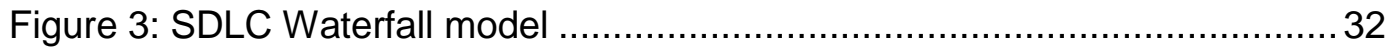

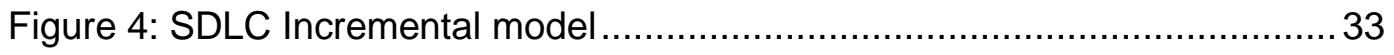

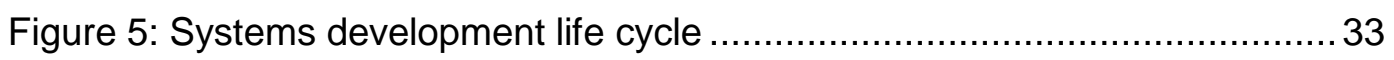

Figure 6: Pasifika Tertiary Students' ICT Skills Development Framework ...........36

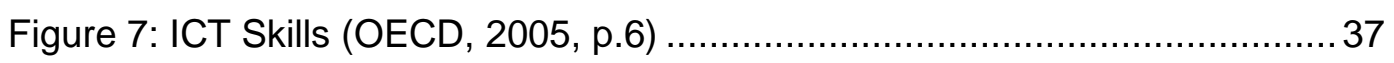

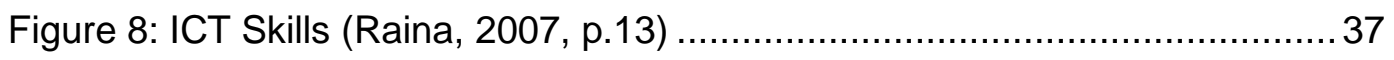

Figure 9: Learning of skills (Wenger, 1998, p.5)......................................... 45

Figure 10: Pasifika Students' ICT Skills Development Framework ...................113

Figure 11: Common personal computer hardware peripherals .......................117

Figure 12: Hardware components that can be found inside the system unit of a

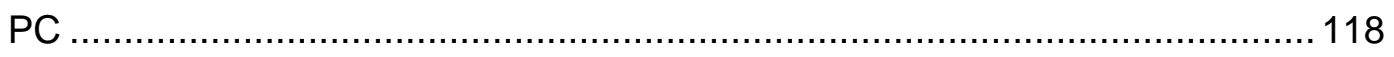

Figure 13: Back view of a PC's system unit showing colour coded connectors 121

Figure 14: Screenshot of MYOB video tutorial on Youtube website ................. 142

Figure 15: Screenshot of the ESL article used for reading practice .................. 144

Figure 16: Screenshot of ESOL video on Youtube website ............................. 145

Figure 17: Respiratory system (EduMission, 2011) ..................................... 146

Figure 18: Screenshots of four Youtube videos explaining the respiratory system

Figure 19: View of the inside of the computer system unit ............................ 151

Figure 20: Screenshot of a sample video to be created by the participants...... 152

Figure 21: Screenshot of a sample spreadsheet used with the Trade participants 155

Figure 22: Screenshot of the Google search box ..................................... 158

Figure 23: Screenshot of the university library search catalogues.................... 159

Figure 24: Secreenshot of the IncyWincy website ...................................... 166

Figure 25: Computer keyboard layout showing the Ctrl keys ......................... 185

Figure 26: Pasifika Students' ICT Skills Development Framework ...................210

Figure 27: Increased ICT skill levels of Pasifika learners ..............................215 


\section{LIST OF ACRONYMS}

The following acronyms have been used throughout the thesis.

$\begin{array}{ll}\text { ALL } & \text { Adult Life and Literacy } \\ \text { CAI } & \text { Computer Assisted Instruction } \\ \text { CBE } & \text { Computer Based Education } \\ \text { CBL } & \text { Computer Based Learning } \\ \text { CMI } & \text { Computer Managed Instruction } \\ \text { ESL } & \text { English as a Second Language } \\ \text { ESOL } & \text { English for Speakers of Other Languages } \\ \text { GTE } & \text { Government Training Establishment } \\ \text { IBM } & \text { International Business Machines } \\ \text { ICT } & \text { Information and Communication Technologies } \\ \text { ITP } & \text { Institute of Technology and Polytechnics } \\ \text { LMS } & \text { Learning Management System } \\ \text { MS } & \text { Microsoft } \\ \text { NZ } & \text { New Zealand } \\ \text { NZQA } & \text { New Zealand Qualifications Authority } \\ \text { NZQF } & \text { New Zealand Qualifications Framework } \\ \text { PE } & \text { Physical Education } \\ \text { PISA } & \text { Programme for International Student Assessment } \\ \text { PTE } & \text { Private Training Establishment } \\ \text { SDLC } & \text { Systems Development Life Cycle } \\ \text { TEC } & \text { Tertiary Education Commission } \\ \text { UK } & \text { United Kingdom } \\ \text { US } & \text { Unit Standard } \\ \text { USA } & \text { United States of America } \\ \text { VOIP } & \text { Voice Over the Internet Protocol } \\ \text { WWW } & \text { World Wide Web } \\ & \end{array}$




\section{GLOSSARY}

\section{Blog}

Derived from the two words we $\underline{b}$ and log; it is a website where a user or users can post information, opinions, and other digital presentations organised in reverse chronological order

\section{E-learning}

Electronic learning (e-learning) refers to the use of ICT to support the teaching and learning process

\section{Employability}

An individual's ability to gain employment.

\section{Formal education}

Learning that is organised formally by a recognised organisation which is assessed and contributes towards a formal qualification.

\section{ICT skills}

Skills required for using ICT to access, manage, integrate, evaluate, and make decisions in order to function in a knowledge society.

\section{Informal education}

Learning that takes place outside the realm of formal education.

\section{Information Technology (IT)}

Computer-based technology that enables the creation, storing, and retrieval of the information.

\section{Information and Communication Technonologies (ICT)}

Umbrella term that refers to digital and computer based technologies that are used to communicate, create, disseminate, store, and manage information. Examples used in this study include private computer networks, internet, computers, mobile phones, and portable hand-held communication devices. 


\section{New Zealand Qualifications Framework (NZQF)}

Governing body that ensures that New Zealand qualifications are credible and robust, ensuring that learners are successful in their chosen endeavours.

\section{Pasifika peoples}

A multi-ethnic and heterogenous group of people who self-identify with Pacific Island nations through ancestry or heritage.

\section{Private Training Establishment (PTE)}

Post-school education providers in New Zealand that offer specialised courses and qualifications.

\section{Talanoa}

A qualitative, ecological and oral research method for research involving Pasifika peoples.

\section{Unit Standard (US)}

A unit standard (US) registered on the New Zealand Qualifications Framework (NZQF) that describes what a learner needs to know or what the learner must be able to achieve.

Wiki

An online collaborative writing tool; it is a web site where users can add and edit online content.

\section{Wananga}

A "teaching and research institution that maintain, advance, and disseminate knowledge, develop intellectual independence, and assist the application of knowledge regarding ahuatanga Maori, [Maori tradition] according to tikanga maori [Maori custom]" (Ministry of Education, 1998, p.11). 


\title{
CHAPTER 1
}

\author{
INTRODUCTION \\ "The pessimist complains about the wind; \\ The optimist expects it to change; \\ The realist adjusts the sails." \\ (Ward, cited in Borysenko, 2009, p.25)
}

\section{Introduction}

In this introductory chapter, an overview of the study is presented. Beginning with a brief statement on the study focus, this chapter offers a chapter-by-chapter overview; and ends with a summary.

\section{Study overview}

Information and Communication Technologies (ICT) are pervasive in our daily lives. ICT has been at the forefront of the $21^{\text {st }}$ century advancements in businesses, governments, and individual activities. ICT has been promoted as tools of modern societies (Wikan \& Molester, 2011) and it has created new opportunities in the education sector. The use of computers and internet-based technologies is widespread in New Zealand tertiary institutions. ICT is utilised to reduce operational costs and to achieve effective course delivery (Krishnaveni \& Meenakumari, 2010). This approach assumes that all students have the relevant skills to use ICT to access the online information, learning resources and also to participate in the online learning forums.

This study explores Pasifika tertiary students' ICT skills and how ICT can be utilised to enhance their learning experiences. For the purpose of this study, learning encounters include both formal and informal ways of learning. Formal learning include all learning activities formally organised by a tertiary institution which includes lectures, tutorials, and computer laboratory work or workshop learning experiences for the trades and kitchen work for the cooking courses. Informal learning experiences refer to all learning experiences not included in the formal learning context. 
Participation of Pasifika students at tertiary education has been growing in the past decade. In 2009, Pasifika students comprised $7 \%$ of the New Zealand tertiary student body (Wensvoort, 2011). While the increasing participation is encouraging, the academic outcomes for students require further work.

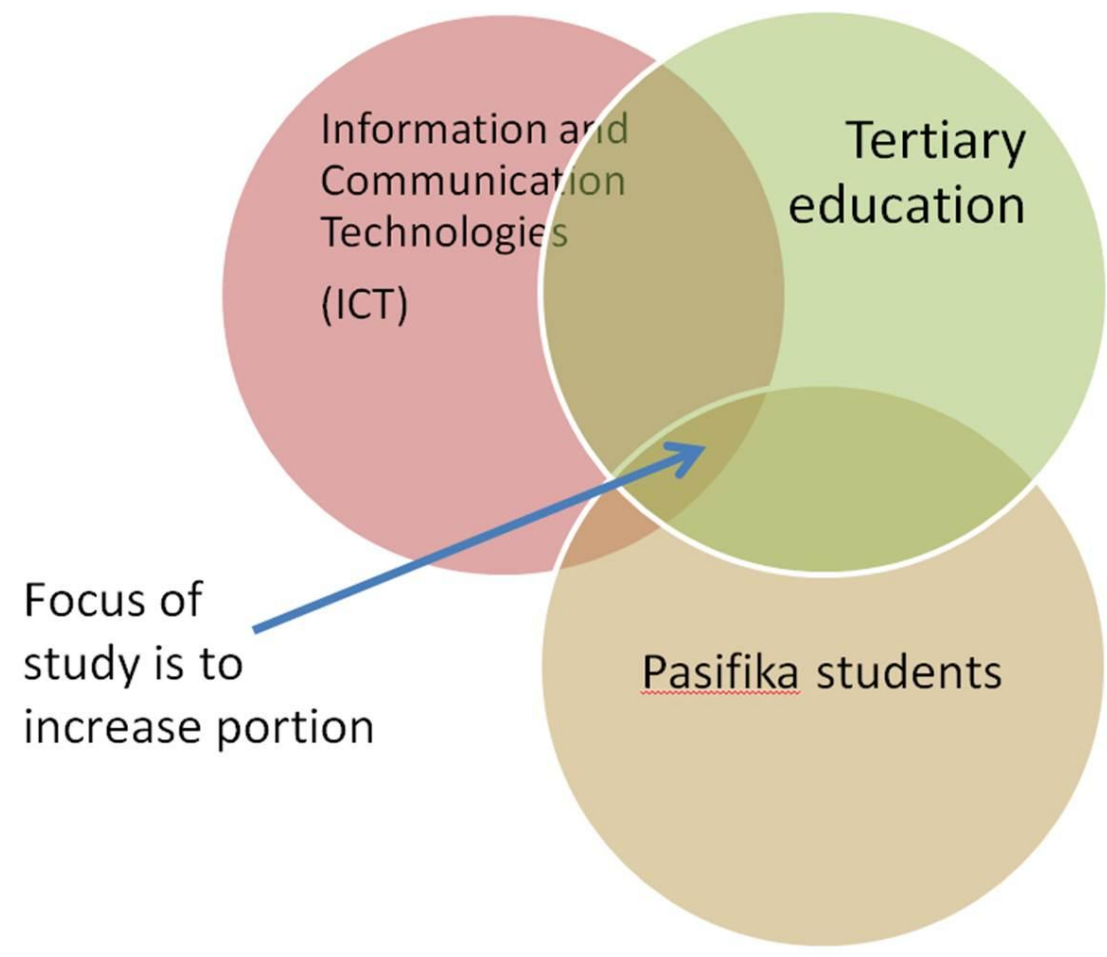

Figure 1: Focus of this study

An objective of this study was to improve the ICT skills of Pasifika tertiary students based on the premise that higher ICT skills may enhance their learning experiences. It is argued that improving the students' learning experiences will contribute to improved educational outcomes. The researcher aspired to influence Pasifika tertiary students to become "the realist [that] adjusts the sails" (Ward, cited in Borysenko, 2009, p.25) in order to sail smoothly in today's digital ocean. Figure 1 shows the conceptual area of focus for this study. The figure is not drawn to scale but it is intended to highlight the small portion where the three spheres of Pasifika students, tertiary education and ICT overlap. Tertiary institutions in New Zealand are increasing their use of ICT while Pasifika students' tertiary participation is increasing. The question is "how do we ensure that Pasifika students are not further disadvantaged with ICT being utilised in tertiary education delivery?"

Chapter two presents the research background and rationale. It offers a definition for the label Pasifika, history of settlement, and demographics of Pasifika peoples. In line with the focus of this study, the participation of Pasifika 
peoples at tertiary level is presented. A goal of tertiary education is employment and therefore the employment history of Pasifika peoples is outlined. Associated with employment is the critical requirement of literacy and numeracy. The two are inseparable - high literacy and numeracy leads to greater employment opportunities. Conversely, low literacy and numeracy leads to fewer employment opportunities. While Pasifika peoples feature highly in unemployment statistics, lack of literacy and numeracy skills have been contributing factors that have plagued those that work hard but cannot get past the manual labour occupations. As stated earlier, ICT may offer Pasifika peoples an opportunity to become "the realist [that] adjusts the sails" (Ward, cited in Borysenko, 2009, p.25). Statistics on Pasifika peoples use of ICT as gathered by Statistics New Zealand is presented. This study argues that increasing ICT skills within this group present the possibility of increased employment opportunities. The second chapter closes with the researcher's position and the research questions.

Chapter three presents the state of the nation regarding the use of ICT in the New Zealand tertiary sector. The focus was on the tertiary students' experience in ICT supported learning environments, particularly with Pasifika learners. Influential in this study was the researcher's background in the field of information technology (IT). IT is an offshoot of computer science and the use of the systems (software) development life cycle (SDLC) is introduced as the foundation for the framework to be used in this study. Literature exploring ICT skills and its relevance to employability skills is presented. The situated learning theory (Lave and Wenger, 1991) informs the way that ICT skills are promoted to the Pasifika learners.

Chapter four explores the use of ICT to support learning at international tertiary institutions. Special attention was placed on the subjects or related courses that the participants in this study were pursuing. These included accounting, marketing, economics, English language (ESOL), physical education (PE), construction trades, IT, hospitality, counselling, and engineering.

Chapter five describes the research orientation. The chapter expands on the research focus and offers an insight into the researcher's position throughout the study. The theoretical lens through which this study was designed and conducted is presented. The ontological, epistemological, and axiological frameworks are outlined to provide a clear understanding of the researcher's reasons for doing things in a particular manner. The research employed a 
qualitative case study approach which necessitated the description of the research setting, participants and the data collection methods. Three data collection methods were utilised to facilitate a triangulation approach. Talanoa, participant observation, and the researcher's reflective journal were the three methods of gathering data. Analysis of the data involved an iterative, spiralling nature that proceeds from the more general to the more specific observations (Creswell, 2008) and guided by the six steps outlined by Miles and Humberman (1994).

Chapter six presents the findings of this study. The Pasifika students' ICT skills development framework (Figure 2) offers a structure for uplifting the ICT skills of the learners. The framework comprises of six phases namely: measure, identify needs, analyse gaps, develop strategies, implement strategies, and monitor and evaluate. Phase one measures the participants' current ICT skill levels. Phase two seeks to identify the participants' learning needs. This is based on the information supplied by the participants indicating their perceived areas of learning needs. Phase three analyses the participants' learning gaps through the matching of the ICT skills measured in Phase one against the learning needs established in Phase 2. From these perceived gaps, the development of ICT based learning resources are identified and ICT based strategies are developed. Phase five comprises the implementation while the final phase six monitors and evaluates the strategies.

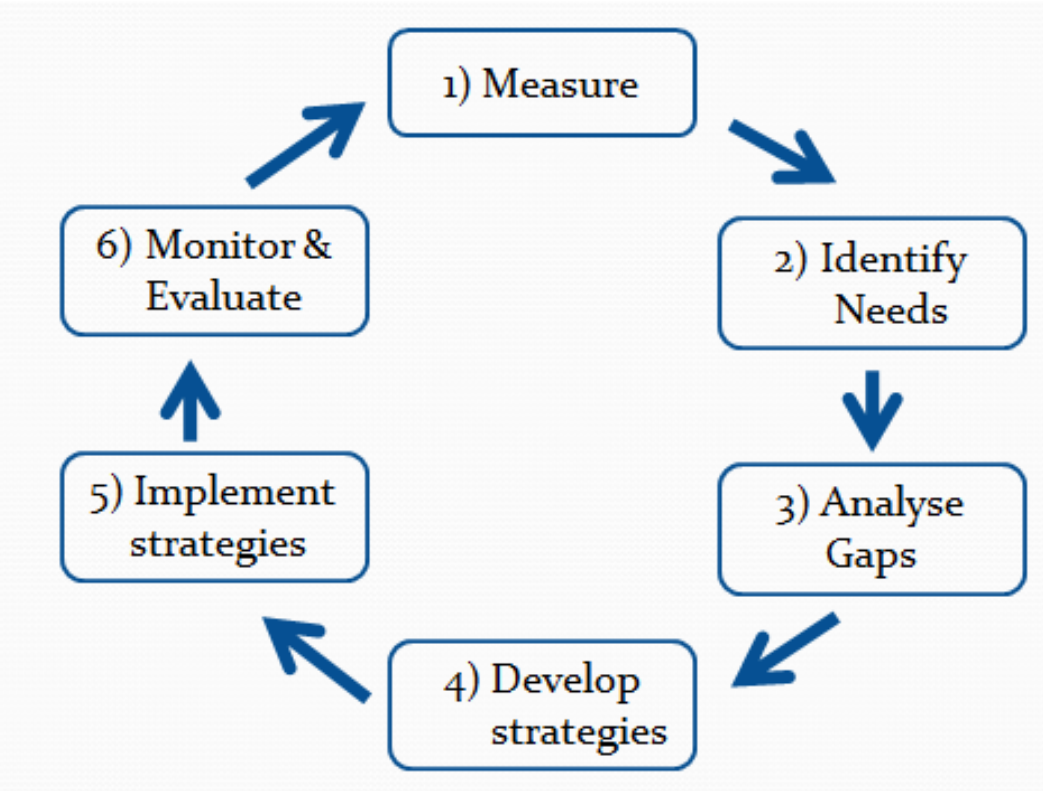

Figure 2: Pasifika students' ICT skills development framework 
Chapter seven offers a discussion that includes barriers faced by the participants in acquiring ICT skills, factors that support ICT skills attainment by the participants, and strategies to enhance Pasifika students' ICT skills. Lastly, the refinement of the Pasifika students' ICT skills development framework is outlined along with recommendations for improvement.

The final chapter provides a summary of all seven chapters of this thesis including some implications of this study relating to practice, institutional policy, and further research.

\section{Summary}

In this first chapter, an overview of the thesis is presented. The main aim of the study was to investigate Pasifika tertiary students' ICT skills and how ICT can be utilised to enhance their learning experiences. Chapter two describes the background and rationale of this study. Literature review is presented in chapters three and four. Chapter three presents the ICT-based learning experiences of New Zealand tertiary students while chapter four explores the experiences of international students using ICT. Chapter five discusses the research methodology followed by the findings in chapter six. Chapter seven offers discussion about the findings and the final chapter eight, presents the conclusions to the study. 


\section{CHAPTER 2}

\section{BACKGROUND AND RATIONALE}

\section{Introduction}

This study argues that uplifting the ICT skills of Pasifika tertiary students will enhance their academic learning experiences. Positive learning experiences will lead to improving academic outcomes. Higher ICT skill levels will increase employment opportunities which will in turn improve the social and economic well-being of Pasifika peoples in the ICT driven $21^{\text {st }}$ century. This chapter outlines the background and the rationale for this study.

The chapter begins with a clarification of the term 'Pasifika' and situates Pasifika peoples in terms of population, employment, participation in tertiary education, and literacy and numeracy. The origin of ICT is presented followed by discussion on the relevance of ICT skills and employability. An insight into Pasifika peoples' ICT use is explored and the later sections include the researcher's position, research questions, and the significance of the study.

\section{Pasifika peoples}

For the purpose of this study, Pasifika peoples refer to a rapidly growing and diverse demographic group in New Zealand (Statistics New Zealand and Ministry of Pacific Island Affairs, 2010). The phrase refers to people who self-identify with Pacific Island nations through ancestry or heritage (Otunuku \& Brown, 2007). Pasifika peoples are not homogeneous, hence the use of "peoples" rather than "people" (Ferguson, Gorinski, Samu, \& Mara, 2008). The term found currency in the education sector where the government in the late 1990 s and early $21^{\text {st }}$ century had focused intensely on the improvement of Pasifika students' academic achievement. In an attempt to improve Pasifika students' academic achievement, government policies such as the first Pasifika Education Plan of 2001 (Anae, Anderson, Benseman, \& Coxon, 2002) and the subsequent plans and strategies (Anae, Mila-Schaaf, Coxon, Mara, \& Sanga, 2010) were initiated. In this study, the focus is on Pasifika peoples in tertiary studies, specifically, Pasifika students or learners. 
Other terms found in the literature that referred to Pasifika people included Pacific Islanders, Pacific Island community, Pacific nations, and Polynesians (Coxon, Anae, Mara, Wendt-Samu, \& Finau, 2002; Mila-Schaaf, 2010). These labels served the purpose of the governing bodies or authorities to meet their objectives but has no meaning to the people referred to by such a term (Gray, 2001). Individuals refer to themselves as Cook Islanders, Tongans, Samoans, Niues, or Fijians and for convenience sake people have reluctantly considered themselves as Pacific Islanders or PIs (Petelo, 2003; Mila-Schaaf, 2010).

The use of the term 'Pasifika' in this study was intended to clarify that the study focused on New Zealand-based Pasifika students. The nature of the research setting in this study only attracted New Zealand-based participants due to the type of courses and the levels offered. This excluded those who had arrived from the Pacific Islands for the sole purpose of education and were classified as international students by the Ministry of Education. Using the term Pasifika students to refer to the participants of this study was influenced by the view that terms used in the past such as Pls had negative connotations (Anae, 1998; Petelo, 2003; Mila-Schaaf, 2010). Therefore, a new term or identity may offer a positive view and bring about hope for a better future for Pasifika people.

The history of Pasifika peoples' settlement in New Zealand has been well documented (Jones, 1986; Krishnan, Schoeffel, \& Warren, 1994; Anae, 1998; Coxon \& Mara, 2000; Gray, 2001; Macpherson, Spoonley, \& Anae, 2001; Nakhid, 2002). New Zealand's economic boom in the 1950 s and 60 s required more unskilled and semi-skilled workers (Anae, 1998; Nakhid, 2002). As a result many people from South Pacific Island nations emigrated to pursue the dream of improving their living standard. Their employment was mainly in the manufacturing industries. However, the economic turndown in the 1980 s led to high unemployment for this group, which magnified their low socio-economic status. Factors such as stereotypical perceptions (Petelo, 2003), racial and institutional discrimination (Nakhid, 2002) further marginalised Pasifika peoples.

The projected population for Pasifika peoples for 2011 was 350,000 (Statistics New Zealand, 2011b). Based on the 2006 census, the Pasifika peoples' population was recorded at 266,000 comprising $6.9 \%$ of the total New Zealand population. Samoan people constituted the largest proportion (49\%) of the total Pasifika population followed by the Cook Islanders (20\%) and Tongans (18\%). 
Three other ethnic groups contributed smaller numbers including Niue (8\%), Fiji (4\%) and Tokelau (2\%). Through intermarriages many younger Pasifika people under the age of twenty identify with more than one ethnicity. Sixty percent of Pasifika peoples were born in New Zealand suggesting that many were younger and have been educated in New Zealand (Statistics New Zealand and Ministry of Pacific Island Affairs, 2010).

For the purpose of this study, a brief overview of the Pasifika peoples' population in the Wellington region is included. An estimated population for Pasifika peoples in the Wellington region for 2011 was 42,000 . This represented an increase from the 2006 census figure of 38,000 (Statistics New Zealand, 2011b). According to the 2006 census, the region has the second largest proportion (13\%) of Pasifika people residing in the area compared to Auckland's $67 \%$ and Canterbury's at $4 \%$. Consistent with the national trend, Samoans recorded the largest proportion (62\%), Cook Islands (20\%), Tokelauans (10\%), Niueans, (4\%), Fijians (3\%), Tuvaluans (1\%) and other Pacific Islands (2\%). A unique trend was observed for Tokelauans where half the Tokelauan population in New Zealand resided in the Wellington region. The proportions of Pacific ethnic group in relation to their total ethnic number that resided in the Wellington region were: Tongans (16\%); Cook Islanders (12\%); Fijians (10\%); Niueans (7\%); and Tokelauans (5\%). Within the Wellington region, slightly over one third of Pasifika people resided in the Porirua City (35\%), followed by Lower Hutt (29\%) and Wellington City (26\%) areas (Statistics New Zealand, 2007b). These figures confirmed that the majority of the Pasifika population resided in urban centres.

\section{Tertiary Education Participation}

Tertiary education in New Zealand is accessed through public tertiary education institutions, Private Training Establishments (PTE) and other providers. Public tertiary education institutions include universities, Institutes of Technologies and Polytechnics (ITP), and wananga. A wananga is a "teaching and research institution that maintain, advance, and disseminate knowledge, develop intellectual independence, and assist the application of knowledge regarding ahuatanga Maori, [Maori tradition] according to tikanga maori [Maori custom]" (Ministry of Education, 1998, p.11). PTEs offered post-school education or vocational education while other providers included Government Training Establishments (GTE). Some examples of GTE included naval training, armed force training, air force, police, fire service, civil defence, Department of Child 
Youth and Family, special-focus education, and career services (Ministry of Education, 1998).

The proportion of Pasifika students in all tertiary education institutions throughout New Zealand had increased from 6\% in 2003 to $7.6 \%$ in 2009. In 2006, the proportion of Pasifika students enrolled in tertiary education $(6.0 \%)$ was lower than the proportion of the Pasifika people (6.9\%) recorded in the $2006 \mathrm{New}$ Zealand population (Wensvoort, 2011). This should not be a point of concern given that the participation rate in 2009 had increased to $7.6 \%$. According to Wensvoort (2011), more Pasifika females $(18,800)$ attending tertiary education than males $(13,200)$ and the most popular field of study for Pasifika tertiary students was management and commerce.

In 2010, Pasifika student participation in tertiary education was mainly at ITPs (37\%) followed by universities (29\%), PTEs (27\%) and wananga (11\%) (Ministry of Education, 2011). A contributing factor for this higher Pasifika participation at ITPs was the wide variety of lower qualifications offered. These were mainly certificates (Levels 1 - 4) and diplomas (Levels 5 - 7). In addition, ITPs had open entry requirements for their courses whereas universities' required higher academic entry requirements for their degree qualifications. More importantly, Pasifika students' literacy and numeracy achievements at college level were a contributing factor to their academic dilemma. This was disclosed in the PISA results outlined under the Literacy and Numeracy section of this chapter.

Statistical evidence compiled by the Ministry of Education highlight the low academic achievement of Pasifika learners which suggest that the education system had failed to provide equal opportunities for all (Wensvoort, 2011). In 1999, Pasifika school leavers were found to be less likely to enter directly to tertiary level studies. One in eleven Pasifika school leavers enrolled at university. Many Pasifika students enrolled at private training enterprises and were mainly pursuing certificate level qualifications (Ministry of Education, 2000). Ten years on in 2010 and this undesirable trend had persisted. In 2010, six in ten Pasifika students at tertiary education were enrolled in certificate qualifications (Ministry of Education, 2011).

A report prepared by Statistics New Zealand and the Ministry of Pacific Island Affairs (2010), revealed that Pasifika students who attended integrated (usually Catholic) or private schools had a higher chance of meeting university entrance 
requirements. In 2005, 25\% of Pasifika students at integrated or private schools met university entry requirements while $12 \%$ of Pasifika students at state schools met the same requirements. This observation offered an opportunity to identify practices at the integrated or private schools that contributed to the higher academic achievement of Pasifika students (Statistics New Zealand and Ministry of Pacific Island Affairs, 2010).

Pasifika people without formal qualifications had the highest unemployment rate (20\%) while lowest for those with university degrees (7.4\%). Those with vocational qualifications (15\%) recorded the second highest unemployment rate. This was a staggering rate, measuring three times the national rate (Ministry of Pacific Island Affairs and Statistics New Zealand, 2002). No explanation was offered for this alarming rate but a possible explanation may lie on the type of qualification completed. Many Pasifika students who completed Level 1-3 certificates may have been enrolled in bridging or foundation courses for higher qualifications which do not necessarily equate to skills for employment. Earle (2010) confirms that Levels 1-3 certificates were equivalent to school qualifications and were intended to prepare people for entry to employment or further education.

A main outcome of tertiary education is employability (Dray, Burke, Hurst, Ferguson, \& Marks-Maran, 2011). Tertiary education through its role in generating and disseminating knowledge directly contributes to a nation's economic status (Brown, Hesketh, \& Williams, 2003). In an increasing competitive job market, those with tertiary educational qualifications stand a better chance of getting employment (Lane, 2011).

\section{Pasifika Students at WelTec}

In 2010, Pasifika students comprised $7.9 \%$ of the WelTec's student population which was an increase from the 7.0\% recorded for 2009 (Wellington Institute of Technology, 2011). In previous years, the proportions were $6.8 \%$ in 2008 and $6.5 \%$ in 2007 (Wellington Institute of Technology, 2009g). While WelTec had enjoyed a steady growth of Pasifika students it was lower than the proportion of the Pasifika population (8\%) in the region (Statistics New Zealand, 2007c). No further breakdown was available from the annual report on the Pasifika students' figures apart from the enrolment proportions stated above. 
Figures obtained from the Ministry of Education's statistics website (http://www.educationcounts.govt.nz/statistics) revealed that the proportions of Pasifika students at WelTec had been fluctuating between four and eight percent from 2003 to 2010. In 2010, three quarters of the Pasifika students at WelTec were enrolled in certificate (Levels 1-4) qualifications, $22 \%$ were enrolled in diplomas, and $10 \%$ were enrolled in degree qualifications (Ministry of Education, 2011). The high number of Pasifika students enrolled in lower qualifications (certificates and diplomas) is consistent with the national trend.

\section{Employment}

Pasifika peoples' employment history had been predominantly in the unskilled and semi-skilled sectors of the labour force (Jones, 1986; Petelo, 2003). The Pacific Economic Development Agency Ltd (2007) confirmed that nearly two thirds (64\%) of the Pasifika peoples' workforce were in low-skilled or semi-skilled occupations. Majority of Pasifika people arrived during the 1950 s and 60 s to fulfil New Zealand's labour shortages. Some had personal goals such as "wanting a better life" or "a better education for their children" (Anae, 1998, p.10). However, economic restructuring in the 1980s and early 1990s resulted in job losses for many Pasifika people who were overrepresented in secondary industries and lower skilled manual occupations (Ministry of Pacific Island Affairs and Statistics New Zealand, 2002). These lower skilled manual occupations were projected to have low future growth resulting in declining employment opportunities for Pasifika people in these sectors.

The labour force participation rate referred to the proportion of people that were legally employable and were classified as employed or unemployed. In New Zealand, these included those who were fifteen years or older. In 2006, the Pasifika people labour force participation rate was recorded at $65 \%$ which was lower than the $69 \%$ for the New Zealand adult population (Ministry of Pacific Island Affairs and Statistics New Zealand, 2010). The flip side of this statistic was that a significant number of Pasifika people were unemployed. The situation is not helped with manufacturing businesses shutting down and outsourcing production to countries with a cheaper labour market (Rochford, 2010; Bachmann \& Braun, 2011).

According to the Ministry of Pacific Island Affairs (2010), advanced trade, technical and professional qualifications in engineering and related technologies, architecture and building are future demand areas. Furthermore, the services 
industry has the best employment opportunities in the future but first Pasifika people need to acquire the relevant skills for participation. The pathway to acquiring these skills lie in tertiary education where Pasifika students will need to complete the relevant degree qualifications or higher. Meanwhile, Pasifika students in high school will need to do well academically, scoring higher grades in literacy and numeracy and other relevant subjects to ensure they have the academic foundations for further tertiary studies. Engler and Smyth (2011) confirm that students with higher school achievement performed better at tertiary level.

The Ministry of Pacific Island Affairs (2010) recommended two ways to improve the employment predicament faced by Pasifika people seeking employment. First, purposeful choices of tertiary qualifications that lead to higher-demand industry sectors as stated earlier. Secondly, up-skilling Pasifika people in highgrowth industries enabling them to progress on the skills ladder. Both approaches require effective schooling and relevant subject choices. A closer examination of the occupational groups that will be in demand by 2019 include specialised managers, housekeeping and restaurant services workers, business professionals, finance and sales associate professionals, personal care workers, salespersons and demonstrators, library, mail and related clerks, computing professionals, nursing and midwifery professionals, writers, artists, entertainment and sports associate (Department of Labour, 2011).

\section{Literacy and Numeracy}

Participation in the twenty-first century workforce demands traditional basic skills that include literacy and numeracy skills (De Coulon, Marcenaro-Gutierrez, \& Vignoles, 2007; Lundetrae, Gabrielsen, \& Mykletun, 2010). Both can be viewed as basic components of human capital (Charette \& Meng, 1998) and are vital components for personal development (Lockyer, Johnson, \& Dyer, 2009). Lundetrae, Gabrielsen, and Mykletun (2010) revealed that in Italy, Norway, Canada, and USA, low numeracy and literacy skills increased the likelihood of unemployment. International studies have attempted to assess the impact of literacy and numeracy on wages or earnings (De Coulon, Marcenaro-Gutierrez, \& Vignoles, 2007). In Ghana, a survey of households found that participation in a literacy program significantly impacted on participants' living standards (Blunch and Verner, 2000). Canadian immigrants' wages was dependent on their literacy skills (Green \& Riddell, 2003). Using proficiency tests to measure literacy and numeracy of USA high school students, Dougherty (2003) found that numeracy 
effected earnings both directly and through college attendance. On the other hand, literacy did not have an effect on earnings but seemed to increase the prospects of college attendance.

In this study literacy refers to the ability to read and write in English while numeracy refers to the ability to understand and work with numbers (Lane, 2011). The literacy and life skills as measured by the Adult Life and Literacy (ALL) used two measures for literacy which included: prose and document literacy skills. Prose literacy involved continuous text found in books and newspaper articles while document literacy involved discontinuous text found in graphs, charts and tables (Satherley \& Lawes, 2007). The ALL survey revealed that Pasifika adults who spent considerable time in formal education scored higher English prose and document literacy skills. Without formal education, Pasifika adults that spoke English in their homes performed well in prose and document literacy skills (Laws, 2008). An analysis report of the 2006 ALL survey revealed that Pasifika adults in both the 16-24 and the 25-65 age groups scored the lowest mean prose and document literacy when compared to other ethnic groups in the same age group (Lane, 2011). Given the Pasifika adults' low literacy measures, personal development becomes a rather challenging endeavour.

The unsatisfactory trend persisted for Pasifika students at college level. The Programme for International Student Assessment (PISA) was an international standardised study that assessed and compared how well countries were preparing their 15-year-old students to meet real-life opportunities and challenges. An alarming trend was uncovered with nearly one third of Pasifika students only completing the simplest reading and maths tasks (Statistics New Zealand and Ministry of Pacific Island Affairs, 2010). While this trend has been highlighted, there needs to be some concerted effort from all those concerned to ensure that there is improvement of Pasifika high school students' literacy and numeracy skills. Without a good grasp of literacy and numeracy, many Pasifika students pursuing any further educational undertaking or skills training will find it challenging. It is therefore unsurprising that educational achievement of Pasifika students at higher levels is unsatisfactory.

\section{Information and Communication Technologies (ICT)}

ICT has been at the forefront of the $21^{\text {st }}$ century advancements in businesses, governments, and individual activities. It is widely accepted that ICT are tools of modern societies (Wikan \& Molester, 2011). ICT refers to all digital technologies 
that are ubiquitous in our daily lives enabling the connection of people and resources. ICT includes a diverse range of technological tools used to communicate, create, disseminate, store, and manage information (Blurton, 1999). The convergence of computer technology and telecommunications has resulted in the increasing popularity and the widespread use of ICT in all aspects of human endeavour. For the purpose of this study, ICT will refer to computer hardware and software, computer networks including the internet, telecommunication devices that enable the users to create, manipulate, and store digital information while at the same time accessing digital resources available on the internet.

In education, the introduction of computers as a learning tool was mainly in the domain of mathematics, physics and engineering. Around the mid-1960s, electronic computers began appearing in universities in America and were initially viewed as an extension of the calculator (Newhouse, 2002). Later on computers were used to teach curriculum and basic skills operating as a means to deliver instruction, supplementing the teachers' classroom instruction. These led to applications such as Computer Assisted Instruction (CAI), Computer Based Education ( $\mathrm{CBE})$, Computer Based Instruction (CBI), Computer Managed Instruction (CMI), and Computer Based Learning (CBL) (Fouts, 2000; Parr \& Fung, 2000). In the late 1970s computers began appearing in offices through the invention of IBM's text editing systems. The introduction of personal computers to replace the electronic typewriters led to the mass training of office staff (Lee, 2004). Training of office workers to use the computer led to the term: computer skills. The success of the computer as an office tool led to education curriculum that involved the development of skill levels required for the work force.

Towards the end of 1980s, the term information technology (IT) emerged to represent the computer igniting a shift of focus from computing technology to the ability to create, store, and retrieve information. Ten years later in 1990, the term IT further evolved to become ICT coinciding with the email and the world wide web (WWW) becoming available to the general public (Pelgrum \& Law, 2003).

The World Wide Web (WWW) began as a graphical based and a more userfriendly interface for the internet where users retrieved information posted by a small group of content experts (Veletsianos, 2011). It has transformed to Web 2.0 which refers to a second generation of the WWW enabling users to collaborate and share information online (Cronin, 2009). Web 2.0 tools such as 
blogs, wikis, multimedia sharing services and social networking systems have progressed the way people use the internet (Papastergiou, Gerodimos, \& Antoniou, 2011).

\section{ICT Skills and Employability}

ICT is central to many $21^{\text {st }}$ century employment opportunities (Lockyer, Johnson, \& Dyer, 2009). Across all industries, ICT investment had increased as businesses sought to improve their bottom line. In Britain, computers were used to improve efficiency (Borghans \& Ter Weel, 2011). Inevitably, investment in ICT education and training is essential for socio-economic development (Bucciarelli, Odoardi, \& Muratore, 2010). Associated with this widespread use of ICT is the demand for employees with ICT skills to operate the new technologies (Lindsay, 2005). For the purpose of this study, ICT skills refer to the ability to use digital technology, communication network tools to access, manage, integrate, evaluate and make decisions in order to function in a knowledge society.

More and more information created by businesses and government departments are now available on the internet (Mohammad, 2010). Government departments in line with government policies on improving information and service deliveries are using ICT to spearhead their efforts. The Australian and Canadian governments perceive ICT and science skills as important factors for economic growth and development in the $21^{\text {st }}$ century (Luu \& Freeman, 2011). While it is widely accepted that ICT will improve organisation's efficiencies, there is a danger that some of already disadvantaged groups of people will be further marginalised in the process. Disadvantaged groups include the poor, unemployed, elderly and minority ethnic groups. Those employed within organisations without ICT skills may be squeezed out while the targeted audience without the relevant ICT skills may not be able to access the online information.

There is a large body of knowledge relating to the definition of employability (De Vos, De Hauw, \& Der Heijden, 2011; Gokuladas, 2011). It is not the intention of the current study to add to it. Employability as used in this study has adopted the definition offered by the European Commission's Education \& Training department. Employability simply refers to a person's capability of gaining employment. Conditions that contribute to the notion of employability will be explored further in the later chapters. Other terms that have been used in the past included: generic skills, core skills, and basic skills. In its simplest form generic skills include human interactive activities such as communication, team 
work, gathering and ordering information, and problem solving (Hager \& Holland, 2006).

\section{Pasifika peoples' ICT use}

The 2009 Household Use of ICT Survey revealed that Pasifika individuals who used the internet in the twelve months prior to December 2009 were only $5 \%$ of the total New Zealand internet users. This was the same proportion for Pasifika people when the survey was done in 2006. The result was the lowest in all the ethnic groups that included Europeans (69\%), Maori (13\%) and others (13\%). Pasifika internet users accessed it for personal use (72\%), formal academic or training $(19 \%)$, working from home $(10 \%)$, voluntary or community work $(8 \%)$, and home-based business (5\%). Places where internet was accessed by Pasifika users were at another person's home (53\%), work (44\%), educational institutions $(38 \%)$, community internet facility (27\%), and commercial internet facility $(25 \%)$ (Statistics New Zealand, 2011a). Statistics relating to internet access in Pasifika households in the past five years (2006-2011) were unavailable.

The World Internet Project New Zealand survey undertaken by researchers at the Auckland University of Technology found that Pasifika people spend more time on the internet at school or tertiary institutions (60\%) than do Asians (50\%) and Maori (50\%), Pakeha (15\%) and other ethnicities (18\%) (Smith et. al, 2010). Based on these findings, it can be deduced that not many Pasifika people accessed the internet from their own homes. The picture presented above highlights that Pasifika people are in danger of falling on the wrong side of the digital divide. Many Pasifika people do not have internet access at home as shown by their high usage at another person's home $(53 \%)$ or at work $(44 \%)$. A report prepared by the Ministry of Pacific Island Affairs and Statistics New Zealand (2002) revealed that $81 \%$ of Pacific households were without internet access. This was higher than the national figure of $58 \%$ for New Zealand households without internet access. Figures for other enthnic groups were unavailable.

The digital divide refers to the notion that people without access or the relevant skills to use ICT may be disadvantaged (Lindsay, 2005; Holmes \& Gardner, 2006; Shieh, Chang, \& Liu, 2011). In the early stages of the internet era, it was perceived that having access to ICT was the critical requirement for participation in the digital era. However, it has been found that in addition to ICT access, relevant ICT skills were just as important. There was no available statistics on 
Pasifika peoples' ICT skills and the indicators stated above hint that many of them were on the wrong side of the digital divide.

Bell, Crothers, Goodwin, Kripalani, Sherman, \& Smith (2008) and Statistics New Zealand (2007a) concur that a digital divide exists between New Zealand households. A household's position on the digital divide was based on access to telecommunication systems such as telephone, internet and facsimile machine. Three characteristics were identified that influence a household's position on the digital divide. Households with higher incomes and households whose members have formal education qualifications are most likely to be on the right side of the digital divide. A third determining factor for the IT adoption is the household composition. Households with a couple and school-age children tended to be more IT ready over other household types. Based on the household characteristics stated above it is evident that many Pasifika households with a median annual income of $\$ 20,500$ could be on the wrong side of the digital divide (Statistics New Zealand, 2007b). Low annual income of many Pasifika peoples result in multi-family households and this may further narrow their chances of being situated on the right side of the digital divide.

Interestingly, access to ICT such as telephone (80\%) and cellular phone (70\%) is high for Pasifika households when compared to New Zealand households. In particular, cellular phones access is nearly as high as the New Zealand households at $72 \%$ (Statistics New Zealand, 2007b). This observed trend may have been a result of the cellular phones affordability, reliability and the convenience that it offered. Brady, Dyson and Asela (2008) disclose that the high adoption and use of mobile phones by indigenous peoples is due to its fit with a cultural strength such as orality. The findings of the ICT-specific survey conducted by Statistics New Zealand (2007a) reveal Pasifika peoples recorded the lowest proportion (50.2\%) of individuals who were not interested in having a cellular phone. Overall, Pasifika peoples used cellular phones just as much as every other person in New Zealand.

Based on national and global trends, Pasifika people will need to become aware of the shift towards online information. Pasifika households throughout New Zealand (40\%) have a lower internet access when compared to all New Zealand households (60\%) (Statistics New Zealand, 2007b, p.29). Despite the low household internet access rate stated earlier, the 2007 Benchmark Survey revealed that more Pasifika (72\%) peoples who were surveyed used the internet 
than Maoris (62\%) (Bell, Crothers, Goodwin, Kripalani, Sherman, \& Smith, 2008). This may suggest that Pasifika people access the internet at other places despite recording low access at home. Low internet access may lead to missed opportunities which will have long term implications. For instance, banks, airlines and other major businesses are exploiting the internet to reduce their operational costs. Services such as on-line banking, e-ticketing, paying bills on-line, and various other approaches have been available online with economic benefits for the users. Pasifika people will miss out if they do not have access to the internet let alone know how to use it.

The field of digital design and creative technologies offer opportunities for Pasifika people to harness the power of ICT for personal, social, and economic benefits. On a personal level, ICT can be used for personal development in whatever areas that one chooses. For example, vast range of information is now readily available online through the internet to assist individuals in decision making. On a social level, ICT offers numerous benefits in maintaining one's social affiliations. Social websites such as Facebook, Bebo and others can help create and maintain social connections despite the physical separation of users. Through the use of ICT, language and cultural maintenance is possible for Pasifika peoples. Furthermore, ICT can also offer opportunities for economic benefits. For example, in the case of Niueans on Niue where they enjoy free high speed internet access, the use of Skype or other Voice Over the Internet Protocol (VOIP) applications enable low-cost communications with friends and relatives outside Niue (Clair, 2003).

\section{Researcher positioning}

In a qualitative research, the role of the researcher is a central component in the process of data collection. Especially where the research topic focuses on ethnic groups, the "insider" researcher offers an added degree of importance to the process (Palmer, 2006). Participants of this study had a traditional cultural connection to the Pacific Islands and the researcher has a similar cultural connection. This situation created a distinct social dynamic whereby the cultural differences between the participants and the researcher were minimised through shared cultural knowledge. For example, Pasifika people's generosity towards their use of time may be an issue for a non-Pasifika person. Through cultural understanding from both parties involved, this issue is easily mitigated. In situations when participants do not arrive on time for scheduled meetings, the researcher understood that some other urgent events may have occurred 
resulting in the participant's non-arrival or late arrival, therefore the need to schedule another meeting.

As a male Pasifika person, Fiji-born and an academic staff member at WelTec since 2001, the researcher was an "insider" in this study. Throughout the researcher's employment at WeITec, few Pasifika students had enrolled in IT courses at the institute and most struggled to successfully complete their studies. In a trimester, Pasifika IT students' number would typically be not more than $10 \%$ of the total number of IT students. Pasifika IT students who successfully completed their studies from the same cohort were typically less than half the original number that started out. Unsurprisingly, this was consistent with the national retention rate of $40 \%$ for Pasifika students at polytechnics (Ministry of Education, 2008c). Given the national trend of Pasifika students' low retention and completion rates, an insider researcher was deemed more acceptable by the participants and able to advocate for them.

The researcher was mindful that as an insider researcher there were challenges inherent to this approach. While the insider status may lead to greater proximity in the research process, it will also highlight a range of social gaps that may otherwise remained hidden. The researcher was born on the island of Rotuma, a Polynesian island situated at 465 kilometres north of Fiji, grew up in Fiji and migrated to New Zealand in 2001. While the researcher fluently speaks Rotuman, Fijian and English, the participants were Samoans, Tongans, Niueans or Tokelauans who may have felt at ease if communication was in their respective languages. In addition, some New Zealand-born participants may have viewed the researcher as an outsider; by not having similar New Zealand experiences as them and therefore not understanding their situations. Furthermore, the view that as an academic staff member at WelTec this may influence their responses was another challenge that the researcher needed to address.

In order to mitigate these challenges, adherence to the following four basic principles was observed: respect, collaboration, honesty, and empowerment (Koloto, Katoanga, \& Tatila, 2006). As Pasifika peoples, showing respect in all interactions is expected and this will ensure the smooth running of the research process. Collaboration between the researcher, participants and other stakeholders will contribute to the success of the research. Honesty throughout the research process will be paramount as this will offer an authentic voice to the 
research. Above all, the research aims to empower the participants to fully engage in the research and to ensure the successful completion of their studies.

As a Pasifika IT professional, the researcher considered his role as a change agent and this study will identify some practical ICT based learning strategies to enhance Pasifika tertiary students' learning experiences. ICT literacy is crucial for the vitality of New Zealanders and more specifically to Pasifika peoples who continue to be at the tail end of most socio-economic statistics. While it is widely known that ICT is driving the knowledge economy, some Pasifika students are oblivious to this and may face the same fate as their ancestors who migrated to New Zealand in the 1950s and 1960s. The current study was aimed to enlighten more Pasifika peoples to take ownership of their destiny through acquiring ICT skills in order to better participate in the knowledge economy.

\section{Research Questions}

The main research question was:

How might Pasifika students at a New Zealand Institute of Technology or Polytechnic (ITP) use ICT to enhance their learning experience at the tertiary level?

This was supported by the following sub-questions:

- What/why are some of the factors that may hinder/support the Pasifika students' use of ICT to enhance their learning experience?

- How do Pasifika students use ICT to enhance their learning experiences?

- What are some ICT skills that may enhance Pasifika students' learning experiences?

\section{Significance of the research}

This study set out to investigate factors that enhanced and/or hindered Pasifika tertiary students' use of ICT to support their learning experience at a New Zealand Institute of Technology or Polytechnic (ITP). Studies on Pasifika tertiary students had mainly involved those enrolled at universities (Petelo, 2003; Davidson-Tomu'a, 2005; Fanene, 2006; Mara, 2007; Chu, 2009) and a handful focused on Pasifika students at ITPs (Latu \& Young, 2003; Clayton, RataSkudder \& Baral, 2004; Koloto, Katoanga, \& Tatila, 2006). In 2009, a total of 32,000 Pasifika students were enrolled at New Zealand tertiary institutions. Most of these students enrolled at polytechnics (33\%) compared to university $(28 \%)$ enrolments (Ministry of Education, 2010a). Given the high number of Pasifika enrolments at polytechnics and the low number of studies undertaken to closely 
examine the situation, it was imperative that this research be undertaken to better understand the situation.

There is a dearth of studies on Pasifika people and ICT. Two sources of data on Pasifika peoples ICT access were from the Statistics New Zealand Household Use of Information and Communication Technology survey (Statistics New Zealand, 2011), and the World Internet Project New Zealand survey (Smith et. al, 2010). Apart from those two surveys there was a study that investigated Pasifika businesses' use of ICT (Manueli, Latu, \& Koh, 2008) and another four studies relating to Pasifika tertiary students (Latu \& Young, 2003; Clayton, Rata-Skudder, \& Baral, 2004; Hodgen, 2006; Koloto, Katoanga \& Tatila, 2006).

This study contributes to the increasing body of literature that seeks to improve educational outcome of Pasifika students (Anae, Mila-Schaaf, Coxon, Mara, \& Sanga, 2010). Furthermore, findings from the study contribute to strategies to progress the shared vision of a brighter future for Pasifika peoples.

The field of IT and related industries are a growing industry that offers an opportunity for Pasifika peoples to leapfrog into the digital age. While there are issues surrounding literacy and numeracy amongst Pasifika peoples (Satherley \& Lawes, 2007), the use of ICT can greatly assist in improving their literacy and numeracy skills. This study investigated practical ICT-based strategies to enhance the Pasifika tertiary students' learning experience so that they can better participate in the digital age.

Finally, there is significance in the methodology employed in this study. As stated, the researcher is an insider investigating an insider issue, using an insider talanoa approach and associated protocols and understandings. The researcher is an insider academic staff member of the Institute within which the students undertook their studies. The students too are insiders; members of the Pasifika communities, residents of the Wellington region and experiencing ICT outcomes that are similar in nature. This study offers further insights into the context of insider research into Pasifika peoples' spaces of learning and their use of ICT. 


\section{Summary}

In this second chapter, the background and rationale for this study was discussed. The research argued that uplifting ICT skills of Pasifika tertiary students will enhance their learning experiences. Pasifika referred to peoples who self-identify with Pacific Island nations through ancestory or heritage. Pasifika peoples' participation in tertiary has been steadily increasing since 2003 but their academic achievements have been a national issue. An aim of tertiary education is employment and given the Pasifika peoples' low academic achievements in tertiary education, their employment history continue to be in the unskilled sectors of the work force. Persistent with the low academic achievement and unemployment is low literacy and numeracy.

ICT may offer more Pasifika peoples an opportunity to bring them up to par with the rest of New Zealand in the $21^{\text {st }}$ century. ICT has been at the forefront of advancements in businesses, governments, and individual activities. As such, higher ICT skills may improve the chances of employment for Pasifika people. Currently, many Pasifika people do not use the internet frequently and many of them are in danger of falling on the wrong side of the digital divide.

This study was influenced by the premise that improving Pasifika tertiary students' use of ICT may enhance their learning experiences. Learning experiences in this study include formal and informal learning opportunities. Armed with higher ICT skills, Pasifika students can complete their learning assessments leading to successful academic outcomes. Higher academic achievements lead to high employment prospects for Pasifika peoples. In addition, Pasifika tertiary students with advanced ICT skills can influence their families and communities in uplifting Pasifika peoples' ICT skills. 


\section{CHAPTER 3}

\section{LITERATURE REVIEW}

\section{Introduction}

This chapter reviews the literature covering four areas namely ICT-supported learning in the New Zealand tertiary education sector, systems development, situated learning, and Pasifika students learning styles. ICT supported learning in the tertiary education sector is widespread however there are variations within disciplines. Given the focus of the study, a section exploring Pasifika tertiary students' experiences on the use of ICT is presented. The last three sections cover systems development, situated learning and Pasifika learning styles. Systems development is included due to its role in the development of the framework to be used in this study. Situated learning was regarded as an appropriate learning approach for inproving Pasifika tertiary students ICT skills.

\section{ICT in New Zealand Tertiary Education Sector}

The use of ICT in the New Zealand tertiary sector has been largely driven by the government's Tertiary Education Strategy 2002-2007 and the recommendations of subsequent strategies. Backed by government funding, the ICT Strategic Framework for Education provided a "mechanism to guide and co-ordinate ICT investment towards the government's vision of improved education outcomes" (Ministry of Education, 2006, p.1). This framework supported the government's digital strategy that aimed to propel New Zealand to be a world leader in the use of ICT and to realise the economic, social, environmental and cultural goals to benefit the populace (Ministry of Economic Development, 2008).

Three significant trends emerged in the tertiary education landscape that led tertiary institutions to reassess how they conducted their core business. The trends included: the diversifying student body, ubiquitous ICT, and new educational goals (Jeffrey, Atkins, Laurs, \& Mann, 2006; Johnson, Cowie, De Lange, \& Hight, 2009). With cost effective technologies for educational administration and course delivery, institutions invested in ICT to harness its potential (Krishnaveni \& Meenakumari, 2010). Some aspects of tertiary education that have utilised ICT are evident in students' enrolment systems, 
distribution of course materials, preparing assignments, checking test and exam marks, communication, and research.

E-learning (electronic learning) refers to the use of ICT to support teaching and learning (Johnson, Cowie, De Lange, Fallon, Hight, \& Khoo, 2011). At first, elearning initiatives were utilised at higher qualifications and mainly deployed by universities (Mitchell, Clayton, Gower, Barr, \& Bright, 2005). An increase in elearning offered by tertiary institutions throughout New Zealand had been recorded at $44 \%$ in 2004 to $48 \%$ in 2008 . In the bachelor degree qualifications, e-learning had increased from $65 \%$ in 2004 to $72 \%$ in 2008 while it declined from $22 \%$ to $19 \%$ in the certificate level qualifications in the same period. ICT that were utilised included the internet, video and audio conferencing, and interactive whiteboards (Guiney, 2011).

Adoption of e-learning in New Zealand institutes of technology or polytechnics (ITPs) had also increased but was found to be lagging behind universities (Marshall, 2005; Hodgen, 2006; Ham and Wenmoth, 2007). Possible explanations for this trend was lack of funds for ICT, lack of support from senior management level, lack of an institutional e-learning policy amongst other things (Mitchell, Clayton, Gower, Barr, \& Bright, 2005). In addition, the provision of formal staff development at the institutions was basic training and inadequate. Wilson (2011) confirmed that support for the adoption of e-learning may be possible if driven by senior management or supported through external funding.

While ICT was widely available at tertiary institutions, some lecturers were reluctant to adopt ICT in their teaching practices. Tertiary educators held various views that included e-learning as a tool and equipment, facilitator for interaction, for learning, reduction in distance between the educators and learners, and a collaborative tool (Stein, Shephard, \& Harris, 2011). Student teachers at a New Zealand university revealed the prevalence of conventional teacher-centred approach (Allan, 2007). Although the students were introduced to ICT, they were enculturated along the traditional teaching styles. The study confirms that technology on its own will not motivate lecturers to acquire new skills required for embedding ICT in their work. This may suggest that the pedagogical capability of teaching staff was lower than their technical capability as discovered by Elgort (2005), and Ham and Wenmoth (2007). The lower skills of staff to use ICT in their work may affect the many benefits that ICT can offer. 


\section{Experiences of New Zealand Tertiary Students in ICT Supported Learning}

ICT supported learning is widespread amongst New Zealand tertiary education institutions. A wide range of ICT have been deployed to meet the challenges of the diverse student body, and new funding models while at the same time provide additional support for academic staff to extend learning beyond the face-to-face interactions with students. The ICT discussed in this section include learning management systems such as Blackboard, e-learning tools such as Google Earth, and the virtual classroom.

Blackboard is a proprietary Learning Management System (LMS). A LMS is the "infrastructure that delivers and manages instructional content, identifies an individual and organisational learning goals, tracks the progress towards meeting those goals, and collects and presents data for supervising and learning process of an organisation as a whole" (Watson \& Watson, 2007, p.28). Blackboard provides lecturers a secure place to share electronic resources for their students to access via the internet. In addition, Blackboard enables students to participate in on-line discussion between fellow students and the lecturer. Most New Zealand tertiary institutes use Blackboard or Moodle as their learning management system. The main difference between the two is that Blackboard has to be purchased at thousands of dollars while Moodle is free of charge.

The perception of business undergraduates at a New Zealand university towards Blackboard was reasonably high. Participants rated their experience as positive and were eager to enrol in another course delivered in the same mode (Petrova \& Sinclair, 2005; Higgins \& Krieg, 2008). In another study by Elgort, Smith, \& Toland (2008) involving students in a Masters of Information Management course at another New Zealand university revealed a similar outcome. The study investigated the participants' perception of their learning experiences in using Blackboard. Many of the participants had never used Blackboard before but were very positive about using it in their team-based project (Elgort, Smith, \& Toland, 2008). Another stuty titled, Blackboard@Otago: A student perspective, revealed that students "increasingly expect online access to learning resources in a high quality professional environment." (Aman, Butson, Epere, Hussein, \& Thomson, 2009, p.39) Based on this statement, students' expectations towards ICT must be noted and lecturers need to match this expectation to ensure that students stay motivated during their studies. 
A multiple case study at a New Zealand university found that e-learning offered effective ways to manage the demands of various tertiary cohorts (Johnson, Cowie, De Lange, Falloon, Hight, \& Khoo, 2011). The authors defined e-learning "as resources and activities using the internet and the World Wide Web to support teaching and learning." (Johnson et al., 2011, p.499). The cohorts comprised students from the Earth and Ocean Science, Education, Screen and Media Studies, and the pre-degree university academic skills programme. Elearning tools used in the study included Google Earth for the Earth and Ocean Science students, the use of a virtual classroom (VC) to support students who were distance learners, the use of image manipulation software by the Screen and Media Studies students, and the use of the university's learning management system (Moodle) to support pre-degree students. The study found that e-learning tools can enhance the students' conceptual, visual, and spatial thinking. However, they warn that the curriculum must be designed carefully and monitored given that not all students may embrace ICT.

In a study by Giddings, Campbell, and Maclaren (2006) on Health science students enrolled in a research methods course at a New Zealand university revealed that their preferences for ICT supported learning were due to its flexibility and the option of staying employed. The interactive on-line programme involved computer based activities such as games, quizzes, international web links, and real-time graphics. The participants who were mainly working professionals were able to complete the course without the hassles of attending classes and above all they were able to stay employed (Giddings, Campbell, \& Maclaren, 2006). Business undergraduate participants at another New Zealand university identified a number of advantages of ICT supported learning (Petrova, 2001). These included flexibility, lower travelling costs, less time consumed for travelling, easier to submit assignments on- line, less distraction from peers and the ability to study wherever and whenever.

Participants from three New Zealand tertiary institutions (two universities and an institute of technology) were surveyed to ascertain their use and perceptions of the internet as a communication tool and source of information and knowledge (Theunissen \& Theunissen, 2007). The survey found that the three most common uses of the internet by participants were searching for information, communication via emails, and searching for videos or music. The "younger" participants (under 25 years of age) associated the internet with entertainment while the older participants perceived the printed source was more reliable than 
the online version (Theunissen \& Theunissen, 2007). A study by Sheriffden (2007) involving participants from a large New Zealand based institute of technology found that participants preferred ICT as a complement to the conventional face-to-face teaching. The ICT investigated in this study was the internet for accessing course materials and research, and email for communication with tutors and peers. Even though participants found the ICT comfortable and convenient, they opposed the idea of a total online learning environment (Sheriffdeen, 2007).

An area which is beneficial for Pasifika learners is the use of ICT to enhance learners' numeracy and literacy skills. Davis, Fletcher, Brooker, Everatt, Gillon, Mackey, \& Morrow (2010) offered key success characteristics of using ICT for adult literacy, language and numeracy (LLN) in New Zealand tertiary institutes. Their report used the term e-learning where they defined e-learning as "the use of digital technologies to support learning and teaching" (p.16). Based on their definition, digital technologies are included in ICT. They reveal that ICT is more effective when it is used to support face-to-face training. In addition, computer games are powerful tools to re-engage younger adults with LLN. Wright (2010) suggests Pasifika peoples can benefit from the use of ICT that fits their respective cultures and lives.

Davis, Fletcher \& Absalom (2010) identified a number of factors for the sustained innovations in e-learning and the embedding of literacy, language and numeracy needs. These included good leadership, academic support, professional and curriculum development, e-learning development and maturity, and initiatives for Maori and Pasifika people.

Most of the studies discussed above involved participants enrolled at New Zealand universities and only two of the studies involved participants at institutes of technology or polytechnics (ITPs). In addition, all the studies were initiated by the institutes in an attempt to gauge the effectiveness of their ICT use in students' learning within their institutions. All studies discussed above confirmed that university students were more receptive to ICT supported learning. On the other hand, anecdotal evidence suggests that the same conclusion could not be made for the ITP students given the different academic abilities of these two groups of students. Students that enrol at universities would have met the higher entry requirements when compared to students enrolled at ITPs. Egler (2011) confirm that students with NCEA level 2 without University Entrance (UE) achievement 
were highly likely to pursue lower level certificate or diplomas whereas fewer students with the same level of attainment pursued degree-level studies. This highlights the need for more studies focussing on ITP sector students given that more Pasifika students are enrolled in this sector than in universities.

\section{Pasifika Tertiary Students}

Pasifika people understood and placed great importance in education and increasingly on tertiary education (Anae, Anderson, Benseman, \& Coxon, 2002). This is evident in the Pasifika students' enrolments at tertiary institutions that have steadily grown from 24,962 in 2002 to 31,868 in 2007 (Wensvoort, 2011). The proportion of Pasifika tertiary students was around $7 \%$ of the total tertiary students' population. Despite the ascending Pasifika students' enrolment numbers, successful completion has been disappointing (Wensvoort, 2011). Reasons for this undesirable outcome were complex and varied ranging from student related issues to institutional barriers (Jones, 1986; Nakhid, 2002; Petelo, 2003).

Tertiary education offers an opportunity for all young Pasifika people to enhance their knowledge and skills. The reality that many of these young people face is that they do not possess the required prior knowledge to successfully complete tertiary studies. For example, only three in ten of Pasifika school leavers qualify to attend university (Ministry of Education, 2010b). Based on this low attainment by Pasifika school leavers, the same challenges would be expected at the tertiary level. Harkess, Murray, Parkin, and Dalgety (2005) reaffirm the importance of achieving senior secondary school qualifications which facilitates easy access to tertiary education, a wide range of employment opportunities, and the flexibility to change jobs leading to better social and economic outcomes. Numerous studies have been undertaken to examine ways to improve the Pasifika students' attainment at the compulsory schooling level (Jones, 1986; Nakhid, 2002; Dickie, 2008; Ferguson, Gorinski, Wendt-Samu, \& Mara, 2008) and recommendations have been made to address the challenge.

Two studies demonstrate the influence that educational institutions have on Pasifika students' learning outcomes. Nakhid's (2002) study focused on a college and it is relevant to tertiary education. She argues that the organisational routines and school practices inhibit Pasifika students from forming an identity for themselves. The identifying process, as described by Nakhid (2002) enables Pasifika students to construct their own self-identity within the school context. 
The process requires support and to be valued by the school in order to enhance Pasifika students' achievements. The second study was undertaken more than 25 years ago but nevertheless reflects the influence that education institutions have on Pasifika learners. Jones (1986) affirms that the New Zealand school system exists to maintain the existing social relations of dominance and subordination. Jones's study explains how teachers unwittingly encourage the active participation of certain students through pedagogical interactions which precludes Pasifika students from acquiring the relevant knowledge or skills. Some of these practices are still prominent today in tertiary education classrooms. For example, lecturers promote the banking model of education where knowledge is deposited into the students' brains for later use. Petelo (2003) highlight institutional barriers in her study focussing on Samoan students at a New Zealand university.

At the tertiary level, the English language is the main language of communication and the demands for academic reading and writing are inevitable. Of concern was the decreasing prose literacy of Pasifika 16-24 year olds (Lawes, 2009). Prose literacy is a measure of one's understanding and use of information available in newspapers, magazines, novels, brochures, manuals or flyers. While there are many contributing factors for the low academic achievements of Pasifika learners, one of these may be their inability to master the English for academic purposes. Davidson-Tomu'a (2005) and Fanene (2006) concur that academic success at the tertiary level is associated with the ability to read and write English for academic purposes. Both Amituanai-Toloa (2005) and Jeurissen (2007) found that Samoan students in primary school levels in New Zealand faced difficulty in mastering the English language. These studies illuminate an area that many Pasifika tertiary students require additional academic support to ensure that they are successful in their studies.

\section{ICT and Pasifika Tertiary Students}

Research on ICT and Pasifika tertiary students is growing slowly in New Zealand. Five studies were located that were related to the topic in the period 2000-2010. A study involving students from Pacific Islands studying at the University of the South Pacific based in Suva, Fiji has been included due to its relevance to this study. Hodgen (2006) offered statistics on Pasifika tertiary students' programmes that required the use of the internet. Koloto, Katoanga, and Tatila (2006) identified critical success factors for effective use of e-learning by Pasifika learners. Two studies highlighted issues and experiences of Pasifika learners 
with e-learning (Clayton, Rata-Skudder, \& Baral, 2004; Latu \& Young, 2003). In both studies e-learning referred to the use of ICT to support learning. The fifth study was commissioned by The Open Polytechnic of New Zealand to ascertain the barriers and access levels of computers for Pasifika students (Kathryn Hall Research and Evaluation, 2005). A sixth study investigated the readiness for elearning of students at the University of the South Pacific (Raturi, Hogan, \& HeluThaman, 2011).

According to Hodgen (2006), 41\% of Pacific learners at tertiary institutions across New Zealand enrolled in programmes that required Internet access. While this was lower than the overall tertiary students' population proportion of $45 \%$, it was envisaged that it will rapidly grow in the future (Hodgen, 2006). Recent participation figures show that the proportion of Pasifika e-learning participation at bachelor degree level grew from $68 \%$ in 2004 to $72 \%$ in 2008 . In the certificate level qualification, Pasifika e-learners also grew from 22\% in 2004 to 26\% in 2008 (Guiney, 2011). Historically, most Pasifika tertiary students (62\%) were enrolled in certificate levels at institutes of technology and polytechnics (Ministry of Education, 2011) and the widespread use of ICT by these institutes will coerce them to become e-learners.

Koloto, Katoanga, and Tatila (2006) examined the experiences of Pasifika tertiary e-learners. The e-learning tools included virtual learning environment, webbased research, discussion boards, computer-based assessments, authored web pages, learning software, electronic whiteboard, video conferencing, streaming video or audio, and mobile or wireless device. Advantages of e-learning revealed by participants were: effective communication tools, readily available information, easy access to learning and course materials, and cost savings in terms of travelling time and fuel costs. Critical success factors for the effective use of elearning by Pacific learners include: readiness for tertiary study, supportive institutions, family support, quality staff, peer support, and course delivery. Clayton, Rata-Skudder, and Baral (2004) offered similar suggestions from their exploratory study on Pasifika e-learners at an Auckland-based private training establishment called BEST Training. They recommend that the learning environment must be comfortable for Pasifika e-learners, accessibility to the ICT that is to be used, the use of a blended approach, and the significance of team building and face-to-face sessions for the learners. 
An exploratory study to identify and measure barriers to accessing ICT was commissioned by The Open Polytechnic of New Zealand (TOPNZ). The study found that South Auckland-based Pasifika learners had high (90\%) access to computers at home (Kathryn Hall Research and Evaluation Ltd, 2005). The findings of this study can not generalised due to its small sample size of 69 . This high ICT uptake of Pasifika participants (90\%) in the study contradicts the low national uptake of computers in Pasifika households (39\%) and the lowest internet access of Pasifika people (23\%) when compared to other ethnic groups (Statistics New Zealand, 2004). An explanation for the high ICT uptake of Pasifika students in the study was possibly the fact that it is a distance education and therefore students required computers to access their learning resources. It was therefore unsurprising that Pasifika students enrolled through TOPNZ had access to computers because it was a course requirement.

It is evident from the five studies discussed above that there is an urgent need to determine how Pasifika tertiary students are coping with the added demand of ICT on their studies. Given the economic downturn of 2011 and the impact of ICT on the workforce and more specifically in the tertiary sector, it is imperative that Pasifika peoples are better prepared for the future. Innovative ways of using available ICT or adapting ICT need to be identified and made known to more Pasifika peoples to better prepare them for tertiary studies and also for the workforce.

In a study undertaken outside of New Zealand but focusing on Pasifika students, Raturi, Hogan, and Helu-Thaman (2011) investigated the readiness of students enrolled at the University of the South Pacific to use ICT required for the distance education delivery. Participants in the survey included students from other Pacific Island countries but the majority were from Fiji. The study found that students perceived their ICT skills to be excellent and were comfortable in the use of computer applications and the internet.

\section{Systems Development Life Cycle (SDLC)}

The following discussion presents a brief historical background of SDLC and its role in software development. This is essential as this will highlight the connection that the SDLC has with the Pasifika Tertiary Students' ICT Skills Development Framework. 


\section{The Origins of SDLC}

The Systems Development Life Cycle (SDLC) first emerged in the late 1960s where it was used to develop large scale functional business software systems. In the 1950s and most of the 1960s there was no industry wide or formalised methodology for software development (Avison \& Fitzgerald, 2003). Prior to the introduction of the SDLC process, software was developed through a "code and fix" approach. The SDLC introduced a structured approach and had several phases that included design, implementation, and testing that were recommended for a software development project to undertake (Futrell, Shafer, \& Shafer, 2002). A number of SDLC models that were found in the literature included the waterfall model, the incremental model and the spiral model.

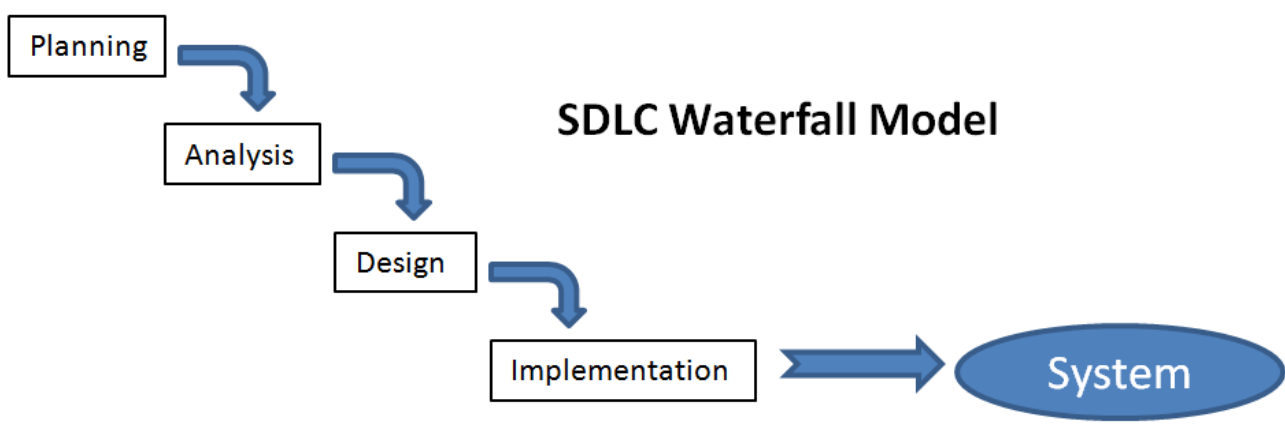

Figure 3: SDLC Waterfall model

The original SDLC model was the waterfall model whereby the output of each phase became the input for the next (Royce, 1970). There were many different variations of the waterfall model with different phase names and in some cases additional phases have been introduced, resulting in the number of phases varying from four to seven. The incremental model was developed to overcome the linear and sequential approach of the waterfall model (Kossiakoff, Sweet, Seymour, \& Biemer, 2011). The incremental model was an iterative process of the waterfall model that focused on delivering an operational product with each increment. The spiral model combined the best features of the waterfall model and the incremental model and included an additional element of risk analysis. 


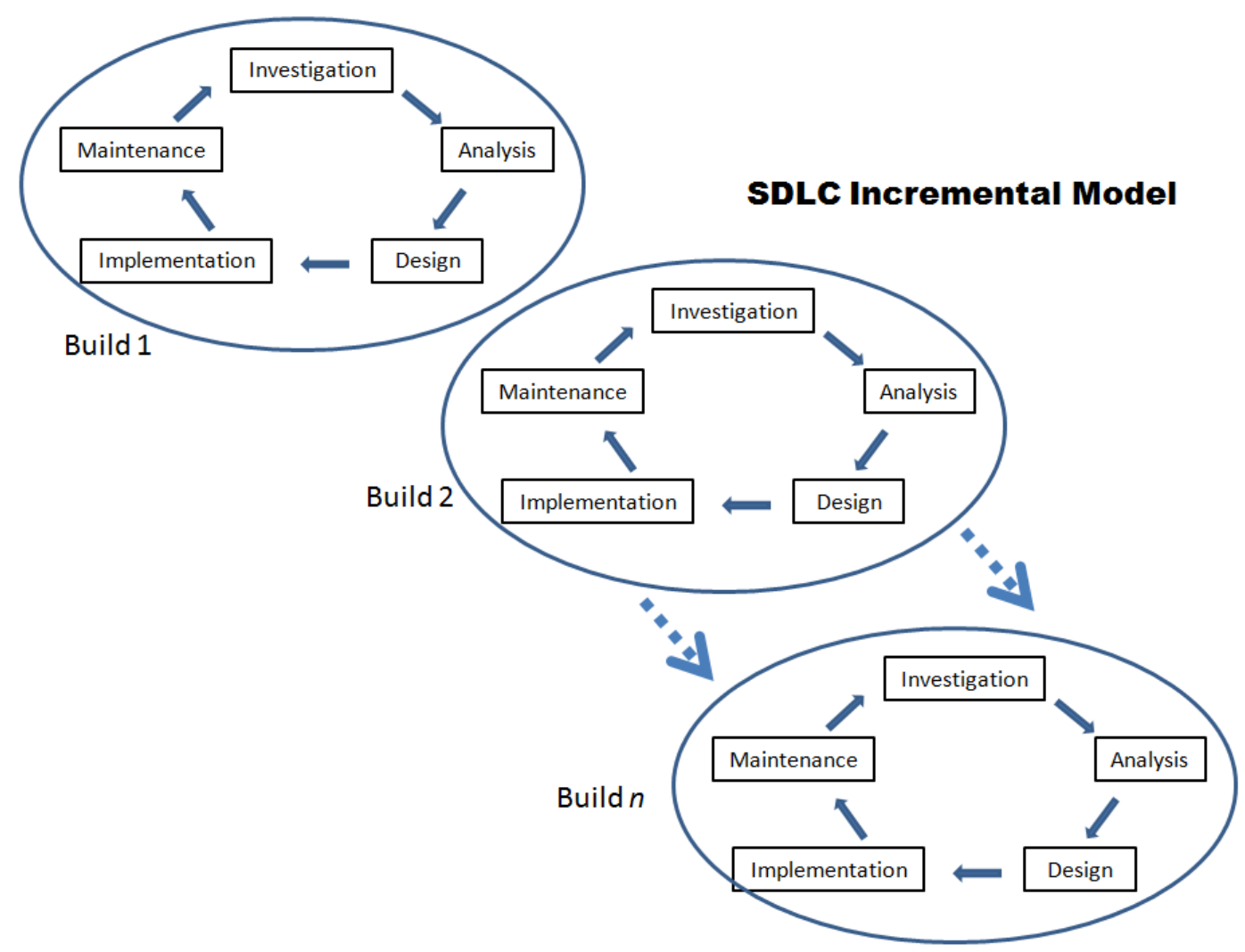

Figure 4: SDLC Incremental model

The SDLC process applies to information system development projects to ensure that all functions and user requirements and agency strategic goals and objectives were satisfied. The SDLC offer a structured and standardised process comprising a number of phases for any system development project. These phases include: planning, analysis, design, development, implementation, and review and maintenance (Dennis, Wixom, \& Roth, 2006).

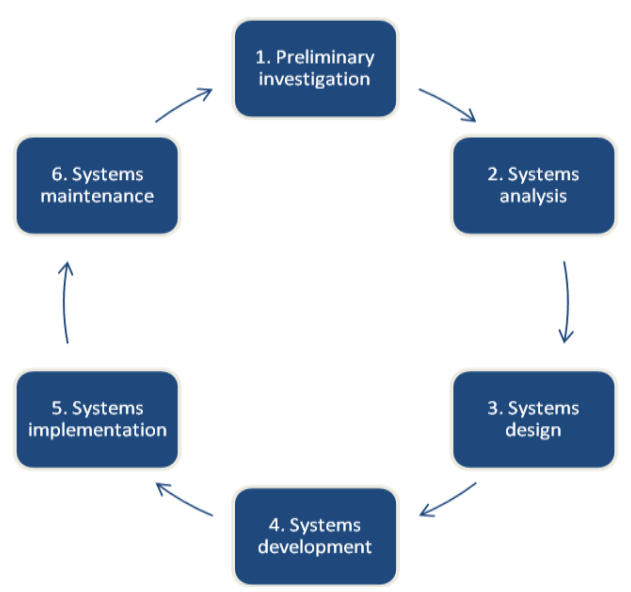

Figure 5: Systems development life cycle

(Laxmi and Kumar, 2007, p.21) 


\section{Phases of the SDLC}

The planning phase includes the feasibility study and the initial system investigation. The feasibility study examines the current system, how it is coping with the current demands, current deficiencies, new requirements that have emerged, and possible solutions (Lewis, 2008). Pending the outcome of the feasibility study, the next stage involves the detailed fact finding phase. The system investigation examines the functional requirements of the current system and whether these requirements are being achieved. This is followed by examining the requirements of the new system and how it will meet the new challenges, any imposed constraints, the range of data types, the anticipated workload of the new system, exceptional conditions, and problems of the present system. Overall, the information from the system investigation will be in greater detail than the feasibility study (Avison \& Fitzgerald, 2003).

The second phase, namely the systems analysis phase, is guided by the following questions: Why do the problems exist? Why were the current solutions adopted? What are some alternative solutions? Can the proposed system handle future demands? The system analysis phase attempts to understand all aspects of the current system and why it was developed to where it is now, and how the new system will improve things for the future (Avison \& Fitzgerald, 2003).

After a thorough systems analysis has been undertaken the next phase in the SDLC is the systems design phase. The design phase begins with a preliminary design or a "rough draft" of the proposed system. The preliminary design is then followed by the detailed design of the new system. Some tools or techniques employed in the design phase include computer-aided software engineering (CASE) tools to accelerate the process of software development at the same time improving the quality of the new system. CASE tools help system analysts to develop a prototype so that users can test and evaluate design concepts of how the proposed system can improve current practices. The fourth phase of the SDLC is the systems development phase. The development phase involves the acquisition of software and hardware and the testing of the new system. In the design phase, the decision to build the software or to purchase it was made. Therefore, in the development phase the decision is followed accordingly. Similarly, the decision made at the design phase on using existing hardware or purchasing new hardware is also followed. Thorough testing of the new system is vital as this is the crucial stage before the implementation phase (Dixit \& Kumar, 2007). 
The fifth phase is the implementation phase which involves the conversion and migration of files from the current system to the new system. The implementation phase can be undertaken in a number of ways: direct, parallel, phased, or pilot approach. Direct implementation means users simply stop using the current system and start using the new system. Parallel implementation enables the two systems to co-exist until such time when the new system is determined to be capable of running on its own and the current system is made redundant. Phased implementation introduces parts or phases of the new system to enable users to test its capabilities. Pilot implementation enables a few users to test the new system before its full implementation. Systems documentation and user training is the final task for the implementation phase. The last phase in the SDLC is the systems maintenance. This is a never ending phase as the new system requires on-going adjustments and improvements to meet the conditions and new demands of users (Dixit \& Kumar, 2007).

The original SDLC model was developed to handle large software projects spanning long periods of time and involving many people. For the purpose of this study, the SDLC has been adapted using the same phases but the details for each phase has been reorganised to enable the researcher who is the only people involved in this study to identify ready made solutions as opposed to developing ICT applications to meet the objectives of the study.

\section{Pasifika Tertiary Students' ICT Skills Development Framework}

Some organisations have changed the standard SDLC model slightly to meet their specific needs (Barnard, 2008). The Pasifika Tertiary Students' ICT Skills Development Framework (PTSISDF) was an adaptation of the SDLC discussed above. The SDLC is an industry-proven model for software development providing systematic and well-structured approaches that software development companies have adopted in the past forty years. It defined a quality level meeting industry and organisational requirements (Walsh \& Johnson, 2001). The PTSISDF was aimed to provide a systematic structured approach to manage the various activities intended to uplift the participants' ICT skills and to enhance the successful outcomes of the study.

The PTSISDF comprised six phases that included: measure, identify needs, analyse gaps, develop strategies, implement strategies, and monitor and evaluate the strategies. The names of the phases have been purposefully 
shortened to enable the names to fit the boxes in the diagram. The framework exists as a cycle and therefore it can operate for as many cycles as required. An outline of how the framework was used is provided in the methodology chapter.

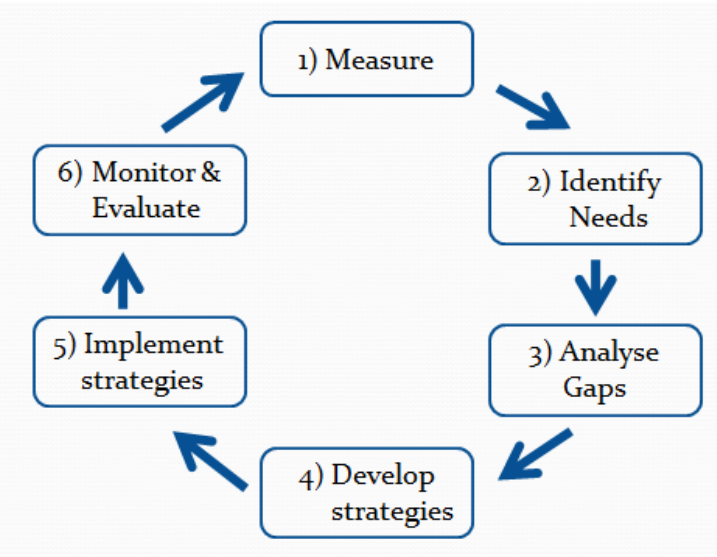

Figure 6: Pasifika Tertiary Students' ICT Skills Development Framework

\section{ICT Skills}

This section outlines two aspects of ICT skills. It begins with the definitions of ICT skills as derived from the literature followed by the impact of ICT skills on the national economy. A high number of Pasifika peoples are reported to be unemployed (Statistics New Zealand \& Ministry of Pacific Island Affairs, 2010). Unemployment arises when individuals do not possess skills that are in demand by the market. The researcher holds the view that Pasifika peoples with the relevant ICT skills may enable them to find employment.

There is no universally accepted definition for ICT skills. As a result, ICT skills refer to different things in different parts of the world. This section will begin by discussing three definitions for ICT skills that were identified from the literature. First, the Organisation for Economic Co-operation and Development (OECD, 2005) offers three categories of ICT competencies namely: ICT specialist, advanced user, and the basic user. The ICT specialist is capable of developing, operating, and maintaining ICT systems. For the ICT specialist, ICTs constitute the main part of their employment. The advanced user has advanced capabilities in using general and sector-specific software tools. The basic user is a competent user of generic software tools to participate in the information society. E-business skills refer to skills that are needed to utilise the internet for business purposes. 


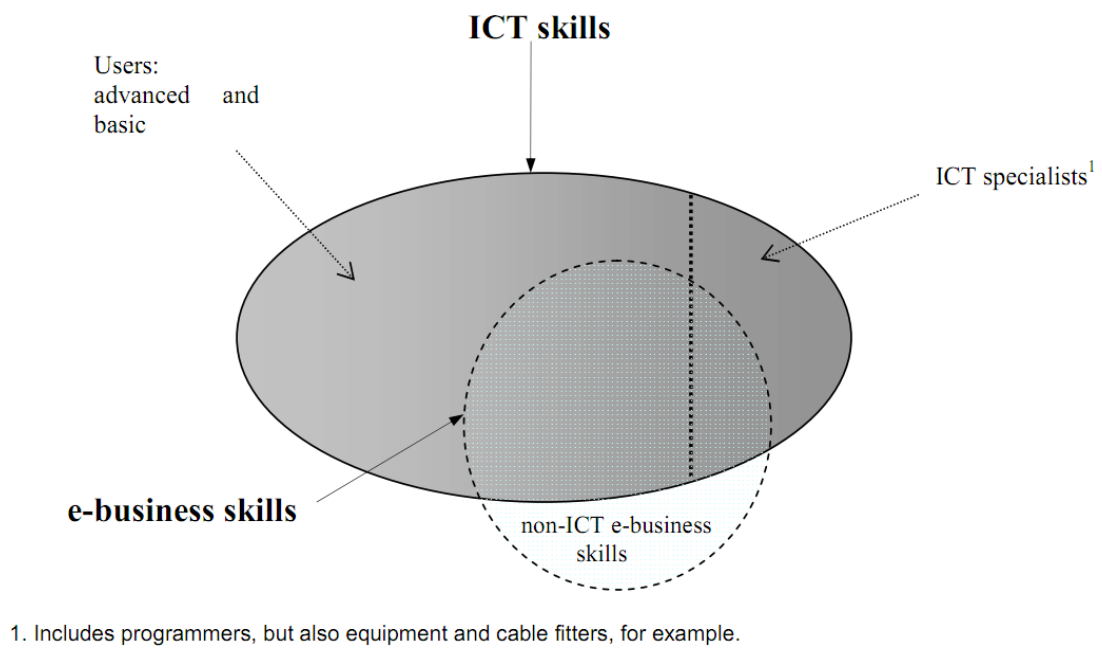

Figure 7: ICT Skills (OECD, 2005, p.6)

Second, the United Nations' Asian and Pacific Training Centre for Information and Communication Technology for Development define ICT skills under two major categories: ICT professionals, and ICT users. Each major category has sub-categories as shown in the diagram below (Raina, 2007). The intersection of the two major categories comprise of ICT professionals who work outside the ICT industry.

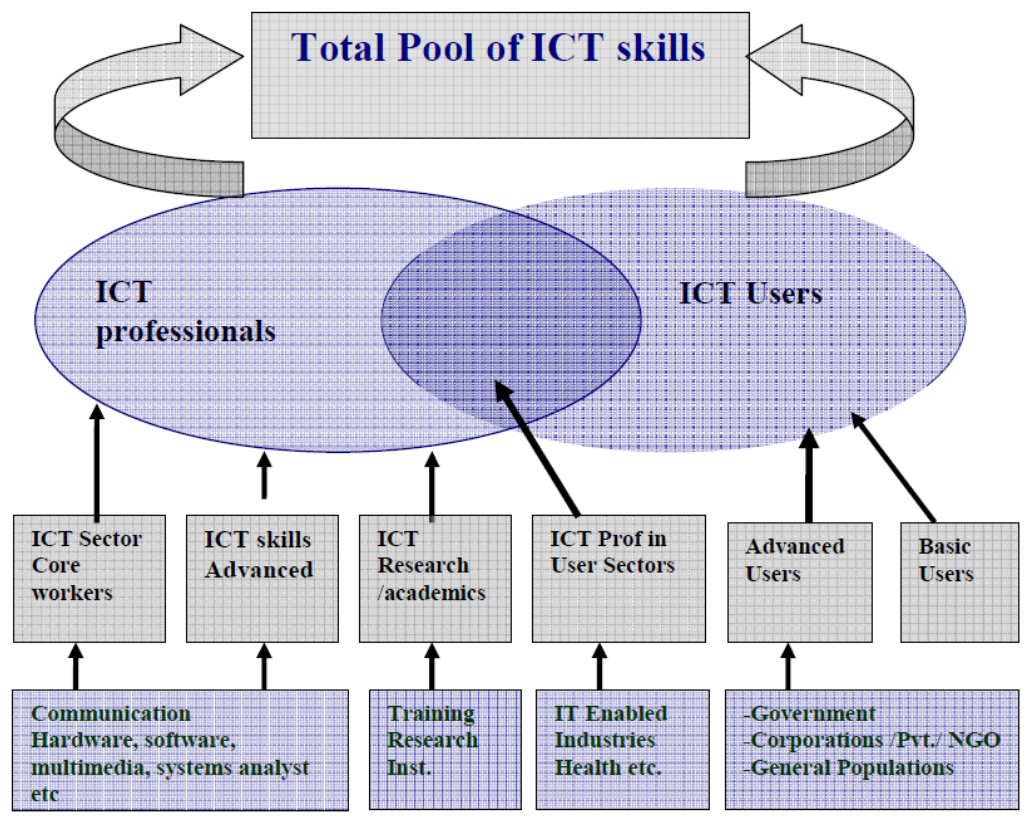

Figure 8: ICT Skills (Raina, 2007, p.13)

Third, the Commission of the European Communities (2010) define e-skills covering "three main categories: ICT practitioner skills; ICT user skills; and ebusiness skills" (p.20). The ICT practitioner skills refer to the "abilities required for researching, developing, designing, strategic planning, managing, producing, 
consulting, marketing, selling, integrating, installing, administering, maintaining, supporting and servicing ICT systems" (p.20). The ICT user skills refer to the "abilities required for the effective application of ICT systems and devices by the individual" (p.20). Generally, this includes the abilities required for the confident and critical use of ICT for work, leisure, learning and communication. E-business skills refer to the capabilities to "exploit opportunities provided by ICT, notably the Internet; to ensure more efficient and effective performance of different types of organisations; to explore possibilities for new ways of conducting business/administrative and organisational processes; and/or to establish new businesses." (p.20)

A new term is now being promoted by the European Communities and that is eskills. The European e-Skills Forum (2004) define e-skills as a sub-set of the broader range of talents and skills that are required for the global knowledge economy. Skills essential for competitiveness in the global knowledge economy include the ability to manage across national and cultural borders, to nurture and grow innovation across network-based teams, and to engage all stakeholders in sharing knowledge and information through computer networks. E-skills comprise the following three skills: ICT user skills, ICT practitioner skills, and ebusiness skills. ICT user skills include the ability of an individual to use ICT systems and devices. ICT practitioner skills include the ability to research, design and develop, manage, produce, consult, market and sell, integrate, install and administer, support and service an ICT system. E-business skills include the ability to exploit opportunities that ICT has to offer in order to conduct business and organisational processes effectively and efficiently (Lanvin, 2008).

It is evident from the three definitions offered by the OECD (2005), UN Asian and Pacific Training Centre (Raina, 2007) and the Commission of the European Communities (2010) that ICT skills are a broad, dynamic and evolving phenomenon. The term has its roots in computer skills which simply referred to the skills required to operate or use a computer. As the computer became a part of the information technology (IT), the term evolved to IT skills which later became ICT when communication became an integral part of IT. Currently, ICT is now replaced with "e" (electronic) whereby ICT skills are now a subset of eskills. For the purpose of this study, ICT skills and e-skills will refer to the required skills to use ICT. The focus will be on the users as opposed to creators of ICT. 


\section{Impact of ICT skills on the economy}

The significance of ICT to the economy (The World Bank, 2009) and ICT skills for employment has been widely accepted in developed countries (Akooje \& Arends, 2009). In Australia, ICT is a major driver of economic growth and productivity where it is used to enhance efficiency and innovation (Department of Communications, Information Technology and the Arts, 2006). ICT is the backbone of communications while offering the means to access, store and manipulate data to provide timely and critical information to business, government, research, education, health and many others. A study conducted in 2005 found a strong correlation between productivity growth and ICT use and intensity (Department of Communications, Information Technology and the Arts, 2005). This was evident in ICT intensive services such as communication, electricity, finance and wholesale trade.

In the United States of America between 1995 and 2002, ICT was responsible for two-thirds of total factor growth in the country's productivity and also including all the growth in the labour productivity (Atkinson, 2007). Four aspects have been identified as contributing factors for ICT contributing more to productivity. First, ICT were relatively new and were very easy to implement to improve efficiencies. Second, in addition to automating tasks, ICT had widespread complementary ripple effects such as the opportunity to reengineer processes. Thirdly, ICT enables more people to work better and faster. Furthermore, ICT collapses time and space enabling users to share resources efficiently spurring competition and more efficient division of labour.

As organisations invest more in new and advanced ICT, the demand for people with the relevant skills will increase. In the mid-2008, the global ICT market was estimated at US\$3.8 trillion with seventy percent derived from governments and businesses spending (New Zealand Trade and Enterprise, 2011) At the same time, there are many and varied factors that may trigger a shortage in the number of people with the required skills. The adoption of the latest ICT may cause a demand for people with the relevant skills. Equally, businesses that still use older ICT may find it harder to find people who have the expertise to maintain their ICT. In addition, ICT skills are required to access information and services, leisure, health and social networking.

ICT skills are an important entry ticket to the job market, especially for people who strive towards better paid jobs (Peng \& Eunni, 2011). Basic ICT skills that 
include the use of email, basic word processing, spreadsheet and database applications have over the past ten years become part of a standard set of skills for white-collar jobs (Lindsay, 2005). A number of factors contribute to this widespread expectation from employers. Firstly, the rapid increase of computer use in private businesses and public institutions, evident in certain industries such as finance, marketing, and in functional areas such as back-office administration where it is the norm. Secondly, the vastly improved and more affordable price of personal computers has enabled more people to acquire their own and to teach themselves how to use the computer and associated software (Lindsay, 2005). At the same time, mobile phone has evolved from simply receiving and making voice calls to browsing the internet and multiple other uses (Chesley, 2010). These devices have become an integral part of our daily lives and the need for the relevant skills to utilise them is inevitable.

As more ICT are adopted across all economic sectors the demand for ICT skills amongst workers will increase. The global economic crisis has led to more people re-skilling and up-skilling in the hope to rejoin the work force. The older workforce who is returning to work indicated that the number one skill that they required training in is ICT skills (AARP, 2008). Furthermore, the $21^{\text {st }}$ century is also known as the digital era whereby in most developed countries more than half the employment opportunities require the use of a computer (Workforce Development Council of Seattle-King County, 2007).

The New Zealand Trade and Enterprise (2011) define the ICT industry to include the wireless infrastructure, health IT, digital content, payment, geospatial, telecommunication and agricultural technology amongst others. New Zealand's ICT industry contributes more than $\$ 19$ billion to the economy each year. Based on the assumption that $70 \%$ of the workforce achieved productivity improvement through the use of ICT in one year, an estimated annual productivity gain of $\$ 1.7$ billion can be achieved over ten years (Bunker, 2010). The potential to use ICT within the New Zealand workforce has not been fully utilised. However, the limited number of suitably qualified and experienced staff in the ICT industry has hindered the growth of the industry for many years. A survey commissioned by the Ministry of Economic Development revealed that companies were in need of intermediate or advanced ICT skills in the categories of management, sales/marketing and technical (Mitchell, 2009). This is consistent with the global trend of the shortage of skilled ICT workforce. 
Literature relating to ICT skills and employment in New Zealand is mainly from government departments and few from the private sector. The New Zealand Computer Society (2011) recognises the need to develop ICT skills of New Zealanders. It has a number of initiatives to address digital numeracy in New Zealand. It uses the International Computer in Driving License (ICDL) and the ecitizen end user certification in an attempt to coordinate and standardise the push to improve ICT skills of the workforce.

Researchers from the University of Washington identify three roles that basic ICT skills play in supporting individuals to secure employment (Garrido, Badshah, \& Coward, 2009). First, basic ICT skills serve as gateway skills or entry tickets as stated above. Job applicants without IT skills certification can be excluded from consideration. A practice in some New Zealand employment recruitment agencies is to request all job applicants to undertake a practical IT skills test. Failing the test would eliminate the applicant from progressing any further in the recruitment process. Second, basic ICT skills are one among many necessary skills. Other necessary skills include communication, critical thinking, problem solving, and team player amongst others. Third, basic ICT skills serve as a catalyst for other key skills development. It has been found that once the gateway function has been met, accessing or improving other necessary skills become taken for granted.

\section{Employability}

In this section, the definition of employability is explored despite Harvey's (2001) warning that it is rarely explicitly and clearly defined. According to Hillage and Pollard (1998), employability refers to the ability to get initial employment, maintain employment and access alternative employment if the need arises. For a person, employability is dependent on attributes such as their knowledge, skills and their attitudes. In addition, the person's ability to use and present these attributes to prospective employers may influence employability. A crucial factor that influences employability is the context within which a person seeks work.

Another definition of employability refers to a combination of factors and processes that enhance an individual's chances to obtain employment, remain employed or to advance in a workplace (Garrido, Sullivan, \& Gordon, 2010). The concept of employability in this definition focuses on an individual's skills and skill development. 
Hillage and Pollard (1998) propose four critical factors of employability which includes employability assets, the deployment and presentation of the assets, and the context within which the individual is based. Firstly, employability assets comprise of baseline, intermediate and high level assets. Baseline assets are minimum skill requirements such as basic skills and essential personal qualities such as reliability and integrity. Intermediate assets include occupational specific skills, generic skills such as communication and problem solving, and key personal qualities such as motivation and initiative. High level assets include skills that contribute to the organisational performance.

The second critical factor identified by Hillage and Pollard (1998) was the deployment of the assets outlined above. Deployment refers to a set of skills that include: career management, job search, and a strategic approach. Career management skills require an awareness of the type of jobs of interest; an awareness of the existing job opportunities and the entry level requirements; decision making and development of a strategy to progress from the current situation to a better situation in the future; and transition skills. Transition skills include job search skills and a strategic approach. Job search requires identifying where to finds jobs, and access to formal and informal networks which assists in the process. A strategic approach demands adaptability to market developments and being realistic about job opportunities. This may demand flexibility towards the types of jobs and the location in which they are available (Hillage \& Pollard, 1998).

The third critical factor of employability proposed by Hillage and Pollard (1998) was the presentation of the employability assets. Presentation involves the preparing and presenting of the curriculum vitae (CV), records of achievement, references and testimonies. The $\mathrm{CV}$ outlines the detailed information about academic and vocational qualifications, work experience and other relevant personal qualities. Furthermore, oral presentation of the relevant information during interviews contributes immensely to a successful outcome (Hillage \& Pollard, 1998).

According to Hillage and Pollard (1998), the fourth and a crucial factor of employability is the context of personal circumstance and the labour market. The ability to secure employment is dependent on internal and external circumstances and how an individual recognises the two forces and identifies a way to navigate between the two. Personal circumstances include: caring responsibilities, 
disabilities, and household status are some examples that may influence a person's ability to seek employment opportunities. External factors may include macro-economic demands which affect the job market; labour market regulations and benefit rules; and employer recruitment preferences.

While ICT skills have been established as a vital skill in seeking employment, it must be emphasised that there are other skills that will futher increase likelihood of employment. These skills are referred to as employability skills.

\section{Employability Skills}

Employability skills refer to a widespread generic work-related competencies and personal qualities which are outlined by employers (Commonwealth of Australia, 2009). This is consistent with an earlier definition found in the 2002 report Employability Skills for the Future stating that it refers to "skills required not only to gain employment but also to progress within an enterprise so as to achieve one's potential and contribute successfully to enterprise strategic directions" (Department of Education, Science and Training, 2002, p.3). The report also presented a framework which consisted of personal qualities and eight employability skills. The personal qualities were loyalty, commitment, honesty and integrity, enthusiasm, reliability, personal presentation, common sense, positive self-esteem, sense of humour, balanced attitude to work and home life, ability to deal with pressure, motivation, and adaptability. The eight employability skills included communication, team work, problem-solving, initiative and enterprise, planning and organising, self-management, learning, and technology skills.

The American Society for Training and Development (ASTD) identified three themes that served as foundational skills for effective participation in a workplace. The three themes included basic skills, thinking skills, and personal qualities. Reading, writing, basic mathematical skills, and communication skills were regarded as basic skills. Creative thinking, problem solving, and lifelong learning were identified as thinking skills while personal qualities involved taking individual responsibility and operating with integrity within the work environment (Carnevale, Gainer, \& Meltzer, 1990).

The New Zealand Skills Strategy 2008-2012 championed by the Tertiary Education Commission (TEC) is aimed to ensure that individuals and organisations co-operate and develop the skills required for the workplace in the 
future. Interestingly, the strategy is focused on improving literacy, language and numeracy skills. The plan defined literacy as "the written and oral language that language people use in their everyday life and work; it includes reading, writing, speaking and listening. Skills in this area are essential for good communication, critical thinking and problem-solving in the workforce." (Tertiary Education Commission, 2008, p.6) Numeracy on the other hand is defined as "the bridge between mathematics and real life" including the application of mathematics to everyday life activities.

All the above stated skills can be supported with the innovative use of ICT. The four critical factors of employability outlined earlier which included employability assets, deployment and presentation of assets and the individual's context can be mitigated with the use of ICT (Hillage \& Pollard, 1998). All these factors, ways to meet them and other relevant information can be presented to anyone interested through a website. In this way, interested individuals can access the information and make further enquiries to improve their employability status.

\section{Learning of skills}

Generally, skills are acquired through a number of ways which includes: formal education, work experience, training, natural abilities, and other ways such as self-training and informal learning (Lopez-Bassols, 2002). For the purpose of this study, formal education refers to education undertaken at the compulsory education sector which includes the primary and secondary school system followed by tertiary education. Formal education is "assessed by a nationally recognised body and contributes to a nationally recognised qualification" (Scott \& Lane, 2010, p.1).

The formal education approach is a primary mechanism for the development of skills for most New Zealanders. The Industry Training Federation (ITF) in New Zealand is responsible for training in the workplaces mainly in the trades sector. Over 185,000 trainees received workplace training through the ITO and this number represents approximately one quarter of all tertiary education learners in New Zealand (Moses, 2010). The focus of this study will be on the other ways that ICT skills can be acquired which includes self-training and informal learning.

In this study, informal learning will be defined based on the five dimensions outlined by Callan, Cervantes, and Loomis (2011). Informal learning is nondidactic, socially collaborative, undertaken in meaningful activity, identified by the 
learner, and has no formal assessment. This is the learning experience that the participants will encounter to enhance their ICT skills.

A social learning theory known as situated learning theory proposed by Lave and Wenger (1991) placed learning in the context of our daily lived experiences. In other words, learning is undertaken through social participation. This is in contrast with the assumption that learning is an individual process, has a beginning and an ending, and has to be separated from other activities. Wenger posits that humans are social beings, knowledge is a matter of competence with respect to a valued undertaking, knowledge is acquired through participation in the pursuit of such undertaking, and meaning is a result of learning. Wenger (1998) identified four components essential for characterising social participation as a process of learning. These included a community, identity, meaning, and practice. He argued that humans learn in order to belong to a community. In the process of learning humans acquire an identity relevant to the community. Furthermore, learning by doing or practice enables the learner to experience what is learnt and to better understand the meaning of what is learnt. The diagram below clearly demonstrates the concept and the connectedness of the four essential components.

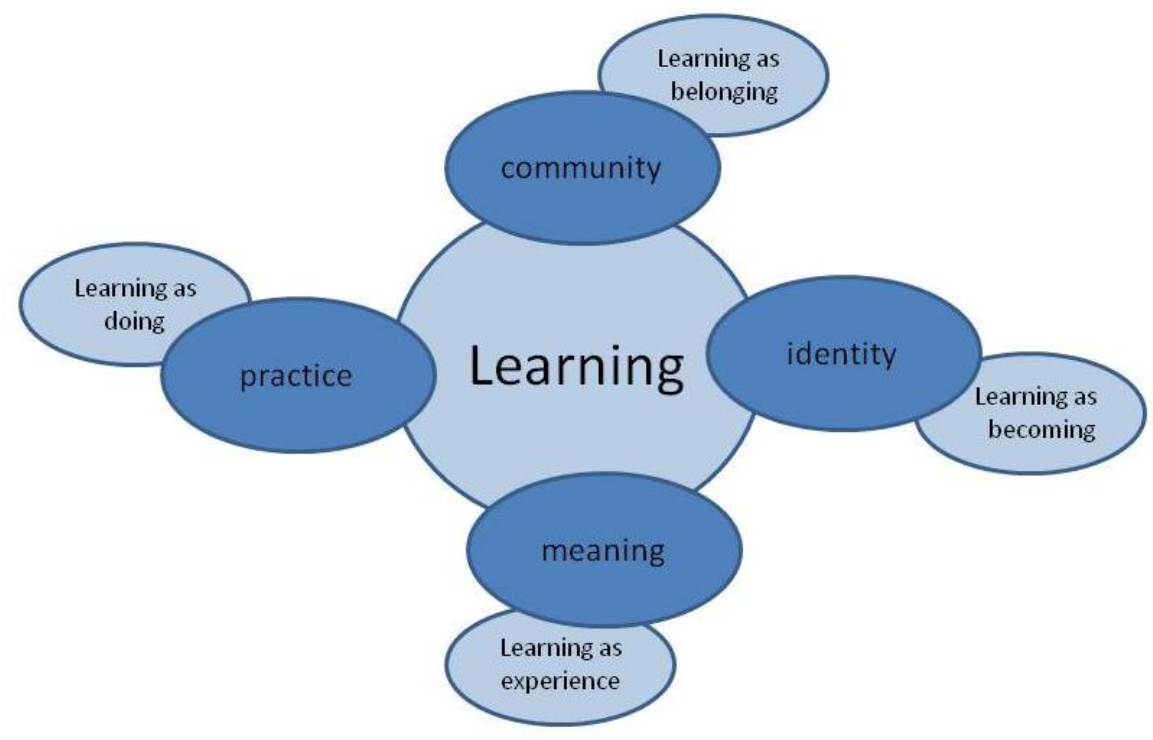

Figure 9: Learning of skills (Wenger, 1998, p.5)

\section{Situated Learning Theory}

Situated learning theory (SLT) is often credited to the work of Lave and Wenger (1991) although it can be viewed as an extension of earlier work by Vygotsky's Mind in Society (1978) and situated cognition (Brown, Collins, \& Duguid, 1989). Vygotsky (1978) argued that students learn through social development. Further 
detail in Vygotsky's approach was presented by Brown, Collins, and Duguid (1989) where they argued that knowledge is situated and is a product of the activity, context, and the culture in which it is developed and used. The activity used to develop and deploy the knowledge could not be separated from the learning process and cognition. Ignoring the situated nature of cognition may lead to different learning results.

Brown, Collins, and Duguid (1989) exemplify the connection between situated knowledge and learning through the vocabulary teaching study undertaken by Miller and Gildea (1987). Miller and Gildea's study examined how vocabulary was taught in school and how vocabulary was learned outside school. In school, students learnt the definitions of a word from a dictionary accompanied by a few exemplary sentences, in contrast to outside the classroom where words were learnt in the context of everyday conversations. Miller and Gildea further revealed that students in the classroom using the teaching approach outlined above learnt between 100-200 words per year. In comparison, students who learnt outside the classroom were found to have learnt over thousand words per year.

Brown, Collins, and Duguid (1989) likened the dictionary-based learning approach to abstract teaching of concepts detached from authentic situations as widely practised in the school system. Understanding is developed through continued, situated use and involved complex social negotiations. They further argued that concepts were situated requiring activities to progress its development and the consideration of conceptual knowledge was similar to a set of tools. Generally, a tool is defined as a device designed for a purpose. A tool is better understood through its use and the knowledge acquired through its use increases the user's appreciation at the same time adopting the inherent culture associated with the tool. It is widely known that people who use a tool actively develop a rich tacit knowledge of the environment in which the tool is used and the tool itself. The knowledge is continually enhanced, challenged or modified with each interaction. An extension of this analogy is that a tool can be used in more than one way by different users. Tools and the way they are used reflect on the users, the context of activities where the tool is used and framed by the world view of the users.

In the same way, Brown, Collins, and Duguid (1989) argued that conceptual tools have similar characteristics as physical tools. Conceptual tools are only 
meaningful if one understands the community or the culture that uses them. Their meaning is not fixed but developed through negotiation of the community of users. It can be viewed that conceptual tools are a function of the culture and the activities relevant for their development. Based on this comparison, Brown, Collins, and Duguid (1989) explained that students in a classroom setup are expected to use the tools of a profession without being given the opportunity to adopt its culture. In order to use the tools, students must enter that community and learn its culture to better understand and appreciate the tools. This learning process leads to enculturation.

Situated learning as presented by Lave and Wenger (1991) is a sociocultural theory which argues that learning takes places in particular social practices. Legitimate peripheral participation (LPP) was introduced as a notion to describe the learning process within a community of practice. LPP offers a way to describe the relationships between expert and the learners, the activities, identities, artefacts, communities of knowledge and their practices. The phrase (LPP) may imply that there may be an illegitimate or central participation but Lave and Wenger (1991) contend that there is no such thing. Legitimacy in the LPP context refers to a defining characteristic sense of belonging while peripheral refers to the multiple, varied, more or less engaged, and inclusive ways of being part of the community of practice.

For the learner, the legitimate peripheral status offers more than an observational position. It offers participation as a way of learning as the learner enters the community of practice. A community of practice can be a formal or informal group of individuals with a common interest within any aspect of life. Lave and Wenger (1991) outline that not all communities is a community of practice. Members of a community of practice participate at multiple levels, hold multiple interests, contribute differently to community activities, and hold varied viewpoints.

According to Wenger (1998), communities of practices are everywhere, individuals may belong to several communities of practice at any given time, and membership to the communities of practice may change over time for various reasons. A community of practice has three dimensions comprising of mutual involvement, joint enterprise, and shared norms (Wenger, 1998). Examples of communities of practice include families, workers at workplaces, students at schools, musical bands, radio enthusiasts, recovering alcoholics, scientists, 
online forums, young gangs, and many others. Families in their everyday existence develop specific practices, routines, rituals, artefacts, symbols, conventions, and stories. As new members enter the community, in this case the family, they slowly learn the culture of the family and over time acquire the identity of the family while becoming a family member.

Workers organise themselves through participation with colleagues to satisfy customer needs resulting in work completion. Within the work environment, they may develop multiple identities and may participate in multiple communities of practice (Wenger, 1998). For example, they may be an employee of the company or organisation at the same time. They may be a member of a department or section with a specialised role with the company. Furthermore, an employee may be a member of a fitness group that meet twice a week and goes out for a walk during the lunch break. Students at school form their own communities of practice which may support the goals of the school or other selfdetermined goals. Within the classroom walls, students may be members of a community of practice that promotes their learning of the formal or informal curriculum.

In this study, situated learning theory was identified as an appropriate theory to drive the aims of the study. Firstly, it was perceived that the acquiring of ICT skills was crucial for Pasifika tertiary students not only in their current programs of study but also in their day to day activities. SLT promotes learning in a social context and the use of communities of practice, a concept that is already in existence amongst Pasifika peoples. The only difference in this study is that the focus of the proposed community of practice is on ICT and the development of the associated skills for efficiently and effectively using the various ICT.

\section{Pasifika Students' Learning Styles}

Learning styles is a contentious concept (Wolf, 2007). There are a number of associated theories and as many as 71 models (Coffield, Moseley, Hall, \& Ecclestone, 2004). The following section will present the identified literature covering Pasifika students' learning styles at tertiary education level. The studies are presented in a chronological order.

Pasikale (1996) echoed Jarvis's (1987) concern that cognitive style and learning style are two different concepts. Cognitive style refers to the thought processes while learning style refers to the ways that people undertake learning. Based on 
these definitions, generalisations that all Pasifika learners prefer group work or discussions because they are from an oral culture require close examination. Pasikale (1996) found that Pasifika learners' preferred learning styles were at two levels: the process, and their attitude and behaviour. A variety of needs and preferences were stated. One third of the learners preferred the teacher to first demonstrate accompanied with clear explanations while the learners watched followed by some practice by the student before showing it to the teacher. Group processes identified by one fifth of learners were group discussions and team work. A smaller number of learners preferred to "figure it out" first before seeking the teacher's assistance while the majority of learners emphasised that practice was crucial for learning (Pasikale, 1996).

The holistic view that Pasifika peoples have towards learning is described in the following paragraph. The "learning place is a family place" (Pasikale \& Yaw, 1998, p.36) and the "family place is a learning place" (p.36) were concepts that guided the work of the Pasefika Education and Employment Training Organisation (PEETO). Staff at PEETO strived to meet the aspirations and goals of the Pasifika learners. This was how they measured the quality of their work. In their view, the creation of a family atmosphere will foster a culturally safe environment which will enhance learners' confidence and self-esteem resulting in positive academic outcomes. The family atmosphere included both physical resemblance and interactions amongst members and visitors. Staff and students expressed a strong sense of belonging to the institute that enabled greater interaction between all members. Group-based learning was identified as an effective learning strategy. Group work upholds the family principles whereby responsibilities are shared while mistakes are rectified in a culturally safe environment (Pasikale \& Yaw, 1998).

In their study of five private training establishments that catered mainly for Pasifika learners, Pasikale and Yaw (1998) outlined that Pasifika learners preferred group activities and team work. They argued that communal approaches were culturally familiar for the learners where individual inhibitions were resolved in a culturally safe environment. Learners were generally uncomfortable with lectures and book-based learning which demanded reading and comprehension. Reasons attributed to this discomfort were the learners' oral culture and their English literacy deficiencies. Furthermore, Pasifika learners enjoyed learning that involved all the senses. This approach was reinforced 
through demonstrations, hands-on activities, field trips, work experience, and one-on-one coaching.

Another approach that the literature indicated was Pasifika peoples preferred mentoring. Mentoring is a practice that appeared to have a positive effect for Pasifika learners. Anae, Anderson, Benseman and Coxon (2002) described the MALAGA mentoring initiative as a positive approach to motivate Pasifika learners. The initiative aimed to provide participants with the necessary skills to achieve balance amongst the various social, academic, work and cultural commitments faced by many participants. The programme involved: hands-on mentoring; group career planning; study skills activities; public speaking exercises (debates); sports and recreational activities, life and study-skills workshops; traditional/contemporary weaving, painting, stitching, art; and motivational career programmes where speakers give talks to participants.

Meanwhile, Latu and Young (2003) allude that the root cause of Pasifika students' poor academic performance lies in their differing cultural background. They reveal that prior to Christian missionaries' arrival to the Pacific region, the traditional mode of teaching and learning involved supervising, observing, and doing together. In the case of building a canoe, the learner must watch the teacher or the expert very closely use the carving axe, before trying to emulate the actions of the teacher. The teacher then supervises the leaner's actions and provides guidance to ensure that the student improves their skill. This approach is similar to the master-apprenticeship outlined under the situated learning section.

A literature review on Pasifika learners in the classroom identified a number of areas that required attention to improve the participation of Pasifika learners (Ferguson, Gorinski, Wendt-Samu, \& Mara, 2008). These included: consciousness of cultural difference; identity development; interpersonal relationships; language; confident engaged learner; knowledge acquisition; and reflective and self-evaluation. The authors warned that teachers need to be aware of the historical positioning of Pasifika peoples in New Zealand and their disempowerment. Many Pasifika learners are descendants of those who migrated in the 1960s through to the early 1970s to meet New Zealand's labour market needs. Unfortunately, the education system has not equitably developed their skills and abilities. The realisation of Pasifika learners' diverse cultures may help teachers and educators engage the learners better. 
Pasifika learners are identified through multiple identities. The term Pasifika is a term used to identify people from different island countries in the Pacific. At school a different label such as Pacific Islander (PI) may be used, while at home in New Zealand the learner is referred to as a Samoan (Anae, 1998), Tongan or Cook Islander, depending on the learner's ethnicity (Petelo, 2003). For those that frequent their parents' country of origin find themselves mocked by some of their relatives based on the view that they were born in New Zealand and so they are referred to as Kiwis. According to Wright (2011), cultural identification is problematic for children from intermarriages with other non-Pacific ethnicities. These multiple identities may be problematic to reconcile for some Pasifika learners which may affect their academic outcomes.

Two distinct factors that influence the academic achievement of minority ethnic groups within a dominant culture include classroom interaction and language (Sheets, 2009). Within the dominant culture classroom where English is used for communication, some Pasifika learners who are not fluent in the language do not participate fearing that they may use a word incorrectly or mispronounce it. Selfdoubt and the thought of others laughing at their mistakes contribute to learners' reluctance to speak-up. Another point of tension for some Pasifika learners is the contrasting expectations between the home and the school environment (Dickie, 2001). At home, many Pasifika learners are taught to respect elders, teachers and those in authority and this implies that they should not question teachers. Asking questions may be viewed as rude (Schoeffel \& Meleisea, 1994). At school, Pasifika learners are encouraged to ask questions and some learners find it difficult to participate due to the internal conflicts of their upbringing versus the classroom expectation.

Engaging Pasifika learners demands a number of changes to the current practice. The ability to value the cultural backgrounds of the learners and the maintenance of their cultural identities is a crucial component of engaging Pasifika learners (Alton-Lee, 2003). Pasifika learners should be encouraged to exhibit their cultural identities appropriately while at the same time have these cultural identities to be reflected in the curriculum and also in the learning environment. Alton-Lee (2003) argues that this will lead to culturally safe environments which may support Pasifika learners thus improving their academic achievements. 
In addition, culturally responsive pedagogical practice and content can further engage Pasifika learners. This is based on Vygotsky's (1978) argument that learning may be enhanced by using resources already known to the learner to build new knowledge. Teachers who employ culturally responsive pedagogies capture learners' interest and improve the learners' knowledge. Language used and attitude displayed by teachers can either motivate or discourage the learners.

Two studies included in this section were undertaken outside of New Zealand and involved students from the South Pacific island countries attending the University of the South Pacific in Suva, Fiji. It is deemed relevant to this study based on the fact that Pasifika peoples in this study originate from South Pacific island countries. Deo and Phan (2006) employed different confirmatory factor analysis models to investigate the possible multidimensionality of students' approaches to learning. They found a two first-factor model that promoted two major types of learning orientation that included reproducing and meaning (Richardson, 1994). The second study by Helu-Thaman (2009) revealed that many Pacific learners were right-brain dominated which was evident in their creativity, holistic, circular and people-oriented focus as opposed to left-brain dominated that was prevalent in abstract thinking, compartmentalised and issuefocused thinking. She outlined Pacific indigenous learning strategies as observation, imitation, and trial and error. In an earlier study, Ho, Holmes and Cooper (2004) revealed that traditional learning styles common in the Pacific Islands focus on collective, holistic and reciprocity. Prior to the arrival of the missionaries, education took place during socialisation in an informal setting.

Based on the literature outlined relating to Pasifika students' learning styles, it is evident that there is no one single approach that will meet the wide range of learning needs for this group of learners. Studies undertaken nearly 20 years ago (Pasikale, 1996; Pasikale \& Yaw, 1998) may be relevant to a small group of current learners. The studies revealed that some Pasifika learners preferred to be shown first while others preferred to "figure it out first" and only sought the teacher's assistance once they got stuck. Meanwhile, studies undertaken in the past 10 years (Ferguson, Gorinski, Wendt-Samu, \& Mara, 2008; Sheets, 2009; Wright, 2011) suggest Pasifika learners' faced different challenges in their pursuit of further education. These challenges included identity development, interpersonal relationship, language, confident engaged learner, knowledge acquisition, and reflective and self-evaluation. The identified challenges varied from learner to learner and therefore demanded a variety of approaches to 
ensure that Pasifika learners were supported during their learning journey. The role of culture in some Pasifika learners can not be ignored. For this group of learners, the use of familiar culturally responsive pedagogy may offer the opportunity to engage them.

\section{Summary}

In this chapter, literature was reviewed confirming that ICT adoption by New Zealand tertiary institutions was largely influenced by the government strategies. The review identified three trends that had emerged which contributed to the rapid ICT adoption. These included the diversifying of the student body, widespread use of ICT, and new educational goals set by the government. The experience of New Zealand tertiary students in the use of ICT-assisted learning was widely positive. ICTs ranged from learning management systems such as Blackboard and Moodle, the use of internet-based resources such as Google Earth, on-line quizzes, and internet-based communication (email and chat rooms). Literature on Pasifika tertiary students and ICT is scarce but there is evidence that ICT can contribute to improve Pasifika students' academic outcomes.

The systems development life cycle offers a framework that can be modified to guide the process of uplifting ICT skills of Pasifika students. ICT skills refer to the skills to use ICT to meet personal or professional requirements. ICT skills immensely contribute to a country economy while at the same time increasing the possibility in acquiring employment. The situated learning theory was the theory adopted to assist Pasifika students to uplift their ICT skills. It is perceived that the situated learning theory is congruent to Pasifika learning styles. 


\section{CHAPTER 4}

\section{INTERNATIONAL STUDIES ON ICT-SUPPORTED LEARNING}

\section{Introduction}

In this chapter, literature gathered focused on international studies on the use of ICT to support learning in selected disciplines offered at tertiary institutions. Disciplines relating to the programmes of study undertaken by participants in this study have been identified and presented. The disciplines include business and related disciplines, English language learning, Physical Education (PE), construction trades, hospitality, counselling and nursing, computer science, information technology and engineering.

Strong claims were made for ICT supported life-long learning as a means to offer equal educational, employment, social and life-long opportunities for various members of societies. Web 2.0 technologies have captured the attention of educators in the Asia, Europe and the United States of America (USA). Web 2.0 tools such as blogs, wikis, multimedia sharing services, and social networking systems, allow users to create their content, share and collaborate with others (Papastergiou, Gerodimos, \& Antoniou, 2011). The term blog is derived from the words web and log, is a website where a user or users can post information, opinions, and other digital presentations organised in reverse chronological order (Wang, 2006). A functionality of blogs is the automatic alerting of users or followers whenever a new entry is posted. In contrast to blogs, wikis are websites that are developed collaboratively by users who can add, edit, and remove information on the site. Wikis encourage communal constructivism through highly hyperlinked web pages (Holmes \& Gardner, 2006). It is essentially a collection of interlinked web pages created through the collaboration of a number of people. 


\section{Business related disciplines}

The following section outlines the use of ICT to support tertiary students in four business disciplines that include accounting, marketing, economics, and computing. These disciples were chosen based on the programmes of study that the participants of this study were undertaking. It must be noted the participants in this study were enrolled in lower qualifications (diploma) than those involved in the studies (undergraduates) presented in this section. This section presents some of the studies undertaken outside New Zealand that focused on the use of ICT to support the delivery of four business related disciplines that may offer strategies to enhance the Pasifika business studies students' learning experience.

\section{Accounting}

The use of computers in accounting education in American universities began in the late 1960s (Borthick \& Clark, 1987). Accounting students in Australia and New Zealand tertiary institutions initially received their computing exposure in computer science classes rather than accounting classes (Kent \& Linnegar, 1988). The availability of cost effective computer technologies was difficult for accounting educators to further ignore the benefits such as improved student performances, efficiency, and effective course delivery (Boyce, 1999). The importance of ICT skills within accounting and finance qualifications was influenced by the respective professions. These professions viewed ICT skills as a fundamental requirement for good professionals (Stoner, 2009).

An investigation of the ICT skills of first year undergraduate accounting students at a Malaysian university found that participants' ICT skills were at a moderate level (Lai, 2008). Five categories of ICT users were identified which included explorers (5\%), pioneers (42\%), sceptics (38\%), paranoids (13\%), and laggards (2\%). Explorers and pioneers were perceived as technology leaders who were willing to adopt new technology as soon as it was available. In a survey of ICT skills of accounting students at a Scottish university, Stoner (2009) found that database and spreadsheet skills of participants were lower than expected. Other ICT skills such as familiarity with Windows, using a word processor, using email, and using the World Wide Web were found to be at a good level.

Selwyn, Marriott and Marriott (2000) explored the rationales and motivations for accounting undergraduate students to use ICT during their studies. The participants were from two United Kingdom (UK) universities. Three main 
themes emerged from this study that were classified as short term, medium term, and long term factors. Short term factors included students' immediate concern relating to assessments such as assignments, examinations and other forms of assessments. Medium term factors included course-related concerns resulting in their final degree classification. Lastly, long term factors included the relevance of ICT in their professional and personal lives after their studies.

A survey was conducted to examine the learning benefits of using Blackboard to support the teaching of Introduction to Financial Accounting to undergraduate students at a UK business college. The study found that student interaction with Blackboard contributed positively to their participation and mental effort. Students identified five features of Backboard that contributed to their satisfaction. These included online chat, online assessment, access to lecture notes, answers to tutorial questions, and class announcements (Basioudis \& De Lange, 2009). Similar findings were obtained in a study that was undertaken for first year Bachelor of Business in an Australian university (De Lange, Suwardy, \& Mavondo, 2003) and second year Accounting students at a New Zealand university (Wells, De Lange, \& Fieger, 2008).

Potter and Johnston (2006) examined the effect of an interactive on-line learning system known as MarlinaLS for second year accounting students and their examination performance. MarlinaLS was used by students in the Cost Management course at an Australian university. The learning system was purposefully built by the university to supplement the content delivery for approximately six hundred students enrolled in one semester. MarlinaLS comprised of three modules. The first module consisted of short answer, narrative-type questions, and longer, interactive style questions. Students were required to attempt the pre-selected questions on the system prior to attending the tutorial. The study found that the learning outcomes of students who used the system improved as reflected in their examination performance. This suggests an advantage of using ICT for accounting students.

At another Australian university, Jebeile and Abeysekera (2010) investigated an online interactive computer-assisted learning module called WEBLEARN. The ICT innovation was developed to deliver the topic of cash flow statement preparations for first-year accounting students. This was based on the premise that preparation of the cash flow statement involved a number of technical skills which takes a long time for students to comprehend. WEBLEARN provided 
students with over twenty worked examples with varying levels of difficulty. Majority of users found the innovation easy to use. Furthermore, it enabled users to problem solve and identified any mistakes that the users made.

Students' satisfaction and valuation of web-based lecture recording technologies (WBLT) was explored by Taplin, Low, and Brown (2011). The WBLT is a digital video recording system which recorded the face to face lectures and later delivered the videos on the web. The system was used to deliver two accounting units. The first group was for over six hundred students who were second year undergraduate students in a financial accounting paper. The second group was a postgraduate course comprising of one hundred and fifty students. The study found that participants did not use the WBLT and were less likely to have positive statements about it. The findings were different from those obtained by Woo et al (2008) and Gosper et al (2008) who found that their participants enjoyed using web-based learning resources and these resources positively influenced their learning experiences.

Undergraduate accounting students at an Australian university used blogs as an engagement and a reflective tool. To enhance deep learning and critical thinking skills, students were required to read real world corporate annual reports and relate them to the Accounting concepts discussed in class and post their reflections on blogs (Joshi \& Chugh, 2009). The study found that using blogs enhanced the participants' technological and accounting knowledge.

An evaluation of wikis as a learning tool for Masters in Business Administration students, entrepreneurs and academics found that all participants had positive experiences. It was concluded that wikis was an innovative, low-cost technological tool effective in integrating entrepreneurial and experiential learning (Halcro \& Smith, 2011). A case study involving six first year Master of Commerce accounting students investigated how the students experienced the use of wiki for cooperative and collaborative teamwork (Alyousef \& Picard, 2011). The study found that the online teamwork involved more cooperative practice and very little collaboration. The authors argued that the participants' behaviour reflected the workplace practices whereby employees divided up tasks, discussed online, reported back to their managers, and further refined their work.

Overal, the studies presented above confirm that Accouting students studying at universities in Malaysia, UK, and Australia shared a positive view towards the use 
of ICT in their studies. The ICT included generic office software applications, Blackboard, specifically developed interactive on-line learning systems such as MarlinaLS and WEBLEARN, web-based videos, blogs, and wikis.

\section{Business Marketing}

The use of computer technology in business marketing education had been mostly in simulations, cases, games, and experimental exercise (Grimm, Skinner, \& Ferrell, 1979). A business simulation game was a form of experiential learning that attempted to engage and entertain the participants while at the same time delivered curriculum related topics. The first recorded use of a business simulation game was in a business policy course at the University of Washington in 1957 (Watson, 1981). A game, “The Marketing Management Simulation”, developed for introductory marketing courses was used to determine whether good gamers were consistently good (Wellington and Faria, 1996). The study found that good performers spent more time making decisions and their accuracy improved as they played the game more. The attitudes of poor performers became less positive while the attitudes of good performers became more positive.

Case analysis has been widely utilised as an educational tool for training marketing students (Mentzer, Cox, \& Meadow, 1983). The marketing cases along with accompanying computer analysis software assisted students in understanding the nature and interactions of marketing components as well as their interaction with other business components. In an introductory marketing course, a computer-assisted instruction (CAI) tutorial package was used to assist students prepare for the end of semester examination (Morris and Byers, 1988). Two weeks before the examination students were given access to a computer generated quiz to assist them in reviewing the course content. The study found that students who accessed the package performed better than those who did not use the package.

Manowaluilou (2008) investigated the ICT skills levels of undergraduate students when they enrolled in the Bachelor of Marketing degree at six universities in Thailand. The study found that there was statistically a significant difference in the ICT levels of students when they enrolled and when they graduated.

Final-year marketing students at a United Kingdom university took part in a study to examine the effectiveness of using a game-based course to deliver the 
Marketing Management in Practice course. The Marketplace online game was used whereby students operated virtual companies competing against each other for market share and position. Skills developed during the game included product design, finance, advertising, promotion and sales force expenditure. A high number of participants $(80 \%)$ revealed that they enjoyed the course more than other courses that they had completed (Whitton \& Hynes, 2006).

Undergraduate students majoring in business marketing at an American university were involved in creating an interactive course textbook using wiki software (Cronin, 2009). The study found that while the students' collaborative skills were improved, the benefits of wikis on students' learning were not assessed. Workman (2008) also developed a wiki for a Principles of Marketing class at another American university. The goals of the project were to increase student engagement and the development of students' communication skills.

Blogs have been used in marketing education to enhance experiential learning and to improve the students' soft skills. Second year undergraduate students in a marketing management course at a European university were required to set up their own blogs and post several blog entries during the semester (Kaplan, Piskin, \& Bol, 2010). The topic for the blog needed to be related to marketing theory or practice. Some related examples were "advertising campaigns, television commercials, new products, company acquisitions, a university policy, a service experience, changes in personal consumption preferences, and a recent event in the immediate environment" (Kaplan, Piskin, \& Bol, 2010, p.54). The study found that using blogs enabled participants to clearly conceptualise and understand the marketing theory and practice. In addition, participants improved their writing and critical thinking skills.

The use of ICT in Business marketing students had been in simulations, case analysis tools, games and experimental exercises, wikis, and blogs. The studies presented above confirm that ICT has a positive influence on the students' learning experience.

\section{Economics}

The use of ICT on economic students has been widely researched (Agarwal and Day, 1998; Brown \& Liedholm, 2002; Savage, 2009; Joerding, 2010). ICT employed to support economic students included computer-based and internetbased tools. 
Agarwal and Day (1998) examined the influence of using the internet on economic education. Internet tools were used for communication via emails, discussion lists and the World Wide Web (WWW or web) for the distribution of information. Participants in the study were students in undergraduate macroeconomics and graduate microeconomics courses. The study found that using emails, discussion lists and the web significantly enhanced the teaching of economics theory for two reasons. First, communication through emails and discussion lists between the instructors and the students were faster. Second, the internet assignments and the use of web by students enabled hands-on experience for students to better understand the real life implications of economics theory.

Brown and Liedholm, (2002) investigated the effects of new technologies on student learning at an American university. The Principles of Microeconomics course was delivered to over seven hundred students in three different groups through three different modes: face-to-face, hybrid, and virtual. Students in the face-to-face group attended lectures where Powerpoint slides were used. Students in the hybrid group attended the face-to-face lectures and received supplementary problem sets and practice quizzes. Students in the virtual group did not attend the face-to-face lectures but accessed streaming lecture videos of the face-to-face lectures and the supplementary resources available to the hybrid group. The study found that students in the virtual group performed significantly worse on the examinations than those in the face-to-face group. Students in the virtual group struggled to apply basic concepts in advanced situations.

Savage (2009) evaluated the effect of using ICT on the students' performance based on the end of semester examination results. Students in an intermediate microeconomics class at an American university were taught through two different approaches. The first approach was through the traditional 'chalk and talk' approach without any technology. The second approach was through the use of technology that comprised a tablet computer, a digital pen, a wireless microphone, a web camera, and the Tegrity Instructor Software. At the end of each session, the recorded lecture with full audio and video was made available for students on the web. The study found that using the technology in this particular instance did not have any substantive effect on the students' examination performance. An explanation given by the researcher for this outcome was that the video replay did not provide students with any new problem 
solving opportunities that students may use to learn the relatively complex, integrated content required for the examination.

Joerding (2010) investigated the use of Individual Student Exercise Generating System (ISEGS) to support students in an introductory economics class. ISEGS presents the user with a unique exercise consisting of a sequence of questions which has a unique, definitive and precise answer for that particular user. Each user has a different exercise derived from a template which ensures that users can constructively collaborate for their individual exercise. The study found that students who used the ISEGS showed statistically significant improvement in their exam performance when compared to students who received traditional paper-based assignments.

Simulation exercises have been found to be a mechanism for introducing collaborative learning in economic education (Santos, 2002; Schimdt, 2003; Lengwiler, 2004; Bolton, 2005). The Financial System Simulator (FSS) was developed to introduce the topic of domestic and international consequences of monetary policy to undergraduate students. Users of the game communicate directly to each other and the simulation provided immediate outcomes for their decisions. The users revealed that the game helped their understanding of the monetary policy while keeping them motivated and interested (Santos, 2002). In a course in economic history, a web-based simulation program was introduced to teach issues of public finance and economic growth based on American economic history. Using the simulation, users build transportation infrastructure which affects transportation costs, allowing realistic calculations of trade flows between cities. According to Schimdt (2003), the simulation enabled students to obtain a deeper understanding of the underlying economic principles.

Another simulation, the Monetary Policy Simulation Game (MoPoS) puts the player in the role of the central bank governor. The game aimed to simulate the effects of the monetary authority and how it affects the economy. In addition, the game offered an alternative to the traditional teaching method (Lengwiler, 2004). Teaching the Alonso model of a household's location choice to intermediate microeconomics students was assisted with the use of computer simulation models. The simulations introduced basic concepts and also introduced complex scenarios without demanding mathematical skills beyond the students' levels. A benefit of the simulation was the time taken to demonstrate the complex scenarios enabling students to focus on more numeric examples (Bolton, 2005). 
In a classroom situation, it is a time consuming exercise for the lecturer to explain in detail the finer points in the Alonso model. The simulation on the other hand, overcomes this challenge by providing visual aids that assists students to comprehend the model.

Using the animated television show The Simpsons to teach basic economics principles to American college students was explored by Luccasen and Thomas (2010). The Simpsons is classified as a comedy and the researchers found that humour worked wonders for students who had the impression that economics was difficult. Hall (2005) was the first to propose using The Simpsons to teach an introductory course in microeconomics. Scenes from The Simpsons were used to illustrate basic economic concepts at the same time stimulating students' discussions and engagement. Historically, the use of television to teach economics in America began with The American Economy (Saunders, 1964) for secondary school teachers and later in the Economics USA (Grimes, Krehbiel, Nielsen, \& Niss, 1989) for students.

\section{Computing}

Hawi (2010) investigated the factors that business students encountered in the computer programming course offered by the Computer Science at the Notre Dame University (Lebanon). Participants revealed ten barriers that impacted on their achievement. These included different learning strategy, lack of study, lack of practice, perceived difficulty of programming, lack of effort, appropriate teaching methods, exam anxiety, cheating, lack of time, and unfair treatment.

\section{English language learning}

Computer Assisted Language Learning (CALL) software applications have been around since the 1960s. "Tell Me More" is a CALL product that was used in a study at a Malaysian polytechnic to assist students learning the English language. The study found that students indicated positive perceptions on the product's ease of use, usefulness and suitability for their learning requirements. Students enjoyed listening, speaking and pronunciation activities while they found reading, grammar and vocabulary activities dull (Yunus, Hashim, Embi, \& Lubis, 2010). A multimedia listening activity involving a video of an academic lecture was prepared to assist students in English as a Second Language (ESL) course at a large university in the United States Midwest. The participants were mainly Asian international students studying in America. The eleven-minute video of an astronomy lecture was divided into ten segments of approximately 30 
to 90 seconds. Each segment was accompanied by a multiple choice comprehension question. Two help options were provided that included subtitles and the transcript. The study found that participants used the subtitles more frequently and for longer periods of time than the transcript. This showed the participants' preference to viewing the video over reading the transcript (Grurovic \& Hegelheimer, 2007).

Alabbad (2011) investigated the attitude of Saudi Arabian university students towards the use of computers and the internet for improving their English language proficiencies. First-year Bachelor of Arts students were required to conduct a research project about a travel destination of their own choice. Project requirements included flights and transportation, accommodation, tourist attraction, and food and restaurants. Final projects were to be submitted in both printed form and electronic form before being uploaded to a website. At the conclusion of the course, students were expected to present their projects in class. The pre-test and post-test analysis revealed that there was a significant improvement in the students' attitude towards ICT supported learning.

\section{Web 2.0}

Supporting and improving formal English writing skills of tertiary students through the use of Web 2.0 tools has been explored by many researchers (Klimova, 2010; Miyazoe \& Anderson, 2009; Mompean, 2010; Sun, 2010). Extensive writing on blogs offered an opportunity for English language students to improve their writing skills (Mompean, 2010). English writing skills of Taiwanese university undergraduate students were examined to ascertain any improvements when using blogs (Sun, 2010). At the beginning of the semester, students were introduced to the in-house blogging system. Only registered users could write on the blogs and students' identification numbers were used instead of their names. Students were required to make a total of thirty entries on the blog site and comment to ten other classmates' blog entries during the semester. The study found that the overall writing skills of participants were enhanced. In addition, a positive attitude towards writing was achieved while promoting an independent monitoring of students' writing through feedback and comments from the followers of the students' blogs (Sun, 2010).

Students at the University of Hradec Kralove (Czech Republic) used Wikipedia to improve their English academic writing skills (Klimova, 2010). A student assessment involved writing an entry for Wikipedia. The assignment motivated 
the students, provided a real-life use of their learnt skills while ensuring authentic writing, improving spelling, grammatical and minimising other errors while facts were verified before published. Miyazoe and Anderson (2009) examined the effectiveness of using three Web 2.0 tools to improve the English language writing skills of students at a Tokyo university. In a blended learning course, the authors used forums, blogs and wikis to enhance students' writing skills. The study found that students enjoyed the experience and favoured wikis the most, followed by blogs and forums. An explanation offered by the authors was that students used wikis most because of the requirements for collaborative work whereas blogs were perceived as private writing. While some students indicated that they read other students' blogs, they did not comment on them.

\section{Mobile Phones}

The use of mobile phones in tertiary education had been on administrative support, tutor support, subject learning, and in-class use (Brett, 2011). In the following section, studies on the use of mobile phones to support subject learning and in-class use will be explored. Thornton and Houser (2005) explored the use of mobile phones to support EFL students at a Japanese university. Students received short lessons of less than one hundred words of text on their mobile phones three times a day. The lessons consisted of five words and their definitions, the use of each word in multiple contexts, a review of previously introduced vocabulary, and story episodes with the target words used. Most students preferred receiving the mini-lessons on their mobile phones and requested to continue receiving further lessons on their mobile phones.

Stockwell (2007) investigated the use of an intelligent mobile phone-based vocabulary tutor to assist students in an advanced class of English as a Foreign Language (EFL) course. Vocabulary activities were accessed by the users through their mobile phones or via an internet-connected computer. The system kept logs of all access along with a profile of terms that the user found difficult and presented these terms to the learner more frequently than less difficult terms. The study found that users performed better when they used a desktop computer when compared to the mobile phone. The preference of the computer over the mobile phone was mainly due to the mobile phone's small size screen and small keypad when compared to the computer.

In a study involving thirty Taiwanese high school students, the effectiveness of using short message service (SMS) to improve the learning of English vocabulary 
was explored (Lu, 2008). The students were divided into two groups with equal numbers. At the beginning of the week, one group received fourteen new words via text messages sent to their mobile phones while the other group received printed materials. The students were tested at the end of the week. In the second week, the group that received text messages received their new words in printed form while the other group received their new words via text messages. The study found that students who received text messages had greater vocabulary gains over their paper-based counterparts.

Browne and Culligan (2008) investigated free software available for mobile phones and computers to efficiently develop the vocabulary of students in an English as a Second Language (ESL) and EFL class. The authors examined the vocabulary levels for second language learners which were recorded to be at least three thousand words by Laufer (1992) and five thousand by Hirsch and Nation (1992).

Cavus and Ibrahim (2009) investigated the use of Short Message Service (SMS) text messaging to teach new technical English words to first year students at a Cyprus university. The study involved forty-five students and found that students enjoyed the learning experience through an innovative way of using mobile phones.

Stockwell (2010) examined the effect of using mobile phones for vocabulary activities over a desktop computer. The study involved one hundred and seventy five pre-intermediate learners of English at a Japanese university over a three year period (2007-2009). The study found that students preferred the use of mobile phones despite the longer time it took for students to do the same task on the computer. Using the mobile phones enabled the students to access learning materials from anywhere at anytime they preferred. Students' current vocabulary was assessed using an online testing application before the students' missing vocabulary was taught through the use of flashcards and games.

Basoglu and Akdemir (2010) explored the use of flashcards and mobile phones to improve the vocabulary of first year university students at a Turkish university. Flashcards were widely used in language learning classes. The study found that using mobile phones was more effective in improving the students' vocabulary over the traditional flashcards. 


\section{Physical Education (PE)}

The following section presents the use of ICT in PE. Despite the lack of standards in the use of ICT in PE, there is an awareness of the potential of ICT in PE. Videos have been a very popular technology based on its ability to provide visual feedback. In addition, video analysis software has been found to be useful to analyse the videos. As a result of the need to use ICT, the curriculum for PE teachers has been revised to ensure that future PE teachers have the relevant skills to use ICT in their teaching practice.

The use of ICT to support PE and sports pedagogy has gained widespread acceptance (Thomas \& Stratton, 2006; Weir and Connor, 2009) resulting in the need to prepare ICT proficient PE teachers (Tearle and Golden, 2008; Papastergiou, 2010; Colasante, 2011). Thomas and Stratton (2006) explored the ICT use in PE departments in English schools and found different hardware and software and application across the departments. They concluded that this was due to a lack of consensus and standards in training and the type of ICT to be used. On the whole, the PE fraternity in English schools welcomed the integration of ICT into the PE curriculum.

According to Schmidt and Lee (1999) feedback is a major factor in the improvement of sport skill performance. During training, athletes actively work on minimising errors. Using visual feedback via videotaped performance assists in improving their performance. Videos are powerful tools for motivating learners, demonstrating concepts, and modelling performances (Weir and Connor, 2009; Liebermann et al., 2002). Benefits of using videos in training include its relative low cost, accessibility and portability (Liebermann et al., 2002). Other benefits of using video in PE included the possibility of playing a brief moving picture backwards and forwards highlighting the correct technique, and further observation and analysis using computer software (Green, 2002).

Instructional video analysis software provides immediate feedback to improve performance and techniques. In a study, PE undergraduate students at the RMIT University, Melbourne, Australia used a video annotation tool for improving their teaching practice. The study revealed that participants appreciated the ability to analyse the videos, categorise and add annotations to segments of the video (Colasante, 2011). In other situations, the use of computer-graphics modelling to demonstrate muscle activation and contraction dynamics was explored by Barrett, Knoek van Soest, and Neal (2002). While the values predicted by the 
model may not reflect actual muscle behaviour, the output values were considered valid for demonstrating the key concepts.

But in order to use ICT, PE teachers must be competent users of these technologies. As a result, the Department of Physical Education and Sports Science at the University of Thessaly (Greece) undertook a study to design and implement two ICT-based courses and to investigate the students' response to the courses and the instructors' experiences (Papastergiou, 2010). The study found that students were overall positive towards the courses and instructors were able to acquire basic multimedia and web development skills to be used in their future instructional practices.

PE undergraduate students at a Greek university were introduced to blogging in a study to examine the effects on students' knowledge acquisition of four specific basketball skills and their ICT self-efficacy (Papastergiou, Gerodimos, \& Antoniou, 2011). A class blog was created and students were invited to showcase their performances of the skills by creating multimedia posts on the skills. This approach was deemed appropriate for this group of students based on the premise that PE content is light on text-based discourse and multiple representations enhance students' learning. The instructors, peers, and an external expert offered comments on the students' posts. Participants undertook a pre-test and post-test experimental design and significant gains were found in the participants' ICT efficacy while no significant gains were detected in the acquisition of the skills.

Students from two English secondary schools were involved in a study to investigate the use of wikis to enhance students' learning in PE (Hastie, Casey, \& Tarter, 2010). The students were divided into teams of four or five members. Each team was required to design an "invasion game" from scratch. An invasion game's strategic goal is to gain possession of an object, for example a ball or Frisbee, and move it to a designated location to score points. Popular invasion games include football, basketball and hockey. The study found that a higher quality learning experience was achieved through the 24 hours, seven days per week access to wikis together with the creation of an extended community of practice. 


\section{Construction trades}

Teaching and learning in the construction trades are synonymous with "handson" learning and associated with apprenticeship programs. Typically, an apprentice began his apprenticeship by observing the experienced tradesman carry out relevant tasks. While performing the tasks, the tradesman explained what he was doing and why he was using a particular technique. Over time, the apprentice gets the opportunity to try things out under the guidance and supervision of the experienced tradesman. The learning process is related to the behaviourism theory (Dickson et al, 2011). In the construction trades, behaviourism is viewed as a pillar in teaching practical skills. For instance, in bricklaying, the repetitive nature of laying one brick after another improves the student's skill. Guidance and proper feedback from the experienced tradesman will enhance the student's workmanship, improve productivity and safer work practices.

In the construction trades, lack of experience was found to be a major contributing factor to construction errors which may lead to injury due to unsafe work practices (Dickson et al, 2011). In a scenario where the availability of experienced tradesmen to mentor trainees is low, there is the increased risk of making a higher number of mistakes. The high error levels can undermine quality, performance, and health and safety issues. ICT when managed and organized properly can alleviate some of the identified areas to ensure that trainees receive the required training.

Construction programmes offered through tertiary training providers offer the theoretical and fundamental knowledge in the classroom. While the classroom learning offers an opportunity for students to acquire the fundamental knowledge, it lacks the depth of the hands-on experience that an apprentice receives on the work site. To compensate for this, ICT has been seen as the means to deliver an alternative to the real world experience for the students. Video-based learning resources have been employed to provide a high degree of realism. Some reported drawbacks for using videos in the teaching of construction trades included: difficulty in modifying information on video unless a new version is made; insufficient details captured for a given step or process; and difficulty to consult on-site to review a particular operation or task (Dickson et al, 2011). Rapid developments in the digital video technology can overcome some of these setbacks. For example, the smaller size and hand-held digital video cameras capable of recording and playing back the videos will enable the review of 
required tasks on-site. Along with the larger digital storage devices that are now part of these videos will make some of these drawbacks a non-issue.

\section{Computer-based games}

Another way to provide real-life situations for the classrooms was through the use of games developed for the construction industry. According to Nassar (2002), one of the earliest games developed in 1969 was the "Construction Management Game". The game stimulates the bidding process in the construction industry. Other games have been developed to enhance project management skills (CONSTRUCTO), improve bidding skills (SuperBid), understand contract negotiation (Negotiation Game), illustrate the dependency of workflow variability on overall performance (Parade of Trade Game), project costs estimation (Lego Bridge Game), marketing (The Marketing Game), and the management of equipment (ER Game).

For work safety practices, a computer game was designed to teach a construction trade topic of trench safety. The topic included "hazards like falling in, being struck by falling objects, trench collapses and trench collapse causes and prevention" (Dickson et al, 2011, p.121). Prior to the study, the topic was delivered through printed materials accompanied by classroom discussions, videos and accident statistics. Assessment for this topic included a quiz at the end of the learning period. The study revealed that the game technology offered an engaging, rich learning environment, replicating the construction environment and circumstances where the knowledge would be later applied. The use of ICT enabled the teaching of topics that is potentially dangerous or difficult to present in real-life.

\section{Computer-based simulations}

Computer-based simulations offer a dynamic representation of some part of the real world by using computer models and moving it through time (Chen \& Levinson, 2006). It has been found to be an effective way to provide practical construction knowledge and for training in expensive machinery (Park, Chan, \& Ingawale-Verma, 2003). A mobile crane simulator was developed to satisfy the request for a low-cost but effective vehicle for training and licensing of mobile crane operators in Taiwan (Huang \& Gau, 2003). Another forklift simulation was developed using game engines by Juang, Hung, and Kang (2010). A game engine, also known as a physics engine, is a library or a framework that masks the low-level detailed physics that drives the virtual reality (VR) applications. 
Physics effects such as gravity, collision response are simulated through complex calculations. The mobile crane and forklift simulations demonstrate the potentials that ICT can offer to the teaching of construction trades courses.

Benefits of computer-based simulations in education include the provision of hands-on experience for students, learning by doing, interactive learning environment, diversified teaching strategies, development of higher levels of intellectual engagement, and motivating students to learn (Chen \& Levinson, 2006).

Le Gallais (2001) asserted that ICT played a meaningful part in the support of construction skills development. A study was undertaken to explore the issues faced by the construction industry and its training providers and the opportunities that ICT can play in the construction curriculum (Le Gallais, 2001). Problems involved in construction training included: some employers were reluctant to provide adequate training, students' low retention and achievement rates, ageing workforce leading to low recruitment, public perception of construction as a career, and the industry's vulnerability to global economic pressures. The study found that ICT was capable of delivering cost effective and efficient 'state of the art' training for the industry.

A study involving first year diploma students within the horticulture and environmental science at an Australian vocational training institute found that student's ICT skills were vital for their learning (Verezub, Grossi, Howard, \& Watkins, 2008). Effective use of the internet demanded new literacy skills such as metacognitive reading comprehension strategies. Developing these skills supports the students' learning experience.

\section{Information Technology (IT) and Computer Science (CS)}

This section comprises of studies focussing on IT and CS students. The section outlines various reasons for dropping out of IT or CS courses, and factors that influence persistence and strategies deployed to engage IT and CS students. The associated studies under each section are presented in chronological order.

IT and CS students at universities in Australia (Corney, Teague, \& Thomas, 2010; Carbone, Wond \& Ceddia, 2011), Finland (Kinnunen \& Malmi, 2006), Ireland (Bergin \& Reilly, 2005) and the United States of America (Beaubouef \& 
Mason, 2005) record the highest dropout rates from their enrolled programs of study.

\section{Reasons for attrition}

Beaubouef and Mason (2005) outlined seven reasons for the high attrition rate of CS students at an American university. First, students received poor advice before enrolling by school advisers, parents, and peers, or during college. Some students based their choice on previous experience using word processors, spreadsheets, and the web browser. Second, maths and problem solving skills are essential components of CS. Poor maths and problem solving skills creates a perception that CS is too hard. Third, poorly designed lab courses led students to a state of despair and for some reduced motivation. Fourth, lack of practice or feedback due to large student numbers. Fifth, the use of graduate students as teachers for undergraduates devalued the undergraduates. Sixth, students who leave had not fully developed adequate study habits and important project management skills. This included the management of time and resources to complete assignments before the due dates. Lastly, the choice of programming language and the order of delivering the traditional procedural programming first then object oriented programming after or vice-visa.

Bergin and Reilly (2005) examined fifteen factors that may influence the academic performance of first year programming students at an Irish university. The examined factors covered prior academic knowledge, prior computer experience, self-perception of programming skills, comfort level on the course content, and specific cognitive skills. The study found that comfort level and high scores in maths and science in high school were strongly correlated to good performance in the programming course. Furthermore, the strongest relationship existed between the students' perception of their understanding and their programming achievements.

Kinnunen and Malmi (2006) investigated the reasons for students dropping-out of a first year CS course. Through qualitative interviews, the authors revealed that the most frequent reasons for leaving were lack of time and lack of motivation. These reasons were caused by a perceived difficulty of the course, general difficulties in time management and study skills, and the preference of something else. The study found that over time drop out reasons cumulated. Using motivation as major reason for students leaving CS courses, Corney, Teague, \& Thomas (2010) redeveloped a first year introduction to IT course that consisted of 
a collaborative learning environment. The new course was found to better engaged the students resulting in a lower attrition rate and a higher pass rate.

Biggers, Brauer, and Yilmaz (2008) investigated the perceptions of computer science students who completed and those that did not complete the programme. A major view held by students who left the programme was that computer science was antisocial. This view was mainly influenced by the leavers' experiences in programming classes which were loaded with assignments that students failed to connect to the real world. Other reasons for leaving included a loss of interest, unpreparedness, and unclear career options after completion of studies.

In a phenomenographic study, Berglund et al (2009) investigated teachers' experiences of students learning in CS courses. The authors revealed five factors that led to student failure. These included the inherent difficulty of the subjects, intrinsic features, prior experience, students' attitudes and behaviour, and the diversity of approach. Intrinsic features of students comprised of 'magical' feature, natural ability, 'correct' way of thinking, gender, and culture and language. Students' attitude included effort and hard work, study habits, proactive, presumptions, emotions, and motivation.

Barlow-Jones and Van der Westhuizen (2011) investigated factors that contributed to the achievement of black African students enrolled in the National Diploma IT at a South African university. The study identified English language levels, ICT skills levels, socio-economic circumstances, and academic study skills as contributing factors to the students' low academic achievements.

\section{Factors that influence persistence}

Carter, Jernejcic, and Lim (2007) investigated the possibility that success factors in CS courses were influenced by the students' culture. The authors identified four factors that contributed to success in CS courses. The factors included a strong maths background, comfort level in CS, personality traits, and learning styles. Barker, McDowell, \& Kalahar (2009) employed a survey to investigate the factors that influence first year students to persist in computer science courses. Based on a linear regression, the survey found that students who developed peer networks amongst other computer science students were more likely to persist in their first year. 
Sustelo and Guerreiro (2010) analysed the self-reflections of first year programming students at a Portuguese university. The self-reflections focused on the students' study habits and the skills that they acquired from the course. The study identified eight competencies of successful students. These included the ability to work independently, wanting more than a mere passing grade, selfdiscipline, good work habits, effective study skills, ability to program, good understanding of technology, desire to learn, and good communication skills. Stoilescu and Egodawatte (2010) advocated the importance of hard work in terms of the long hours necessary to complete programming projects.

Coughlan and Swift (2011) evaluated the learning experience of first year computer science undergraduate students in a study skills course at an English (UK) university. The study skills delivered included writing skills, presentation delivery, critical thinking, and group work. Participants offered positive ratings about the course. Campbell and Johnstone (2010) investigated the connection between the learning style of first year programming students and their achievement level. They found that there was no connection between a student's learning style and his/her achievement level.

\section{Computer-based animation}

Taylor and Pountney (2009) compared the perceived usefulness of animated and static learning resources for teaching two fundamental mathematical concepts namely vectors and matrices. Vectors are used to represent points in space that denotes the position of objects, or the vertices of a triangle mesh in a computer game object. Matrices, on the other hand, are used to transform vectors through scaling, rotation, or reflection. The traditional text book uses 2-dimensional diagrams to represent them graphically. In Taylor and Pountney's study, eighty eight first year computing students at a UK university were involved. The students viewed both the animated and static learning materials. Students indicated that the animated learning materials were useful in their understanding of abstract concepts.

\section{Blogs and podcasts}

A survey on the effect of blogs and podcasts on Computer Science students at an Australian university of technology confirmed a significant effect of media richness on user acceptance of blogs (Saeed, Yang \& Sinnappan, 2010). Meeting the needs of first year Computer Science students is vital for their continuation of studies. The use of social-network-based learning environment 
was implemented to enhance the students' interaction on course related issues and social matters. Peerspace is a tool designed to strengthen and reinforce learned concepts while maintaining social connection to fellow students ( $\mathrm{Li}$, Dong, Untch \& Jagadeesh, 2011). The use of blogging has also been investigated to support the learning of computer science students at an Austrian university (Holzinger, Kickmeier-Rust \& Ebner, 2009). Information Systems undergraduates at a Hong Kong university employed blogs to enhance their cognitive and social knowledge construction (Du \& Wagner, 2007). The study confirmed the benefit of using blogs as a knowledge construction tool and a social learning medium. Another study involving postgraduate IT students demonstrated that blogs were effective educational tools that involved reading other learners' blogs, receiving feedback on their blogs, previewing other learners' blogs and feedback (Churchill, 2009).

\section{Computer games}

Using computer games to motivate CS students have also been examined. Researchers have confirmed that game-based learning was highly engaging, motivating, enjoyable, and effective (Gee, 2004; Muratet, Torguet, Jessel \& Viallet, 2009; Papastergiou, 2009). In an introductory class to a programming language (Unix), students participated in a treasure hunt type of game. The game was played on a wiki which supplemented the course text book. Assessment of the course was an automatic graded lab-based exam (Moy, 2011). Computer science undergraduate courses offered on-line have been found to be less successful than face-to-face. Reasons for this trend included students' reluctance to read printed materials such as text books, complete required exercises, and an inability to try things out on their own (McDonald, Dorn \& McDonald, 2004).

\section{Hospitality}

The hospitality industry is a broad industry comprising of service industries and fields within the tourism industry. In this section the studies presented will outline two areas that include the use of ICT within the hospitality industry and its use to support training.

\section{Use of ICT in the Hospitality Industry}

ICT have impacted the way many American hospitality and tourism businesses have operated since 1980s (Buhalis \& Law, 2008). Different ICT offered competitive advantage, improved productivity, streamlined finance tracking, and 
customer service expansion (Siguaw, Enz, \& Namasivayan, 2000; Kim, Lee \& Law, 2008). Some examples were the computer reservation system (CRS) of the 1970s, global distribution systems (GDS) in the late 1980s, and the internet in the 1990s which imposed a paradigm shift in the industry.

Sigala (2007) explored the use of Radio Frequency Identification (RFI) technologies to intergrate customer communications with the food supply chain to improve accuracy, efficiency, personalised interaction, and the security of the foodservice marketing, production, and distribution.

Ip, Leung, and Law (2011) outlined seven dimensions of ICT use in the hospitality industry that included human resources and training, security, reservation, revenue management, marketing, guest services, and strategies and operational management. In the USA, ICT usage in the restaurant sector was highest in the clerical roles, medium in integrated roles, and lowest in tactical roles. ICT was used to communicate with stakeholders (customers, suppliers, employees, and management) through email, on-line ordering, and on-line bidding. The most highly used software packages were the word processor and the spreadsheet (Huber, Hancer, \& George, 2010). People intending to work in the industry whether in operational, supervisory, and managerial roles need to develop skills associated with ICT (Lashley \& Rowson, 2008).

\section{ICT-based training}

In the late 90s, training of foodservice professionals and staff was essential but it had become increasingly difficult to train new employees properly (Harris \& Bonn, 2000). The most common type of training tool was texts and manuals. Computer-based training was found to be a cost and time effective solution. Graham and Lambert (1995) utilised computer-based illustrations to efficiently train undergraduate restaurant management students. The computer-based illustrations highlighted discrepancies in basic food safety principles found in restaurants. Painter (2000) revealed that teaching garnishing and napkin folding to hospitality students can be effectively done with a computer-based video when compared to the paper-based instructions along with diagrams.

Cantoni, Kalbaska, and Inversini (2009) investigated the role of e-learning in tourism and hospitality. The authors adopted the European Union definition of elearning as "the use of new multimedia technologies and the Internet to improve the quality of learning by facilitating access to resources and services as well as 
remote exchanges and collaboration" (Commission of the European Communities, 2010, p. 1). The study found that all on-line tourism and hospitality courses belonged to four main categories: academic, corporate, destination management organisation (DMO), and independent. Academic online courses were offered by official registered academic establishments. Corporate online courses were offered by a company or an institution within the industry targeting its employees as well as travel agents who have links to the company. Some examples were Academie Accor North America Corporate Training, Royal Caribbean Cruise Lines Corporate University, and Hilton University. DMO online courses were offered by DMOs that can be a national or regional body to travel agents or tour operators who sell the country or region as a tourist destination. Some examples were the South Africa tourism expert course and the Switzerland Travel Academy. Lastly, independent online courses were those not included in any of the three categories stated earlier. Some examples were the Gourmet Cooking and Catering Program and the Certificate Course in Ecotourism/Food and Beverage Management (Cantoni, Kalbaska \& Inversini, 2009).

Students in a hospitality course at an American university participated in a survey to gauge their perception on the usefulness of an Internet-based simulation aimed at developing competencies and improving course performance. BuildYourOwnBusiness or BYBO was the simulation used for students to plan, open and operate their own hospitality business. Some features of BYBO include group interactions, hiring a peer manager, and online group discussions. BYBO offers real-time business simulation enabling users to plan, save, purchase, manage, and problem-solve as required in businesses such as restaurants, hotels, bistros, nightclubs, pubs or resorts. The study confirmed that participants were positive about their experiences with BYBO (Douglas, Miller, Kwansa, \& Cummings, 2007).

In an earlier study, another simulation package, Cornell Restaurant Administration Simulation Exercise (CRASE), was used to develop financial skills of hospitality undergraduates at two UK universities. CRASE offered the students an insight into the connection between theories of finance, accounting and operations management to practice. Seventy-seven participants offered positive comments about CRASE. Participants were satisfied with CRASE due to its informal approach, fun way to learn, transfer of theory to practice, minimised 
the fear of accounts, helped with other operations and modules, and it offered practical implementation of finance (Curland and Fawcett, 2001).

Singh, Kim, and Feinstein (2011) investigated the use of the internet-based training by American chain restaurants. Using internet-based training offered benefits such as low costs, easy access, and ease of updating training materials when compared to paper-based training manuals. The study found that companies with annual revenue of over one billion dollars used internet-based training for new and current employees.

\section{Counselling}

In this section, the literature located and presented focuses on ICT-based learning in counselling. Counselling students and practitioners can benefit immensely from the use of ICT (Oraegbunam, 2009). ICT supported counsellor education pedagogical principles such as active learning. Active learning involves students doing things and reflecting on the things that they are involved in leading to a better understanding of the subject matter (Baggerly, 2002). The types of ICT used in counselling education included the course web sites, multimedia presentation software packages (such as MS PowerPoint), movie clips, videoconferencing, and videotaping in laboratory sessions.

\section{Internet-based}

Using internet tools to share learning resources and communicate between students has been widespread. A course website acts as a communication hub for students. Through the course website, students accessed critical and urgent information such as assignment questions, due dates, and messages from staff to students (Baggerly, 2002). Online courses and instruction had been used by counselling education providers to disseminate information to students. Kenny (2008) explored web-based training for counselling students at an American university. Information on child maltreatment previously printed and handed to students was made available to the students through a website. Students were expected to read the information and answer questions set to test the participants' knowledge as well as case vignettes that required students to determine a course of action. Immediate feedback on their responses was provided from the website along with a thorough outline of the correct response.

Rambo-Igney and Brinthaupt (2008) explored the use of a hybrid learning approach that employed online instruction through the internet to support the 
face-to-face interaction. The hybrid learning format involved a face-to-face meeting every two weeks and online discussions on a regular basis. The fortnightly face-to-face meeting facilitated discussion of recommended chapters, live demonstrations of counselling techniques and theories by the professor, and practice of counselling techniques with other class members. The online discussions took place at a chat-room available through a website. The professor facilitated the discussion by asking questions related to the recommended chapters and students were expected to actively participate in the exchange of ideas. Daily and weekly contact with students through the discussion boards or emails enabled the professor to get to know the students personally. The authors confirmed that the application of hybrid learning approach enhanced students' overall learning experience while promoting a community of learning.

\section{Computer assisted instruction}

The use of computers in counsellor training dates back to the 1960s where computer programmes (such as Client 1, ELIZA, PLATO DCS, and MORTON) were used to generate empathetic responses (Hayes, 2008). These computer programs were classified as computer simulations which were used to develop counselling skills. Baggerly (2002) described the use of presentations with graphic software packages (such as MS Powerpoint) to enhance the classroom presentations with colourful, dynamic displays of counselling topics, images of prominent counsellors, and video clips of counselling skills.

Karper, Robinson, and Casado (2005) investigated the influence of computer aided instruction on the counselling students' academic achievement. Two groups of students at an American university were taught the same introductory counselling course through two delivery methods. One group received the course content through a computer-assisted environment while the second group received the same content through the traditional classroom setting. The computer-assisted environment delivered the course content using Powerpoint slides, movies, video clips, and other multimedia-enhanced materials. In addition, students had access to computers, internet, and software to view the movies, video clips, and other multimedia-enhanced materials. The traditional classroom did not have any of the technologies used in the technology-assisted environment and totally relied on the verbal presentation of the material and writing on the whiteboard during the presentation. The study found that the 
computer-assisted environment enhanced the academic achievement of students.

A recent study investigated the ICT skills required for counselling students at a Malaysian university to be successful in the workplace (Yusop, Sulaiman, \& Abdullah, 2008). The study found five ICT skills that were in demand. ICT skills were required in searching information, interpreting results of computerised psychological testing programs, quality report writing, public speaking, and electronic database management.

\section{Videos}

According to Audet and Pare (2009), the use of video recordings was a common technological application in counsellor education. Video recordings of counselling sessions or role-play enabled the demonstration of specific counselling concepts, modelling of appropriate behaviour, and enhanced the learning process of trainee counsellors (Baggerly, 2002; Keats, 2008). Videos enabled the students to understand abstract theoretical discussions, observe how an intervention looked like in real life, and offered a reference point where they could plan their own approach (Audet \& Pare, 2009).

In another study, video technology acted as a vehicle for delivering an effective approach to counsellor skills training (Hayes, 2008). Through video technology students could analyse therapeutic relationships. Part of the learning process involved viewing of videotapes of counselling sessions and answering questions relating to the process, the verbal and non-verbal behaviours of counsellor and the client, and the skills deployed by the counsellor. Counsellor educators also used videos and DVDs of popular movies to illustrate specific behaviours for students to recognise (Baggerly, 2002).

\section{Videoconferencing}

Interactive videoconferencing enables synchronous two-way video and audio communications in real time (Baggerly, 2002). There are two main benefits of videoconferencing. First, interaction between an expert counsellor and students is possible at lower costs in terms of travelling cost and travelling time. An expert located in one country could address a group of students in another country without leaving their country. Similarly, counselling students at an institute could meet with other students through videoconferencing to discuss matters relating to their studies or understanding of certain counselling concepts. 
Videoconferencing could be valuable for counselling students within the same institution but based at different campuses.

Rapisarda and Jencius (2005) explored the use of videoconferencing to enhance multicultural counselling education. Counselling students at an American university participated in four videoconference sessions with counsellors in Turkey, Bolivia, South Carolina, and Arizona. Five themes emerged from the exploration. First, participants agreed that videoconferencing enhanced their learning. Second, participants revealed that the experience broadened their worldview. Third, participants valued the first-hand experience, opportunity to converse in real-time with experts from outside their worlds, and sharing ideas. Fourth, participants' shared an interest in using technology in the future for personal or work related areas. Lastly, participants requested a need to prepare before the teleconference to further enhance the interchange.

\section{Engineering}

In the field of engineering, the use of ICT to support student learning is presented in the studies outlined in the following section. Engineering subjects are very theoretical and the preferred method of delivery is the lecture format (Deshpande \& Huang, 2009). Using lectures cater for the large number of students and this was accompanied with rigorous problem solving organised in tutorial format. Many first year engineering students face difficulty in understanding fundamental concepts and basic engineering principles (Deliktas, 2008). Using computer simulations is one of the many ways to assist students in learning these concepts and principles as experienced by students at Austrian (Bauer, Wenninger, Haase, \& Fischer, 2011), Indian (Karmakar, Roy, Kumbhakar \& Nafalski, 200), and Portuguese universities (Domingues, Rocha, Dourado, Alves \& Fereira, 2010). Similarly, engineering students at a UK university were taught business management skills through a web-based strategy game (Begum \& Newman, 2011). Lastly, students living in Egypt were able to complete an Italian university qualification through internet-based learning technologies (Assante \& Sepe, 2011).

\section{Computer animations, simulations and games}

Ellis (2004) examined the impact of animation on adult learners for a topic (Boolean algebra) in an engineering course. Participants in the study comprised of thirty-eight participants' whose ages were between 25 and 50 and enrolled in a two-year continuing education programme. The participants were randomly 
assigned to one of two groups: a control group and an experimental group. The study found that the participants who used the animations understood Boolean algebra at a significantly higher rate than those who used the written tutorial.

Electrical engineering students at the Vienna University of Technology (Austria) used a computer simulation to assist their learning in a basic course called Digital Systems (Bauer, Wenninger, Haase, \& Fischer, 2011). Traditionally, the course was delivered through weekly face-to-face lectures and laboratory work for the students. The laboratory work involved students using evaluation boards, power supplies and logic analyzers. That approach was replaced through a computer simulation and an illustration tool that students can download and run on a personal computer. Another simulation was experienced by many Indian electrical and electronics engineering students (Karmakar, Roy, Kumbhakar \& Nafalski, 2009). Due to the high student numbers and high cost of laboratory equipment, the creation of the high voltage virtual laboratory offered a cost effective tool for the universities. Virtual laboratories have also been developed for biochemical engineering students at the University of Minho (Domingues, Rocha, Dourado, Alves \& Fereira, 2010). The web-based virtual laboratory offered animations, videos, and control of virtual experiments. A high number of students confirmed the value of the virtual laboratory in supporting their learning experience.

Final year students in the Aeronautical and Automotive Engineering degrees at the Loughborough University were taught business management skills through a computer simulation game (Begum \& Newman, 2011). The web-based game called "Venture Strategy" required students to enter the microcomputer industry through marketing, product development, accounting, finance and manufacturing, financial analysis, business partnership negotiations, human resource management and e-commerce.

\section{Internet-based}

Engineering students at the Helwan University in Egypt were able to study for an Italian qualification through an internet-based e-learning environment. The learning environment was supported through a videoconference integrated system, a broadband internet connection, a satellite television system and satellite internet. Professors from the International Telematic University Uninettuno (ITUU) in Italy delivered on-line video lessons for the Egyptian students (Assante and Sepe, 2011). Laboratory experiments to provide practical 
experience for engineering students is important, unavoidable, and expensive. To overcome the costly exercise, engineering students at a Serbian university perform laboratory experiments via an internet-based laboratory (Stefanovic, Matijevic, Cvijetkovic, \& Simic, 2007).

'Youtube Fridays' was a strategy employed by Liberatore (2010) to engage first year engineering students in the Introduction to Engineering Thermodynamics class. It began as a fun way to start a 8am class on Friday to a standard teaching technique. Students were enticed to choose a video that related to the topics covered in class. Some examples of videos selected by the students showed water condensing behind a jet engine (sometimes referred to as contrail). The author argued that using Youtube was necessary to engage the technologycentric students.

\section{Self-efficacy of first year engineering students}

Self-efficacy refers to a student's judgement that they are capable of organising and performing activities to achieve a predetermined type of performance (Bandura, 1997). Self-efficacy had been found to influence engineering students' behaviour either positively or negatively (Fantz, Siller, \& DeMiranda, 2011). A study to explore the relationship between pre-college experiences and selfefficacy for first year engineering students found that students with higher exposure to engineering content prior to enrolling in engineering had higher selfefficacy in engineering (Fant, Siller, \& Demiranda, 2011). The authors confirm that students who had hobbies in programming, electronics, producing video games, robotics, and model rockets had higher self-efficacy in engineering. 


\section{Summary}

This chapter outlined the current use of ICT to support tertiary students at institutions outside of New Zealand. The studies are categorised in terms of their relevance to the participants in this study. The disciplines include accounting, business marketing, economics, computing, English, physical education (PE), construction trades, information technology (IT), hospitality, counselling, and engineering.

The studies confirm some possibilities that ICT can offer to all disciplines. ICT discussed in this chapter include all those presented in the previous chapter and ones that had not been reported to be in use in New Zealand. These include internet resources such as blogs, wikis, Youtube videos, computer based animations, simulations, and even the use of mobile phones to support students learning English. 


\section{CHAPTER 5}

\section{RESEARCH METHODOLOGY}

\section{Introduction}

This chapter outlines the research methodology of this study. It begins with the research focus and the researcher's position in the study. The research orientation presents the ontological, epistemological, and axiological underpinnings of this research. The study is informed by social constructivism and uses qualitative case study as the research strategy to answer the research questions. Talanoa, participant observation and the researcher's reflective journal offers the means to data collection. Data analysis adhered to the theoretical propositions of the study.

\section{Research Focus}

Pasifika students' retention and successful completion in education has been a topic of concern for the New Zealand government, Pasifika communities and tertiary institutions over the past ten years (Ministry of Education, 2010a). Recent educational reforms have focused attention on raising students' academic achievements. This study investigates how ICT can enhance Pasifika tertiary students' learning experience. The researcher argues that higher ICT skills for Pasifika students can contribute to successful educational outcomes for these learners. ICTs' impact on students' learning outcomes had been widely researched and promoted in Europe, United Kingdom, United States of America, and Australia. Most of the New Zealand-based literature gathered for the ten years (2000-2010) focused mainly on mainstream learners. Four New Zealandbased studies that focused on ICT supported learning for Pasifika tertiary students were found (Latu \& Young, 2003; Clayton, Rata-Skudder, \& Baral, 2004; Hodgen, 2006; Koloto, Katoanga \& Tatila, 2006). The identified literature focusing on the use of ICT in the New Zealand tertiary education sector was mainly undertaken by the institutions and intended to gauge their use of ICT while few investigated the students' experience. 
The researcher firmly believes that ICT has the potential to support Pasifika learners in improving their educational outcomes. The OECD Programme for International Student Assessment (PISA) 2006 confirms that there is a positive and significant effect on the students' frequent use of computers and their science scores (Spiezia, 2011). While the view is further supported by international studies as outlined in Chapter 4, the need to investigate the context for Pasifika tertiary students is crucial to facilitate the adoption of ICT to support Pasifika learners' learning needs. As more New Zealand tertiary institutions implement e-learning strategies there is an urgent need for sound pedagogical knowledge in relation to e-learning and Pasifika learners' needs. Failing this will only prolong the long-tail of Pasifika learners' educational underachievement.

Pedagogy that empowers Pasifika learners is vital for the improvement of their academic achievements. Ferguson, Gorinski, Wendt-Samu, and Mara (2008) offer a Pasifika adaptation of the dimensions of diversity pedagogy outlined by Sheets (2005). According to Sheets (2005), diversity pedagogy has eight dimensional elements representing the teacher's pedagogical behaviour and the student's corresponding cultural display. The diversity pedagogy is based on the premise that the teacher and student's behaviour stimulates the learning process. Elements of the teacher's pedagogical behaviour include: diversity, identity, social interaction, culturally safe classroom context, language, culturally inclusive content, instruction, and assessment (Sheets, 2005).

The Pasifika adaptation included seven dimensions namely cultural distinctiveness, identities, communication and social interaction, indigenous and heritage languages, co-constructed classroom contexts, culturally responsive pedagogical practice and content, and assessment and evaluation. Cultural distinctiveness acknowledges the Pasifika learners distinct cultural backgrounds and the generational changes that the younger Pasifika learners are experiencing with their culture. Identities of learners are vital for their survival within their learning environment therefore providing the opportunity to belong to an accepted group must be encouraged. The need to feel a sense of belonging and reinforced by seeing oneself within the learning environment provides the positive signs for Pasifika learners to attain the desired outcomes of the education system (Nakhid, 2002; Ferguson, Gorinski, Wendt-Samu, \& Mara, 2008). The Pasifika adaptation of the diversity pedagogy will only be useful if the teacher uses it. Failing to change the teacher's current practice will only serve to maintain the current status quo. 
Social interaction within the classroom environment and language are two distinct contributing factors to academic achievements of learners. English is the language used in the learning environment and Pasifika students' mastery of the language is lower than expected as captured in the Adult Life and Literacy survey (Lawes, 2009; Lane, 2011) and Programme for International Student Assessment surveys (Statistics New Zealand and Ministry of Pacific Island Affairs, 2010). Poor command of the English language will impact on the communication in the learning environment. The co-construction of the classroom context empowers the learners and values their prior experiences and knowledge. Culturally responsive pedagogies and content enables the learners to identify themselves within the learning environment. Lastly, assessment and evaluation processes used may have life-long implications on the learners and their families. Ferguson, Gorinski, Wendt-Samu, and Mara (2008) suggest that assessment systems that are conducive to Pasifika school learners are formative oriented as opposed to the summative assessments based on exams. Obviously there are aspects of the exam process that does not support Pasifika learners which warrants an investigation to uncover practical alternatives.

Another contributing factor to successful achievement of learners is teacher beliefs. Teacher beliefs are highly influenced by their own personal backgrounds (Sheets, 2009). As a result, the teacher's interaction with the learner can be a positive or a negative influence. Nieto (2008) contends that attitudes and practices of teachers, communities, and society dramatically influence the opportunities for success of students from various backgrounds. This is evident in the case of Pasifika learners (Jones, 1986; Nakhid, 2002). The learner is powerless in influencing their teacher's beliefs. However learners with advanced ICT skills can overcome this situation. While the lack of engagement from the teacher may hinder students' learning accessing learning sources that are freely available on the internet can assist the learner to meet assessment requirements.

Pasifika people are urged to view ICT as an essential tool for the $21^{\text {st }}$ century. Generally, a tool is created for a particular purpose, based on certain assumptions and worldviews inherited from the creator of the tool. In order to use a computer, it is assumed that a user has some basic computer skills such as the familiarity with the computer keyboard layout and the associated functions of the keys. To use the computer mouse, it is assumed that the user understands that moving the mouse on a flat surface moves a corresponding pointer on the computer screen and clicking the left-mouse button to activate a predetermined action. How or where the user acquires these skills are the user's 
responsibility. Another common assumption when using the internet is that it assumes that the user can read the English language because English is the pseudo-language of the internet. Majority of the websites are in the English language. In the same way, while ICT may be a wonderful and empowering tool, it may be ineffective for those without the relevant knowhow.

A long term benefit included as an aim for this study is to uplift the ICT skills of Pasifika tertiary students enhancing their life-long skills and also employability skills. This aim was based on the premise that higher or advanced ICT skills are vital for life-long learning and employability in the knowledge economy. While the first aim of the current study was to ensure that Pasifika students successfully complete their studies through ICT, the second aim focused on transforming Pasifika students into life-long learners with ICT as the enabling tool. It is therefore imperative that this study be undertaken to explore the available options and to empower Pasifika learners who in turn will be the change agents within their respective communities.

\section{Researcher Positioning}

The researcher has over 15 years of experience in teaching computer related courses at the tertiary entry level and is aware of past and present uses of ICT to support learning. Courses taught by the researcher included personal computer hardware maintenance, networking, programming, computer games design and development, and web and multimedia design. While studies have been international studies had been identified in the literature review, there is the need to adapt ICT to meet the needs of non-mainstream learners in the New Zealand tertiary sector. The researcher holds the view that ICT, when developed or adapted appropriately for any learner, will greatly impact their motivation to learn, thereby leading to positive educational outcomes. The current challenge is developing a critical mass of Pasifika people with appropriate ICT skills to meet the demand.

Tertiary education delivery in New Zealand is dominated by the traditional approach of involving lectures supported by text-book based learning and tutorials or laboratory work (Elgort, 2005; Ham \& Wenmoth, 2007). Learners with adequate academic skills such as English reading and comprehension from text sources, listening and comprehending the main points delivered in lectures, and writing legible answers to questions set out on an examination paper stand a fair chance of passing courses. Unfortunately, those that lack these skills have a 
lower chance of passing their courses. The text books used in the courses that Pasifika students undertake are written in English and one obvious requirement for the learners is the ability to read and comprehend the text.

A similar dilemma is currently faced by Pasifika tertiary students with ICTsupported learning. While studies have been undertaken to investigate the effectiveness of ICT-supported learning, only a handful of studies included Pasifika tertiary learners. Excluding them in a study, removes them from the solution. While other studies reveal that ICT have played a role in improving the learning outcomes of students, these students were not Pasifika students. McLoughlin and Oliver (1999) advise that delivery of online educational resources must account for different cultural variables, specific learning needs, learners' preferences, and learning styles.

In a qualitative research, the role of the researcher is a central component in the process of data collection. Especially where the research involves ethnic minority groups, the "insider" research offers an added degree of importance to the process (Palmer, 2006). In this study, the research involves Pasifika students and the researcher is also identified as a Pasifika person. The researcher is from Rotuma a Polynesian island situated six hundred miles north-west of the Fiji Islands. Rotuma has been part of Fiji since 1881 after the paramount chiefs of the seven districts on the island ceded Rotuma to Britain.

\section{Insider Research}

In this study, the situation between the participants and the researcher presents a seamless social dynamic. The cultural similarities between the participants and the researcher are minimised through their shared cultural knowledge (Bishop, 2008). Many participants assumed that the researcher as one of them as exemplified in a question posed by a prospective participant - 'Are you Sa?' which meant 'are you a Samoan?' Furthermore, Pasifika peoples' generosity towards their use of time may be an issue for a non-Pasifika researcher. Through cultural understanding from both parties involved this issue is easily mitigated. In situations when participants do not arrive on time for scheduled meetings, the researcher understands that another urgent event has occurred resulting in the participant's non-arrival or late arrival therefore the need to schedule another meeting.

As a Pasifika IT professional, the researcher considers his role as a change agent and this study will identify some practical strategies in using ICT to support 
Pasifika tertiary students' successful completion of their studies. This can be viewed as a struggle for development and to liberate Pasifika peoples (Smith, 2008). ICT literacy is crucial for the vitality of New Zealanders and more specifically to Pasifika peoples who continue to be at the tail end of most socioeconomic statistics. While it is widely known that ICT is driving the knowledge economy, some Pasifika students are oblivious to this and may face the same fate encountered by their ancestors who migrated to New Zealand in the 1950s and 1960s. The current study aims to enlighten Pasifika peoples to take ownership of their destiny through the development of their ICT skills enabling them to better participate in the knowledge economy.

\section{Sometimes an Insider, Sometimes an Outsider}

Insider research has challenges inherent in the approach. While the insider status may lead to greater proximity in the research process, it also highlights a range of social gaps that may otherwise remaine hidden (Heley, 2011). For example, the researcher was born on the island of Rotuma, grew up in Fiji and migrated to New Zealand in 2001. While the researcher fluently speaks Rotuman, Fijian and English, most of the participants were Samoans, Tongans, Niueans or Tokelauns who may feel more comfortable if communication was in their respective languages. In addition, some New Zealand-born participants may view the researcher as an outsider. While the researcher is a Polynesian, he may not have similar experiences as theirs and therefore he may not fully understand their situations. Furthermore, the view that the researcher as an academic staff member may hold the power and therefore influence participants' responses is another challenge that needs to be addressed.

In order to mitigate these challenges, adherence to the following four basic principles was observed: respect, collaboration, honesty, and empowerment (Koloto, Katoanga, \& Tatila, 2006). Showing respect to others in all interactions is expected and this will ensure the smooth running of the research process. Collaboration between the researcher, participants and other stakeholders will contribute to the success of the research. Honesty throughout the research process will be paramount as this will offer an authentic voice to the research. Above all, the research aims to empower the participants to fully engage in the research while enhancing their learning experience. 


\section{Research Orientation}

According to Walter (2010) research methodology is the theoretical lens through which a research is designed and conducted. There are three core components of research methodology that includes the researcher's standpoint, theoretical conceptual framework and paradigm, and the research methods. First, the researcher's standpoint is influenced by the researcher's ontological, epistemological, and axiological frameworks. Second, the conceptual framework is a theoretical map of how the data is conceptualised, analysed, and interpreted to answer the research questions. The conceptual framework is informed by a number of theories that are part of a theoretical paradigm. Lastly, the research methods are the tools that are used to collect the research data.

\section{Ontology}

Ontology is defined as the study of the nature or essence of things (Opie, 2004) or the nature of reality (Scott \& Morrison, 2006; Schraw \& Olafson, 2008). The researcher holds the view that there are multiple realities socially constructed by people. Consequently, these constructs impact on people's lives and their interactions with others (Patton, 2002; Lodico, Spaulding, \& Voegtle, 2006). The researcher's ontological viewpoint had been influenced by his upbringing and past life experiences. The foundation was influenced through a strict Christian belief system and traditional Rotuman customary practices from birth to the researcher's late-teens. The researcher's upbringing was moulded through his home environment and later on during the four years spent at the boarding high school managed by the Methodist Church of Fiji.

At first, through the influence of readings from the Bible the researcher believed that God created the universe. However, this view was to be later challenged when the researcher took high school science subjects that offered an alternative explanation to how the universe was created. In science, the origin of the universe was explained by the Big Bang theory and human beings were a result of evolution. During the researcher's high school and university undergraduate years where the researcher pursued a science degree, the prominent ontological stance was positivism. This was mainly the result of the researcher's enthusiasm in subjects such as mathematics, physics, chemistry and engineering. Becoming a teacher was another turning point for the researcher, when the positivist viewpoint was challenged as the researcher strived towards improving his teaching practice. 
Pajares (1992) indicated that teachers' beliefs influenced their perception which in turn affected their classroom practice. In other words, teachers acted upon what they believed. Over the years of teaching computer related courses, the researcher had been intrigued by some of his students' inability to grasp mathematically based concepts. Amongst other things, mathematical skills are an essential component of computer technology (Beaubouef \& Mason, 2005). A recurring question was "why do some students find maths so hard to understand?" Numerous approaches have been tested and solutions had been found at the same time other challenges have been identified requiring further investigation. The following example aims to describe the researcher's ontological framework applied in a class that was part of his teaching responsibility and was not involved in this study.

Students in an introductory programming course taught by the researcher were given an assignment to write a currency converter computer program. An internet-based currency calculator that was available from a commercial bank's website was shown as an example to demonstrate the expected outcome. Students were told that their currency converter would take New Zealand currency as an input and convert it to five different currencies that included Australian, British, Indian, Japanese, and Fijian currencies. In a tutorial class of twenty students, at least two students would be able to complete the assignment without any assistance from the researcher. The remaining members of the class would require some form of assistance from the researcher to enable them to complete the assignment.

Students' learning prior to the assignment focused on learning the programming language and using some of the programming language tools that were to be applied in this assignment. The researcher's usual approach in helping the students was to sit next to the student and ask the individual student 'what is it that you don't understand?' This approach was rather a time consuming exercise. Each student would require between five to fifteen minutes but the researcher strongly felt it was necessary. The researcher believed that it was his responsibility to offer the students the required assistance and guidance to enable them to solve the problem on their own.

A week before the assignment's due date, a two-hour long computer laboratory session was allocated for students to work on the assignment. During this session approximately half the class would have received one-on-one help from the researcher. This approach meant that the remaining students had missed the 
opportunity to get one-on-one help from the researcher and additional time would be required. Instead of committing an additional two hours, the researcher used ten to fifteen minutes during the lecture session to share and clarify the challenges or questions raised by the students from the lab class to the whole class. In this way, the researcher aimed to answer questions that some students may have from those who did not receive one-on-one assistance during the lab session. During the following lab class, an opportunity was offered to help those who did not receive one-on-one assistance during the previous class. It had been observed that less than half of the number of remaining students sought help. This observation led the researcher to believe that the clarification given in class had achieved its purpose.

In the following semester the questions raised by the students were embedded as part of the lecture material. A variety of examples covering the questions raised from previous students were used to help the current students better understand the researcher's expectations. This on-going practice had been very effective in preparing the students before they tackled the assignment.

Based on these observations, the researcher had concluded that his students were missing problem solving and math skills. These skills were not explicitly part of the introductory programming course but were assumed to be skills students brought to the course. The introductory programming course focused mainly on teaching the programming language syntax, data structures, memory structures, and control structures. A number of assumptions were made for the assignment. First, students would be able to obtain the foreign exchange rates from a commercial banks website. Second, students understood the requirements for the currency converter program.

One of these requirements was the manipulation of the input and the exchange rate to obtain the currency equivalence. To calculate the equivalent of one hundred New Zealand dollars in the Australian currency, it was assumed that the student was capable of using the given currency exchange rate and to perform the required calculation. The calculation involved multiplying the exchange rate and the amount in New Zealand currency. Many students struggled to understand this number manipulation. For these students the researcher used various ways to assist them in understanding the situation. One of these ways included the use of a scenario involving an exchange rate of one percent. With this simplified rate, one New Zealand dollar equals one Australian dollar. When 
the exchange rate was increased to two percent, some students were able to detect what was required to be done.

The basis of this example was that the researcher believed that the students had different realities. After attending the lectures, and attempting the lab exercises, the assignment aimed to assess the students' ability to undertake problem solving. In other words, the researcher's expectation was reflected in the assignment question and along with it was his expectation that all his students would be successful if he had taught the students well. While it was an assessment for the students, the researcher felt that it was an assessment of his ability to teach the course content to the students.

The researcher's belief that there were multiple realities and this greatly influenced the researcher's teaching practices. However, this was not obvious to the researcher until his $\mathrm{PhD}$ journey that facilitated the unpacking of his actions. The researcher's early upbringing and the influence of the Christian worldviews had contributed to the researcher's practices. For instance, the biblical verse from Mathew 7:12 "do to others as what you would have them do to you" was an example of the researcher's worldview that led the researcher to go the extra mile in ensuring that his students understood what he had taught them.

At the same time, the researcher was aware that not all his students held the same worldview that he held. Therefore the researcher did not hesitate to transcend to the students' level of understanding and then from there the researcher worked on moving the students' understanding to where the researcher wanted them to be. In many cases, this was possible through listening to the challenges that the student was facing. Based on the information, the researcher offered further examples or alternative explanations to improve the student's understanding of the subject matter.

In some cases, while listening to the students, other matters totally unrelated to the assignment emerged. When this situation arises, the researcher helps the student to solve their immediate problem - a real life problem solving exercise. This is based on the belief that once that problem has been resolved the student can focus on the researcher's course assignment. A situation that occurred during class involved a mature male student who had just received a phone call from his daughter's school that she was feeling unwell and required him to pick his daughter from school. The class was into the first half-hour. When the researcher sat next to him and asked 'how can I help?' His reply had nothing to do with the assignment but was about his sick daughter to be picked from school. 
Before the student left the class, the researcher advised him to send an email with his questions relating to the assignment. Later, the student sent an email with his questions to which the researcher replied and offered to meet the student during his lunch break on the following day to clarify other matters if required.

In this study, the subject matter is ICT and its associated skills. The ontological nature of the subject matter is viewed as positivist. In other words, there is only one truth in as far as ICT is concerned. ICT was created based on scientific assumptions and therefore inherited the ontological assumptions related to science, mathematics, and engineering.

\section{Epistemology}

Epistemology refers to the theory of knowledge (Fox, 1999) driven by the two main questions: "What is knowledge?" and "How can we know?" A third question arises for those that know something is "How do you know what you know?" (Greco, 1999, p.1) For the purpose of this study, epistemology refers to how the researcher knows the reality that he wished to describe. This study adheres to the interpretive paradigm whereby the researcher and the participants are engaged in an interactive process (Mertens, 1998). The interpretive paradigm accentuates that research is a result of the researcher's values and therefore were inseparable. The interpretive paradigm attempts to "understand, explain, and demystify social reality through the eyes of different participants" (Cohen, Manion \& Morrison, 2007, p.19).

This study is a result of the researcher's motivation to better understand what factors contribute to Pasifika students' academic underachievement. A lot of questions have been raised through the news media about the state of academic achievement of Pasifika students. Based on the notion that high academic achievements will lead to better employment opportunities (Earle, 2010), it is crucial that Pasifika students' situation is thoroughly examined. Accordingly, this study aims to explore ways of alleviating this undesirable situation. For the purpose of this study, the knowledge of interest belongs to the field of information and communication technologies (ICT). The researcher has acquired ICT knowledge through various sources which is to be transferred to the students through face-to-face interactions, or mediated through ICT. The following example aims to describe the researcher's epistemological beliefs as applied in his teaching practice.

A year prior to this study, the researcher was assigned to teach an introductory to multimedia design course in one semester. The course content and other 
resources such as lecture notes, computer laboratory notes and tutorial questions had been developed by a colleague. An assessment required students to develop a website on a predetermined topic. After the first semester of using the same learning materials, the researcher found that about one third of students had decided not to complete the assessment. Two main reasons gathered from students for not completing the assignment included the view that it was a boring topic and that it was too hard to find resources.

In the following semester, the researcher decided to change the assignment topic from a predetermined one to a topic that the students chose. The students' results at the end of semester were surprisingly better than the previous semester. The researcher observed that students were more engaged and were motivated in their chosen topic and they felt accountable for completing the assignment.

The researcher's "ways of knowing" that influenced his practice as outlined above can be described as socially constructed (Adler, 2011). At first, the assignment was given out as initially designed with a predetermined topic. The students' end of semester results prompted the question 'is there a way to improve the results?' This led to the decision to change from a predetermined topic to the students' choice of topic. Underlying this choice was the belief that students had different ways of knowing. Providing them with the opportunity to choose their topics empowered them. This increased their interest and they led the direction of their learning (McDowall, 2010). The researcher played the role of a facilitator or a guide that assisted the students to expand their knowledge in the field of web design and also in their chosen topics.

In this study, the epistemological assumption is socially constructed (Adler, 2011). Participants will learn how to use ICT to enhance their learning experience. Similar to the researcher's experience presented above, it is influenced by the belief that through social interaction, participants will create knowledge which will empower them.

\section{Axiology}

Axiology is derived from two Greek words - axios or worth and logos or reason, theory (Hart, 1971). It is the theory of value where value refers to quality. Axiology offers a framework for defining the relationship between humans and their environment. Values include things and events that support human survival and the enhancement of life that fuels the quest for knowledge of reality. Notions of good and bad, right and wrong, beautiful and ugly are some examples of the 
values that humans use on a daily basis. Humans not only value, but hold and use a scale of values associated with some degree and quality of satisfactions.

While the study of values have led to ethics (or moral value) and aesthetics (or sensori-emotional values), the researcher upholds Christian values that were implanted upon him in his formative years. These values include: compassion, endurance, forgiveness, friendship, honesty, hope, humility, justice, respect, service, thankfulness, and wisdom. These are values common to Pasifika peoples include "respect, reciprocity, communalism, collective responsibility, gerontocracy, humility, love, service, and spirituality" (Anae, Coxon, Mara, Wendt-Samu, \& Finau, 2001, p.14). The Health Research Council of New Zealand (2004, p.2) offer an overlapping list which includes "relationship, respect, reciprocity, cultural competency, utility, rights, balance, protection, and participation".

In this study, values that are taken for granted by Pasifika peoples will be used throughout the study. These will include all the values stated earlier: compassion, communalism, collective responsibility, endurance, forgiveness, friendship, honesty, hope, humility, justice, respect, service, thankfulness, reciprocity, gerontocracy, love, spirituality, relationship, cultural competency, utility, rights, balance, protection, and participation.

\section{Qualitative Research}

Qualitative research including naturalistic inquiry or constructivism (Lincoln \& Guba, 1985), is the process of investigating where the researcher gathers, organizes, and interprets the gathered data with the use of the eyes and ears as filters (Lichtman, 2006). The participant's view based on the context in which they expressed their view highlight the meaning that they hold (Creswell, 2008). Qualitative research focuses on uncovering the meaning of a phenomenon for those involved. As such, qualitative researchers attempt to uncover people's interpretation of their experiences, how they construct their worlds, and what meaning they derive from their experiences (Merriam, 2009). In educational research, the researcher depends on participants' views based on broad and general questions and collects high volumes of text-based data. The data is then described and analysed to construct themes that are influenced by the researcher's subjective and biased viewpoint (Creswell, 2008). The case study was the chosen research strategy for this study. 


\section{Case Study}

Case study is one of the most common qualitative research strategies which focuses on understanding the interplaying forces within a single setting (Eisenhardt, 2002). According to Merriam (1988), case study is a research design that can accommodate a multi-disciplinary and philosophical perspective. Yin (2009) offers a two-fold technical definition for case study. The first part concerns the scope of a case study confirming that it is an empirical inquiry that investigates a contemporary phenomenon in depth and within its real-life context. The second part concerns with the other technical characteristics such as data collection and data analysis strategies. Further, Yin (2009) affirms that case study is a suitable strategy when answering research questions on "how" and "why". This resonates well with this study's research question on "How might Pasifika students at a New Zealand institute of technology use ICT to enhance their learning experience?"

Choosing to use case study was mainly influenced by some of its advantages. These included the ease of understanding its results, immediate intelligibility, capturing unique features that may otherwise be lost in other approaches, strong on reality, undertaken by a single researcher, and embraces unanticipated and uncontrolled variables (Cohen, Manion, \& Morrison, 2007). The strong reality of the case study makes it attractive for this study as the results offer a step for action.

Weaknesses of the case study approach do exist and it is acknowledged. It is not the intention of this study to offer generalizability. In this research, the case study offers an insight into how Pasifika students at a tertiary institution can be assisted with the use of ICT. The selection of participants is biased, personal and subjective (Cohen, Manion, \& Morrison, 2007). Admittedly, the case study is prone to observer biases despite attempts to address reflexivity. Despite these weaknesses, the researcher's ontological and epistemological world views have been upheld through the use of the case study.

The current study aims to contribute to the body of knowledge seeking remedies to the wider challenge of uplifting Pasifika students' educational achievement. The researcher argues that advanced ICT skill levels of Pasifika students may enhance their academic achievements. The study explores practical ways of mitigating this challenge. 


\section{Research Setting}

The study was undertaken at the Wellington Institute of Technology's (WelTec) Petone campus in Lower Hutt. WelTec is classified as an institute of technology or polytechnic (ITP) in the New Zealand tertiary education sector. It has three other campuses: Wellington city, Auckland, and Christchurch. It is one of the three ITPS in the Wellington region. The other two are Whitireia Community Polytechnic in Porirua city and The Open Polytechnic of New Zealand (TOPNZ) in Woburn, Lower Hutt. WelTec has a trade focus while Whitireia focuses on creative arts and community health. TOPNZ, on the other hand, focuses mainly on distance learning. The three ITPs do offer courses in business management and information technology (IT) or information systems management.

The choice of this setting was mainly influenced by practical reasons. This study is self-funded and therefore the researcher was mindful of additional costs in terms of time and money if the study was undertaken elsewhere. WelTec's main campus at Petone was where most Pasifika participants were enrolled. At the Petone campus, venues for interaction between the researcher and participants included the Pasifika Centre, Learning Commons, students' cafeteria, and students' computer labs. The Pasifika Centre is a dedicated area where students can do private study, meet other Pasifika students or just to 'hang-out'. It is located on the ground floor of the Tower Building. The centre consists of a lounge ( $5 \mathrm{~m}$ long $\times 3 \mathrm{~m}$ wide), a small kitchen area ( $4 \mathrm{~m}$ long $\times 2 \mathrm{~m}$ wide) with a washing sink, a fridge and hot water urn, a study room ( $5 \mathrm{~m}$ long $\times 5 \mathrm{~m}$ wide), and the manager's office $(5 \mathrm{~m}$ long $\times 4 \mathrm{~m}$ wide). The study room has two personal computers that were connected to WelTec's local area network enabling students to access internal and external online resources required for their studies.

The Learning Commons is situated on the first floor of the Tower Block. This space is used by all WelTec students and includes the main library, discussion rooms, and personal computer connected to the institute's network for the staff and students to use. The learning commons has an open plan layout where students are allowed to work in groups or individually. The students' cafeteria is located on the north side on the ground floor of the Tower Block while students' computer labs are located on the fourth, fifth and sixth floor of the Tower Block.

\section{Research Participants}

In 2009, Pasifika students comprised $7 \%$ of WelTec's total student population. In terms of equivalent full-time (EFT) enrolments, 309 EFTS were recorded for 
Pasifika students (Wellington Institute of Technology, 2010). Twenty eight fulltime Pasifika students participated in this study. All participants were enrolled at the WelTec's Petone campus during two academic years (March - November 2009 and 2010). There were 15 females and 13 males. Although the gender distribution of the total number of Pasifika students at the institute favoured females in a 2:1 ratio, a gender balance was sought for this study. This proved to be a challenge as male students tended to 'hang out' with their classmates and were less likely to seek academic support. Based on Tertiary Education Commission's age distribution ranges, four of the participants were between the 18-19 age group, twelve in 20-24 age group, nine in the 25-39 age group, and three in the 40 and above age group. The ethnicities of participants comprised of 18 Samoans, four Fijians, three Tongans, and one each from the Cook Islands, Kiribati, and Papua New Guinea.

Nearly half of the participants (13) were enrolled in the Business Studies programmes, followed by four in the English Language (ESOL), three from Exercise Science, two each from the Construction Trades, Information Technology, and Hospitality, and one each from Counselling \& Alcohol and Drug Studies, and Engineering Technology. The high representation of participants in the Business Studies programmes is consistent with the national trend where the highest field of study for Pasifika students was office studies (Wensvoort, 2011). More than half of the participants in the Business studies programmes were completing qualifications in office administration. Fifteen participants were enrolled in certificate (Levels 1-4), eleven in diploma (Levels $5 \& 6$ ), and two in degree qualifications. The level of qualifications attempted by the participants was also consistent with the national trend where Pasifika students were mainly enrolled in the certificate and diploma levels (Wensvoort, 2011).

\section{Data Collection}

The nature of the current study and the chosen research methods places the researcher at the heart of the data collection, analysis and interpretation. In other words, the researcher is the primary research instrument. As such, the researcher must demonstrate the ability to distinguish between what is important and what is not. Researcher bias must be acknowledged and relevant strategies implemented to mitigate the bias (Gray, 2009). The adoption of a reflexive stance was used throughout this study. This involves self-awareness, understanding the power dynamics in the research process, co-creation of knowledge, and awareness of the implications of the shared knowledge. Three 
data collection methods were employed in the study. These include talanoa, participant observation, and researcher's reflective journal.

\section{Talanoa}

Talanoa is a research method for research involving Pasifika peoples. HeluThaman (2001) asserts that talanoa is a qualitative, ecological and oral interactive inquiry method. In a research context, talanoa can enable the researcher and participants to connect at a deeper level which facilitates the coconstruction of authentic, rich contextual and inter-related knowledge. It is subjective, mostly oral and collaborative in nature.

The word talanoa is a familiar word for Pasifika peoples who have connections to Fiji, Samoa and Tonga. A Fijian dictionary defines talanoa as "to chat; to tell stories; to relate something; to chat to someone; to chat together; to chat together about; a story, account, legend" (Capell, 1991, p. 214). For Samoans it means conversation between people (Robinson \& Robinson, 2005); or critical dialogue (Kolone-Collins, 2010). The Tongan dictionary compiled by Churchward (1959) defines talanoa as informal talk, storytelling or to narrate an experience. According to Halapua (2003) talanoa is derived from the two words tala and noa. Tala means talking or telling stories while noa means nothing to hide.

The researcher who is a Rotuman had spent his primary and secondary education years (between the ages of five to 17) in rural Fiji. Consequently, he can speak, write and read Fijian fluently. In the Fijian context, the word talanoa has multiple meanings as recorded in the Fijian dictionary (Capell, 1991). It is a verb and a noun. In an informal context, the statement "au via mai talanoa ga" [I'm here to chat] exemplifies talanoa as a verb. This is a typical response by someone who unexpectedly drops-in and when posed with the question "la, sa va'cava?" [So, how are you?]. As the chatting unfolds, the statement "na noqu $i$ talanoa vei Jone..." [my story to John...] has moved talanoa from a verb to a noun. In the informal context, there is no set agenda and talanoa will take its own course depending on whatever topics the participants wish to share.

However, in a formal context, the statement "au kerea me daru mai talanoa mada ..." [I request that we have a meeting...] exemplifies talanoa as a verb. In this scenario, there will be a meeting and therefore has a purpose. A distinction needs to be made from the more formal Fijian term of bose which refers to a formal meeting which includes an agenda, the adherence to Western formal 
meeting protocols such as the need for a chairperson, quorum, minute taker and others. When a request for talanoa is made, the instigator has a purpose in mind. In this situation, talanoa has a purpose or intent but whether the purpose will be achieved is unknown. In comparison, in a bose meeting rules as stated above are strictly adhered to whereas in talanoa there is a purpose but it is left to the participants' goodwill to contribute to this purpose.

The discourse on talanoa as a philosophy was championed by Dr. Sitiveni Halapua. Following the May 2000 coup in Fiji, Halapua (2004) proposed the use of the talanoa process to engage the diverse groups to address the challenges facing the nation. Earlier, Halapua (2003) argued that the talanoa process involves an open, honest sharing of ideas, views or experiences without any hidden agenda in a face-to-face situation. This is based on the premise that Pasifika peoples' worldviews are shaped, reshaped, and challenged through talanoa. In addition, talanoa had been in use for generations in some South Pacific nations including Fiji, Tonga, and Samoa. It had been used as a means to settle disputes, or differences amongst members of the communities.

Talanoa is widely promoted by Pasifika academics and researchers in the New Zealand education sector. It is argued that talanoa is a culturally appropriate qualitative research method for research involving Pasifika peoples (Otsuka, 2006; Vaioleti, 2006). Six doctoral theses completed at four separate New Zealand universities had employed talanoa as a research method to varying degrees (Nabobo-Baba, 2005; Otsuka, 2006; Maclntyre, 2008; Farrelly, 2009; Prescott, 2009; Ruru, 2010). Four of the six theses involved ethnic Fijian participants while two involved Tongan participants. For the studies undertaken in Fiji, two of the researchers were non-Fijians (Otsuka, 2006; Farrelly, 2009) while the other two studies were undertaken by Tongan researchers involving Tongan participants (Maclntyre, 2008; Prescott, 2009).

Farrelly (2009) explored how a community-based ecotourism project in rural Fiji negotiated the demands of Western entrepreneurship and the traditional Fijian way of living. Farelly (2009) set out to use unstructured interviews but 'fell into' talanoa which became her primary methodology. She argued that talanoa was synonymous with the phenomenological approaches that she had identified to use in the field. Otsuka (2005) examined how cultural differences of ethnic Fijians and Indo-Fijian high school students influenced their educational achievements. The data gathering methods employed by Otsuka (2005) included 
survey questionnaire followed by face-to-face interviews with some participants. Later, Otsuka (2006) proposed talanoa research as a culturally appropriate research design for research involving ethnic Fijians as participants. He argued that the ethnic Fijians communal way of living influenced their behaviour and therefore the use of culturally inappropriate research methods may lead to unreliable and invalid data.

Nabobo-Baba (2005) examined Indigenous Fijian epistemologies and how it impacted on the education of indigenous Fijians. She outlined that her study was a vanua research whereby the research topic and questions are based on, related to, or have implications to the vanua. Vanua includes people (past and present), clan belongingness, and clan roles. It also includes the land and the connectedness between custodianship and genealogy. She defined talanoa as a process involving two or more people that adhere to protocol which includes humility and embodies Fijian culture in the process. It is guided by rules of relationship and kinship, shared knowledge, epistemologies and worldviews. Her definition of talanoa was influenced by her research context and she concluded that talanoa was the approach utilised to tap into her participants' knowledge.

Ruru (2010) examined the effectiveness of international aid for teacher development and employed a range of research methods which included participant observations, focus groups, and semi-structured interviews through talanoa sessions. He outlined that talanoa was used as a research tool for gaining access to people's knowledge, opinions, and feelings. This seemed to have been influenced by Nabobo-Baba's (2005) study. Ruru (2010) discussed the talanoa approach which is in agreement with Vaioleti (2006) who argued that talanoa was a research methodology.

Maclntyre (2008) investigated how Tongan mothers in New Zealand contributed to their children's education. Maclntyre (2008) employed talanoa as an interviewing method given that all participants in her study were already familiar with the talanoa process from a Tongan viewpoint. During talanoa participants may use verbal as well as non-verbal cues to communicate their thoughts, views, or stories. Prescott (2009) investigated key financial and entrepreneurial factors that ensured sustainability of Tongan businesses operating in New Zealand. Prescott (2009) employed talanoa as a method for collecting data. 
From the six doctoral theses, there is a need to further explore and clarify the use of talanoa in qualitative research. While the six researchers may claim to have used talanoa as a research methodology or a research method there is still room for further talanoa to ensure its credibility and rigour. Farelly (2009) challenged the inherent implication of using interviews as a research method involving ethnic Fijians. She revealed that the word interview implicitly places power in the interviewer's hands to determine the interview questions and the interview outcome. Otsuka (2005) did not use talanoa during his study but recommended that the talanoa research methodology be used for any future research involving ethnic Fijians. Nabobo-Baba (2005) emphasised that talanoa is more than an interview. Ruru (2010) on the other hand outlined the talanoa approach as a research methodology and conducted semi-constructed interviews through talanoa.

Both Maclntyre (2008) and Prescott (2009) articulated talanoa from a Tongan viewpoint and were clear in their discussions. Maclntyre (2008) argued that talanoa was an appropriate and practical tool for her study. Participants in her study were able to use the Tongan language which expressed their emotions and enabled the talanoa to reach malie (spiritual connectedness of participants) and mafana (warmth). Prescott (2009) offered a detailed account of the talanoa process from the Tongan context and how he applied it in his study.

The motivation to use talanoa as a data gathering method in this study was aimed at upholding Pasifika peoples' ontological and epistemological frameworks. In this way, the study strives to provide a positive outcome to the Pasifika community (Penetito \& Sanga, 2003). Talanoa is a familiar term to participants in this study who were mainly Samoans, Tongans, and Fijians. It is widely used to refer to anything from general to the more topic specific conversation at many different levels. Another influencing factor in this choice was the unwelcoming connotation of formal research words such as "interviews". A few writers reveal that many Pasifika peoples have negative experiences and associate the word "interview" with "being in trouble" and the interrogative process with authority (Farelly, 2009; Vaioleti, 2006). 


\section{Advantages of Talanoa}

An advantage of talanoa is its empowering nature. Vaioleti (2006) argues that using Western research methodologies to undertake research on Pasifika peoples is doomed to fail due to a number of reasons. Firstly, the objective nature of traditional research methodologies disempowers many Pasifika participants who tend to view the world in a holistic manner. This holistic worldview makes it challenging for Pasifika peoples who are first-time research participants to traverse between the communal and individual domains. For many first-time research participants, the individualistic viewpoint is frowned upon or discouraged by their families or communities but this is in contrast to research objectives where an individual's view is sought during the research process. The anxiety caused by an impending research interview and the request for answers during a limited time frame may lead participants to avoid scheduled interview appointments or provide a white lie during the interview as a coping strategy (Otsuka, 2006). This may be an explanation for the reluctance of some Pasifika people to engage as research participants (Davidson, 2005; Dickie, 2001). The anxiety caused by the interview process may have prompted the often-asked question of "How long will this take?" (Vaioleti, 2006, p. 22). This statement may suggest that the participant is trying to mitigate the anxiety associated with the interview process.

A second advantage of talanoa is its flexibility. An aspect of traditional research methodologies is the predetermined, rigid guidelines that need to be followed in order to achieve validity and reliability. Cohen, Manion \& Morrison (2007) state that reliability in qualitative methodologies may be achieved through "fidelity to real life, context and situation specific, authenticity, comprehensiveness, detail, honesty, depth of response and meaningfulness to the respondents" (p.149). In research involving Pasifika people, the notion of being faithful to real life may be achieved if familiar practices are adopted. Similarly, authentic responses can only be accessed when participants perceive that their needs are being met.

Vaioleti (2006) highlights that talanoa ensures power sharing between all parties. During talanoa, a participant can direct the discussion to whatever topic he/she perceives relevant and appropriate. The researcher, on the other hand, must show compassion, and reciprocate in a similar manner. In a structured or semistructured interview process, the researcher poses a question and the participant is expected to provide the answers. This requirement puts the participant under the spotlight and causes undue stress for the participant to provide an immediate 
answer. During talanoa the emphasise is not on obtaining an immediate response but enables participants to think, reflect and articulate their initial thinking if any exists and also accepts further ammendments if necessary. In other words, talanoa enables an ongoing dialogue as opposed to an absolute answer with no modifications allowed.

A fourth advantage of talanoa is familiarity. Familiarity in this case refers to the implied meaning and understanding of the talanoa process. Participants in this study who were mainly Samoans, Tongans, and Fijians were familiar with the talanoa process based on their own cultural context. Upon receiving the invitation for talanoa, all participants were observed to be at ease. This was in contrast with an earlier request for an interview in which a reply from a prospective participant was, "What for? Am I in trouble?" The reply revealed a preconceived view of the interview process. Further investigation confirmed that the response from the prospective participant was influenced by past experiences whereby the word interview involved interrogation by the authorities especially those in power.

A fifth advantage of talanoa is that it is guided by Pasifika values. Participants in a talanoa adhere to values and protocols that are implicit to the process. These include "respect, reciprocity, communalism, collective responsibility, gerontocracy, humility, love, service, and spirituality" (Anae, Coxon, Mara, Wendt-Samu \& Finau, 2001, p.14). The stated list is not intended to exclude others but to give examples of some of the intrinsic values and protocols associated with talanoa. Honesty is another implicit value that contributes to the validity and authenticity of the gathered data.

\section{Disadvantages of Talanoa}

A demand of talanoa is the duration. Time demands can become a disadvantage for research using talanoa. Adhering to a strict time-frame may deny participants time to articulate their true feelings about the focal topic. The first step in talanoa is the request by the instigator approaching a participant. Depending on the relevance of the topic to the participant, the participant may accept the request and propose a time or deny the request. Between the time of acceptance and the proposed time, the participant will have had some time to reflect on the focal topic. At the first talanoa session, the participant will then articulate his/her views to which other participants will be expected to reciprocate. During the first talanoa session, a participant's view may be reinforced by other participants or 
challenged. When other participants' reciprocate with their views, they may agree or disagree with other participants to which further discussions will arise. At the end of the first talanoa session, all participants will depart feeling either satisfied with the outcome or dissatisfied. In the second talanoa session, the participants will then attempt to reassess their understanding of the topic. The danger in this approach is that it may take more time than anticipated to reach data saturation.

A second disadvantage of talanoa is flexibility. While it is stated earlier that it is an advantage it can easily become a disadvantage if the researcher does not manage it properly. Due to its power sharing nature, dominant participants may steer the discussion to topics that are irrelevant to the researcher. The role of the researcher is to be alert to the situation and to slowly steer the discussion to the intended direction. However, if the researcher fails to do this in the current talanoa session then every attempt must be made in the next session. This flexibility will affect the number of talanoa sessions required to gather the required data for a study.

A third disadvantage of talanoa is the interpretations of the unspoken actions or body language of participants. During talanoa participants may use gestures to assist their verbal expression of their point of view. Herein lies a challenge for both the researcher and the participants. In a situation where the researcher and participants have common cultural background, experiences and other areas of interest, the unspoken actions may be correctly interpreted. However, if there are fewer common grounds, there is a higher possibility of incorrect interpretations of the unspoken actions. In this study, most of the participants had limited prior experiences with computers and therefore articulating their view points became challenging where the need to use technical terms. Refering to specific computer hardware components was observed to be a mentally demanding exercise for participants.

Lastly, talanoa can not be equated to other research methods such as semistructured, unstructured interviews, and ethnographic interviews. In semistructured interviews, the interviewer directs the interview with a set of predetermined questions (Wilkinson \& Birmingham, 2003). In this study, talanoa has similar characteristics as the unstructured interview (Bryman, 2008) or the informal conversational interview as described by Patton (2002). Data gathered during talanoa will be different from one participant to the other and inherently may be difficult to analyse. According to Patton (2002), informal conversational 
interview offers "flexibility, spontaneity, and responsiveness to individual differences and situational changes" (p.343). While there are some similarities, talanoa transcends deeper than unstructured interviews. For Pasifika peoples, talanoa builds lifelong relationships and therefore can not be treated as an isolated event that satisfies the sole purpose of a study.

\section{Participant Observation}

Gray (2009) state that participant observation is largely qualitative, closely associated with ethnographic methodology, and focuses on meanings that people place on their actions. It is a data gathering method where the researcher achieves intimate knowledge of the participants in the group's natural setting. Further, Adler and Alder (2008) argue that participant observation has a particularly strong theoretical basis in symbolic interactionism. Three main reasons for using this approach include: researchers are less likely to impose their own social reality and interpretation on the social world researched; gaining access to areas that could not be normally accessed because of the significant personal risks for the researcher; and understanding why specific practices occur, and its origins and changes over time (Matthews \& Ross, 2010).

Employing participant observation in the study was necessary to verify data gathered through talanoa relating to participants' ICT skills as well as changes or improvements in these skills. Further, participant observation enabled the researcher to observe behaviour that was not evident during the talanoa sessions. Heley (2011) advises that from an engaged position, the participantobserver can obtain a far more accurate and including nuances of the participants' behaviour. Field notes were taken to capture the observations and impressions of the interactions. Digital photos were also taken where possible with the participants consent. Participant observations were undertaken at the Pasifika Centre, the Learning Commons, and the students' computer labs.

\section{Researcher's Reflective Journal}

The relevance of a researcher's reflective journal approach to the research process is gaining wider acceptance within qualitative research. After all, qualitative research is associated with richness of the collected data to illuminate the findings. A reflective journal is a strategy that can facilitate reflexivity while offering the opportunity to examine the researcher's personal assumptions and goals, clarify individual belief systems and subjectivities (Ortlipp, 2008). Reflections offer the opportunity to learn from past experiences and the reflection 
maximises the experience. Furthermore, keeping a journal imposes a discipline and captures the experience of key events immediately after they occur and before the passage of time erodes the experience (Coglan \& Brannick, 2010).

In this study, the strategy of maintaining a research journal was emphasised by the secondary supervisor during the proposal writing stage in February, 2008. The advice was enthusiastically adopted by the researcher. It soon became a rather daunting challenge managing the journal entries. Initial journal entries included list of things to do, list of appointments with key people, meeting briefs. During the early data gathering stage (Etherington, 2004), journal entries evolved from brief notes to the researcher's reflection on meetings with participants. More detailed entries were recorded as the researcher gained a better understanding of the requirements of the reflective journal. This included the initial experience and impressions of various situations and later a reflection on the same situations.

\section{Data Analysis}

Data analysis involves the discovering and determining of patterns in the data, identifying trends and offering an explanation to the trends (Hitchcock \& Huges, 1995; Patton, 2002; Newby, 2010). In qualitative research, there is a variety of techniques to choose from but the chosen techniques are dependent on the research questions. Mertens (2005) and Suter (2006) contend that qualitative data analysis evolves throughout the period of the study. They also suggest that creativity, divergent thinking, an acute perception among ambiguity, and strong writing skills are essential for qualitative data analysis.

In this study, data analysis involved an iterative, spiralling nature that proceeds from more general to the more specific observations (Creswell, 2008). Data analysis began informally during talanoa and participant observation sessions. This enabled the researcher to determine and improve subsequent data collection activities, collect missing information and other relevant issues (Gall, Gall \& Borg, 2007). This proved to be a very useful technique for the researcher who was still new to research data gathering processes.

The data analysis was guided by the six steps outlined by Miles \& Humberman (1994). First, codes to be given to the first set of field notes from the talanoa sessions and the participant observations. Second, personal reflections and other comments are to be recorded alongside the field notes. Third, the 
researcher will need to sort and sift through the data to identify similar phrases, relationships between variables, identify themes, existence of differences between subgroups, and common sequences. Fourth, the researcher will need to identify these patterns and processes, commonalities, and differences and take them out of the field in next cycle of data gathering. Fifth, the researcher will begin elaborating a small set of generalization that explains the gathered data. Lastly, the researcher will examine the generalizations to determine whether the data is consistent with existing theories or the emergent of a new one.

\section{Validity and Reliability}

In a qualitative case study, the importance of validity and reliability cannot be ignored. According to Hammersley (1990), validity refers to the truth of an account that accurately represent a social phenomena to which it represent while reliability refers to the "degree of consistence with which instances are assigned to the same category by different observers or by the same observer on different occasions" (Hammersley, 1992, p.67). Data derived from a case is from a limited source or particular samples or situations and can undermine its credibility if not considered appropriately (Gray, 2009). Assessing the validity and reliability of a qualitative case study involves the examination of its component parts. Merriam (2001) offers three strategies to enhance the validity and reliability of qualitative studies that include internal validity, reliability and external validity.

Internal validity considers the questions of how the research findings match reality. Internal validity can be enhanced through six approaches. These include triangulation, member checks, prolonged time spent in the field, peer briefing, rich and thick descriptions, declaring researcher bias, reporting of discrepant information, and the use of an external auditor to review the project (Creswell, 2009; Glesne, 2006). In this study, internal validity is achieved through triangulation whereby data was gathered through three different methods. Through talanoa the opportunity for the participants to verify what they have said is pursued. The eighteen months of data gathering ensured that ample time is taken for the data to reach saturation point. Peer briefing was undertaking between the researcher and four individuals who were work colleagues of the researcher and were experts in IT and Pasifika peoples.

Reliability generally refers to the extent to which the same results can be obtained if a study is repeated. However, replication of a qualitative study may not yield the same result. As such, an appropriate term for reliability in qualitative 
study is dependability or consistency. Strategies to ensure dependability include the clarification of the researcher's position, use of multiple data collection methods, and clear explanation of how data was collected, how categories were derived and how decisions were made throughout the study (Merriam, 2001). For this study, reliability is achieved through the use of multiple data sources, precise explanations of how data was gathered, how categories were derived, and how the decisions were made through the study.

External validity relates to the generalisability of the findings. A strategy to strengthen a qualitative study's external validity includes the provision of enough description to enable readers to make their own comparison with their circumstances and whether the findings are transferable. A second strategy involves describing how typical case is compared with others in the same class enabling the readers to make their evaluation of their circumstances. A third strategy includes the use of several sites, cases, or situations to maximise diversity in the examined phenomena (Merriam, 2001). To maximise external validity, the first two strategies stated above were used to guide the study.

In this study, strategies outlined by Merriam (2001) offered the guidelines to ensure validity and reliability. The strategies include internal validity, reliability, and external validity. Internal validity can be achieved by collecting data from multiple sources through talanoa, and participant observations. Throughout the study, data gathered from participants through talanoa and participant observation was continuously presented to the participants to ensure that it had been correctly interpreted. Furthermore, the study was undertaken over a prolonged period of time (18 months) to ensure that ample time was given for data to reach a saturation point.

The researcher, as the principal instrument in this study, had purposefully chosen to use talanoa as a data gathering method. Through talanoa the researcher strived to uphold the diverse construction of realities that participants held in their minds. While the researcher held the view that higher ICT skills may enhance the participants' learning experience, many participants did not share the same viewpoint. Through talanoa rich and thick descriptions shared by the participants and the opportunity to capture discrepant information may enhance internal validity. Using talanoa ensures that all participants are committed to a shared outcome. This in a way affects the quality, validity and trustworthiness of the shared knowledge. 


\section{Ethical Issues}

Human ethics approval was granted by the Victoria University of Wellington's Faculty of Education Human Ethics Committee on February 23, 2009 (TKM2008/46, RM6163) and WelTec's Ethics Committee on March 27, 2009. In accordance with the human ethics guidelines, data gathered for the study was accessed only by the researcher and his supervisors. All written materials were kept in a locked file and only accessed by the researcher. All electronic information was password protected and only accessed by the researcher.

Throughout the study, the wellbeing of the participants was a top priority. Ethical issues were carefully considered at the early stages of the study and it was deemed as an on-going process. These include informed consent for all participants, participants' privacy, confidentiality, anonymity, protection of participants' from any form of harm (physical, emotional, or other). To ensure that participants made informed choices, sufficient time was devoted to clarify the research process and complemented by printed materials.

\section{Summary}

The aim of this chapter was to describe the research methodology. Influenced by the researcher's motivation to undertake the study, the corresponding research paradigms were identified to answer the research questions. The research explored the factors that influenced Pasifika students' academic achievement and how ICT could enhance their learning experience. The study was informed by an interpretive paradigm that supports multiple realities that are socially constructed by people. Qualitative case study was employed to gain insights into the participants' worlds and to better understand their experiences. Data was gathered through multiple methods to enable triangulation to ensure the consistency of the data. Data analysis involved an iterative, spiralling approach beginning from a more general to the more specific observation guided by the six steps outlined by Miles and Humberman's (1994). The study aims to offer an explanation of the particular mix of ethnicities of Pasifika tertiary students' performance in a particular learning institution thus the generalisability of these findings should be carefully considered. 


\section{CHAPTER 6}

\section{THE FINDINGS}

\section{Introduction}

This chapter discusses the findings of the study. The Pasifika Tertiary Students' ICT Skills Development Framework is presented outlining its six phases. The framework was an adaptation of the systems development life cycle, a software development framework. The first phase of the development framework focused on measuring the participants' skills in using a personal computer, mobile phone, computer networks, and the internet. The second phase identified the participants' ICT skills requirements based on their programme of study. The analysis of the ICT skills gaps was the third phase which involved the matching of the participants' ICT skills and the ICT requirements of their programme of study. Based on the identified ICT skills gaps, strategies were developed to assist the participants in meeting the requirements of their programmes. Developed strategies were implemented in phase five, and monitored and evaluated in the final phase six.

\section{Pasifika Tertiary Students' ICT Skills Development Framework}

The Pasifika Tertiary Students' ICT Skills Development framework set out the six phases for uplifting ICT skills of participants. It was derived from the systems development life cycle (SDLC), a framework for software development that emerged in the 1960s for the development of large scale software for large businesses (Avison \& Fitzgerald, 1995). SDLC was originally designed to improve the management and control of computer software development and it is now used more generally for the development of all types of systems (Patterson, 2004). It imposed various degrees of discipline to the process of developing software by making the process efficient and predictable. Initially, software was developed as a product but today it can be a product as well as a vehicle for delivering a product. SDLC involved at least five main phases, namely: planning, analysis, design, implementation, and maintenance (Pressman, 2001). 
Six phases were adapted for the Pasifika Tertiary Students' ICT Skills Development framework. The first phase involved measuring Pasifika tertiary students' current ICT skills. The second focused on identifying the students' ICT skills needs based on their programmes of study. The third phase analysed ICT skills gaps based on the students current ICT skills level and the required ICT skills level for their programmes of study. The fourth phase involved the development of ICT based learning strategies to support the students learning experience. The fifth phase was the implementation of the strategies. The sixth and final phase centred on monitoring and evaluating the strategies.

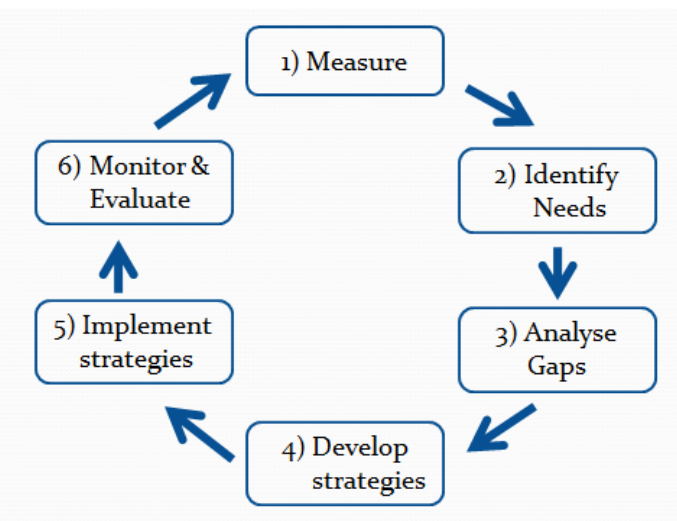

Figure 10: Pasifika Students' ICT Skills Development Framework

\section{Motivations for the Use of the SDLC}

The primary goals for using SDLC in developing a framework for enhancing the ICT skills of Pasifika tertiary students is closely associated with the original goals of SDLC. These included the need to develop a high quality system, establish strong management controls over the development process, and to maximise the productivity of the development team (Bender RBT, 2003). Based on the researcher's IT knowledge and experience, he was convinced that SDLC as a proven model was a feasible option (Avison \& Fitzegerald, 2003). The researcher was interested in developing a high quality system to deliver the expected outcome. In addition, the model offered the researcher the means and know-how to manage the developmental process and to maximise the available resources.

The strategies to uplift the ICT skills of participants were developed through the involvement of the participants. This was a vital step to ensure that the strategy met the participants' needs to complete the assessments in their programmes of study. Similar to the user involvement in software development, the opportunity to fine tune the software is vital to minimise user frustrations that may lead to their reluctance to use the software (Majid, Noor, Adnan, \& Mansor, 2010). In the 
same way, the participants in this study were engaged throughout the study and the strategies that worked were only possible through the participant involvement. User engagement enabled the development of strategies that were relevant to the user thus meeting their individual needs while at the same time meeting the expectations of the researcher.

\section{Talanoa as used in this study}

In this study, talanoa was used prominently to gather data from participants and to disseminate the developed strategies aimed to uplift the participants ICT skill levels. The number of talanoa sessions for each participant or group of participants ranged from two to fourty-four sessions. Participants in this study were not known to the researcher prior to the study nor were they students in classes that the researcher taught. Prospective participants were initially approached by the researcher and were invited to an individual or group talanoa sessions. This approach was aimed at informing prospective participants of the researcher's intention and also to enable them to get to know the researcher. At this early stage participants were also informed of the research protocols as stipulated by the university research ethics, relevant consent forms, and contacts persons (supervisor and university contact person) if participants wished to find out more about the study.

Typically, the first two talanoa sessions was aimed at introducing the researcher and his intentions. Based on the participants' responses or reaction towards the proposition, the researcher then slowly probed further with questions aimed at identifying the types of ICT that the participants were using, both for their studies and non-study study related activities. The questions varied from one talanoa session to another depending on the participants' response or familiarity with a particular ICT. While the study focussed on the ICT that participants used in their studies, the researcher also assisted those who were interested in ICT that they had access to or were interested in but were outside their fields of study.

\section{Phase 1 - Measure Current ICT Skills Level of Participants}

Determining the students' ICT skills prior to the commencing their tertiary studies was crucial because of the implications that this had on their learning experience (Stoner, 2009). The first phase of the ICT skills development framework set out to ascertain the ICT skill levels of the participants. Despite the widespread use of ICT, many American college students lacked the ICT and relevant skills to locate, evaluate and use the oversupply of information (Katz, 2007). A similar trend was 
observed for Belgian university students where a considerable number were not very proficient computer users (Verhoeven, Heerwegh, \& de Wit, 2011). In a study of Australian university students, Crecthley (2007) conceded that students with some ICT skills prior to their tertiary studies have an advantage over those who lack these skills. During the ten years that the researcher worked at the research site, he observed that many Pasifika students enrolled at the institute did not possess the expected ICT skills to meet the demands of their studies.

Most programmes of study offered at New Zealand ITPs required students to use ICTs such as computers, the internet and specialised ICTs for content delivery, support services and administration (Guiney, 2011). In developed countries such as the USA, England, Japan, India and Israel, improving ICT skills of tertiary students have become a pedagogical issue (Wongyu, 2005). Relevant to the participants in this study, Hodgen (2005) affirm that forty-one percent of Pasifika tertiary students throughout New Zealand had some internet access requirement. Internet access demands were significantly higher in New Zealand universities (66\%) but lower in ITPs (33\%). The researcher argued that the level of students' ICT skills may positively or negatively impact on their learning experience. Measuring the participants' ICT skills began with their knowledge and skills in using a personal computer and common devices such as a printer, digital camera, and a scanner. The participants' use of a mobile phone and the internet to meet the demands of tertiary studies was also explored.

In this study, the National Certificate in Computing (Level 2) qualification on the New Zealand Qualification Authority (NZQA) framework was used as the benchmark for the participants' personal computer skills. Two factors influenced the choice of this benchmark. Firstly, all participants in the current study were enrolled in Level 3 qualifications or above. It was therefore assumed that participants possessed the lower level ICT skills (Level 2) that were required for their programme of study. Secondly, the tertiary institution accepted the students through its open entry requirements and assumed enrolled students possessed basic level ICT skills to successfully complete the qualification. In the current study, the basic ICT skills level were equivalent to the NZQA Level 2 National Certificate in Computing. Additional measures were included to determine the participants' use of mobile phones and the internet to support their learning at the tertiary institute. 
The National Certificate in Computing (Level 2) included two unit standards (US) 2780 and 2781 (New Zealand Qualification Authority, 2011). A unit standard (US) registered on the New Zealand Qualifications Framework (NZQF) describes what a learner needs to know or what the learner must be able to achieve. The requirements for US 2780 included the ability to demonstrate the following:

- Knowledge of the personal computer (PC) hardware components

- Knowledge of the operation of system and application software

- Operate a printer

- Complete basic operation and maintenance procedures for a PC

- Knowledge of ergonomic requirements for the safe operation of a PC

The requirements for US 2781 included the ability to demonstrate the following:

- Knowledge of file management

- Identify common threats to computer data stored on a PC

- Knowledge of data protection measures

- Knowledge of ethical issues related to computer data stored on computer systems

Participants' use of mobile phones and the internet to enhance their learning experience were also investigated. The guiding questions were: "how do you use your mobile phone to support your learning? How do you use the internet and what internet resources do you use to support your learning?" Mobile phones offer an opportunity to support learning outside of the classroom by providing content and feedback to students whenever and wherever they need them. For example, mobile phones could be used to improve students' English vocabulary (Ibrahim \& Cavus, 2009; Baso \& Akdemir, 2010).

The internet offered a variety of applications that ITPs were using to provide information to students, deliver courses, and manage their operations (Jeffrey, Atkins, Laurs, \& Mann, 2006). From the ITPs viewpoint, all information pertaining to courses and the organisation had been placed on the institute's website and students were informed to access them online. In addition, tutors placed their teaching resources on the institute's computer network and expected students to access them as required. At the beginning of every trimester, newly enrolled students were shown how to access the institute's computer network and where to find the relevant resources. Students who were ICT literate easily understood how and where to access the resources to support their learning. In addition, 
students were expected to be able to use the internet to locate resources on the World Wide Web (WWW).

Through talanoa participants were invited to share their experiences on the use of a personal computer. At first nearly all participants revealed that they could use a computer. However, through further talanoa and participant observation, it was found that participants' self-evaluation of their computer knowledge and skills were higher than their observed or actual skills. This finding was similar to a study that found US college student perceptions of their computer skills were higher than their actual abilities (Grant, Malloy, \& Murphy, 2009).

\section{Unit Standard 2780 (US 2780).}

The first requirement for US 2780 explored the participants' knowledge of the personal computer hardware components. All participants were able to identify the visible and commonly used peripherals. The peripherals included the computer screen or monitor, keyboard, mouse, printer, scanner, speakers, and digital camera (Gookin, 2010). Four participants correctly identified the system unit. The system unit is the rectangular shaped metal case that houses the internal components used to process and store that computer data (Savage \& Vogel, 2009). Interestingly, the system unit was referred to by four different names. Thirteen participants called it the "computer", two participants used the "case", the "computer box" by one participant, and a participant identified it as the "CPU". The remaining participants were unsure what name to use.

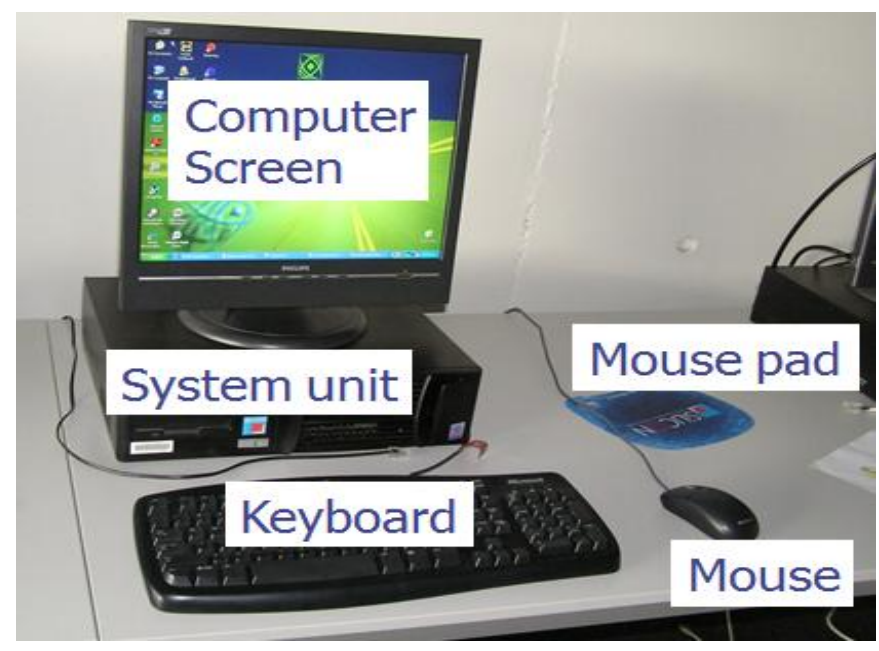

Figure 11: Common personal computer hardware peripherals

Further exploration of the participants' knowledge of the hardware components inside the computer's system unit revealed that sixteen participants were 
uncertain about these enclosed components. Inside the system unit, components of interest for the current study included the central processing unit (CPU), motherboard, random access memory (RAM), read only memory (ROM), and the hard drive (Gookin, 2010). The CPU is the most important component of the computer and is also referred to as the brain of the computer (Cisco Networking Academy, 2011). The motherboard is the main circuitry board that holds all the internal components together. RAM is used to temporarily store the computer programs and data when the computer is in use. RAM loses all the data and programs when the power supply to the computer is terminated. ROM on the other hand stores a limited amount of data or program permanently. The hard disk drive is a permanent storage device which stores all the programs that the computer uses (Muller, 2010).

Four participants confirmed that they had viewed the inside of a PC's system unit. An advantage of viewing the enclosed components was that it enhanced the participants' knowledge of the components and it improved their understanding of the components' interaction in relation to the flow of data between them. This approach promoted active learning as recommended in a number of studies (Paul \& Mukhopadhyay, 2005; Lee, 2008; Chavan, 2011). Active learning involves the students in the learning process as opposed to passive learning where students listen to someone explaining it without the students experiencing it firsthand. The process of active learning enables the students to build their knowledge based on their experience.

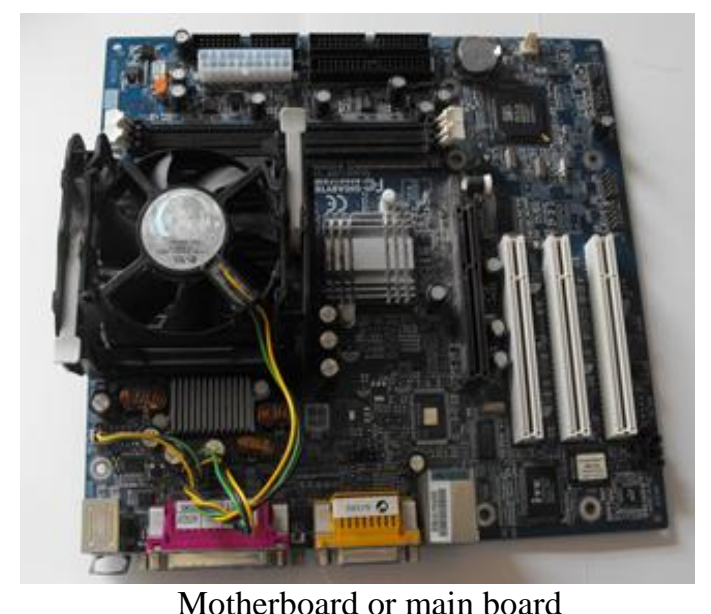

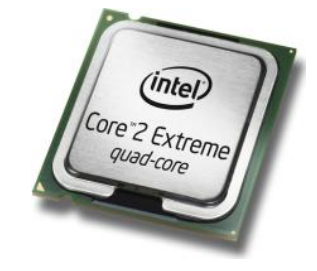

Microprocessor (CPU)

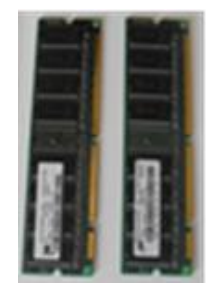

Computer memory (RAM)

Figure 12: Hardware components that can be found inside the system unit of a PC

Eric: I was in a computer course last year and that was when I first saw the components inside the system unit ....At first they all ... looked the 
same, like the motherboard, hard drive, CPU, RAM, ROM and others. But after two or three weeks of lab work removing the components out of the system unit and putting them back in... it helped me remember the different components and their functions.

The four participants who had viewed the inside of the system unit prior to this study were able to identify the components and describe their general functions in terms of input, output, storage, and processing roles. For example, the CDROM drive was noted as an input or output device, the RAM was for temporary storage, and the CPU was for processing (Muller, 2010).

All participants were familiar with the distinction between computer hardware and software but their knowledge and use of software in general were at different levels. While all the participants had used Windows XP or Vista and Windows 7, only six were aware of the purpose and operation of the system software. System software referred to a group of computer software designed specifically to operate and manage the computer hardware while providing a stable and secure platform for running other software applications (Stair \& Reynolds, 2010). Participants' familiarity with certain software was influenced by their regular use of the software and the relevance of the software's purpose to the users. For example, Microsoft Word and the Internet Explorer were the two most popular applications amongst all participants. Microsoft Word, a word processor was used for the preparation of application letters, CVs, and other typed documents while the Internet Explorer was used for browsing the Internet.

Other software applications that participants had used depended on their past experiences. Four participants in the 18-20 age group and who had left school within the past two years had learnt how to use Microsoft applications such as Word, Excel, Access and PowerPoint at school. Through their peers, participants in this group were able to use other software applications generally associated with entertainment. Software for copying audio CDs or movies on DVDs, ripping music, video files and video or computer games were popular amongst participants in this group. Ripping is the process of copying music from CDs or movies from DVDs to a PC (Muir, 2010).

Seven participants had used web-based applications for downloading or sharing music and video files. Participants referred to websites such as www.bearshare.com, www.kazaa.com, and www.limewire.com. Kazza is a peer- 
to-peer (P2P) software system optimised for sharing large files. It is used to access music and large video files on remote machines (Bidgoll, 2004). Bearshare and Limewire are similar to Kazaa where users swap music and video files online and both run on the Gnutella network (Pogue and Goldstein, 2005). Using these file-sharing applications also increases the risk of downloading malicious software into the user's PC.

Software applications used by participants who were above 24 years of age were associated with their places of past employment. For example, participants who had worked in an office environment were familiar with MS Word, MS Excel, and in one particular case to a sector specific application such as MYOB (Mind Your Own Business), an accounting software package (Neish, 2009). For those participants who were employed in non-office environments, such as a warehouse or outdoor based employment, their exposure to computer software was very limited. Six participants who were in this group had a computer at their homes and had observed others use a computer software but had not used one themselves.

The third requirement of the US 2780 included the ability to operate a computer printer. All participants revealed with ease the ability to send typed material prepared on the computer to the printer. This included printing MS Word documents, emails and web pages from the Internet. However, in the event that a hardware or software fault occurred, seven participants demonstrated a number of basic strategies to resolve the fault. The strategies included checking the printer for visible faults such as paper jam, empty paper tray, and empty toner cartridge. Two participants were able to check for computer network related faults accessed through the computer software's printer settings.

The fourth requirement of the US 2780 was concerned with basic computer maintenance procedures. This included the turning on and off of the power supply to the computer, connecting and disconnecting power cables to the system unit and other computer peripherals, connecting and disconnecting data cables from the back of system unit (Andrews, 2010). The computer keyboard, mouse, computer screen, and the printer are peripherals that need to be connected to the relevant ports in order for them to perform their designated roles. 
Five participants revealed with confidence the procedures required for basic computer maintenance. A participant remarked that connecting the data cables was easy given the colour coding (refer to diagram) that the computer manufacturers use for the data connecters and the unique shapes of the ports (Andrews, 2010). As an example, the participant referred to the mouse and keyboard connectors. The connector at the end of the mouse cable was coloured green matching the mouse port located at the back of the system unit. Similarly, the keyboard connector at the end of the keyboard cable was coloured purple matching the keyboard port located at the back of the system unit.

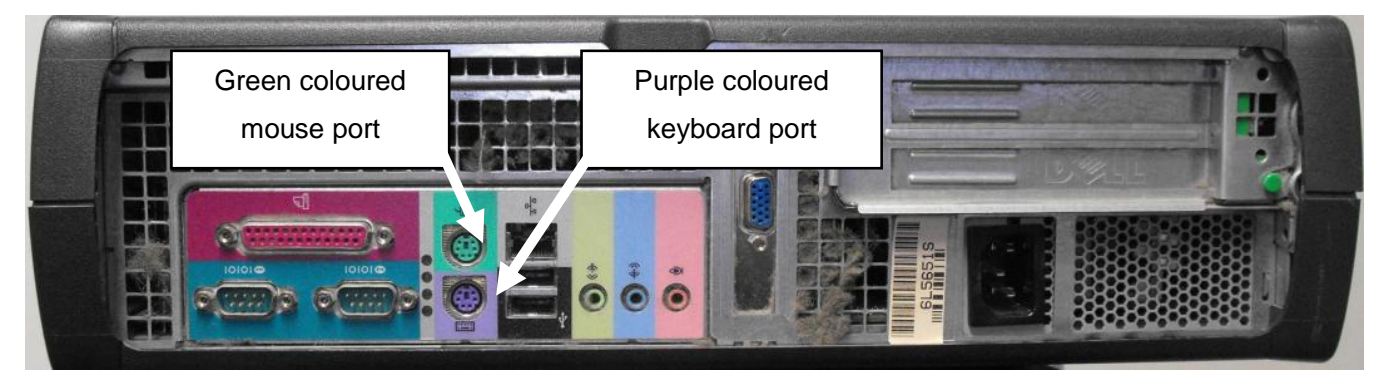

Figure 13: Rear view of a PC's system unit showing colour coded connectors

The fifth and final requirement of the US 2780 focused on ergonomics requirements. Ergonomics focused on the interaction between people, their work place and the environment (Dul \& Weerdmeester, 2008). In particular concern was the effects of the tools, equipment and other work related conditions that affect people and the environment. Ergonomics attempts to minimise the health risks due to repetitive strain injuries, fatigue and unhealthy working conditions (Chasen, 2009). As daily users of computers, participants were requested to explain some of their ergonomic practices to safeguard their health and wellbeing. Nearly half of the participants confirmed that they were unaware of what ergonomics was all about. Of those that were aware of ergonomics, six participants were able to share their ergonomic practices. These included sitting posture while using the computer, the height of the seat, feet placement on the floor, position and height of the computer screen from their eyes, and the position of the hands. Four participants out of the six discussed the need for break periods from working on the computer and a routine of exercises to minimise muscle fatigue. The exercise routine included arms, back and fingers stretching.

\section{Unit Standard 2781 (US 2781)}

The US 2781 in the NZQA Level 2 National Certificate in Computing focused on the management and the protection of data on a personal computer system. There were four elements that included: file management, common threats to 
stored data, data protection measures, and ethical issues relating to the management of stored computer data. File management involved locating folders or files stored on the computer system, creating folders, naming folders based on the contents, and copying, moving or deleting files or folders whenever required. All participants were capable of creating a folder and naming them appropriately. In addition, file manipulation techniques such as copying, moving and deleting were accomplished despite the varying times taken by each participant to accomplish a technique.

The second element of US 2781 focused on the identification and description of common threats to data stored on a personal computer system. All participants were aware of at least a threat to data stored on a personal computer system. These included unauthorised access by a computer hacker, computer virus, spyware or malware, and hardware break-down. A computer hacker refers to someone who maliciously breaks into a computer system for personal gain (Beaver, 2010). A computer virus is a computer program designed to infect other computer programs by modifying them to include an evolved copy of itself (Harley, Slade, \& Gattiker, 2001). Malware is a computer program that runs on your computer and makes your system do what the creator of the malware designed it to do. Malware is the abbreviation of malicious software (Skoudis \& Zeltser, 2004). In addition, threats to data caused by natural disasters such as earthquake, flooding, and fire were discussed by nine participants.

The third element of US 2781 dealt with measures to protect data stored on a personal computer system. This included practices such as saving their work frequently, making back-up copies, checking for computer viruses. In addition, preventing unauthorised physical access to data, unauthorised log-in access by others, using secure passwords, and installing up to date antivirus software were other practices required to ensure data security. Four participants stated at least two practices that included the use of secure passwords, and the use of up to date antivirus software. Most participants acknowledged the need to protect their stored data but did not have any practices in place.

The fourth and final element of US 2781 focused on ethical issues related to the management of data held in a computer system. This included copyright, piracy, individual privacy, and organisational confidentiality. Participants acknowledged these ethical issues but were reluctant to share any further details. 
Vive: Copyright laws protect people who make computer software but why does software have to be expensive? I'm a full-time student with a young family to support and so I can't afford to spend over $\$ 100$ to buy MS Office for my home computer. I asked a cousin if he can help and he installed MS Office on our computer. Whenever our computer plays up, I just call him and he comes whenever he can to fix it.

Vive's perception towards her need for the software to enable her to pursue her tertiary studies was found to be a common view held by tertiary students. Rawlinson and Lupton (2007) in a study of university students in America and China found that students perceived that the use of unlicensed software was acceptable behaviour. Participants of this study justify their actions for downloading movies, games, and music although they admit that their actions unacceptable.

Jack: I usually download movies from the internet through Limewire. ...l know it's illegal but it's free. After I watch it a few times... I delete it.

Kai: I enjoy playing computer games but it's expensive to buy. So whenever my friends get a new game I always ask for a copy. When there's a new game we take turns in buying it... the buyer keeps the original and the others get a copy.....

Lysonki and Durvasula (2008) reported that illegal downloading of music and videos is common amongst college students in America. While the participants in this study were aware of the nature of their actions, it did not stop them from accessing the music, videos or the games. Echoed in the participants' statements were the dilemmas that they faced in terms of their need for computer software, movies, and games and their financial situation as students. Their action had been dictated by their needs despite knowing that it was an illegal act.

\section{Mobile Phone Use}

In addition to the participants' computer skills, their use of mobile phones to enhance their learning experience was also investigated. All participants had access to a mobile phone and all were competent users of their respective phones. The high use of mobile phone was unsurprising as there was also a high percentage of the New Zealand population (85\%) that used mobile phones. The proportion of Pasifika peoples throughout New Zealand that used mobiles 
phones was recorded at $74 \%$, lower than Maori at $83 \%$ and Europeans at $87 \%$ (Statistics New Zealand, 2009). International studies on tertiary students' use of mobile phones revealed a similar pattern of high usage (Karim, Darus, \& Hussin, 2006; Junco, Merson, \& Salter, 2010).

All participants maintained that the primary purpose for their mobile phone was to facilitate communication (Cheung and Hew, 2009; Santos and Ali, 2011). Participants who had family responsibilities affirmed that the mobile phone enabled direct communication between them and other family members. In the case of parents who had children at school, the mobile phone was vital in keeping in touch with them. Five participants who were parents revealed that they had young children at home under the care of other family members. The mobile phone offered some peace of mind while they were attending classes. Iqbal (2010) identified two main categories for the reasons people give for their use of mobile phones which may clarify the participants' use of their mobile phones. The categories were intrinsic and instrumental. Intrinsic reasons included social, mobility, immediacy, privacy, and status while instrumental referred to the use of the phone as a utility.

The type of mobile phones that participants used ranged from the standard mobile phone to the ones with cameras, audio and video recording capabilities. The preferred payment method of mobile phone service for most participants in this study was pre-paid. Seventeen participants were on pre-paid accounts while eleven were on monthly account plans. The main reason for using prepaid was the flexibility that it offered. Three participants revealed that they were on monthly account plans and they changed to pre-paid accounts when they discovered that they could save between twenty to fifty dollars a month.

\section{Use of Mobile Phone to Support Learning}

Four participants shared their own experiences relating to the use of their mobile phone to support their learning. The first participant used her mobile phone to take a photo of a diagram that was drawn on the whiteboard (Clough, Jones, McAndrew, \& Scanlon, 2007; Cheung \& Hew, 2009). At first she tried to draw the diagram on her writing pad but realised that she could not include all the details that was added on the whiteboard.

Ini: At the start of a 3 hours long lab session, the tutor started drawing a diagram on the board to give us an overview of what we were going to do. 
I started copying the diagram as he explained and added more detail to the diagram. Towards the end, I realised I couldn't keep up. Lucky for me, I had my mobile phone on my desk. I looked at it and thought... why don't I take a photo of the diagram? So when the tutor turned to the board to write some more stuff, I quickly picked my phone and took 3 photos before he turned around.

During lab on the following week, we had to create a similar diagram and lucky for me I took the photos. I was able to finish the lab on time ....

The second participant confessed that she 'borrowed' the idea from a friend who had been recording the lecture on days that she was feeling tired. The participant tried it once and found the recording very useful in capturing things that she had missed (Clough, Jones, McAndrew, \& Scanlon, 2007; Cheung \& Hew, 2009). She emphasised that the quality of the recording depended on where she sat during the class. As a result, she made certain she arrived early to class so that she could sit at the front row seats, close to where the lecturer usually stood.

The third participant revealed that using his mobile phone to support his learning started as "kind of a joke" but he later realised that it was a useful learning resource. It started when he used his mobile phone to video record (Cheung \& Hew, 2009) his friend's demonstration of a class exercise relating to postural assessments. He alluded that due to his below average English skills he struggled to understand what was delivered in class. Unsure of how the exercise was supposed to be done correctly, he begged his friend to perform the demonstration and he video recorded it. After viewing the video a few times, he gained enough confidence to try it out on his own. More practice enabled him to master the exercise and he was better prepared for the following classes. Over time he extended his technique to video recording (Clough, Jones, McAndrew, \& Scanlon, 2007) other class members whom he had befriended. The participant could not muster enough courage to request his tutor if he could video record his demonstration to help him with his studies.

Jack: It would be awesome if I could video [record] our tutor when he does demos in class. That way I can look at it after class... you know... he talks too fast... I have no idea what he says half the time... 
The fourth participant jested that he used his mobile phone to confirm where and when his next class was going to be held from his class mates. This enabled him to be punctual and to overcome his natural tendency to arrive late.

John: Good thing I have a cell phone. Sometimes I forget when our next class is gonna be... I just text my mates and ask them... one time I went to fix up something during our lunch break. I thought it was going to take half hour... like that... Lucky for me I text my mate and ask him when our class gonna start. Straight away I came back to class rather than waiting in that office...

This final scenario demonstrated the use of the mobile phone to acquire information essential for the participant at a particular point in time. This approach has potential for supporting the students' learning whereby they could pose questions to their classmates or even an automated system that provides them with the relevant information (Santos \& Ali, 2011).

\section{Internet use}

Determination of participants' skills in using the internet was the last part in Phase 1, the measuring phase. All participants indicated that they had used the internet for a number of reasons. The most common use of the internet by the participants was for communication through emails and social networking accounts (Waller \& Waller, 2000). Electronic mails (email) were sent to other family members, friends, classmates, and course tutors. Through talanoa all participants confirmed that they had a personal email account prior to beginning their tertiary studies. All participants gave assurance of their ability to create a new email, retrieve and reply to an email. Another useful feature of emails and relevant to the participants' learning experience was the ability to attach files to an outbound email (Miller, 2007). Two participants required guidance in utilising this feature. Probing into the participants' ability to create new email accounts uncovered that not all participants were confident in creating a new email account on any of the popular free web-based email providers such as Gmail, Yahoo, or Hotmail. Eight participants required assistance in creating a new email account.

The second most common form of internet-based communication used by the participants was through social networking websites (Ryan, 2011). While social networking may be synonymous with the internet age, it was a concept that has existed as long as humans (Coyle \& Vaughn, 2008). Social networking websites 
offered members the ability to create a personal profile web page where they can post comments, photos, music, and videos (Safko, 2010). Membership is free but a new user has to register before an account is created. Members then invited other members as friends who could post messages on their pages, view photos and share music and videos. Personal pages had privacy settings that could be activated to keep the personal page private and to be viewed only by the user's friends or be made public whereby anyone could view the page (Bottle Tree Books, 2007).

Twenty two participants had a social network account. Out of this number, twenty had an account with Bebo while two had accounts with Bebo and Facebook. The Facebook website was launched in 2004 while the Bebo website followed in 2005. The participants' main reason for obtaining a social network account was connecting with friends (Dunne \& Lawlor, 2010). Participants acknowledged that they created a Bebo account because a friend or a family member had one. In other words, participants' engagement in the social network website was due to a ripple effect triggered by a friend or family member and they in turn may influence those around them. Participants confirmed that through the social networking website they were able to remain close with their friends and family members who had relocated elsewhere.

Ini : With Bebo I can share my photos with my family and friends back at home. My sister always "pokes" me and posts funny comments on my photos. When I'm bored I always get on Bebo to read my friend's comments on my photos and laugh and put replies to their comments. I can be on Bebo for hours... looking at my friends' pages and posting comments on their stuff.

Mei : Bebo is cool! I get to see what my cuzzies [cousins] in Oz [Australia] are up to! They always post wicked photos of where they've been ... sometimes I wish I was there... hanging out with them.

Based on what the participants have shared and evident in the above statements, participants used social networks to seek and receive social support (Selwyn, 2009). Using Bebo or Facebook enabled participants to maintain their social connections and to overcome a feeling of isolation. This was vital for their social well-being and may offer an opportunity for support in their learning experience. 
The second most common use of the internet by the participants was accessing information. The type of information sought ranged from news from the participants' home countries, sports, and current affairs. Participants concurred that the internet offered information at your fingertips.

Taba: Every day I read the online newspaper from home. It's good the newspapers put the stories on the internet so everyone can read it. I usually spend about half hour a day reading the stories so I'm up to date with what's happening there. My family always get a shock when I talk to them on the phone and I start asking them about what I read from the internet [online newspaper].

Eric : I follow the Rugby Super 14 competition and I can check the match results whenever I use the Internet. I'm in a group with my friends and a few work mates and we play in the Super 14 Virtual Rugby competition. Mondays is always fun because that's when we find out who's leading our group.

The Super 14 Virtual Rugby competition was an Internet website where Super 14 rugby followers could register and join existing groups or form new groups with other members to predict the weekly match results. Points are awarded for choosing the winning team and the score margin.

The third most common use of the internet by participants was for entertainment. Participants revealed that they were drawn to the internet because a friend had shown them or sent an email with links to some 'cool stuff'. Participants talked about a variety of their favourite Youtube videos ranging from music videos, movie clips, television programmes, rugby games highlights, comedies and their hobbies. For instance, participant recommended to the researcher to check out a Youtube video by a North American comedian by the name of Russell Peters. Two participants shared their favourite Youtube video by the Laughing Samoans.

The fourth most common use of the internet by participants was searching for information (Kirszner \& Mandell, 2009). All participants revealed that they had previously used a search engine. Participants had used one of the following search engines: Google, Yahoo and MSN. Sixteen participants gave up using the search engine after their second attempt at searching. Most participants did not know that the keywords used in a search affected the search results. They 
were unaware that by changing the keywords, the search may yield what they required. In addition, the initial search results may offer keywords that could narrow the search. An observed practice was to type in long string of words and in several cases, the exact questions were typed into the Google search box. Related to their studies, participants rarely used the internet to search for related or alternative sources apart from the ones suggested by their tutors.

Other uses of the internet revealed by nine participants included on-line purchases and using Skype as a "free" telephone service. Seven participants confirmed that they had purchased items on-line. Purchased items included clothes, mobile phones, digital cameras, and portable MP3 players from Trademe, New Zealand's leading on-line auction website. A participant purchased electronic airline tickets from an airline website, a sports event tickets, and holiday accommodation on-line.

Skype is an internet software application that enables users to talk in real-time for free (Gough, 2006). Unlike the telephone system where the users are charged based on the duration of their usage, Skype users only pay for the monthly internet connection charge and without the additional calling charges. Five participants revealed that they had used Skype to talk to friends and relatives overseas. While the use of Skype was widespread globally (Gough, 2006; Ganguly \& Bhatnagar, 2008), the number of participants who had used it for communication was still low. An explanation to this low update may have been due to the low awareness of this application to the participants.

\section{Phase 2 - Identify ICT Skills Needs}

The second phase in the Pasifika students ICT skills development framework investigated the learning needs of the participants. The learning needs were derived from the participants' perception of what they felt were required of them in order to meet the academic requirements in the programme of study. In other words, the area in which participants indicated that they needed academic assistance was identified as a learning need. Based on this identified need, the researcher would then investigate how ICT could be used to support the participants learning experience. Participants for this study were enrolled in Business Studies programmes, English Language course (ESOL), Exercise Science programme, Construction trades, Information Technology (IT), Hospitality, Counselling \& Alcohol and Drug Studies, and Engineering 
Technology. The following discussion was based on the information shared by the participants relating to their programmes of study.

\section{Business Studies}

During the data gathering period for this study, participants enrolled in the Business Studies diploma qualification were studying a compulsory course called Business Computing. Other courses included in the diploma qualification included Accounting Principles, Commercial Law, Economic Environment, Organisation and Management, Fundamental of Marketing, and Business Communication (Wellington Institute of Technology, 2009a). The diploma qualification was to be completed in two academic years of full-time study.

The aim of the Business Computing course was to promote the basic computer user to an intermediate or advanced computer user of generic office applications such as MS Word, Excel, PowerPoint and Access. These software applications fall in the main categories namely, the word processor, spreadsheet, presentation software, and the database management software (O'Leary \& O'Leary, 2008). Furthermore, this group of students were introduced to basic computer theory essential for evaluating necessary technologies to meet individual business needs.

Seven participants in this study were enrolled in the Business Computing course and four of them revealed that the course requirements caused them discomfort. The course requirements included the need to explain and evaluate components of an information system to meet business requirements (Wellington Institute of Technology, 2009a). The learning outcomes of the course were:

1. Explain and evaluate components of an information system that included procedures, computer hardware and software, people, and computer data.

2. Discuss and evaluate communication technologies that included communication channels, communication devices, computer networks, and Internet technology.

3. Discuss and recommend actions in relation to ethical and legal compliance requirements, security risks, tools and procedures for minimising the risks, and occupational health and safety concerns.

4. Improve skills on software functions available in commonly used office applications. 
Insights shared by four female participants enrolled in the Business Computing course revealed that more time was required for them to fully comprehend the computer theory. The female participants perceived that the computer hardware component of their course was male oriented because it involved removing hardware components if the components stopped working (Kizito, 2011). Their attitude changed when the researcher assured them that the most effective way to better understand how the computer worked along with the purpose of each component was to learn through experiential learning. This meant that they would see the components inside the system unit and also be involved in removing and replacing them from the system unit.

Six participants were enrolled in the Certificate in Business Studies. Four of the six participants revealed that learning a new software application that they have not used before was a daunting challenge and more time was required to comprehend the new material. Generally, participants in Business Studies programmes confirmed that courses in their programmes of study demanded a lot of reading and report writing which they found challenging and time consuming.

Participants in the Business Studies programmes revealed that the type of support available from the institution to improve their ICT skills included the free Computing Made Easy (CME) courses and one-on-one tutorial with a learning support staff member. The CME courses were NZQA Level 2 courses that were self-paced and self-directed. Courses included: Using Windows XP or Vista, Keyboarding, Word processing, Spreadsheets, Internet and email, PowerPoint, Publisher, MYOB, Access database, Manage your own digital photos, Send and receive instant messages, Safety online, and Advanced email techniques. Students intending to complete the CME courses were required to register before they were given the course materials. The materials included step by step instructions on how to use the software applications and there were no assessments. Students completed the courses at their own pace and a tutor was available to assist them if required.

\section{English for Speakers of Other Languages (ESOL)}

There were two programmes offered under the ESOL School. Two participants in this study were enrolled in the General ESOL (Level 1 and 2) programme while another two participants were enrolled in the English for Further Studies (EFS Level 3) programme. The aim of the EFS programme was to improve the 
students' English proficiency to a level suitable for further tertiary level studies (Wellington Institute of Technology, 2009b). Through talanoa the two participants enrolled in the EFS programme confirmed that their programme involved some word processing skills. The participants understood that higher ICT skills could enhance their learning experience however they felt it was not crucial for their current situation.

According to the participants enrolled in the ESOL programmes, their classroom experience involved a lot of tutor-led activities, individual student activities, a mixture of group work, role plays, and in-class discussions (Parcha, Stout, \& Jurkowitz, 2005). Their tutors wrote on the white board frequently and supplemented this with photocopied notes and exercises for individual and group work. Other equipment used in their classes included a tape player for listening exercises, a tape recorder for oral language sessions (Wood, 1968) and a video player and television set to present visual learning materials. Their tutors had suggested the use of the internet resources but they had never pursued that in class. As a result, participants did not know where to find the internet resources.

The ESOL participants reiterated that their course required a lot of reading and listening English text, writing and occasionally oral participation in class. Their current view was that ICT skills was not a major requirement in the programme of study therefore they could ignore it for now. Participants revealed that they had to use the computer for word processing and they found it manageable.

\section{Exercise Science, Construction Trades, and Hospitality}

Participants enrolled in the Exercise Science programmes, Construction trades, and Hospitality stated that while they were not taught any software applications in their courses, their tutors expected them to learn how to use relevant software applications in their own free time. Tutors in these programmes used computers in their course delivery and expected students to submit computer typed assignments. The programme outlines did not indicate the use of computers or the internet by the students but tutors used ICT whenever they felt appropriate.

\section{Counselling \& Alcohol and Drug Studies (CADS)}

The sole participant in the counselling diploma perceived that there was a benefit to improving her ICT skills especially in the use of the internet to access materials for her assignments. The participant indicated in Phase 1 that she was a competent user of the computer and she was keen to improve her skills further. 


\section{Information Technology (IT) and Engineering}

Participants in the Information Technology (IT) programmes and Engineering Technology revealed that their past experience contributed very little to the demands of their chosen programmes of study. A participant shared his frustration on how he assumed that as a mature student, having already acquired a university degree and nearly ten years of work experience would prepare him to cope better.

Eric : In my first programming class, it was like in a different country!! The tutor was using a language...I've never heard before. After the first week, I thought of quitting because I felt so dumb... but somehow I put myself through it and....I'm still here, aye!

The sole participant enrolled in the Engineering Technology programme explained that she was lost during her first few weeks because she found the course content incomprehensible (Schreuders, Mannon, \& Rutherford, 2009). The IT and Engineering programmes extensively used computers in every course and students were expected to learn a lot during a sixteen weeks long semester.

\section{Phase 3 - Analyse Gaps}

The third phase in the Pasifika students ICT skills development framework was the analysing of the participants' learning gaps that may require ICT-assisted learning. The gaps were identified through the matching of the participants' current ICT skills against the demands of their programmes of study. Programme documents relevant to the participants' programmes of study were scrutinised and ICT requirements were obtained from the participants through talanoa. The programme documents used in this phase were those available from the students and were given in class. The requirements were then matched against the participants' measured ICT skills levels obtained from Phase 1 of the ICT skills development framework. In addition, through talanoa participants were invited to share their own assessment of their ability to meet the demands of their chosen field of study using ICT. Similar to the previous phase the following discussions centred on the participants' programme of study.

\section{Business Studies}

The Business Computing course was a compulsory course for the Diploma in Business Studies. The course outline offered a well defined requirement that 
was used for analysing the participants' learning gaps. An entry requirement for this qualification was based on the applicant's age. Applicants under twenty years old were required to have acquired 50 credits at the National Certificate of Education Achievement (NCEA) Level 2 and a satisfactory standard of literacy in English or Te Reo Maori and numeracy in Mathematics or Pangarau or equivalent (Wellington Institute of Technology, 2009a). For applicants over twenty years old, entry was granted provided the institute was satisfied of the applicant's ability to undertake the course. All participants in this study had English as a second or third language, therefore all were required to have obtained a score of 6.0 in the International English Language Testing System (IELTS) or have scored 550 in the Test of English as a Foreign Language (TOEFL).

ICT skills requirements were not listed in the entry requirements for the Business Studies qualification but participants concur that it was essential to ensure their successful completion of their studies. According to the participants, the use of ICT in businesses was widespread (Stoner, 2009), therefore intermediate ICT skills were essential for tertiary graduates to secure employment in the current employment market. Webb (2006) demonstrated that ICT skills were regarded as commodities that could increase human capital.

An observed characteristic of the Business Studies participants was their age. Most of the participants were over twenty years of age therefore their entry requirements were assessed by the institute. One of the gaps identified by the participants was their inadequate command of the English language (Harb and El-Shaarawi, 2007; Watty, Jackson, \& Yu, 2010). Three participants enrolled in Business Studies programmes confirmed that they had completed the English Language for Further Studies programme as a prerequisite. The participants' command of the English language was identified as an area that needed attention as their successful completion of their courses hinged on their ability to read English text, write assignments, and communicate to their classmates and tutors.

Other skills not stated by the participants but have been widely promoted as essential skills for business studies students included language relevant to the business profession, problem solving, analysis and planning, decision making, critical thinking, creativity, team work, and communication (Yu \& Boulton-Lewis, 
2008). Most of these skills were not explicitly outlined but were embedded in their course work requirements.

\section{English for Speakers of Other Languages (ESOL)}

The second group of participants were enrolled in the ESOL programmes. Two participants were enrolled in English for Further Studies (EFS) programme while two participants were in the General English programme. The EFS programme focused on improving students' English skills in order to pursue further tertiary level studies. The contents of this programme included improving the students' English reading, listening, speaking, and writing skills. There was a component on word processing and document production. Participants enrolled in ESOL programmes were unaware of the capability of ICT in enhancing their learning experience and they would benefit tremendously if their ICT skills were improved.

The use of ICT to support ESOL students is widespread in most aspects of the ESOL learning activities such as listening, speaking and pronunciation (Yunus et al, 2010), and writing (Miyazoe \& Anderson, 2009; Klimona, 2010; Mompean, 2010; Sun, 2010). This must not be forced upon the participants as they were not comfortable with the use of the computer and the internet. The approach will be based on what the participants were interested in and to support their learning experience in their classroom.

\section{Exercise Science}

The third group comprised of three male participants who were enrolled in the Exercise Science programmes. Exercise science is an interdisciplinary field combining concepts from the fields of biology, physics, mathematics, chemistry, psychology, and medicine (Karmen, 2001). Exercise Science examined the effects of exercise and physical activity on people in order to optimize their physical and mental health (Brown, 2001). Participants in this group were mainly sport-oriented type of people. They enjoyed the physical activities associated with sports and exercise. Participants in this group insisted that improving their ICT skills was not a high priority because it was perceived as irrelevant to their field of study.

Two participants were enrolled in the Certificate in Exercise Science programme while the third participant was in the diploma level. The certificate programme comprised of nine topics that included: nutrition, anatomy, exercise physiology and communication, fitness testing principles and practices, weights and 
resistance training, group training and instruction, anthropometry, small business skills, and industry work placement (Wellington Institute of Technology, 2009c). During talanoa a participant revealed that in the exercise physiology class, they were taught the respiratory system and involved identifying parts of the respiratory system (Lew, 2009). Along with the identification process was the required explanations of how the lungs, alveoli, and bronchi worked.

The small business skills and marketing topics were topics that the researcher felt would require ICT skills. While this was only one out of the nine topics, business skills demanded computer skills and generally ICT skills. This was based on the current trend that business communications and processes have been computerised (Veen, 2009). In addition, marketing demanded some level of ICT skills for preparing a letter, a business flyer, an email and many other business related tasks supporting the operations of a small business.

\section{Construction Trades}

The fourth group of participants were enrolled in the Construction trades and had been working in their respective trades before embarking on further studies. This group comprised of two mature male adults who had families to support. A participant was enrolled in the Certificate in Carpentry (Level 3) and the other in the Certificate in Plumbing and Gasfitting (Level 3). The programme content for carpentry included construction health and safety, carpentry theory, woodworking machine use and safety, trade quantities and calculations, building site work experience in house construction, practical workshop projects, and on-site work experience (Wellington Institute of Technology, 2009d).

The "trade quantities and calculations" topic was initially viewed by the researcher as an area where ICT could be explored to support the participants. While students in the carpentry class used calculators to assist in calculations, the ability to use a computer and the relevant software applications would put students in good stead in large scale building projects (Le Gallais, 2001).

Findings in Phase 1 revealed that participants in this group had the lowest ICT skills. Both participants in this group were very reluctant to sit in front of the computer to use it. One of the participants joked that there was a computer at his home and he usually asked his children to do things for him. Both participants held the view that the computer was not their thing and if required they would ask someone to do it for them. 
Initially, both participants concurred that ICT skills were not essential for their trades. When asked if they had considered self-employment as a possible prospect, both participants positively endorsed the opportunity of becoming selfemployed. Operating a small business demanded more than the trade skills to ensure the overall running of the business. In the construction industry, larger contractors use smaller subcontractors to reduce construction cost forces. Consequently, the subcontractors bid for work on construction projects and this bidding process would give subcontractors with ICT skills an advantage over subcontractors who lacked ICT skills (Albers et al, 1997). The two participants would be in a more competitive position if their ICT skills were enhanced.

\section{Information Technology (IT)}

Two participants were enrolled in IT programmes. They revealed that ICT skills demanded in their programme of study were much higher than they anticipated. This revelation was common among students who based their expectation on their past experiences of computing and were shocked to find that IT programmes did not match their expectations (Adya \& Kaiser, 2005).

Participants in this group had the highest IT skills levels as measured in Phase 1 of the ICT skills development framework. However, participants acknowledged that they lacked skills in programming languages, computer networking and IT mathematics. Mathematics in computer science and engineering is inevitable due to its role in these two fields (Sancho, 1986). The entry requirements for IT programmes was 42 credits at Level 3 NCEA or higher and both participants met these requirements.

\section{Hospitality}

The two participants were enrolled in the Hospitality programmes comprised of a mature female in her early thirties and a twenty year old male. They both expressed similar views as those shared by the participants enrolled in the Construction trades programmes. Both participants in the Hospitality programmes agreed that while ICT had a positive impact on the industry as a whole, their immediate course content did not require ICT skills. The female participant was enrolled in the Certificate in Patisserie (Level 4) qualification while the other was enrolled in the Certificate in Food Preparation and Culinary Arts (Level 4). 
The patisserie programme documents stated a topic named "Costing, budgets and control" (Wellington Institute of Technology, 2009e). The participant in this programme clarified that students had used calculators to perform the costing and budgeting exercises. The participant reiterated that the calculations were very straight forward and she was capable of undertaking future costing requirements with the help of a calculator.

During talanoa the female participant revealed that she had "accidently" started working as a cook and she found it exciting. Although she dreamt of being a primary school teacher when she was at high school and during one of the school holidays she found employment at a restaurant as a kitchen hand. The money she received at the time gave her some freedom and as she shared "the rest was history". Six years later she moved to Australia and that was when she came to the realisation that a tertiary qualification was her ticket to advance her career. She returned to New Zealand to pursue tertiary training.

According to the participants, their learning experience involved the tutor explaining a bit of theory relating to the topic for the day or the week before proceeding to perform the demonstration (Hegarty, 2004). Students on the other hand, attempt to imitate their tutor's demonstration. According to Woolcock (2011), the teaching focus of the tutors tended to be limited to the skills to be assessed. This was perceived as a side effect of the competency based training paradigm offered through vocational training establishments (Hager, 2004).

\section{Counselling \& Alcohol and Drug Studies}

The sole female participant enrolled in the Counselling \& Alcohol and Drug Studies revealed that her courses demanded a lot of research, reading and writing. During the time of this study, she was in the first year of the Diploma in Counselling. Some of the courses that she identified that she felt that she may need help with included counselling theories, impact of social policy on current issues in NZ society, introduction to individual and social psychology, and psychological theory and practice (Wellington Institute of Technology, 2009f). The research component demanded searching for relevant reading resources in counselling theories and other topics for assignments from the library and online sources. The participant acknowledged that while she considered herself a competent computer and internet user, she was aware that there were lots more things that she needed to learn to maximise the use of ICT to support her studies. 


\section{Engineering Technology}

The sole female participant enrolled in the Engineering Technology programme made a similar revelation to the one offered by the two participants in the IT programmes. The participant stated that ICT skills were generally in high demand and the ability to quickly learn how to use the new engineering software that she used in class would be advantageous. In addition to the sentiments outlined above, the participant confided that there were only two other female students in her class of nearly thirty students in total. The low number of females in the engineering field was unsurprising given the societal and historical context of the engineering profession (Larkin \& Quinn, 2011).

\section{Phase 4 - Developing Strategies to Enhance Participants' ICT skills}

The fourth phase of the ICT skills development framework involved the development of strategies to enhance the participants' learning experience through ICT. The developed strategies were guided by the data gathered from the participants through talanoa and informed by the situated learning theory (Lave \& Wenger, 1991) and the cognitive theory of multimedia learning (Mayer, 2009). The strategies were divided into two main categories. The first category focused on group requirements influenced by the participants' programme of study. There were eight groups that included: Business Studies, ESOL, Exercise Science, Construction trades, IT, Hospitality, Counselling \& Alcohol and Drug Studies, and the Engineering Technology. The second category focused on individual requirements from members within a group and for the programmes with only one or two participants.

The first strategy developed to enhance participants' ICT skills was the ICT talanoa. This strategy sought to unravel the learning challenges that the participants face in their chosen programmes of study and attempted to identify ways that ICT can support the participants in their learning. The strategy enabled the researcher to explore the participants' current ICT skills level and to identify any online resources that could complement the participants supplied resources. These resources included course outlines, recommended text book and other resources supplied by the tutors. The resources offered guidelines to ensure that the developed strategies were suitable and relevant for the participants' programme requirements. Words or phrases used by participants during talanoa were noted and used to ensure consistency and where possible correlated to terminologies used in the prescribed text book and the course outline. This strategy endeavoured to scaffold the participants' knowledge to the required level 
as outlined in the course documentations. The ICT talanoa strategy was ongoing to ensure that participants were involved throughout the remaining phases of the ICT skills development framework.

\section{Business Studies}

In this group of Business Studies participants, seven participants were enrolled in the diploma qualification while six were in the certificate qualification. Three strategies were designed to enhance the ICT skills of participants enrolled in the Diploma in Business Studies. The first strategy was the ICT talanoa. This strategy offered the opportunity for the participants to articulate their current understanding of their course content and other relevant experiences. This strategy aimed at enabling participants to construct their own understanding of concepts (Porter, Lee, Simon, \& Zingaro, 2011). Four participants enrolled in the Business Studies diploma had indicated the need for further academic assistance in one of the compulsory course called Business Computing. Participants concurred that the text-book based learning approach employed in their course was challenging (Pritchard \& Nasr, 2004; Huang, 2006).

The prescribed text book for the Business Computing course was "Computing Essentials" written by Timothy O'Leary and Linda O'Leary. Students enrolled in the course were required to read sections from the text book as outlined by their tutor before a class. This requirement placed a huge demand on the participants' readings skills (Zhang, 2008) which the students have acknowledged to be a challenge. Comprehension is the ultimate goal of reading and sadly comprehension failure could lead to course failure (Lipka \& Siegel, 2011). According to a participant, the tutor's expectation was that reading the text book gave students some prior understanding of the topic before the tutor elaborated on it. Furthermore, any questions raised by students from their recommended readings prior to the class were answered during the class. This was the pedagogy employed by the tutor.

In the second ICT talanoa session, a participant revealed that a learning outcome for the Business Computing course involved explaining and the evaluation of the components of an information system. An information system has five components that included: people, procedures, software, hardware, and data (O'Leary \& O'Leary, 2008). To assist the participants with the computer hardware component, the researcher proposed to show the participants the inside of the system unit. Consequently, the third and fourth ICT talanoa session 
with this group of participants was spent in the computer hardware lab. The computer hardware lab was a dedicated lab where IT students intending to pursue a career as computer hardware technicians were taught. The researcher had access to the lab and this was where he conducted some of his classes for IT students.

In the computer hardware lab, participants viewed firsthand the components inside the system unit. This aspect of the strategy was informed by the situated learning theory (Lave \& Wenger, 1991). According to the situated learning theory, learning must be embedded within activity, context and the culture in which it encompassed. In addition, the social interaction between the participants and the researcher during the informal learning session would enhance the participants' learning experience. This was in contrast to the participants' past learning experience in formal settings in which the tutor spoke because he/she had the knowledge while the students listened and tried to absorb everything that the tutor uttered (Leveson, 2004).

The second strategy was the use of visual aids to assist the participants in their recollection of computer hardware components' names. The participants' rapid familiarity with the names of the different components would enhance their ability to identify and articulate the functions of these components. The visual aids included digital photos of the hardware components taken during the lab visit and the use of short videos (Sugahara \& Borland, 2006). These visual aids were aimed to entice the participants into an improved comprehension of the newly acquired knowledge.

The third strategy was aimed at further reinforcing the computer hardware components and their different functions. The strategy required participants to design and develop a multimedia learning resource that could assist the participants further improve their understanding of the subject matter. Furthermore, the resource would enable others to better understand the subject content that the participants had initially found challenging. An aspect of this resource that would be beneficial to others was the delivery of the subject matter in a Pacific language. In this case, the resource would benefit future students who shared the same language as the participants.

For the Business Studies participants in the certificate qualification, two strategies were developed based on the information gathered during the first three phases 
of the ICT skills development framework. The first strategy was the ICT talanoa as explained earlier. Participants in this group identified the need for support in the use of a sector-specific computer application. Participants revealed that in their programme of study, they were introduced to an accounting software called Mind Your Own Business (MYOB). MYOB is used by many small businesses in New Zealand. The participants perceived that their lack of prior exposure to MYOB hindered their ability to keep up with the classroom learning.

The second strategy for this group involved the use of a number of internet resources to enhance the resources acquired from classes. This included five tutorial videos from Youtube based on the MYOB software which were shown to the participants. Using the videos as a tool to support the teaching resources was influenced by the advantages that the videos had to offer (Brecht and Ogliby, 2008). The video titles were: MYOB Setup - Accounts List; MYOB Setup - Tax Codes; MYOB Setup - Sales Layout; MYOB Sales Screen; and MYOB - Intro to Bank Register. A screen-shot of one of the videos is shown below.

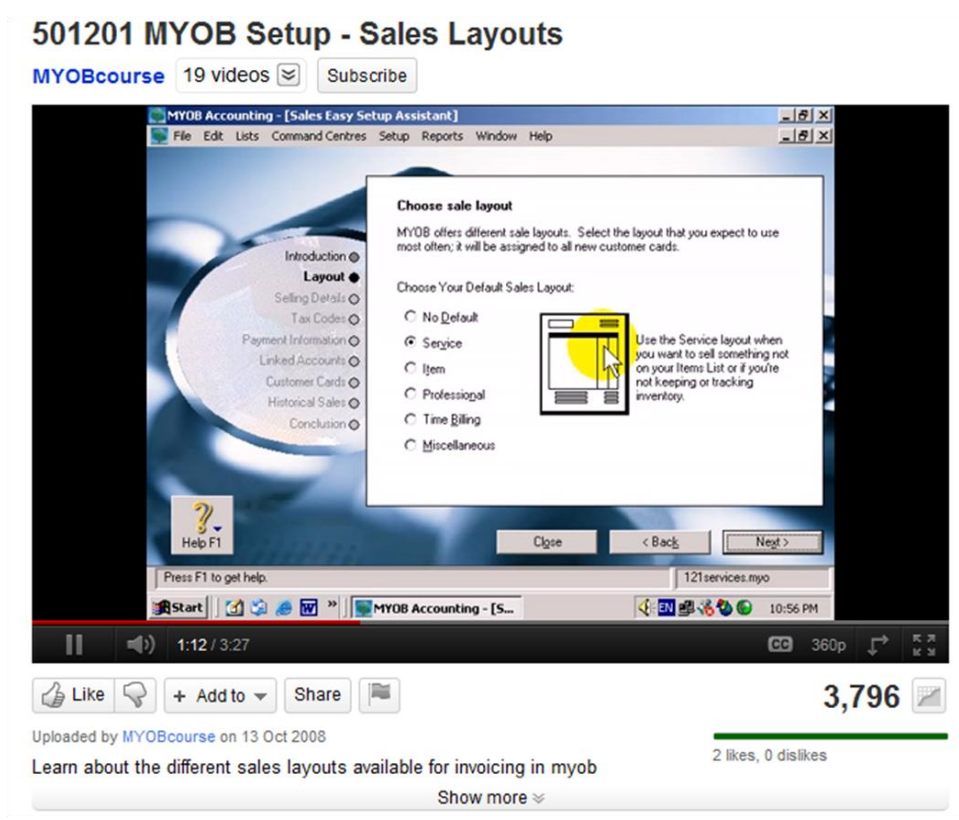

Figure 14: Screenshot of MYOB video tutorial on Youtube website

\section{English for Speakers of Other Languages (ESOL)}

The second group comprised participants enrolled in the ESOL programme. During Phase 3 of the ICT skills development framework it was established that participants from this group rarely used ICT for learning in class. According to the programme outline, there was a topic out of the six topics that involved word processing and document production. Participants' learning experience could be greatly enhanced if their ICT skills were improved. The ICT skills of participants in this group were at a basic level. As such, the strategies were aimed at 
complementing aspects of their programme contents. The first strategy was the ICT talanoa where the researcher engaged the participants in sharing their learning experience paying close attention to their successful moments and apprehensions in class.

The second strategy developed for the ESOL participants was the use of internet resources to supplement the learning materials given in class. Participants conveyed their desire to improve their English reading, listening, speaking, and writing skills. This strategy was guided by the study undertaken by El-Omari (2011) where tapes and tape recorders were used. A resource available from the internet was identified and shown to the participants. It was from the English as a Second Language (ESL) website (http://es/news.org.nz/) which provided an audio file (MP3 format) along with the text for users to listen to the audio file as they followed with the text. A wide selection of topics was available from this website.

A sample used for this strategy was titled "Swine Flu Again" available at http://eslnews.org.nz/?p=1093. The first step required the participant to play the audio file while reading the printed text (print-out) silently. Improving the participants' listening and reading skills were the expected outcome of the first step. This step was to be repeated until the participant was familiar with the text. The second step involved the participant reading the text aloud while the audio file was played. Improving the participants' pronunciation skills was the intended outcome of the second step. This step was repeated until a minimum of five mistakes were made during a cycle although some flexibility may be exercised to ensure that the participant does not feel pressured into completing the reading. Repetition was essential as it served as a mediation tool (Ganem-Gutierrez, 2009). The third step required the participant to read the text aloud but without playing the recorded text. This step was also repeated until the participant could read the text comfortably. To establish the participants' progress, participants' were requested to record how many times they repeated each step for each recorded audio file. 


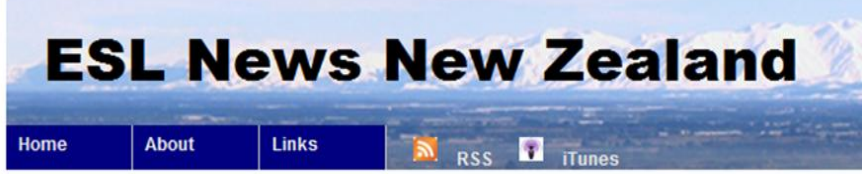

\begin{abstract}
Swine Flu again
June 15, 2009, fled under Environment, Traqedies.
Tags: doctor, health, worker

$4>$

Swine Flu Again [2:38m]: Hide Player | Play in Popup | Downiosd

The H1N1 flu - which is also called Swine flu - is now causing some worry in New Zealand as well as the rest of the world. The World Health Organisation is now calling this a pandemic which means that it is now global and spreads within each country as well as between countries. In New Zealand, at first the only people to get this flu were those who had travelled to Mexico or the US. See April 27th 2009. Australia reported many cases in the last two weeks and some people returning from Australia brought the flu with them. Now it is spreading to people who have had no contact with travellers. It is also spreading very fast. The numbers have jumped very quickly from a few to more than 100 .

The New Zealand Medical Officer of Health says that the best way to stop this flu from spreading is to stay at home. Workers should stay home from work. Westlake Girls' High School have told all year 12 girls and eight teachers to stay home this week because some Year 12 students have the flu. Other schools have cancelled one class and a day care centre had to close after children became sick.

People who have the flu should not visit the doctor because they could spread the flu to others in the waiting room. They should phone their doctor or phone the Healthline 0800 611116.
\end{abstract}

Figure 15: Screenshot of the ESL article used for reading practice

Another internet resource that was introduced to the participants was ESOL videos available on Youtube. Videos are a powerful tool for ESOL students due to its motivational and entertaining influence (Chen, 2011). Youtube is a popular internet video website where users uploaded their videos onto the website for others to view (Walczyk, 2008; Cuddy, 2010).

An example of a six minutes long video found on the Youtube website was titled "An ESOL classroom resource: fruit and vegetables". (http://www.youtube.com/watch?v=TMQ33RJ4DHE). Demonstrations on how to search for other relevant learning videos on Youtube was given to the participants. 


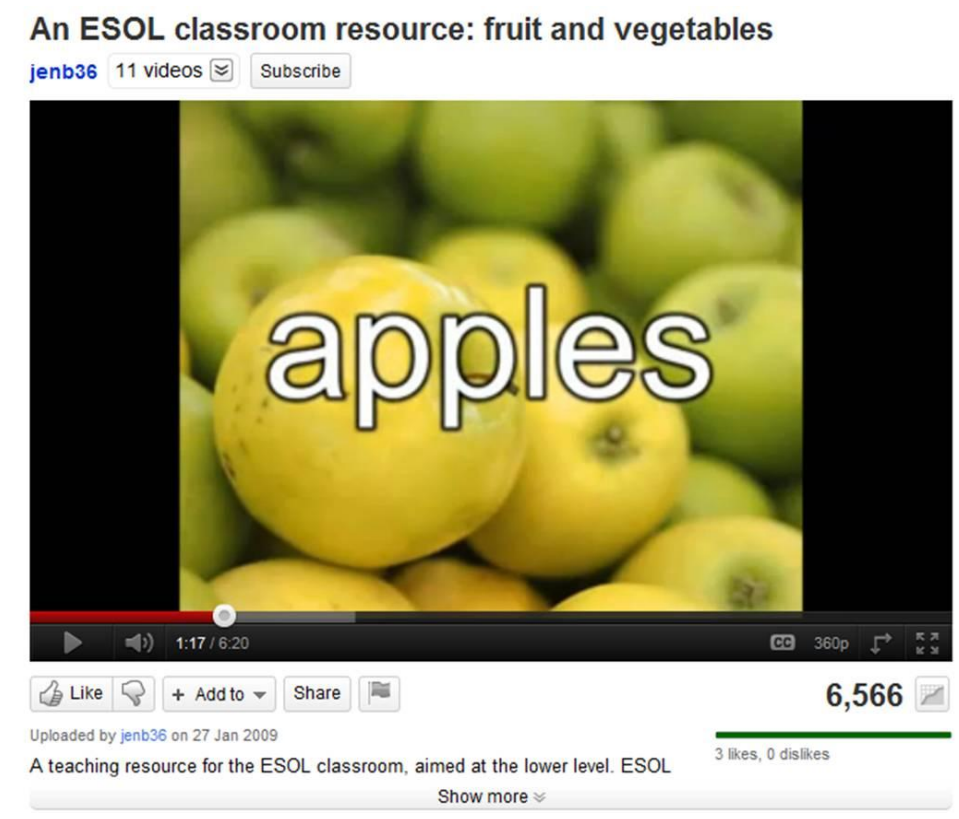

Figure 16: Screenshot of ESOL video on Youtube website

The third strategy developed for the ESOL participants was the use of a software application called Microsoft Movie Maker to create a multimedia learning resource. The content of the learning resource was created by the participants and it assisted the participants to prepare for a class presentation. To familiarise themselves with the Windows Movie Maker software, participants recorded their voice as they read the text supplied in the second strategy (Buechler, 2009). The participant's recorded voice offered the participant an opportunity to hear their voice and to give them an immediate evaluation of their reading ability. Once they reached a level of self-confidence and awareness of how to use Windows Movie Maker they were encouraged to complete the second part (Gipp, 2009). This involved the participant recording a presentation to be delivered to their class.

\section{Exercise Science}

The third group involved participants enrolled in the Exercise Science programmes. The first three phases of the ICT skills development framework established that participants in this group were not involved in learning how to use ICT in their courses. However, the use of ICT was prevalent in the programme content delivery. Tutors expected their students to learn how to use computer applications and the internet in their own time. Students who lacked the basic computers skills were recommended to enrol in the Free Computing course offered by the institute. The tutors used computers and the internet to prepare the course materials and expected students to use ICT to complete assignments. These included locating and accessing of internet resources for 
assignments, the use of the word processor for typing assignments, and the use of email for communication with the tutors.

Two strategies were developed for the participants in the Exercise Science programmes. The first strategy was the ICT talanoa. As described earlier, this strategy was aimed to gather further information from the participants to ensure that the developed strategies were relevant and within the participants' programme expectations. Based on the talanoa findings, a number of internet resources were identified.

The second strategy was the use of digital resources to complement the resources distributed to the participants in class. A participant revealed that they had covered in class the respiratory system and the parts of the respiratory system. During the class, the participant had received a printout of the PowerPoint that the tutor has used to present the respiratory system. This printout was used as a guide to locate supplementary resources from the internet. The following diagram was presented to assist the participant in their revision of the classroom learning materials.

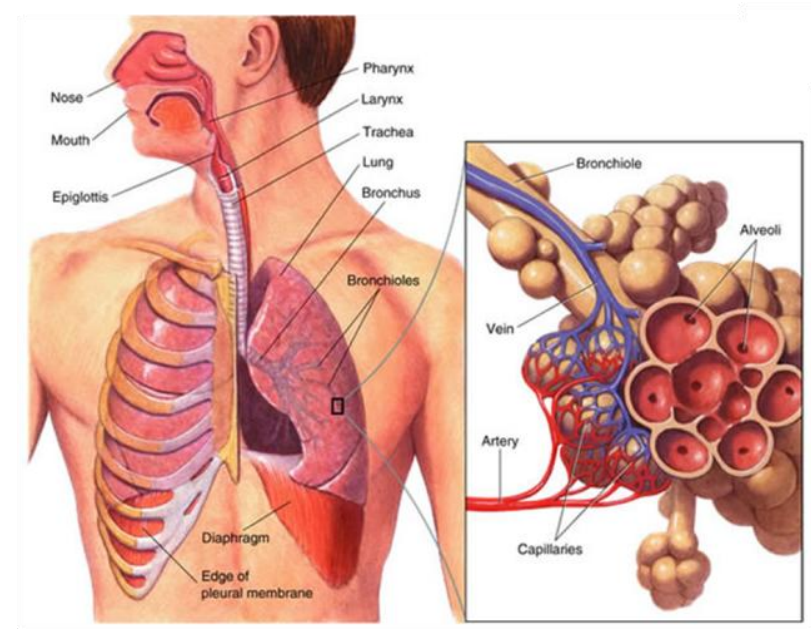

Figure 17: Respiratory system (EduMission, 2011)

Another four internet sources were presented to the participants. These were Youtube videos covering the respiratory system. 


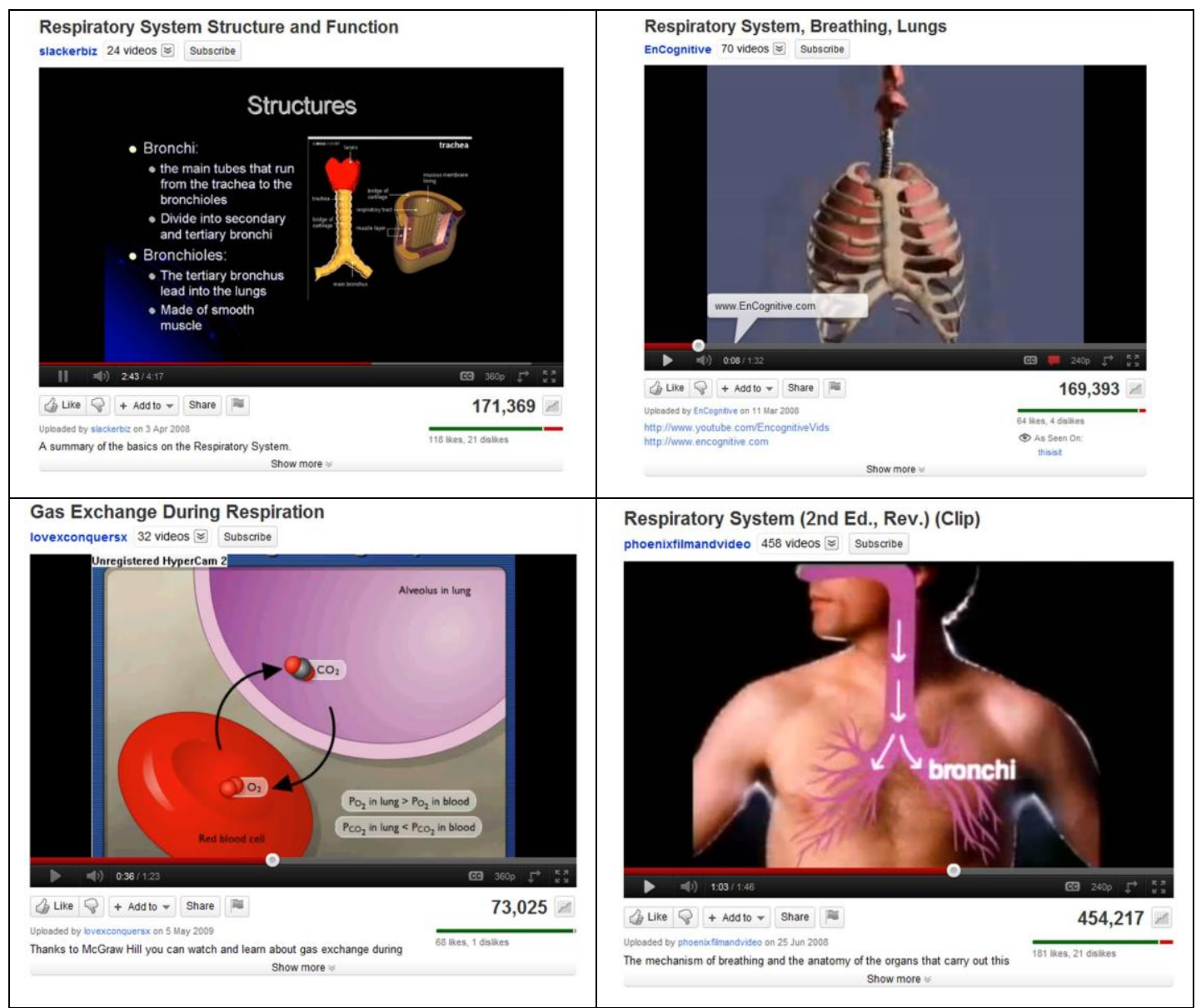

Figure 18: Screenshots of four videos available on Youtube that explained the respiratory system

\section{Construction Trades}

The fourth group of participants in this study composed of those enrolled in the Construction trades. The first three phase of the ICT skills development framework uncovered that participants in this group were mainly male students and had the lowest ICT skills amongst all participants. Participants enrolled in the Constructions trades conceived that ICT was not part of their industry therefore improving their ICT skills level were not essential for their future careers. Participants' programme content included a topic titled trade quantities and calculations. In this topic, participants confirmed that the use of a pocket calculator was sufficient for their purpose.

Two strategies were developed for participants enrolled in the Construction trades. The first strategy was the ICT talanoa. As stated earlier, this strategy enabled the participants to confide the challenges that they faced in their programme of study. Data gathered from the ICT talanoa enabled the researcher to develop strategies that were engaging and motivated the participants to improve their ICT skills. 
The second strategy developed for this group of participants included the exploration and demonstration of a number of relevant software applications. The first application was Microsoft's spreadsheet, MS Excel. The spreadsheet was introduced to the participants to assist them on the topic titled trade quantities and calculations. Using examples of the calculations from the class exercises, the same calculations were demonstrated using formulas in MS Excel. The emphasis was placed on the repetitive nature of manual calculations and how efficient the MS Excel performed the same calculations. Furthermore, the ability to store the file containing the calculations for future use and the relative ease of retrieving the file and making any further changes. A second software application was the word processor, MS Word. The aim of familiarising the participants with the word processor was based on the perceived need to prepare a quotation for a project and for any business correspondence. Participants were also shown how to use search engines and other construction trades related websites.

\section{Information Technology (IT)}

The fifth group in the study was composed of participants enrolled in IT programmes. There were two strategies developed for the two participants enrolled in the IT programmes. The first strategy was the ICT talanoa. As stated earlier, this group of participants had the highest level ICT skills amongst all participants. However, participants in this group revealed that ICT skills demanded in their studies were higher than they had anticipated.

The second strategy developed for this group involved the improvement of the participants' internet searching skills. To make this strategy engaging for the participant, the need to use a relevant topic was essential. In this case, the topic chosen by one of the participants was "extreme programming". The participant revealed that his first attempt to find more about this topic was the use of the search engine, Google (Sherman, 2005) and that did not yield much. He further commented that he had tried Google Scholar (http://scholar.google.co.nz/) and that also did not yield much. Google Scholar is a Google search engine that specialises in locating scholarly literature (Coombs \& DeLeon, 2007). 
A first step in the second strategy was the exploration of the participants' awareness of the different search engines available (Hock, 2010) and how each one organised the vast information available on the internet. An alternative search engine is AltaVista (http://www.altavista.com/) was planned to be trialled to determine if it yielded different results. The researcher had tested this out and found that AltaVista yielded better results for keywords "extreme programming". The second step was the use of a search refining technique based on two approaches: tactics and strategies (Xie \& Joo, 2010). Tactics include moves that an individual applied in the search process. A search tactic may include search formulation tactic and term tactic. These are applied in the formulation and reformulation of searches as well as to help select and revise terms to be used in a search.

\section{Hospitality}

The sixth group in the study was composed of participants enrolled in the Hospitality programmes. Data gathered in the first three phases of the ICT skills development framework suggested that ICT was not a core component for the Hospitality programmes. However, ICT played a supportive and complementary role in the Hospitality industry. A component of the programme was titled costing, budgets and control. Two strategies were developed for participants enrolled in the Hospitality programmes. The first one was the ICT talanoa.

The second strategy was similar to the one developed for the Construction trades group. The participants would be introduced to the spreadsheet and the examples used would be based on the classroom exercises. This was aimed at improving the reliability and efficiency of costing, budgeting and control of their work. The advice offered by Sneed and Kresse (1988) is very relevant to this group of participants. According to Sneed and Kresse (1988), spreadsheets are useful for creating financial models that simulates, forecasts, and explains the performance of a foodservice operation. Tasks such as daily reports, monthly summaries, food and labour costs analysis, budgeting, goal seeking, financial ratio development, and cash reconciliation can be easily and efficiently accomplished with a spreadsheet.

\section{Counselling \& Alcohol and Drug Studies}

Two strategies were developed for the participant enrolled in the Counselling \& Alcohol and Drug Studies programme. The first strategy was the ICT talanoa. The second strategy involved the development of advanced internet searching 
skills. Strategies developed for the participant enrolled in the Engineering Technology programme were similar to the one developed for the participants enrolled in IT programmes.

\section{Phase 5 - Implement Strategies}

The fifth phase of the ICT skills development framework involved the implementation of the developed strategies. Discussion for Phase 5 adhered closely to the layout of the previously discussed phase. The implementation phase was iterative in nature. The researcher developed strategies and implemented them. Due to the limited period of contact with the participants, the strategies were implemented within a week or two after the development phase. Implementation of the proposed strategies was deemed by the researcher as successful when the strategies had an immediate impact on the participants' studies. When participants did not indicate a favourable outcome, the strategies were revised and noted for later use. In the event that strategies did not benefit the current participants immediately, the researcher was satisfied that it may be beneficial in his future teaching responsibilities.

ICT talanoa was very popular amongst all participants. It offered a forum for participants to share their academic triumphs and challenges that they encountered while studying at tertiary level. Based on the challenges, strategies developed were geared to lessen the impact of the perceived challenges. Overall, participants were encouraged to uplift their ICT skills to broaden their long-term employability skills.

\section{Business Studies}

Participants enrolled in the Diploma in Business Studies were easily motivated with the developed strategies. Three strategies designed for this group of participants included ICT talanoa, use of digital visual aids to enhance students' learning, and the participants' involvement in the design and development of a multimedia learning resource. The first two out of the three strategies were enthusiastically supported. ICT talanoa was a motivational forum amongst the Business Studies participants as reflected in the following statement by one of the participants. 
Senia: I like talanoa. I can say whatever l'm thinking... right or wrong, I just say it...[laughter] and then we talk about what I mean and after that you understand my point... but in class it's a different story altogether... I want to say something but l'm too shy to say it... so I just keep quiet...

During this study, the researcher observed that participants needed a forum to articulate their thoughts without fear. Talanoa offered the participants a forum to 'be themselves' and to say whatever they truly felt at that point in time. The researcher noted that during talanoa the participants from this group came prepared with questions to ask, uncertainties to be clarified and even requests to read and offer feedback on assignments. This was all entertained to the researcher's best of ability based on the Pasifika value of reciprocity.

All participants completing the Business Computing course highly valued the experience of seeing firsthand the connections between the computer screen, keyboard, mouse to the system unit, and the inside of a personal computer. This was made possible during the two visits to the computer hardware labs where the researcher conducted some of his classes. According to a participant, the experience enabled her to better understand the theory and how all the hardware components work together.

Palepa: For me, seeing the inside of the computer helps me heaps. You know I learn better by touching and seeing and this really helps me picture the hard disk, the memory and even the CPU.

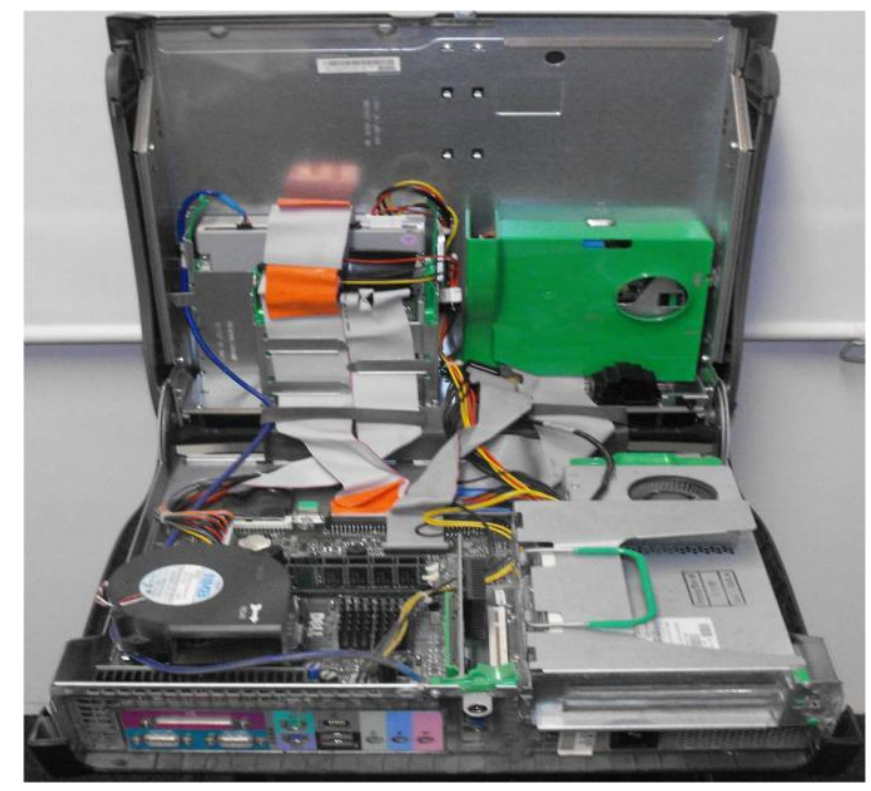

Figure 19: View of the inside of the computer system unit 
The third strategy was not completed due to time constraints. Participants had sixteen weeks to complete the Business Computing course and also to prepare for an examination on the final week. Consequently, participants' availability towards the end of the trimester was not feasible. A screenshot of what this strategy may have achieved is shown below. Windows Movie Maker was used to create the video. This strategy involved the design and development of a ten minutes long video that introduced the main hardware components of the personal computer to the viewers. As explained in the previous phase, the use of a Pacific language would have enabled others to learn about this topic in their own Pacific language.

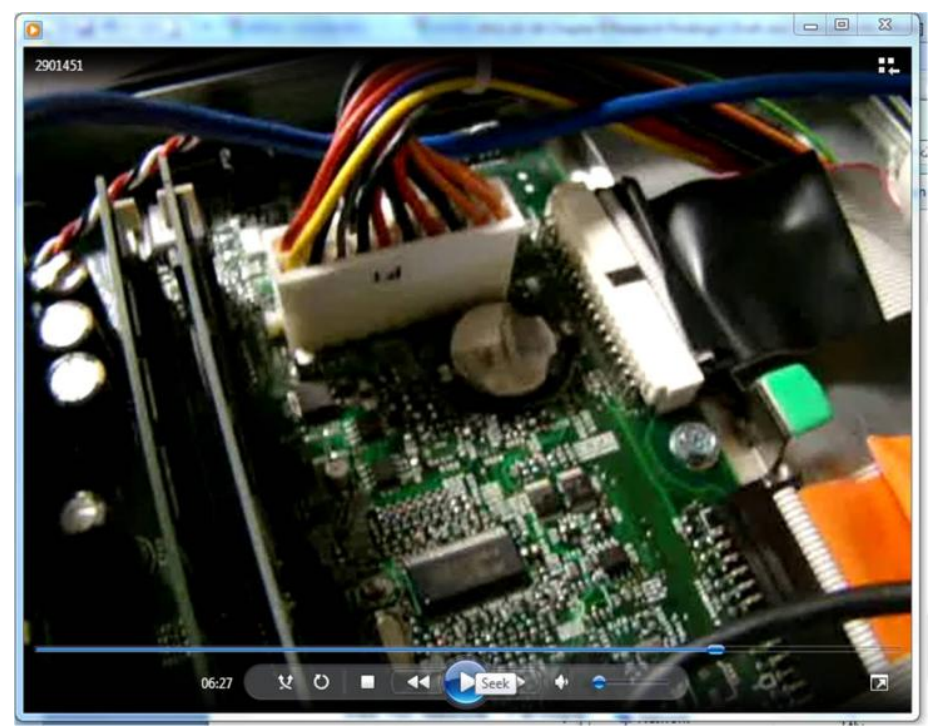

Figure 20: Screenshot of a sample video to be created by the participants

Participants enrolled in the Business Studies certificate were engaged and directly benefitted from the ICT talanoa and the internet resources provided to complement their learning materials. The five Youtube videos presented were well received and a participant confessed that he was unaware that Youtube had MYOB video tutorials.

Taabo: I thought Youtube had only music and movies... never thought it had MYOB tutorials... Good thing you showed us... now I know where to look if I get stuck... 


\section{English for Speakers of Other Languages (ESOL)}

Four participants were enrolled in ESOL programmes; two were in the General English for Speakers of Other Languages (GESOL, Levels 1 and 2) programme and two were in the English for Further Study (EFL, Level 3) programme. The Levels 1 and 2 programmes focused on developing skills in English writing, speaking, reading, listening, grammar and vocabulary. Students in this GESOL programme were given a worksheet with twenty words to be learnt for a week. Students were required to identify the part of the speech, meaning, collocation, and the family words. During the first two weeks of the course the tutor showed the students how to use a dictionary and students were expected to complete their worksheet before a short test at the end of the week.

During the second talanoa session, the researcher was shown the worksheet and he noted that one of the participants had used a pencil to write on the sheet. The participant revealed that using a pencil enabled him to make changes during the class discussions. The researcher suggested that the worksheet be typed up using the word processor (ie MS Word) so that the participants can have a blank sheet to write on during the class discussion. The suggestion was accepted and it offered the researcher an opportunity to encourage the participants to use the computer as much as possible to enhance their computer skills.

Both participants confirmed to have used the word processor (MS Word) before but were unsure about changing the page layout from the normal or portrait orientation to landscape. Inserting a table with five columns and twenty one rows in the document was also included in the demonstration. The document was saved to one of the participant's allocated storage space on the institute's network data storage drives. The document was also printed so that the participants can write any additional information. The document offered an extra resource for the students to revise their weekly vocabulary list.

Participants enrolled in the EFL programme were impressed with the internet resources introduced in their group's second strategy. Headsets that included a headphone and microphone were supplied to enable participants to hear the audio file and also to record their voices while they read the supplied text. Participants were extremely appreciative when they were allowed to take the headsets home to facilitate more practice. The resource (http://eslnews.org.nz/) offered articles on various categories that enabled participants to practice their English listening, reading and speaking skills. It was recommended that the 
accompanying text be printed out and for participants to spend at least an hour a day following the three steps.

A participant had queried if the audio file could be downloaded and played on other audio playing devices such as a portable MP3 player and car stereo system (Chambers, 2006). The researcher showed the participants how to download and save the files on a blank CD so that the audio files could be played on a CDplayer (Sprague and Pixley, 2008).

The third strategy was successful in enhancing the participants learning experience and it enabled the participants to create their own learning resources. A participant queried the researcher if the videos they created could be placed on Youtube. When assured that it was possible, the participant commented:

Now I can show my friends how to make movies for Youtube with Movie Maker. We've been taking videos from the camera and l've been wanting to add my favourite songs with my own pics [pictures]...this is so cool!

\section{Exercise Science}

Strategies developed for the three participants enrolled in the Exercise Science programme were well received. Internet resources on the respiratory system offered alternative learning materials and were perceived by the participants as exciting and motivating.

Kuru: The videos are unreal... I can watch them any time... you gonna have to look for some more, yea bro?

A participant was already convinced that ICT had a positive impact on students' learning.

Jack: I know computers and video analysis are widely used in professional sports... our tutors are not using them to help us learn... they use PowerPoint for our lectures and Word to type our handouts and stuff... but like YouTube videos are awesome resources... even better if they had high quality cameras for our gym work... 


\section{Construction trades}

Participants enrolled in the Construction trades were reluctant to use the computer and the internet as proposed for the second strategy. When introduced to the spreadsheet as identified in the previous phase, the participants confided that using computers made them feel uncomfortable. Despite their reservations in using a computer, they were eager to see what the researcher had to share with them.

John: I don't think I can use a computer... but I'm sure I can get someone to do things [on the computer] for me... show us what you've got...

Based on an estimating spreadsheet sourced from the internet, the researcher attempted to convince the participants that the spreadsheet will help improve their work. An example used to demonstrate this was the estimation for any given project. (http://en.wikipedia.org/wiki/File:Estimating Spreadsheet.png)

\begin{tabular}{|c|c|c|c|c|c|c|c|c|c|}
\hline Work Item & Vendor & Labor & Equipment & Materials & Subcontr. & Subtotal & Markup \% & Markup & Total \\
\hline Permits/Fees & City of Los Angeles & & & & $\$ 1,500.00$ & $\$ 1,500.00$ & & $\$ 0.00$ & \begin{tabular}{|l|l|} 
& $\$ 1,500.00$ \\
\end{tabular} \\
\hline Excavation & & $\$ 6,000.00$ & $\$ 8,000.00$ & $\$ 500.00$ & & $\$ 14,500.00$ & $15.00 \%$ & $\$ 2,175.00$ & $\$ 16,675.00$ \\
\hline Utilities & & $\$ 3,500.00$ & $\$ 2,500.00$ & $\$ 2,750.00$ & $\$ 1,000.00$ & $\$ 99,750.00$ & $15.00 \%$ & $\$ 1,462.50$ & $\$ 11,212.50$ \\
\hline Water Well & & & & & & $\$ 0.00$ & & $\$ 0.00$ & $\$ 0.00$ \\
\hline Septic Tank & & & & & & $\$ 0.00$ & & $\$ 0.00$ & $\$ 0.00$ \\
\hline Foundation & Connie's Concrete & & & & $\$ 3,500.00$ & $\$ 3,500.00$ & $5.00 \%$ & $\$ 175.00$ & $\$ 3,675.00$ \\
\hline Concrete Flatwork & Connie's Concrete & & & & $\$ 1,900.00$ & $\$ 1.900 .00$ & $5.00 \%$ & $\$ 95.00$ & $\$ 1,995.00$ \\
\hline Framing & & $\$ 3,500.00$ & $\$ 1,500.00$ & $\$ 9,000.00$ & & $\$ 14,000.00$ & $15.00 \%$ & $\$ 2,100.00$ & $\$ 16,100.00$ \\
\hline Roofing & Robert's Roofing & & & & $\$ 3,500.00$ & $\$ 3,500.00$ & $5.00 \%$ & $\$ 175.00$ & $\$ 3,675.00$ \\
\hline Windows/Ext Doors & Wally's Windows & & & & $\$ 8,000.00$ & $\$ 8,000.00$ & $5.00 \%$ & $\$ 400.00$ & $\$ 8,400.00$ \\
\hline Garage Door & Gary's Garage Doors & & & & $\$ 2,250.00$ & $\$ 2,250.00$ & $5.00 \%$ & $\$ 112.50$ & $\$ 2,362.50$ \\
\hline Siding & & & & & & $\$ 0.00$ & & 80.00 & $\$ 0.00$ \\
\hline Electrical & Emie's Electric & & & & $\$ 18,500.00$ & $\$ 18,500.00$ & $5.00 \%$ & $\$ 925.00$ & $\$ 19,425.00$ \\
\hline Plumbing & Mac's Mechanical & & & & $\$ 16,500.00$ & $\$ 16,500.00$ & $5.00 \%$ & $\$ 825.00$ & $\$ 17,325.00$ \\
\hline HVAC & Mac's Mechanical & & & & $\$ 23,000.00$ & $\$ 23,000.00$ & $5.00 \%$ & $\$ 1,150.00$ & $\$ 24,150.00$ \\
\hline Insulation & & $\$ 3,500.00$ & & $\$ 1,000.00$ & & $\$ 4,500.00$ & & $\$ 0.00$ & $\$ 4,500.00$ \\
\hline Masonry & Mason's Masonry & & & & $\$ 14,500.00$ & $\$ 14,500.00$ & $5.00 \%$ & 5725.00 & $\$ 15,225.00$ \\
\hline Drywall & Doug's Drywall & & & & $\$ 12,500.00$ & $\$ 12,500.00$ & $5.00 \%$ & $\$ 625.00$ & $\$ 13,125.00$ \\
\hline Interior Trim & Doug's Drywall & & & & $\$ 9,000.00$ & $\$ 9,000.00$ & $5.00 \%$ & $\$ 450.00$ & $\$ 9.450 .00$ \\
\hline Painting & Paul's Painting & & & & $\$ 13,500.00$ & $\$ 13,500.00$ & $5.00 \%$ & $\$ 675.00$ & $\$ 14,175.00$ \\
\hline Floor Coverings & Carl's Carpets & & & & $\$ 16,500.00$ & $\$ 16,500.00$ & $5.00 \%$ & $\$ 825.00$ & $\$ 17,325.00$ \\
\hline Cabinets & Ken's Kabinets & & & & $\$ 22,500.00$ & $\$ 22,500.00$ & $5.00 \%$ & $\$ 1,125.00$ & $\$ 23,625.00$ \\
\hline Appliances & Abby's Appliances & $\$ 2,500.00$ & & $\$ 11,500.00$ & & $\$ 14,000.00$ & $15.00 \%$ & $\$ 2,100.00$ & $\$ 16,100.00$ \\
\hline Landscaping & Sonny's Sodding & & & & $\$ 2,750.00$ & $\$ 2,750.00$ & $5.00 \%$ & $\$ 137.50$ & $\$ 2,887.50$ \\
\hline Overhead Costs & & $\$ 10,000.00$ & & & & $\$ 10,000.00$ & $20.00 \%$ & $\$ 2,000.00$ & $\$ 12,000.00$ \\
\hline \multirow[t]{6}{*}{ Other } & & & & & & $\$ 0.00$ & & $\$ 0.00$ & $\$ 0.00$ \\
\hline & & & & & & $\$ 0.00$ & & $\$ 0.00$ & $\$ 0.00$ \\
\hline & & & & & & $\$ 0.00$ & & $\$ 0.00$ & $\$ 0.00$ \\
\hline & & & & & & $\$ 0.00$ & & $\$ 0.00$ & $\$ 0.00$ \\
\hline & & & & & & $\$ 0.00$ & & $\$ 0.00$ & 50.00 \\
\hline & & & & & & $\$ 0.00$ & & 80.00 & $\$ 0.00$ \\
\hline TOTALS & & & & & & $\$ 236,650.00$ & $7.71 \%$ & $\$ 18,257.50$ & $\$ 254,907.50$ \\
\hline
\end{tabular}

Figure 21: Screenshot of a sample spreadsheet used with the Trade participants

The researcher outlined the benefits of using the spreadsheet which included the minimising of human error when performing the calculations, ease of making changes and the spreadsheet can be saved on the computer for later access and use.

The researcher set aside the initially planned second strategy and developed an alternative strategy to enable the participants to overcome their initial fear of computers. An alternative strategy began with a topic that the participants enjoyed. Participants indicated their pastime craze of the Super 14 rugby 
competition. This offered an opportunity to demonstrate to the participants how the internet worked and how they could access the competition scoreboard available at a website and also watch highlights of the weekly games on Youtube. This triggered some excitement in the participants. Later on, the participants showed a bit of enthusiasm to learn how to use the internet to keep up to date with the latest rugby news.

\section{Information Technology (IT)}

Participants enrolled in the IT programmes had specific requests for assistance in their studies. The requests mainly centred on searching for additional resources to clarify or supplement the learning materials supplied in class. This group spent the most time interacting with the researcher. The ICT talanoa was extremely successfully as this enabled the participants to articulate their initial understanding of the subject matter and over time their murky understanding was clarified and reinforced.

The first step in the second strategy developed for this group involved the exploration of the participants' awareness of the different search engines (Hock, 2010). The participants' revealed that they were aware of alternative search engines but felt that there would not be much difference in the results. The first attempt was with the use of AltaVista and that did not seem to yield anything different from Google and Google Scholar. The researcher then introduced another search engine called IncyWincy (http://www.incywincy.com/). IncyWincy is classified as an internet tool that searches deeper than the popular search engines such as Google, Bing, Yahoo, and AltaVista. There are numerous other search engines that are in the same category as IncyWincy and they are referred to as metasearch engines. Metasearch engines combine the power of multiple search engines and web directories (Evans \& Schneider, 2009).

Through the second strategy both participants were satisfied with the improvement in their internet searching skills. In addition to the use of alternative searching tools, such as IncyWincy, Infomanine (http://infomine.ucr.edu/), and Scirus (http://www.scirus.com/srsapp/ ), the participants were introduced to the two approaches named: tactics and strategies (Xie \& Joo, 2010). The participants were delighted that they had discovered alternative pathways to their internet searching skills. A participant stated that while they knew that the resources are out there finding them when required is always the challenge. 
Ini: It can be frustrating when you know it's there but you can't seem to find it...like the last time I was looking for coding [programming] examples for my assignment... I was about to give up... then somehow I typed in the right keywords... and it came up... it's all to do with the right [search] keywords... sometimes you can't find anything because you're using the wrong keyword...

The participant revealed that at times after a few hours of searching, the participant started using the same keywords that had been used previously and as before were unsuccessful. A tactic offered to the participant to minimise the hit and miss approach was the use of a search journal for recording the search keyword activities. A MS Word document was suggested, a table with four columns was created. The first column was for the date, the second column was for the time, the third column was for the search keyword or phrase, and the fourth column was for comments. This was to ensure that a record of the unsuccessful searches was available for later use. With the search journal, the participant had a list of keywords already used and therefore were not wasting time on unsuccessful keywords. This tactic proved to be more efficient and served as an effective tool in overcoming the participant's old haphazard practice.

\section{Hospitality}

The second strategy developed for the two study participants in the hospitality programmes involved the demonstration and training of the two widely used software applications (MS Word and Excel). The participants were observed to be unmotivated and the researcher only managed one session (20 minutes) on the proposed work on spreadsheet before deciding to pursue a request from one of the participants.

Tana: I've seen Word on the computer... I seriously won't be needing it... maybe ask someone when I have to...

Vive: Excel sounds very easy... but how will I know what formula to put in... I know it's supposed to make my work easier but for now l'll stick with my calculator.

A request was made by one of the participants in this group for assistance to design a menu for a restaurant required for a class exercise. The request offered the researcher an opportunity to explore a desktop publishing application with the 
participant. MS Publisher was used and the participant was delighted with the outcome. In addition, the internet resources that were demonstrated were greatly effective. Participants raised further requests such as creating an A3 size poster and a birthday card. These requests made the learning more meaningful for this participant.

\section{Counselling \& Alcohol and Drug Studies (CADS)}

The sole participant enrolled in the CADS programme was competent in using the computer and other software applications such as MS Word and Excel. She was also comfortable with using the internet to access and reply to her emails, check her social network account on Facebook, and she could use the search engine to do basic searches. During talanoa she revealed that she was interested in finding reading resources for her assignments.

Sina: I've used the computer for over ten years. When I started my own business I had no choice but to get to know how to use it... At first it was hard but after a while it was OK... My brother is into IT and so he gets all the silly questions from me... I think I'm good [with computers] but I know there's heaps to learn with computers.

The participant was interested in obtaining research articles relating to "Pacific mental health". She confirmed that she had 'googled it' and she hoped that there were other ways of locating more literature on the topic. The first step explored her understanding on the effect of different keywords used for a search. When discussing this aspect of internet searching, she posed the questions "How do you find alternative keywords?" To assist her, the researcher suggested that they began by using Google and used her topic of interest as a starting point. The phrase "Pacific mental health research" was typed into the Google search box. The researcher emphasised that the phrase must be enclosed with the speech marks (double quotes) as shown in the diagram below.

\section{Google "Pacific mental health research"}

Figure 22: Screenshot of the Google search box

The use of the speech marks (double quotes) around the phrase instructed Google that the user was performing a phrase search. In other words, the search involved the exact words in the exact order without change. This was the first 
time that the participant learnt about the use of speech marks when using more than one word for searches.

Sina: No wonder I get all the crap when I don't use those characters [speech mark] ... see always new things to learn with computers.

This search tactic yielded a number of relevant articles that excited the participant. In reply to her question on alternative keywords, they were derived out of the articles that were perceived as relevant to the user's topic of interest. An example that was found for this particular exercise was the term "pasifika" was used in place of "pacific".

The second step was the suggestion of using alternative search engines. The proposed search engines included AltaVista (http://nz.altavista.com/) and Bing (http://nz.bing.com/). The alternative search engines offered at least two other articles not found earlier. A third step included accessing NZ university library websites and search their research databases. For example, the University of Auckland and the Auckland University of Technology library websites were visited and the digital theses database was searched. The participant was advised to visit the other NZ university websites and to search their research databases.
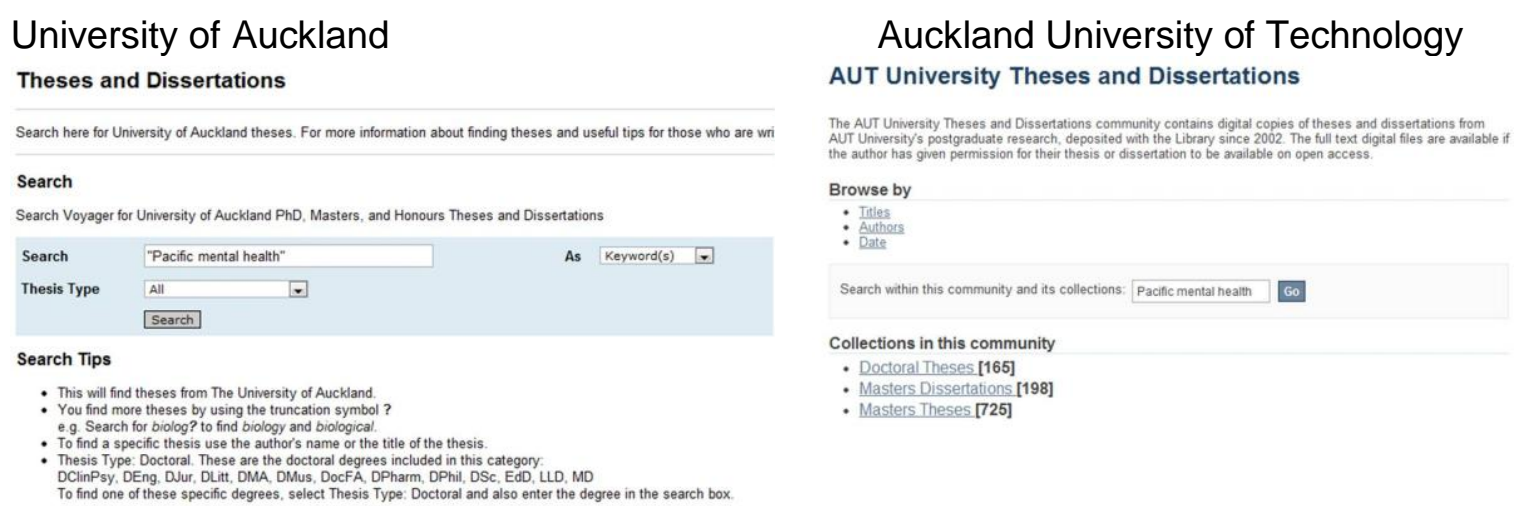

Figure 23: Screenshot of the university library search catalogues

The implementation of strategies for the participant enrolled in the Counselling \& Alcohol and Drug Studies programme went without incident. The participant found the second strategy very useful. Towards the end of the trimester, the participant revealed that she was able to locate resources for assignments and projects with minimal guidance from the researcher. 


\section{Engineering Technology}

The sole research participant in this group was enrolled in the New Zealand Diploma in Civil Engineering. Through the ICT talanoa session, the participant confirmed that she was a confident user of computers, capable of using software applications such as MS Word, Excel, Publisher, and Powerpoint. She added that she had a social network account on Bebo and accessed her account every time she logged onto a computer at the institute of technology. In addition, she checked for emails and read the online newspapers from her home country on a daily basis.

Jess: Everytime I get on the computer... the first I do is log on to Bebo... you know I have to check who's online and if there's any new stuff added by my friends... if nothing's on and if I feel like it then I check my emails...

Despite her admittance that her study programme was hard she did not state any specific areas. As mentioned earlier, engineering had been traditionally viewed as a difficult discipline to pursue (Divjak, Ostroski, \& Hains, 2010).

Jess: You know engineering is hard... sometimes I wonder why l'm doing it... I think my parents will kill me... [laughter] if I fail... especially when they have to pay so much for it... I'm not on a scholarship because they [referring to government scholarships] stopped it...

The participant enrolled in the Engineering Technology programme was only available for the first strategy. The participant became disinterested and did not respond to follow-up emails.

\section{Phase 6 - Monitoring and Evaluation of Strategies}

The sixth and final phase of the Pasifika tertiary students' ICT skills development framework focused on the monitoring and evaluation of the learning strategies. To ensure consistency, discussion on the final phase adhered closely with the format used in Phases 4 and 5. The monitoring and evaluation phase was intended to verify the suitability of the strategies. This was based on the participants' oral feedback and reaction towards the strategies. Favourable comments made by participants indicated success while little or no feedback indicated an unsuccessful strategy from the participant's viewpoint. 
Overall, the ICT talanoa was well received. Participants acknowledged the aim of the strategy and were motivated to articulate their initial comprehension of the subject matter. Initially, participants were apprehensive and were reluctant to participate. Over time they became aware of the immediate benefits of the strategy and were very enthusiastic about expressing their initial views on the topic of discussion. A number of challenges for the researcher were identified during the implementation phase. These included: limited time, unmotivated participants, and the participants' fear of technology.

An ongoing challenge with the strategies was the demands on time. There were two aspects of time management displayed by the study participants. The first was the time limitations for participants who had been involved in the study. Participants needed to be reminded that the allocated time had lapsed and the need for them to attend their scheduled classes was crucial. An apparent trend between the time spent by participants on the strategies and their motivation to learn was observed during the implementation phase. Participants who spent a lot of time with the researcher, spent more time using the strategies and were keen to try new things. Feedback from these participants revealed that they were able to complete course assignments on time and were satisfied with the marks they obtained for their efforts. As a result, participants looked forward to the ICT talanoa sessions.

The second aspect of time management displayed by participants was through their irregular attendance of the talanoa sessions. This study did not pursue the reasons for this pattern of behaviour and it would be something to look into in future studies. Based on a few reasons supplied voluntarily by the participants, the noted trend was something of greater priority that had occurred forcing the participant not to attend the talanoa session.

A second challenge encountered during the implementation phase was the unmotivated participants. The view held by these participants was that using ICT was not necessary in their programme of study and in their careers. In other words, the participants did not perceive the need to use ICT. Despite the researcher's attempts to highlight the need to see the "big picture", participants were still reluctant to jump on to the ICT bandwagon. Participants of this type may require a longer time to convince into accepting that improved ICT skills would put them on good stead for the future. 
Fear of technology was mainly observed with the mature participants. They were fearful of breaking the computer and anxious about using the internet. Other studies have recorded similar observations (Wexler et al., 2011). A term coined for this type of phobia is technophobia (Agbatogun \& Banjo, 2010) or computer phobia (Mcilroy, Sadler \& Boojawon, 2007; Wilson, 1999).

\section{Business Studies}

Participants enrolled in the Diploma in Business Studies may have benefited more if the researcher had alerted them to the relevant internet resources available for other courses. These included accounting principles, commercial law, economic environment, organisation and management, marketing fundamentals, and business communication. Through talanoa with a focus on any of these courses at a particular time may enable the researcher to learn more about the challenges that the participants face. Based on these findings, the supplementary resources can be identified and introduced to the participants.

Alternatively, participants could be asked to discuss aspects of the courses that they find challenging. Based on these revelations, the researcher could explore strategies to enhance their learning experience. One such strategy is a cooperative learning model designed to improve students' performance and retention in introductory accounting courses. The model called supplementary instruction was used in hundreds of campuses throughout America and found to be successful (Etter, Burmeister, \& Elder, 2000).

An area that required more attention with accounting students is the bridging of a perceived gap between the classroom and the real world (Law, Shaffer, \& Stout, 2009). Accounting educators in tertiary institutions extract essential principles, concepts and facts, and deliver them in an abstract and decontextualised environment. This is an area that ICT can be used to assist accounting students in their learning experience. Participants confirmed that their learning experience was textbook based requiring them to read the recommended chapters and answer the questions at the end of each chapter. The following paragraph outlines an ICT based learning resource for an Australian university accounting students.

A compact disc read only memory (CD-ROM) based learning resource had been used in an accounting information system (AIS) course for first year students at an Australian university (Stanley and Edwards, 2005). The resource contained 
three real world case studies aimed at self-directed learning for the students. Each case study used video segments of real life processes to demonstrate the accounting processes used by the organisations. Within the AIS there were six cycles which included general ledger and reporting, revenue, expenditure, payroll, capital acquisition and repay, and production. The user could examine each cycle in detail before attempting the tasks which included summary questions, cycle questions, and summarise case study. This type of resource indicate that there are ready made resources out in the market and if not available may offer an opportunity to develop similar resource to meet the need of New Zealand based students.

\section{English for Speakers of Other Languages (ESOL)}

The four participants enrolled in ESOL programmes had benefited from the supplementary resources that were identified and presented to them. Two participants were involved in a strategy to improve their listening, reading, and speaking skills assisted by the audio files available at the ESL website (http://esInews.org.nz/). All four participants were impressed with the Youtube videos and were keen to find other relevant videos to support their English.

An opportunity that was not explored was the use of the participants' mobile phones to support their learning of the English language. All participants have mobile phones and were competent users of their phones. A strategy focussing on the participants' weekly vocabulary list given out in class could have been explored to support the participants. Lu (2008) confirmed that greater vocabulary gains were observed for Taiwanese college students through the use of short message services (SMS) on mobile phones. Due to the small screen size of mobile phones, it was concluded that learning vocabulary with word lists were the most effective form of instruction on mobile phones (Lu, 2008).

In another study, Italian language learners in Australia were sent English vocabulary, idioms, definitions, and example sentences (Kennedy and Levy, 2008). The participants found the content messages useful and enjoyable. Cavus and Ibrahim (2009) also investigated the use of SMS to support the English language vocabulary learning of first year university students at a Cyprus university. They found that using SMS supported the improvement of the participants learning of new words. 


\section{Exercise Science}

The three participants enrolled in the Exercise Science programmes were impressed with the internet resources but admitted that they do not have the skills to find similar resources. This provides for an opportunity to include internet search skills for future encounters with students from this particular programme. The strategy developed for the participants enrolled in the IT and CADS programmes could be adapted to meet the requirements of Exercise Science students.

\section{Construction trades}

The two participants in this group offered a challenge for the introduction of ICT to support their learning experience. Both participants were over the age of thirty and they strongly felt that using computers were not part of their trades.

In the New Zealand building and construction industry, Doherty (1997) revealed that a large proportion of members used computers. Respondents to the survey included: $52 \%$ as designers (architects, draughtsmen, designers, and engineers), $17 \%$ as builders or sub-trades, $11 \%$ were building officials, and the remaining $20 \%$ as quantity surveyors, suppliers, or educators. Microsoft-based computers were commonly used and the software applications used by the respondents included Computer Aided Design (CAD), AutoCAD, ArchiCAD, and the Microsoft Office Suite (Word, Excel \& Access). The author emphasised that more and more ICT were becoming available to the building and construction industry and it was unwise to ignore them.

The two participants in this study belong to the second identified group of builders or sub-trades (carpentry and plumbing). Despite their conviction that they could survive without the use of computers, support must be provided to ensure that their employability skills are enhanced. Earlier, Niko revealed that he completed his education back at his home island before migrating to New Zealand when he was twenty years old. He stated that he had been in the plumbing trade for over ten years and his employer had sent him to the institute of technology to obtain his trade certification.

Niko: I work for this palagi guy who owns the business. He's a good man... he understands me. I don't muck around when he sends me to a job... I get there straight away and try and finish the job as fast as I can... after I finish I call him up so he can come to check and sign it off. He's been 
telling me to come to tec [WelTec] to get my papers done so I can sign it off myself... that way we can finish more jobs faster and earn heaps of money.

While Niko seemed confident in his plumbing skills he was apprehensive about the tertiary learning environment. One of his main concerns was his English reading and writing skills and the final examinations at the end of his course.

Niko: I'm struggling with all the reading stuff ... I can understand when the tutor explains it in class but when he asks about the stuff in the book... that's when I really really want to shout at him... you know... I'm not good with reading English so I have to keep asking my mate... I must pass the exam so I have to work hard... extra hard. Good thing, [support staff] is there... I see him every day and he explains the stuff I need to read in Samoan...

It was evident that this participant needed additional assistance in English reading, comprehension, and writing. The use of computers to improve these skills were challenging given his lack of computer skills and dislike of computers. However, the company supplied him with a mobile phone and this may offer an opportunity to use the mobile phone to enhance his English reading, comprehension, and writing skills. Given the limited available time (ten weeks) to work with Niko there were no mobile based resources available at hand to assist him but the following discussion will present opportunities that could be further explored.

The participant's admission that his English reading, comprehension and writing needed assistance offered a starting point for the learning of his course content. Richards (2006) identified a powerful motivational factor for improving students' English language skills. Engaging students' transportable identities, in this case as a plumber may offer an opportunity for a higher level of student involvement, effort, and time investment.

There are off-the-shelf products that are currently used internationally to support students in the construction trades. However, these products will require further examination to ascertain their effectiveness in supporting Pasifika learners in the construction trades. For example, a UK based company, Skills2Learn, had developed advanced e-learning resources that may be relevant to the participants' subject areas. The resources included real world environments 
presented through 2D/3D animation, audio, and virtual reality animations. The content is based on the UK's National Vocational Qualifications (NVQ) Levels 2 and 3 in plumbing and gas (Skills2Learn, 2010). Also available are carpentry and joinery e-learning resources. The learning materials are delivered on a DVD and costs from £42 (approximately NZ\$83) for individual packs to £995 (approximately NZ\$1955) for an academic pack.

\section{Information Technology (IT)}

The two participants enrolled in the IT programme were the most interactive group amongst all participants in this study. A request raised by one of the participants involved the search for additional resources to assist in a programming assignment. The programming language used in the assignment was $\mathrm{C}_{++}$. This request offered an opportunity to test drive the use of IncyWincy as discussed in the implementation phase.

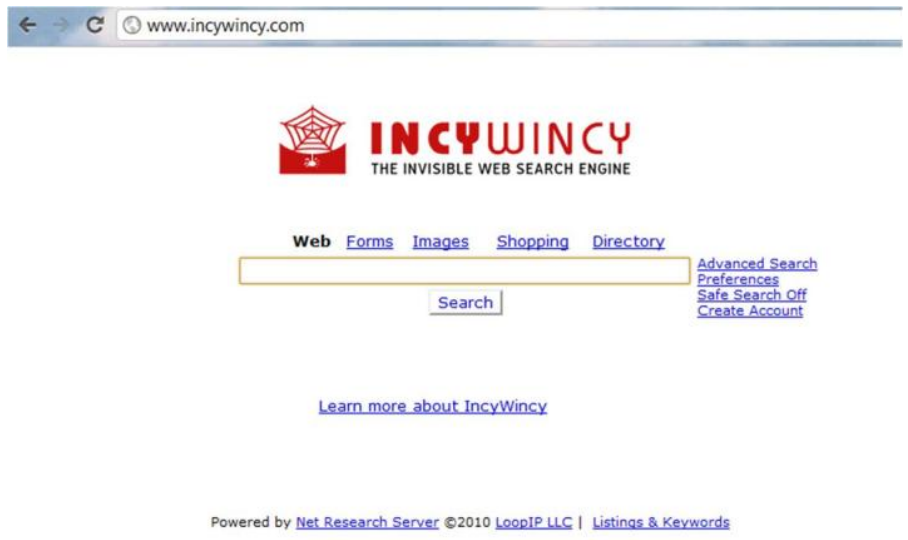

Figure 24: Secreenshot of the IncyWincy website

The first search attempt used the keywords $\mathbf{c + +}$ programming tutorial and resulted with a link to a website called Ultimate Programming Tutorial Page (http://www.thinkbrown.com/programming/) amongst thousand others. On the Ultimate Programming website was a list of $\mathrm{C} / \mathrm{C}++$ tutorials which had a link to a free electronic book with the title "Thinking in C++" by Bruce Eckel (2002). The participant found this search outcome to be exciting. She was particularly overwhelmed by the thought of accessing a copy of a $\mathrm{C}++$ textbook to assist her in her assignment. Available at the same site was another electronic book from the same author with the title "Thinking in Java". The participant wished that she had known about this in the previous semester when she struggled in the Java programming course. 
The two participants enrolled in the IT degree programme confirmed that maths and programming were challenging. Extra time for practice and more effort were required to ensure that the expected learning outcomes were met (Kinnune and Malmi, 2006). More practice demanded more time and was perceived as essential for mastering the programming language, thus improving programming skills (Hawi, 2010).

Eric: My maths is not flash... I have to pass the compulsory maths course so I can continue with my studies... right now it's like swimming in the [Wellington] harbour during a winter storm. It's a struggle...

Ini: Programming in Java is like learning to speak Russian... it's good that there's the learning support people... I have weekly meetings with the [learning support] tutor to help me ... most of the time I'm in the [computer] lab doing the weekly exercises and working on the [programming] assignments...

According to Govender (2009), contributing factors to the perceived difficulty in programming include students' aptitude, cognitive ability, complexity of programming, and activity theory. Students' aptitude in programming is typically influenced by their mathematical skills. These skills included problem solving, abstract reasoning, problem translation, and logical ability (Bergin and Reilly, 2005). It has been widely accepted that students who lack mathematical skills find programming daunting (Divjak, Ostroski, \& Hains, 2010; Balow-Jones \& Van der Westhuizen, 2011). The two participants in this study both echoed that their mathematical skills were 'not flash' and 'it's ok' confirming that both found programming an uphill battle.

Cognitive ability included learning style and motivation (Govender, 2009). Both participants in this study preferred to work alone and sought help from the tutors. Interestingly, the female participant revealed that she felt a sense of isolation in her classroom setting.

Ini: There is another girl in my class but we don't get on well. She's younger than me and seems to get on well with the boys... In class when I'm stuck on something, I usually ask the tutor once or twice... if I don't get it I feel bad to ask again... that's when I can't wait for the class to finish so I can 
go to the learning support services to ask for more help. At the learning support you get one-on-one help and you can go over it until you get it...

Motivation for Eric was extrinsic in nature while Ini's motivation was intrinsic. Eric's motivation to pursue studies in IT can be undermined if he ignored his selfinterests, psychological characteristics or his intellectual abilities. On the other hand, Ini's motivation was based on past experiences with computers which had very little relevance to the actual content of the IT programme (Blignaut and Naude, 2008).

Eric: I want to be a computer programmer because it's a well paid job...so when I finish my studies I can move to Australia and join my mate there... he's in IT as well...

Ini: I love working with computers but I didn't know that programming will be this hard... someone said [that] not many girls are in IT so at least when I finish my studies I'll be one of the few lucky ones...

Computer programming is traditionally a solitary activity (Hanks \& Brandt, 2009). To overcome this solitary practice for Pasifika students a technique called pair programming can be used to overcome some of the challenges of programming alone. Pair programming requires two students to share a single computer to practice computer programming. One student sits at the computer and acts as the "driver" while the other student acts as the "navigator". The role of navigator is to support the "driver" by identifying errors or offering alternative solutions (Lewis, 2011). The pair occasionally changes roles to enable each student to experience firsthand the different skills required for programming (Hanks et al., 2011).

Pair programming had been found to be successful for first year university computer programming students (McDowell, Werner, Bullock, \& Fernald, 2006; Bennedsen and Caspersen, 2007), success in later programming courses (McDowell, Werner, Bullock, \& Fernald, 2006), increased programming student retention (Carver, Henderson, He, Hodges, \& Reese, 2007), higher quality of programs produced (Hanks, McDowell, Draper \& Krnjajic, 2004; Bipp, Lepper, \& Schmedding, 2008), and enjoyment by students (Chaparro, Yuksel, Romero, \& Bryant, 2005). In a scenario where a Pasifika student may be alone in the programming class, it is vital to find another individual whether a fellow student or a tutor to form the pair to ensure that the student benefits from this strategy. 


\section{Hospitality}

The two participants enrolled in the Hospitality programmes were satisfied with the strategies developed to help their learning. The researcher felt that there was more that could have been done but the participants were not forthcoming with their learning experience in the class. In particular, any challenges would have given the researcher something to work on. An opportunity emerged which led to a request for help with the design of the menu. This was seen as a motivation to learn in order to complete the class requirement.

Vive: As my tutor was talking about the homework I was thinking... I know someone who can help with that...

Prior to the second scheduled talanoa session, the researcher acquired resources that had been developed for the Free Computing courses offered at the Institute to provide guidance on how to use the word processor (Microsoft Word) and the desktop publishing software (Microsoft Publisher). During this talanoa session, the researcher demonstrated how to use the word processor before encouraging the participant to practise while the researcher observed and answered any questions. This session took approximately fifty minutes. The participant was asked to do further practice using the word processor based on the Free Computing course handout before the following talanoa session which was scheduled for the next day. In addition, the participant was asked to bring along a hand written menu or a sample of what the participant wanted to be included on the menu.

The fourth talanoa session began with some discussion around the questions that the participant raised. When the participant was satisfied with the answers provided, the researcher proceeded to demonstrate how to organize the layout of the sample menu using the word processor (MS Word). These included features such as: centring text, changing font sizes, selecting suitable font types and applying text colour. In addition, the process of saving of the work file was demonstrated and the researcher emphasised the need to save any work in a location that can be easily found for later use. At the same time the participant asked for clarification and requested for a demonstration on how to insert images to the menu. This was undertaken and the participant was visually amazed at the ease of how changes were made and the flexibility to move from the word processor environment to the internet or web browser (in this case Microsoft's 
Internet Explorer) to locate various images on the web. The final step of sending the document to the printer was demonstrated before the participant was encouraged to try repeating the process a few times to ensure that she could do it confidently at her own pace.

Two days later, the researcher and participant met for the fifth talanoa session where the participant conveyed that she had showed the menu to her tutor. The tutor offered suggestions on some missing items and a couple of minor changes to the layout. At this stage the participant had not fully comprehended how the work saved from previous sessions could be retrieved and further modified. As the researcher demonstrated the process of retrieving the stored file, the participant commented that she thought that everything had to be re-typed. The researcher explained and slowly showed the participant how the mouse was used to highlight or select the relevant text to be modified, positioning of the cursor to any position in order to insert the new text. The participant was given the opportunity to practice retrieving the document and edited some text while the researcher observed and answered any queries that emerged during the process. This session took around forty minutes.

At the completion of the menu creation, the researcher advised the participant that she should look at every opportunity to apply the newly learnt skills. This offer led to other requests for assistance with the same application which was MS Publisher. From this observation, the researcher needed to learn more about the participants' course content to ensure that probing questions be raised to draw out the information required. For example, in the above participant's programme of study, the other courses included: cakes, sponges and paste products; creams, fillings and crazes; food art and presentation; hygiene operations and supervision; fermented and chemically aerated products; costing, budgets and control; fruit and meringue based desserts; decorative mediums and celebration cakes; kitchen maintenance and design; and gelatine and eggs set desserts (Wellington Institute of Technology, 2009e).

Knowing the course content beforehand may enable the researcher to ask more specific questions relating to any of these topics. This was not done during this study as the researcher waited for the participants to indicate topics that they found challenging. When the participants did not raise any challenges, an assumption the researcher made was that they were coping with their studies. 


\section{Counselling \& Alcohol and Drug Studies (CADS)}

The sole participant in the CADS programme was able to improve her internet searching skills and she was satisfied with the support provided by the researcher. While her requests focused on internet searches, the opportunity to enhance her learning in other parts of her programme was not explored. The counselling qualification in which she was enrolled included these courses: client centred practice; counselling theories; impact of social policy on current issues in NZ society; treaty of Waitangi; whakaruruhau; introduction to professional practice; introduction to individual and social psychology; and psychological theory and practice (Wellington Institute of Technology, 2009f).

As stated above, knowing these courses beforehand may enable the researcher to raise probing question relating to what the classroom experiences were for the participant. This may offer information for opportunities to develop strategies that would enhance the learning experience of future students enrolled in this qualification.

\section{Engineering Technology}

The sole female participant enrolled in the Engineering Technology programme discontinued her involvement in this study after the third ICT talanoa session. She did not offer any reasons for her withdrawal and the second strategy developed was not implemented. The strategy sought to improve her internet searching skills based on her general comment that her lecture notes were insufficient to answer the required assignment questions.

During the talanoa session she revealed that a course she was undertaking was Thermodynamics and Heat Transfer amongst others that included Engineering Fundamentals, Engineering Mathematics, Materials (Civil), Land Surveying, Structures, Civil and Structural Drawing, Geotechnical Engineering, Hydraulics, Highway Engineering, Engineering Management, and Engineering Project.

The following discussion focuses on the use of ICT for the delivery of thermodynamics and heat transfer or related courses to explore some possible avenues that may have been used to support the participant in this study. Ridwan, Yap, and Manna (2001) explored the delivery of a web-based thermodynamics and heat transfer course at the National University of Singapore. The learning resources included dynamic multimedia content covering lecture presentations and laboratory work simulations. The authors emphasised that the 
web-based resources were aimed at complementing and reinforcing their face-toface practice. A useful resource available at http://www.thermofluids.net/ was identified by Ridwan, Yap and Manna (2001). The website offered online applications for testing thermodynamics concepts with some accompanying notes.

Ozer, Kenworthy, Brisson, Cravalho, and McKinley (2003) discussed the webbased learning resources for the 'Heat Transfer Modes and Thermal Resistance' topic. The resources included relevant information, simulations, worked examples, exercises, real work examples, and a list of supplementary materials. Ozer and Cravalho (2004) extended the earlier work and discussed additional sections on the 'Open Thermal-Fluid Systems' topic. The additional sections were available under the information section titled, illustrated experiment fluid mechanics, and on-line fluid dynamics lecture. The web-based learning resource was based on a specific pedagogical approach involving apprenticeship, incidental, inductive, deductive, and discovery.

Anderson, Taraban, and Sharma (2005) investigated computer-based learning resources in the introductory thermodynamics course in two American universities. Students accessed learning materials from a CD-ROM which consisted of text, graphics with audio voice-overs, and animations. Other features included interactive questions, short response interactions, coaching interactions, and experimental animations. The study found that most students were prepared to use the computer-based materials.

Microsoft Excel had been used to develop resources to support first year engineering students. Chappell, Taylor, and Woodbury (2008) developed an Excel-based solution to reduce the time students spend on reading steam tables. Calculations for steam properties in an introductory thermodynamics class require students to read steam properties from the relevant tables. This was perceived as a time consuming exercise which took away valuable time from students who should be applying the learning material as opposed to reading values from tables. Huguet, Woodbury, and Taylor (2008) modified the Magnus Holmgren's Xsteam function in Excel to include the ideal gas property functions. The authors added graphical functions allowing students to plot graphs representing the relationship between properties and state. 


\section{Summary}

The Pasifika students' ICT skills development framework (Figure 10) was an adaptation of the systems development life cycle (SDLC). The SDLC emerged in the 1960s where it was used to develop large scale software applications. The Pasifika students' ICT skills development framework was utilised to enhance the learning experiences of the participants. The framework comprised of six phases namely: measure, identify needs, analyse gaps, develop strategies, implement strategies, and monitor and evaluate strategies. The first phase measured the participants' ICT skill levels. The benchmark was the National Certificate in Computing (Level 2) set out by the New Zealand Qualifications Authority. Additional measures were included to determine the participants' use of the internet and mobile phones to support their learning experience.

Participants' ICT skill levels were categorised as basic, intermediate, and suitable. Based on the study's baseline, four participants had basic ICT skills, 16 had intermediate ICT skills, and eight participants had suitable ICT skills. All participants easily identified the name and the purpose of the commonly used computer peripherals such as the computer screen, the keyboard, mouse, printer, and speakers. Four participants correctly identified the system box while the others referred to it as the computer, case, computer box, the CPU or was unsure. Internal components were known to the same four participants while nearly all participants were familiar with the main difference between hardware and software. The main software used by the participants was the Microsoft office suite which included Word, Excel and PowerPoint.

In addition to the participants' computer skills, their use of mobile phones and the internet was also determined. All participants had access to a mobile phone and they were all competent users of their respective phones. Only four participants revealed that they had used their mobile phones to support their learning experience. Three students used their mobile phones to take pictures and record audio and videos of their learning materials to assist them in reviewing the learning materials. The video was used for improving a demonstrated technique in a sports exercise class while the pictures were used in an IT class. The audio recording was undertaken in a Business Studies lecture. The fourth participant used his mobile phone to confirm from his classmates the time and room number for his classes. 
Participants' use of the internet was at varied stages. Participants' main use of the internet was for communication (emails and social networking through Bebo and Facebook) and entertainment. All participants had personal email accounts while twenty two participants had Bebo accounts. The second most common use of the internet was for accessing information. The type of information included news from the participants' home countries, sports, and New Zealand current affairs. The third most common use of the internet was for entertainment. Participants revealed that their family members or friends would send links on email for them to access some "cool stuff". These included videos on Youtube or jokes on other websites. All participants have used or seen someone use search engines but nearly half of the participants were unaware of the impact of keywords while using search engines. Seven participants had made on-line purchases through an on-line auction website, TradeMe, airline tickets, sports event tickets, and holiday accommodation.

The second phase of the Pasifika students' ICT development framework was the identification of the participants' learning needs. The learning needs were based on what the participants perceived they needed some assistance. The findings were presented according to the participants' programme of study which included business studies, ESOL, exercise science, construction trades, hospitality, counselling and alcohol and drug studies, IT and engineering.

Thirteen participants were enrolled in Business Studies programmes. Seven participants were enrolled in the diploma qualification while six were enrolled in the certificate qualification. A compulsory course for the diploma qualification was Business Computing which the participants found challenging. Four participants in the certificate revealed that they needed further assistance with an accounting software application, MYOB.

Four participants were enrolled in ESOL programmes. Two participants were enrolled in the general ESOL programme (Level 2) while the other two were in the English for further studies (Level 3). The participants revealed that they needed more practice with their English reading, listening, and writing.

Three participants were enrolled in the Exercise Science programmes and they confirmed that their courses did not teach them to use computers but they were required to complete their assignments using computers for typing and the internet for researching additional information for their assignments. 
Two participants were enrolled in the constructions trades. They insisted that computers and the internet were not part of their industry therefore there was no need to learn how to use them. The same view was held by the two participants enrolled in the hospitality programmes.

Two participants were enrolled in IT and they revealed that they needed further assistance mainly in maths and computer programming. The sole participant enrolled in engineering confessed that engineering was hard but she did not reveal any particular aspects that she required assistance. A participant was enrolled in the Counselling and Alcohol and Drug Studies was a competent computer user and only needed help in searching the internet for additional resources for her assignments.

The third phase of the Pasifika students' ICT development framework was the analysing of the perceived gaps between the participants' ICT skills measured in the first phase against the learning needs gathered in the second phase. The analysis was led by the researcher in consultation with the participants.

The fourth phase included the development of ICT-based strategies by the researcher to assist the participants in their studies. Based on the perceived gaps in the participants' learning needs a number of strategies were implemented. All participants were involved in the first strategy which was named ICT talanoa. This was essential to focus the purpose of talanoa to the ICT used in the participants' courses. From the first strategy, personalised or more focussed strategies were developed and implemented. The strategies mainly included the use of internet resources that served as supplementary learning resources.

The participants who were completing the Business Computing course were assisted through a number of visits to the computer hardware laboratory that the researcher used for teaching his classes. This enabled the participants to experience first-hand the internal components of the computer. In the hardware laboratory, participants were encouraged to remove the components from inside the computer's system unit. This was followed by further discussion with the researcher before they were asked to return the components to their original position. This strategy was informed by the situated learning theory where learning was undertaken through experience as opposed to an abstract 
approach. In addition, digital visual aids were used to assist participants in their recollection of the hardware components' names.

Participants in the ESOL programmes were introduced to an ESL website which provided text and audio recordings of English articles. Participants were shown how to download the audio files so they can use it on their portable MP3 players while they are away from the computer. The accompanying text improved the participants' listening and reading skills. ESOL participants were also introduced to Youtube videos which presented alternative topics that kept the participants motivated.

The three participants enrolled in the Exercise Science programmes were impressed with the supplementary learning materials. These included a more detailed diagram of the respiratory system and a number of videos sourced from the Youtube website that presented the respiratory system. These resources offered alternative learning materials and were very helpful in their revision of materials they had learnt in class.

The two participants enrolled in the construction trades programmes had the least ICT skills. They were also uninterested in the use of computers and the internet to support their learning. Interestingly, they were interested in the internet for entertainment.

The two participants enrolled in IT were very keen to improve their internet searching skills. They held the view that most resources that they needed were available on-line. They needed advanced internet searching skills. The participants were assisted through a number of search tactics and strategies. A similar approach was undertaken for the participant enrolled in the Counselling and Alcohol and Drugs Studies programme.

The two participants in the hospitality programme were initially reluctant to engage in using ICT to support their learning. They held a similar view to the participants in the construction trades. According to the participants, computers and the internet were not used in kitchen and therefore they were not interested. One of the participants requested assistance in creating a menu as a homework requirement. This offered an opportunity to introduce the desktop publishing software, MS Publisher, to the participant. This incident demonstrated that 
participants may be interested to improve their ICT skills if it is for a course requirement.

The fifth phase of the Pasifika students' ICT development framework was the implementations of the strategies developed in phase four. All the strategies developed for the different groups were implemented without issues except the one developed for the construction trades participants. They were perceived by the researcher as unmotivated learners and an alternative approach had to be taken.

The final phase of the Pasifika students' ICT development framework was the monitoring and evaluation of the developed strategies. Overall ICT talanoa was well received. A challenge encountered by the researcher was the demand on time given by the participants. The participants displayed two aspects of time management. The first was shown by the participants who were fully engaged in the study. Participants needed to be reminded by the researcher that they needed to attend to their timetabled classes. The second aspect of time management displayed by some participants was through their irregular attendance in talanoa sessions. The first group who participated in the talanoa sessions regularly reported satisfaction in meeting their course assessments and highly valued the talanoa. In contrast, participants with irregular attendances were uncomfortable in discussing their academic progress.

Participants enrolled in the Business Studies programmes may have benefited more if the researcher had alerted them to the numerous resources available on the internet for other subjects such as accounting, commercial law, economics, marketing, and business communication. The participants held the view that the researcher was a "computer man" and they refrained from asking him questions unrelated to IT.

Additional work is required to change the view of participants who felt that ICT was not relevant to their programme of study. While they may not use ICT directly, the indirect use of ICT is too hard to ignore. For example, the two participants in the construction trades indicated that they would consider becoming self-employed in the future. To run a small business will definitely require ICT skills to ensure that the costs are kept to a minimum. Sourcing raw materials on-line will help keep the operating costs down. 
In order to better engage the participants, the need to understand most if not all aspects of their programmes of study are vital. This may require the involvement of the tutors who are responsible for the courses so that the support provided for the Pasifika students is consistent with the materials delivered in class. This may also influence the attitude of some of the reluctant learners. 


\section{CHAPTER 7}

\section{DISCUSSION}

\section{Introduction}

This chapter presents a discussion on the findings from this study. It begins with a discussion on the rationale for using talanoa in the study. This is followed by the identified barriers that hinder the Pasifika students' use of ICT to enhance their learning experiences. Some of the barriers were stated by the participants as their excuses for not using ICT. The barriers include lack of interest, and limited ICT access. Other barriers such as unawareness of ICT potentialities, lack of basic skills, and the fear of technology were inferred from comments made the participants and observations made the researcher. Factors that enhanced Pasifika students' use of ICT to support their learning experience include past experience, peer and family support, and self-efficacy. Lastly, some recommendations on ways to use ICT to enhance Pasifika students' learning experiences are presented.

\section{Significance of Talanoa in this study}

Using talanoa throughout this study has been an empowering process for both the participants and the researcher. Talanoa had been vital in gathering the research data and also to disseminate information to participants who needed assistance in their use of ICT. Talanoa had been favoured by the participants over other research methods such as unstructured interviews or action research. As outlined in the methodology chapter, a benefit of using talanoa was the empowerment of the participants, as well as the researcher. Overall, participants who were engaged throughout the study found it very rewarding because it assisted them to better understand the ICT used in their chosen field of study while at the same time improved their overall ICT skills. Similarly, the researcher was satisfied that the research data was gathered through talanoa and the ICT skills development framework was tested. 
Most of the participants (92\%) in this study were first-time research participants and it was perceived that the best way to engage them was to use a research method that was culturally appropriate and relevant (Otsuka, 2006). This was a reason for using talanoa. The participants' familiarity with the talanoa process based on their cultural and traditional experiences enabled participants to be more receptive to the invitation to participate in the study. The participants were mainly Samoans, Tongans, and Fijians whose languages included the word talanoa with similar meaning which is the engagement in a meaningful discussion. In contrast, the researcher found that four prospective participants were apprehensive when data gathering tools such as interview, questionnaire, and focus groups were mentioned as the standard research techniques. Most participants were first-time research participants and were unfamiliar with research requirements such as the participant's consent, research ethics, and the right to withdraw their participation, amongst others. This made the use of talanoa for the study appropriate as it enabled the researcher to thoroughly explain the research process and protocols to participants who were interested while satisfying the needs of those that had other interests.

The flexibility and the intrinsic values of talanoa enabled the researcher to uphold a common practice of Pasifika peoples which is reciprocity. In the traditional and cultural practices of Pasifika peoples, reciprocity is the norm. In this study, the researcher set out to achieve authentic data and faithfulness to real life (Cohen, Marion, \& Morrison, 2007) by adhering to Pasifika peoples' common practices. Reciprocity was achieved through the request for the participants' time and commitment to the study and in return the researcher offered assistance and guidance for the participants' ICT skills. Upholding practices that were familiar and perceived as normal to both the participants and the researcher ensured that both benefited from the interchange. The participants gave their time and shared lived experiences to the researcher and in return the researcher offered guidance and advice on the improvement of the participants' ICT skills.

\section{What are some barriers to Pasifika students acquiring ICT Skills?}

Through talanoa, participants offered insights to their use of ICT. The two commonly stated excuses for not using ICT were the lack of interest in using ICT and the limited access to ICT. Other excuses for not using ICT were inferred from the participants' statements about the ICT or through observations made by the researcher. These included limited awareness of the ICT potentialities, lack 
of foundation or basic skills, and lastly the fear of technology. These excuses offered by participants were classified as barriers to the attainment of ICT skills.

\section{Lack of interest in using ICT}

Generally, the lack of interest in using a tool can be attributed to its perceived relevance by an individual (Cooke \& Greenwood, 2008). Four participants in the study stated that using computers and the internet were not immediate requirements for their chosen programmes of study. These programmes included carpentry, plumbing, food preparation, and patisserie. Participants in the carpentry and plumbing programmes explained that all their classes were conducted in the carpentry and plumbing workshops where not a single computer was to be seen (Thomson \& Lamshed, 2006). It was a valid observation based on the participants' view that ICT does not comprise a core component in their day-to-day learning experience.

Norris (2001) warned that those in manual occupations were less likely to experience ICT use in their day-to-day activities and were in grave danger of becoming caught on the wrong side of the digital divide. The nature of the trades that the above two participants were in could be categorised as manual or semimanual occupations. While ICT skills may not be necessary for these four participants to successfully complete their courses, the direct and indirect use of some ICT is prevalent in their employment sectors. For instance, the use of electronic funds transfer at point of sale (EFTPOS) devices in all retail services was common in NZ and continued to increase (Hughes, 2006). In the case of the four participants, purchasing materials and charging for their services would expose them to the use of computer-based devices.

Inadvertently, the participants' view of ICT such as computers and the internet may have been caused by a lack of understanding of the interconnectedness of digital technologies. ICT offer businesses new ways to organise and manage work, and network with suppliers and customers resulting in efficiency gains (Stare, Jaklic, \& Kotnik, 2006). The rapid advances in the microprocessor technology had resulted in the decreasing physical size of a computer. A spin-off of the microprocessor technology has benefitted the newer mobile phones with their many functions and faster processing capabilities. The use of the mobile phones for communications and also to support business processes is ubiquitous for small business operators and contractors. 


\section{Limited ICT access}

A second identified barrier to the development of the participants' ICT skills was limited ICT access. The results of this study found two aspects of limited ICT access. The first involved limited physical access which is not having a computer at home. The second related to participants who had been to school in the past four years but took subjects that did not use the computers. While the participants had access to computers, it was only during their free time and their use of computers was mainly for social reasons or for entertainment. Limited access in this case included the casual or informal use of computers.

Five participants in this study indicated that they did not have a personal computer and internet access at home. Reasons provided for this situation were affordability and relevance. Affordability was voiced by three study participants, emphasising that as full-time students with limited financial resources, acquiring a personal computer was not practical. A number of studies (Todman \& Dick, 1993; Shashaani, 1994; Meelissen \& Drent, 2008) revealed that individuals with limited financial resources or from lower socio-economic status had lower positive attitudes towards computers. Woodward et al (2011) identified high cost of ICT as a main barrier to accessing ICT for older adults in the USA.

The remaining two participants without computers at home affirmed that computers were not tools of their trades and therefore they perceived it as 'a waste of money'. These participants place themselves in a disadvantage position because some studies have established that home computer use had a strong correlation to higher computer proficiencies at school and at work (Rockman et al, 1999; Madigan, Goodfellow \& Stone, 2007; Luu \& Freeman, 2011). This is based on the view that having a computer at home provides greater access thus enabling more time for practice which leads to higher computer competence for the users.

Relevance of using ICT had been identified earlier as a predictor to the interest in using ICT. Understandably, participants who viewed ICT as irrelevant to their immediate situation were not motivated to access ICT. For these participants, it was only at the Institute that they had been influenced by their tutors or colleagues to use computers and access the internet. 


\section{Lack of awareness of ICT potentialities}

In this study, an individual's lack of knowledge of ICT capabilities was observed to be a barrier to the development of ICT skills (Hashim, 2008; Imran, 2009). Participants enrolled in programmes that did not use ICT in their disciplines held the view that ICT was not necessary for them in their studies. These programmes included ESOL, Exercise Science, Construction Trades, Hospitality, and Counselling \& Alcohol and Drug Studies.

The four participants enrolled in the ESOL programmes were unaware of the capability of ICT to support them in their studies. Influenced by the teaching and learning style offered to them by their tutors, they were led to believe that using computers and the internet was irrelevant to improving their English language skills. However, through talanoa the participants shared their interest in improving their reading, listening and speaking skills. The use of resources available from the English as a Second Language website (http://es/news.org.nz/) which offered a recorded audio file (MP3 file format) and the accompanying script enabled the participant to become aware of some of the benefits that ICT offered. The ability to transfer the audio files and portable listening devices such as MP3 audio players or on to a CD-ROM so that it can played on a car stereo or home radio offered the opportunity to listen to the audio while travelling or while waiting for friends and family members.

Similarly, the participants enrolled in the Exercise Science programmes were unaware of how ICT may be used to support them in their studies. Despite their familiarity with the use of Youtube to access music videos and movies, they were unaware that there were educational videos on the respiratory system on Youtube. The use of videos had been a popular choice for PE educators based on its ability to provide visual feedback (Thomas \& Stratton, 2006; Weir \& Connor, 2009). It was unintentional that one of the participants used his mobile phone to video record the actions of a friend who was demonstrating a class exercise relating to postural assessments. The participant confirmed that he was able to use the video to improve his technique. This observation is supported by the study undertaken by Weir and Connor (2009) who revealed that videos were powerful tools for demonstrating concepts and modelling performances.

The participant enrolled in the Certificate in Patisserie was initially reluctant to use the computer until an assessment involved the preparation of a menu. The participant's tutor had stated to the class that the assessment required the use of 
a computer-based word processor or desktop publishing software. The participant's initial thought was to find someone who knew how to use a computer to help her with her assessment. In this case, the participant sought a talanoa session with the researcher where she revealed the course requirement. At the end of four talanoa sessions, the participant was finally convinced that using the wordprocesor and a computer greatly helped the creation of "a professional looking menu". Furthermore, any additional changes could easily be accomplished as it only required the retrieval of the computer file and amending the relevant sections.

\section{Lack of foundation or basic skills}

For the purpose of this study, foundation or basic skills referred to basic computer keyboard and mouse skills (Ward, Kester \& Kouzekanani, 2009). These include knowledge and understanding of the computer keyboard layout, location and types of keys, and the functions of the special keys such as the Shift, Control, and Alt keys. Furthermore, basic skills include familiarity with how to use the mouse to initiate an event. For example when to use a single or a double click on the mouse buttons and how to navigate within an application such as MS Word. Sayago and Blat (2011) confirmed that first-time computer users have difficulties in understanding computer related terms, remembering steps required to complete a task, recognising software icons, using the mouse, and locating keys on the keyboard.

On a standard computer keyboard, there are two control keys, marked "Ctrl" located on the last column of keys at each end of the keyboard (as shown in the diagram below). The control key is used in conjunction with other keys to trigger a number of predetermined functions. Some examples where the "Ctrl" key is used include: control and the letter "a" (usually represented as Ctrl+"a") to select all the text on a document; control and the letter "c" (Ctrl+"c") to copy a selected object or objects which may be an image or a string of characters such as a word or sentence or a paragraph; control and the letter "v" (Ctrl+" v") to paste the recently copied objects; and control and the letter " $s$ " (Ctrl+"s") to save a currently opened file. There are many other functions that are specific to an application and this approach serves as short-cut keys to access the same functions that can be achieved by following through the windows menu. 


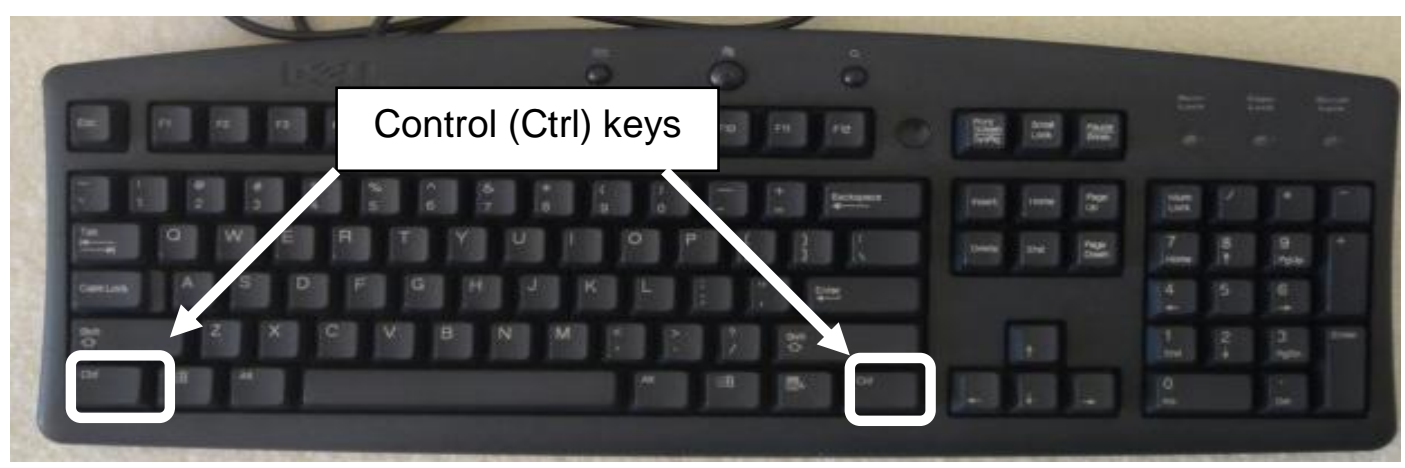

Figure 25: Computer keyboard layout showing the Ctrl keys

Two participants enrolled in the Business Studies programmes revealed that while they had used a computer prior to enrolling, they had very little confidence in using it independently. During talanoa with these participants it was observed that they had just recently started using a computer and they were still finding their way around the keyboard layout. In other words, they were spending a fair bit of time locating the keys on the keyboard. The researcher was asked by one of these participants how to insert page numbers on a MS Word document for an assignment. While guiding the participant on how to insert the page number, the researcher used the following statement: "Press and hold down the control key while pressing the enter key to force a page break". The participant queried, "Where's the control key?" This indicated that the participant lacked some basic understanding of keyboard keys and their respective functions.

\section{Computer phobia}

Computer phobia or the fear of using a computer was earlier defined by Rosen and Weil (1992) as "anxiety about present or future interactions with computers ... negative global attitudes about computers, their operation or societal impact ... self-critical internal dialogue during actual computer interaction or when contemplating future computer interaction" (pp.7-8). Hogan (2009) amended this definition to define technophobia as "anxiety about present or future interactions with computers or computer-related technology" (p.118).

Two participants admitted that they were "afraid of using the computer" due to their unfamiliarity in using it. When requested to disclose more about their situation, Niko stated "I don't know how to use it?" which was accompanied with a shoulder shrug. This may be interpreted as a situation where the participant had no prior knowledge on the use of the computer and need to be shown and slowly guided to ensure that he can gain the confidence in using one. 
Numerous international studies on computer phobia or technophobia have been undertaken but none had been found for New Zealand participants. Levin and Gordon (1989) claim that women were more computer phobic than men; older people were more computer phobic than younger people (Laguna \& Babcock, 1997); and university students were less computer phobic than non-university students (Weil \& Rosen, 1995). According to Wilson (1999), computer phobia can be classified under two categories: practical and ideological. Practical reasons included communicating with, and communicating about computers. Learning the required keyboard skills, computer terminology, or understanding the complex nature of computer systems are some of the practical reasons.

Ideological reasons included: the anti-social and de-humanising nature of computers; association of computers with complex mathematical calculations; role of computers with automation and the displacement of humans in workplaces (Wilson, 1999). The current study did not explore the participants' ideological reasons for their fear of computers or ICT but it can be seen that their concerns were mainly for practical reasons.

\section{Participants' age}

Three participants whose ages were above 24 and had been in the workforce before returning to up-skill in their respective fields were not interested in using computers and the internet. From these participants' view point, computers were things that have recently emerged and the young ones were more accustomed to computers. The participants lacked the knowledge to use ICT and this negatively influenced their interest towards it. Wexler, Drury, Coppola, Tschinkel, and Thomas (2011) suggested that some older adults showed reluctance to use a computer fearing that they might damage it. The attitude of participants in this study could be seen as consistent to the findings from a national survey of Australian nurses by Eley, Fallon, Soar, Buikstra \& Hegney (2008) where age was found to be a barrier to the use of ICT in their work.

\section{Past work experiences}

Past work experience was found to be an influencing factor in four participants' lack of interest in ICT and in particular, the computer. The participant in the carpentry programme stated that he had never used a personal computer in his life and he 'will survive without one'. Cooke and Greenwood (2008) reiterated that those in manual occupations were less likely to be using computers or the internet in their workplaces. Consequently, having no prior experience in using a 
personal computer results in a lack of confidence in using one (Dickson et al., 2005). The perceptions that there was no need to use ICT based on past work experiences further reinforced the participants' resolve that computer skills are not vital for their employment opportunities. Scott and Rockwell (1997) found that experience can serve as a strong predictor of users' voluntary avoidance to use ICT.

\section{What are some factors that support Pasifika students in acquiring ICT Skills?}

The process of identifying factors that contributed positively to Pasifika students' learning ICT skills were similar to the approach discussed earlier in identifying the barriers to their acquiring ICT skills. Through talanoa participants shared stories about how they learnt to use ICT. Two common themes that emerged included: prior learning experiences at high school or at the participants' places of work, and learning from peers or family members. Other stories confirmed a sense of positive self-efficacy for those who were willing to try things out with the ICT used in their programmes of study while those with low self efficacy were reluctant or were slow to acquire the relevant ICT skills.

\section{Prior learning experience}

Forty-three percent of participants in this study revealed that they had learnt how to use computers and the internet while at high school. In other words, prior learning experience was a major contributing factor to the acquisition of the participants' initial ICT skills (Messineo \& DeOllos, 2005). Participants who had been in the high school education system in the past four years prior to this study were found to have acquired ICT skills while at school. There were two ways of acquiring ICT skills as revealed by the participants. The first was through formal learning for those that took computer related subjects. The second was through informal learning for those that did not take computer subjects but learnt ICT skills through their peers.

The participants' prior learning experience in using the computer and the internet positively impacted their tertiary learning in different ways. All participants enrolled in the Business Studies programmes had used computers and the internet prior to their tertiary studies but were at different competence levels. They were all capable of using the computers to type their assignments however they would complete the typing at different times due to their different word processing skills and typing speed. Those with faster typing skills would naturally 
complete the typing earlier than the others with slower typing speeds. Furthermore, those with intermediate word processing skills would be able to format their typed assignment by using features such as bold, italics, inserting page numbers to name a few.

A participant enrolled in an IT programme confirmed that her high school experience influenced her decision to pursue IT studies at tertiary level. This observation was consistent with Taylor and Mounfield's (1994) study where positive experience of students at college level convinced them to pursue further studies in a particular discipline in tertiary education.

\section{Prior work experience}

Sixty-one percent of participants had indicated that they had some work experience prior to enrolling at the tertiary institution. The type of work included office based occupations, warehouse packing and delivery, mail sorting, professional sports, offset printing machinery operations, commercial kitchen, and labouring work. The type of work which required the use of computers enabled the participants to learn computers as part of their work or received training prior to starting work. Those that worked in environments that did not use the computer were highly likely not to use the computers at all. The only opportunity for the use of computers for this group of participants was at home or through friends and relatives.

Participants whose workplaces used computers have acquired some computer skills through their colleagues and were aware of some general functions of the computer. A female participant's work experience began as a secretary or typist at a social services centre. She began as a volunteer at the centre and after a year she was asked to work full-time. At the commencement of her employment she used an electronic typewriter to prepare the office documents and correspondences (Gesthuizen \& Wolbers, 2010). Later, a personal computer was bought for the office and she attended evening classes to learn how to use the computer. In her case, the work requirements dictated her acquisition of the computer skills in order for her to carry out her duties.

Another participant who was well versed with the computer and the internet stated that she taught herself how to use ICT. While it was challenging she considered herself lucky to have a family member and some friends that she relied upon to help her along the way. 
Sina: I've used the computer for over ten years. When I started my own business I had no choice but to get to know how to use it...

A male participant sought the assistance of work colleagues whenever he found using the computer a challenge.

Eric: At work I asked my mates to show me how to do work stuff on the computer ... slowly... slowly... as time went on I tried to do new things and now I want to know more... that's why l'm here.

The sentiments shared by the participants as outlined above confirms that prior learning or use of computers outside of formal education is associated with positive computer attitudes and beliefs. Studies by Van Braak (2004), Bovee, Voogt, \& Meelissen (2007), Meelissen \& Drent (2008), and McCoy (2010) concur that prior work experience enables learners to be confident in the use of newer ICT.

\section{Peer and family network support}

Nearly all participants in this study revealed that their ICT skills were developed or assisted at some point through friends, family members and work colleagues. Similarly, $80 \%$ of all Canadian computer users aged 15 and over received informal guidance from a friend or family member (Dryburgh, 2002). The following statements demonstrated the participants' experiences in acquiring computer skills.

Kai: A lot of the things I know about computers was shown to me by my friends at school...some of them are smart... I just watch them and then try it myself... when I can't do it... I ask them...

Sina: My brother is into IT and so he gets all the silly questions from me...

Eric: I never learnt computers at school... but I was lucky my sister worked at a government department and she knew how to use it. She got one for her kids and every time I visit them... I ask my nephew to show me how to use $i t \ldots$ 
Samuelsson's (2010) investigation of ICT use by 13-year-old Swedish children found that the majority learned their computer skills from older siblings. In a study of Greek children, Vryzas and Tsitouridou (2002) found that many children from low socioeconomic status learnt computing skills from their friends. In contrast, children from more privileged socioeconomic status learnt computing skills from their parents.

Two participants indicated they preferred someone to first show them how things are done on the computer before they tried it themselves. This learning style was observed in some students in a computer skills course at a USA university who preferred hands-on projects and in-class activities over lectures. To satisfy the need for more hand-on, students turned to their peers. More demonstrations and direction were required for teaching MS Excel and web page creation (Martin \& Dunsworth, 2007). A similar observation was recorded for pre-service teachers at a Taiwanese university (Koh, Chai, \& Tsai, 2010).

Kala: In class I just watch my friends do their work and then I slowly try... the tutor keeps telling me "read the handout - it's all in there". I try to read it but it's hard out... it's way easier to watch someone do it and then I try it.

Sieni: It's like... the tutor goes on too fast and I'm like... just show me first how to do it... [participant's friend] always helps me... if I see it then I can figure out what's going on.

\section{Self-efficacy}

Self-efficacy refers to an individual's perceptions of their abilities in a given domain and originated from Bandura's (1977) social cognitive theory. Selfefficacy enables people to control their thoughts, feelings, and actions (Hall, 2008). It is widely accepted that self-efficacy influences an individual's choice of engagement in any given domain, how well they perform, how long they persevere, how they cope and respond to adverse scenarios (Cretchley, 2007; Johnson, 2005). In this study, a participant who was familiar with the use of a search engine (Google) revealed a technique she used to note a website suggested by her tutor for additional information.

Sina: Whenever my tutor writes a web-address I just note the important part... if she writes www.nzac.org.nz l'll just write the name NZ Association of Counsellors and later google it. 
Another participant who had positive experiences with computers at high school level felt she could handle the demands of IT studies at the tertiary education level. While she admitted that studying IT at tertiary was not the same as she had initially perceived, her self-efficacy was still high. High self-efficacy increases the chances of achieving a given task. In some cases, an individual with high self-efficacy may achieve higher than his or her current ability (Pan, 2010). In contrast, an individual with low self-efficacy lends himself or herself to a feeling of fear and apprehension which affects the participant's ICT use. Bandura (1977) proposed four ways to develop self-efficacy. These included the observations of the successful performance of a given task, actual success in performing the task, verbal reassurances by the expert or the teacher, and the reduction of the fear of failure while performing the task.

In the context of this study, participants revealed the desire to be shown how to use ICT first before they attempt to use it. This process is referred to as vicarious modelling (Hutchens, 2010). The second way of developing self-efficacy is the actual success in performing a task or mastery experiences. Mastery experiences were identified as the most powerful mechanism for influencing selfefficacy (Bandura, 1977). Participants had discussed situations where they requested friends or family members to show them how to use the computer. The successful completion of small tasks increases the participants' self-efficacy and may encourage them to try other more demanding tasks. The third approach to improving self-efficacy is through verbal reassurances. Verbal reassurances can be a statement or comment that helps remove someone's doubts or fears. In this study, the use of gestures such as a nod accompanied by a smile and spontaneous laughter greatly assists some of the participants' self-efficacy.

\section{What are some ICT skills that would enhance Pasifika students' learning experience?}

Enhancing the participants' ICT skills was vital to ensure that they were capable of meeting the demands of their studies. The following discussion examines each group of participants based on their programmes of study. The participants were enrolled for qualifications in business studies, ESOL, exercise science, construction trades, IT, hospitality, counselling \& alcohol and drugs, and engineering technology. 
For the purpose of this study, the ICT skill levels were categorised into three levels: the basic, intermediate and acceptable levels. The basic ICT level included the ability to use a mobile phone for communication and the ability to recognise some common hardware peripherals of the personal computer that include the computer screen, keyboard, mouse, printer, and the system unit. The intermediate level includes all the skills of the basic level and the competent use of a personal computer and the internet. The acceptable level was relative to the participants' enrolled programme of study and the student can manage the ICT demands of their programme of study. The basic entry level required the participant to meet most of the requirements for the US 2780. These included knowledge of the PC hardware components, knowledge of the operation of system and application software, and operate a printer. The basic intermediate level required the participant to meet all the requirements for US 2780 and 2781. The acceptable level required the participant to meet all the requirements for US 2780,2871 , the use of the mobile phones and the internet.

\section{Business Studies}

This study found that two Business Studies participants were at the basic entry skill level, seven were at the basic intermediate level, and four were in the acceptable level. The low number of participants with an acceptable level of ICT skills was consistent with an international study involving first year business students at an America university. Wallace and Clariana (2005) found that $36 \%$ of first year students could be exempted from the introductory computer fundamental course if given the choice. However, the majority lacked the necessary computer knowledge, skills, and abilities to meet the demands of their studies.

Participants in this study received support in improving their understanding in some topics of the Business Computing course. Other courses that were part of the Diploma in Business included: Accounting Principles, Commercial Law, Economic Environment, Organisation \& Management, Fundamentals of Marketing, and Business Communication (Wellington Institute of Technology, 2009a). While the participants were also enrolled in other business related courses, they only sought academic assistance in the Business Computing course. An explanation for this may have been the participants' view that the researcher was an "IT man" and not an accounting, economics or commercial law expert. Participants were asked by the researcher if they had any difficulties in their other courses but that did not ignite any response. 
The following section focuses on a number of courses separately to explore studies that had been undertaken elsewhere and to draw out lessons that could be applied to enhance the participants learning experience. The courses included accounting, economics, and marketing fundamentals.

More than twenty-five years ago, Bhaskar and Kaye (1985) asserted that ICT would affect future accounting education. Borthick and Clack (1987) concur that ICT must be integrated to all areas of accounting education. The authors argued that ICT would improve students' learning experience while reducing instruction time and the associated costs. Holt, Boyce, Carnegie and Bigelow (1995) outlined that computer-based learning in accounting would contribute to the development of technical competencies, accounting concepts, issues and ideas. This view was renewed by Nawawi and Ling (2010) stating that ICT was crucial for all accounting graduates. According to Stoner (2009), ICT skills were a fundamental requirement for a good accounting professional. An example of the ICT used in accounting was the online interactive learning module designed to assist first-year accounting students in the preparation of cash flow statement topic (Jebeile \& Abeysekera, 2010).

Studies on the impact of ICT in economics education confirmed that ICT enabled the development of important cognitive skills for effective economic analysis and evaluation (Ping, 2003). ICT enabled the cognitive scaffolding of complex concepts and the interrelated nature of the concepts (Scheraga, 1986; Smith \& Smith, 1989; MacDonald \& Shields, 1998; Katz, 1999; Joerding, 2010) and enabled communication between teachers and students enhancing their understanding of economics (Manning, 1996; Chizmar \& Walbert, 1999; Greenlaw, 1999; Manning \& Riordan, 2000). In addition, ICT enabled students to observe real-life impact of economic theories through simulations (Lumsden \& Scott, 1988; Hallberg, 1996; Agarwal \& Day, 1998; Bredon, 1999; Simkins, 1999; Santos, 2002; Schmidt, 2003; Lengwiler, 2004; Bolton, 2005; Surdam, 2009).

Buzzard, Crittenden, Crittenden, and McCarty (2011) outlined that studies in the use of ICT in marketing education could be classified into two main categories. First, the broad perspective focused on the overall ICT integration trends and its impact on the teaching and learning outcomes. Second, the narrower focus on how particular ICTs had been used in marketing classrooms. With regards to the broad perspective, Ferrell and Ferrell (2002) found that marketing students felt 
that the use of PowerPoint in their classroom was not overused. Robinson (2006) confirmed that ICT usage had a positive relationship with students' learning outcomes. In terms of the narrower focus, the types of ICTs used in marketing classrooms included mobile phones (Day and Kumar, 2010), Web 2.0 (Workman, 2008; Cronin, 2009; Granitz and Koernig, 2011), podcasts (Zahay and Fredricks, 2009), virtual environments such as Second Life (Tuten, 2009).

In the mid-1980s, a nationwide survey funded by the American Assembly of Collegiate Schools of Business (AACSB) found that about one quarter of colleges in America were using computers in business communication courses (Munter, 1986). Computers were used to assist students improve their writing skills, teach word processing, provide students with computerised tutorials, computerised feedback, and for communication. The use of word processors in communication writing was mainly due to the ease of making revisions or changes (McAllister and Louth, 1988). Furthermore, Bernhardt, Edwards, and Wojahn (1989) found that using the computer for writing college compositions produced works that were of a higher quality than the handwritten ones.

The literature review chapter presented further opportunities in using ICT to support learners in business related disciplines. These included using wikis for cooperative learning (Cronin, 2009; Halcro \& Smith, 2011), blogs as a reflective tool (Joshi \& Chugh, 2009); learning management systems such as Blackboard (De Lange, Suwardy \& Mavondo, 2003; Wells, De Lange \& Fieger, 2008; Basioudis \& De Lange, 2009), and computer games for Marketing Management course (Whitton \& Hynes, 2006). It must be noted that all these studies involved university students which are a different group of students when compared to participants in the current study. An opportunity thus exists for the development of learning resources that are suitable for participants in this study.

Numerous resources suitable for the participants studying economics are available online. An example is the Resources for Economists on the Internet (http://rfe.org) and the teaching section offers some useful resources for economics students.

\section{English for Speakers of Other Language (ESOL)}

In this study, four participants were enrolled in ESOL programmes. ICT skill levels of two participants were found to be in the basic entry level while the other two were in the basic intermediate level. The use of ICT to support learning 
English has been widely researched and promoted (Miyazoe \& Anderson, 2009; Klimova, 2010; Mompean, 2010; Sun, 2010). For the purpose of the current study, the ICT proposed for the participants must be relevant to the participants learning context, easy to use, validated from previous studies, and free of charge.

The two participants enrolled in the English for Further Study (Level 3) programme requested more practise in English reading, listening and speaking skills. Reading ability and vocabulary were the two most important things in language learning (Hucking, Haynes, \& Coady, 1993). A strategy that was deployed involved listening to audio files while silent reading the accompanying text available at a website (http://eslnews.org.nz). After listening and silent reading the same article for a number of times, the participants read the text aloud while the audio was played. This step was also repeated a number of times before reading the text without the audio file being played. Repetition served as a mediation tool (Ganem-Gutierrez, 2009) and influenced by spaced repetition (Wozniak, 1990). The final step in this strategy involved recording the reading session and playing it back. This enabled the participant to check their reading accuracy. A study undertaken at The Open University UK investigated the use of ICT to support students in an intermediate French language course (Demouy \& Kukulska-Hulme, 2010). Students received DVD-ROMs which contained video clips for viewing, accompanying transcripts, ability to record themselves, playback their answers as well as to hear model answers.

The development of a similar resource as the one mentioned above for students at The Open University may be something to be pursued in the future. The resources would be developed with Pasifika students as the target users. Improving the participants' listening and speaking skills would be more effective if the researcher was able to provide materials relevant to what the participants were using in class. This would motivate the participants knowing that the extra effort in learning the materials was relevant to their classroom learning. Using the content covered in class to be delivered via ICT could be used for revision by the participants.

All participants in this study had access to a mobile phone and were proficient users of this ICT device. The mobile phone offered an opportunity to enhance the participants' English language learning. While the researcher did not introduce any mobile-based learning strategy for this particular group, the potential to use mobile phones to support the participants' vocabulary learning 
had been investigated in a number of international studies (Browne and Culligan, 2008; Che, Hsieh, \& Kinshuk, 2008; Lu, 2008; Stockwell, 2010). Stockwell (2007) reported that learners generally take more time to complete English vocabulary activities. Two studies explored the use of mobile phones for learning English vocabulary for Japanese university students (Browne and Culligan, 2008); and Taiwanese university students (Che, Hsieh, \& Kinshuk, 2008). Based on these international studies and the participants' access to mobile phones, the opportunity to explore this avenue ought to be considered in future studies.

Two ESOL participants revealed that they had to learn twenty new words in a week aimed at improving their vocabulary. Five words and the definitions could be sent to the participants in a day at two hour intervals (Thorton and Houser, 2005). In four days the two words would have been sent to the participants. In the first day, the first word and its definition would be sent out at 8:30am and the following four words and their definitions at 10:30am, 12:30pm, 2:30pm and 4:30pm. A review section comprising of five true or false questions would be used to assess the participants understanding of the five words and their definitions. The first question would be sent out at 6:30pm and if the correct answer was received a second question would be sent, and the next question would be sent if the correct answer was received.

Another area that requires further exploration was the transportable identities of second language learners. Richards (2006) offered three aspects of language learner identities within a learning environment. These included situated; discourse; and transportable identities. Situated identities referred to situations that are context specific such as the doctor/patient identities in the doctor's examination room or the teacher/student identities in the classroom context. Discourse identities referred to situations where participants orient themselves depending on the topic of discussion such an initiator, listener, and interviewer. Transportable identities referred to latent or implicit identities that are revealed during a conversation, such as the teacher referring to her other identity as a mother, or a social netball player. Using conversation analysis techniques, Richards (2006) found that students were motivated and were engaged when their transportable identities were stimulated. A much higher level of involvement, effort and investment from students were observed when their transportable identities were used. Transportable identities for learners may include sports club fans, pop-stars, and music instrument. 
Based on the ESOL participants' comments, the use of ICT by their tutors was very rare. The tutors used the white board, flip charts, photocopied handouts, and tape recorders to support their teaching methods. It can be seen that the participants' classroom activities did not use ICT due to various constraints that were not explored in this study. In this case, the power of ICT for improving the participants' language learning may be best realized and maximised outside the participants' classroom. However, this will only materialise if the participants accept the value of ICT and with improved ICT skills will greatly assist them in their learning experience.

Lastly the use of videos to enhance the learning experience of ESOL participants cannot be overlooked. Multiple modalities had been found to improve language learning (Sydorenko, 2010). Videos offer a combination of sounds, moving images, and sometimes text resulting in an exciting, motivating and powerful medium for learning English (Chen, 2011). In addition, the videos offer an authentic environment where the language is used and enables the learner to contextualise the learning process. For beginning learners who may find difficulty in comprehending the native English language speakers, the use of subtitled videos may assist them in their learning. The positive influence of subtitled videos and captions for language learners have been investigated in previous studies (Sydorenko, 2010; Winke, Gass, \& Sydorenko, 2010).

For the videos introduced to the ESOL participants, the choice of the video was based on its relevance to the learner. Given that not all videos on Youtube may have subtitles or captions, a strategy that involved participants to insert captions on a video of their choice could be explored. Two free applications (ELAN and ANVIL) that allow users to insert captions to videos could be used in this strategy. The Eudico Linguistic Annotator (ELAN) was developed for study of sign language videos and can be downloaded from http://www.latmpi.eu/tools/elan/download. On the other hand, ANVIL was developed for gesture research and is available from http://www.anvilsoftware.de/download/index.html\#.

\section{Exercise Science}

Exercise science is an interdisciplinary field combining concepts from the fields of biology, physics, mathematics, chemistry, psychology, and medicine (Karmen, 2001). It examines the effects of exercise and physical activity on people in order to optimize their physical and mental health. Exercise science is an offspring of 
physical education (PE) and the literature review had identified some studies on the use of ICT to support PE. The identified studies investigated the use of videos for demonstration (Liebermann et al., 2002; Cortes, Blount, Ringleb, \& Onate, 2011), video analysis software (Colasanet, 2011), blogging (Papastergiou, Gerodimos \& Antonio, 2011), and wikis (Hastie, Casey \& Tarter, 2010). Sorrentino (2000) found that modelling of progressive still photographs presented over a simulated internet site contributed significant improvements to students' front crawl technique.

PE teachers have been demonstrating skills themselves as part of their teaching method (Beashel \& Sibson, 2000) while some have tried using video tapes to support their teaching (Darden \& Shimom, 2000) or use a skilled student to demonstrate the skills. For example, the demonstration of swimming skills is vital in swimming instruction, however, the swimming pool may not be readily available. In this scenario the swimming demonstration tend to be abstract with the teacher attempting to demonstrate in the classroom, a skill that will be performed in the water. This scenario is identical to a situation faced by a participant in the current study. The participant acknowledged the value of the demonstration video he captured on his mobile phone. The video offered visual feedback enabling the participant to enhance skill acquisition (Liebermann et al., 2002; Cortes, Blount, Ringleb, \& Onate, 2011).

The two participants enrolled in the Certificate in Exercise Science programme revealed that they were doing well in their studies. The programme comprised of nine topics that included: nutrition, anatomy, exercise psychology and communication, fitness testing principles and practices, weights and resistance training, group training and instruction, anthropometry, small business skills, and industry work placement. While this study assisted the participants to improve their skills in the use of the software applications such MS Word and MS Excel, there were numerous other opportunities for using ICT to enhance their learning experience in the other topics.

Quennerstedt's (2011) study on practical epistemologies in PE practice may be adapted to meet the participants' course requirements. Quennerstedt's (2011) study involved searching for videos about ongoing physical education practices available on Youtube. The search identified 200 PE lessons from 12 different countries. The videos were categorised into a number of categories that enabled the students to learn the correct movements, observed others trying, learnt 
through imitations, motivated through the praising, and learning in a cooperative environment. For the participants enrolled in the Exercise Science programmes, videos relating to topics such as nutrition, anatomy, exercise physiology, fitness testing principles and practices, weights and resistance training, and anthropometry would be identified and to be used as supplementary learning resources.

Jones (2011) identified some lessons that could be learnt from the way skateboarders use videos to teach and learn skateboarding. A participant in this study had used his mobile phone to video capture a demonstration performed by his friend. Underground Skater (2008) revealed that skateboarding videos were far more effective for learning how to skateboard than printed materials. Moves and tricks were performed by the experts and captured on videos while the learners review the videos over and over again. Fundamental and advanced tricks can be broken up and analysed into more comprehensible sub-steps and sub-techniques. This could be the way for the participant to improve his exercise skills. Self-made videos enable the participant to analyse their past successes and also improve on their past mistakes (Jones, 2011). A high quality hand-held video camera can improve the quality of the recorded video resulting in higher quality learning resources.

\section{Construction Trades}

The two participants enrolled in the Construction Trades were found to have the least ICT skills amongst all the groups that participated in this study. The ICT that they used daily was the mobile phone. They had not used a computer and the internet and were initially very reluctant to learn how to use it. However, they were more receptive to learning when they saw an immediate benefit of using a computer and the internet. This offered an opportunity to explore in terms of identifying an area of interest for the participant that could improve their ICT skills.

ICT have impacted all businesses including the construction trades. Sommerville and Craig (2006) confirmed that construction companies generate, document, store, and share large volumes of information and ICT offer huge savings through efficient and effective processes for managing the information. Some benefits for construction companies using ICT included: improving client satisfaction; cost reduction; improving management; and achieving competitive advantage (Kareem \& Bakar, 2011). A survey of construction companies in a Brazilian city 
revealed that the use of ICT has permeated all functional areas of the participant companies (Michaloski \& Costa, 2010). These included: office automation; communications; information gathering and distribution, purchasing, and project management.

Gann \& Senker (1998) warned that failure to modernise the industry's recruitment and training may lead to skill shortages, soaring prices and substandard quality outputs. Skills shortages become evident during a construction boom caused by a thriving economy or a natural disaster. Under these conditions, labour costs escalate fuelling an inflationary spiral which eventually stifles the growth. The innovative use of ICT in the construction trades can help diffuse the skills shortages hence mediating the boom-bust cycle. Le Gallais (2001) confirmed that there was an urgent need within the British construction industry to use ICT in supporting construction skills development.

One of the participants in the Construction Trades programme indicated a challenge he faced in reading some of the class materials. Based on his easy access to a mobile phone, a strategy employed for the ESOL participants to improve their vocabulary it may be a realistic option to work on to improve his English reading. This is based on the assumption that higher vocabulary would result in improved reading and comprehension (Hirsh and Nation, 1992). The first thing to examine is the type of resources that the participant received from his class. From this, a list of the technical terms can be made and these could be the basis for the vocabulary to assist the participant or future participants enrolled in the same programme. The Virginia Adult Learning Resource Centre (2010) offers two relevant resources that focus on general construction and plumbing.

\section{Information Technology (IT)}

The two participants enrolled in IT programme revealed that programming and mathematics were challenging. Traditionally, mathematics, engineering, and computer science had been viewed as 'hard' subjects (Divjak, Ostroski, \& Hains, 2010). IT which is an offspring of computer science has inherited the 'hard' subject label as many students struggled in programming classes (Chalk et al., 2003; Bennedsen \& Caspersen, 2007; Hanks, et al., 2011). The most important requirement in the Computer Science, IT, and Software Engineering disciplines is programming fundamentals where students are taught programming skills and expected to do small-scale programming. In other words, programming is in the heart of these disciplines (Kinnunen \& Malmi, 2008). Programming fundamentals 
included: "fundamental programming constructs; algorithm and problem solving; fundamental data structures; recursion, and event-driven programming" (Muratet, Torguet, Jessel, \& Viallet, 2009, p.3).

Another challenge for these two participants was the sense of isolation while pursuing an IT qualification. The male participant voiced his eagerness to find other Pasifika students so he could "bounce things around". During the past ten years that the researcher had been employed at the tertiary institute, he noted that not more than five students would enrol in IT programmes at the institute. This low number is consistent with the national figures where twelve percent of the total Pasifika tertiary students were enrolled in IT programmes (Ministry of Education, 2010b). With the use of the internet, a community of learning for Pasifika students studying IT and Pasifika IT people could be formed to support the students in their studies. The Pasifika IT learning community would be informed by the situated learning theory (Lave \& Wenger, 1991).

Pasifika IT students will be the learners in this community of practice and the experts will be Pasifika people who have experience in the field of IT. The three dimensions of a community of practice include mutual involvement, joint enterprise, and share norms (Lave, 1998). Pasifika learners in IT programmes and the Pasifika IT experts will be invited to join the community of practice. The main objective of the learning community is to provide a forum for aspiring Pasifika IT learners to receive academic, social and moral support as they pursue studies in the field of IT. The expected code of conduct for participants and experts will be guided by Pasifika values such as "respect, reciprocity, communalism, collective responsibility, gerontocracy, humility, love, service, and spirituality" (Anae, Coxon, Mara, Wendt-Samu, \& Finau, 2001, p.14). The language of communication will mainly be in English and the use of Pacific languages will be encouraged.

Participants in the community of practice will meet through a blog where only members can participate. Wherever practical participants will be encouraged to meet in person but the online forum will be the main form of interaction. It is envisaged that over time the accumulated questions, answers and comments could be a useful resource for new members. 


\section{Hospitality}

Two participants enrolled in certificate level in Hospitality programmes. One was in food preparation and the second in patisserie. These two fields are subgroups of the cookery or foodservice sector which is part of the hospitality and tourism industry.

The two participants were satisfied with the strategies developed to support their learning. While the researcher identified training resources for MS Word and MS Excel, the participants did not seem enthusiastic about them. However, one of the participants requested for some assistance on the preparation of a menu. This offered an opportunity to work with the participants to improve their skills in the use of the desktop publishing software, MS Publisher. Based on this experience, the researcher felt that the participants will engage if there was an immediate relevance to the participants. In this case, the menu was a homework exercise hence the motivation for the participants to learn how to use the desktop publishing software.

In the foodservice sector, training is vital as it ensures that new employees understand the job and perform efficiently. While it is crucial, it has been found to be an expensive exercise if not managed properly (Singh, Kim, \& Feisntein, 2011). ICT can offer cost effective training resources provided the expertise is available for the businesses to develop their training resources. Multinational companies have developed ICT based training resources to reduce their training costs. For instance, Burger King offers its newly recruited trainees DVD-based training whereby the training involved the preparation of sandwiches on the Virtual Whopper Board (Matsumoto, 2000). The task requires trainees to learn how to make every possible variation on the burger, bun, lettuce, tomato, and condiment theme. In this manner, trainees improve their skills without the company wasting money on the raw materials.

Staff turnover had been a long standing issue in hospitality industry (Blomme, van Rheede, \& Tromp, 2010) and was found to be highest amongst younger employees (DiPietro, Thozhur, \& Milman, 2007). Reasons for dissatisfaction had been identified as pay and compensation, limited opportunities for promotion, recognition of good work, and opportunities for getting qualifications (Harbourne, 1995). Due to the high staff turnover, some organisations were reluctant to invest in training casual or part-time employees (Davies, Taylor, \& Savery, 2001). On the other hand, training is essential to ensure quality service and job satisfaction 
(Mohsin, 2007). A solution for this situation is to use ICT to support the training of potential employees (Shepherd, 2004).

Training videos can be made available through Youtube and prospective employees can be instructed to view the videos at their own time prior to attending a job interview. During the job interview, the employer could test if the prospective employee had learnt the basics from the training videos through a practical test. Other training requirements could be undertaken at the employee's time while the employer focuses only on assessing and correcting the employee.

The two participants in this study confirmed that the electronic-point-of-sale system (EPOS) was the only technology that they used daily at their work places. In this situation, a training video can be prepared for future trainees to prepare them offside before the hands-on fine tuning. The creation of the training video can be the responsibility of the participant who faces a similar requirement as described in the Exercise Science section. A high quality hand-held video camera will produce a better quality training resource than the one taken with a mobile phone. While the participants may not be involved in the back-office operations, EPOS device is part of the larger ICT system that supports a business. Data gathered through the EPOS enable cost analysis, labour scheduling and financial and inventor monitoring (Sigala, 2011). These skills will become valuable skills in the event that these participants consider venturing out into a small business in the future.

\section{Counselling \& Alcohol and Drugs (CADS)}

The sole participant enrolled in the CADS programme was a competent ICT user. Her ICT skills were at an acceptable level and she attributed this to demands put on her when she started her own business. She credited her brother and network of friends for helping her out whenever she needed help with using the ICTs she used in running her business. The main question she raised during this study related to internet search of resources for her assignments. Based on Thatcher's (2008) definition of the types of people performing an internet search, the participant can be classified as a novice. A novice searcher has little experience with internet search.

To enhance the participant's internet searching skills, two tactics were introduced which included keyword tactic and the search engine tactic. The keyword tactic required the user to employ keywords that are substitutes of the keywords used 
earlier. In her case, she was interested in "pacific mental health" and a keyword that was identified was "pasifika" instead of "pacific". The search engine tactic involved the use of a different search engine based on the premise that each search engine follows a different logic and programming styles.

While the participant's immediate concern was to complete her studies, the use of ICT in the counselling field is worth discussing. Email therapy employed the healing power of writing (King, Engi, \& Poulos, 1998) also known as writing therapy (Wright, 2002). Writing therapy taps into the power of reflective, focused writing which demands imagination and creativity. Using emails offered a number of advantages that included: a permanent record; typing offered an externalising mechanism; opportunity to view oneself in print; levelling power dynamics; and the shared experience of the present (Murphy \& Mitchell, 1998). The participant in this study was well versed in the use of email. Proper guidance in the use of emails for counselling patients may greatly impact on her employment opportunities after her studies.

According to Barnard (2010), online counselling is counselling available over the internet. It includes counselling provided via email, text messaging, voice and video links as well as chat rooms and message boards. Richards (2009) identified a number of internet-based psychological support strategies that included online counselling, online psycho-education, and online peer support for mental health patients. Potential benefits of internet based service include costeffective services, reduction of waiting list, maximising of professional's time, and relieving the burden of limited resources (Richards, 2009). Klein and Richards (2001) investigated internet-based individual therapy intervention for patients with panic disorder. They found positive effects of the intervention on reducing panic levels, negative affect, body vigilance, self-efficacy, and panic management.

The widespread use of mobile phone has already been utilised in health care support and slowly been explored in the mental health field (Preziosa, Grassi, Gaggioli, \& Riva, 2009). Text messaging was used for aftercare by German bulimic patients after being discharged from their treatment. For six months patients sent a weekly text message relating to their medical condition to the hospital officials and received corresponding feedback. Results confirmed that patients were satisfied with the aftercare treatment (Bauer, Percevic, Okon, Meermann, \& Kordy, 2003). A similar study was undertaken in UK where the intervention was received moderately by the low number of participants 
(Robinson et al., 2006). Two studies had confirmed the use of text messaging to support college students in the USA (Obermayer, Riley, Asif, \& Jean-Mary, 2004) and New Zealand (Rodgers et al, 2005) to quit smoking.

In the UK, a mandatory accreditation requirement for trainee counsellors at the Diploma level was a personal therapy session (Von Haenisch, 2011). This practice offered the opportunity to use a video camera to capture the therapy sessions for further review and analysis by the participants. Quinn, Hohensil, and Fortune (2002) found that the use of video recording and playback equipment was widespread amongst counsellor training programs within the USA. Participants' consent will need to be acquired and in return the participant will have access to resources that they may use in their practice afterwards. The demonstration of specific counselling concepts, and modelling of best practices can enhance the participants' professional practice (Baum \& Gray, 1992; Keats, 2008). Video demonstrations have been found to be helpful in visualising abstract theoretical discussions and facilitating the students' learning.

\section{Engineering Technology}

The sole female participant enrolled in Engineering Technology discontinued her participation in this study during the first phase of the ICT development framework. The ICT talanoa was the first phase which enabled the researcher to measure the participant's ICT skills. She was a competent computer and internet user. She perceived that studying engineering was hard but she did not offer any specific detail. The courses that she was studying for the diploma qualification included Engineering Fundamentals, Engineering Mathematics, Materials, Thermodynamics and Heat Transfer, Land Surveying, Structures, Civil and Structural Drawing, Geotechnical Engineering, Hydraulics, Highway Engineering, Engineering Management, and Engineering Project.

While this study was not able to explore the reasons for the participant's perception that engineering was hard, the following literature may provide some insight into the common challenges that engineering students face. Generally, students have found engineering mathematics as a difficult subject (Crowther, Thomson, \& Cullingford, 1997; Varsavsky, 2010). When students were asked what made mathematics hard to understand, the common answer was that mathematics was taught without any relevance to engineering. They also suggested that more tutorials were required, more attention to the basics instead 
of rushing to cover the syllabus, more hours per week spent on mathematics, and more teacher-student interaction (Crowther, Thomson, \& Cullingford, 1997).

Meyers, Silliman, Gede, and Ohland (2010) investigated the effect of peer mentoring programmes designed for first-year engineering students. The study found that first-year engineering students approached senior students about social life matters while they approached faculty for course related matters. The study also found that students preferred informal mentoring over formal mentoring administered and assigned by the faculty. The students revealed that the informal mentoring developed naturally out of mutual interest and rapport. This is definitely a point to keep in mind when considering the use of peer mentoring for future engineering students.

Similar to the challenges faced by the two participants enrolled in IT, the participant in Engineering Technology may benefit from the formation of a learning community. During the time of the study the participant was the only Pasifika student enrolled in the programme. While she did not voice any concerns about being the only Pasifika student in her class, it can be assumed that she may have felt isolated at times. In view of the possibility of feeling isolated, a community of practice is proposed to support her and future Pasifika students enrolled in the Engineering programmes. Clark, Dodd, and Coll (2008) promoted the value of learning communities in higher education science and engineering. In a study to assess student outcomes in learning communities at an American university, Waldron and Yungbluth (2007) found that disciplinespecific learning communities produced the highest results in improving students' academic learning outcomes.

\section{Pasifika Students' ICT Skills Development Framework}

The primary objective of the Pasifika Students' ICT Skills Development Framework is to improve the ICT skills of Pasifika students which will enhance their learning experience thus improving academic achievements. ICT are ubiquitous in our daily lives including the tertiary education sector. Higher ICT skills will enable Pasifika students to become lifelong learners and capable of using ICT to enhance their learning experience at the tertiary level. From this study it had been found that participants faced numerous challenges in all aspects of their learning journey. A major hurdle for participants was the mastery of the English language, in particular, reading learning materials supplied in 
class. Using ICT, Pasifika students can improve their English skills which will impact positively on their overall educational outcomes.

The Pasifika students' ICT skills development framework is based on the SDLC model which aims to develop a high quality system, establish strong management controls over the development process, and maximise the productivity of the development team. The systematic developmental approach will offer a framework to ensure that all Pasifika tertiary students benefit from the use of the various learning resources available through the internet. Furthermore, the same framework can be used to develop ICT based resources tailor made for Pasifika learners.

\section{Talanoa as a research method}

The value of talanoa in this study cannot be underestimated. Talanoa enabled the participants and the researcher to initially meet and establish relationships. Throughout the study, talanoa enabled data gathering, information sharing and verification, and the implementation of the Pasifika ICT Skills Development Framework. The decision to use talanoa was successful in seeking the engagement of Pasifika tertiary students in a culturally safe environment to enhance their ICT skills. Earlier studies by Dickie (2001), Petelo (2003), and Davidson-Toumoua (2005) had documented the need to offer a culturally safe environment for Pasifika students to prosper academically. In this case, talanoa offered the conditions that enabled participants to articulate their true feelings and experiences in their respective programmes of study.

In this study, talanoa can be described as a type of unstructured interview. For the purpose of this thesis, talanoa refers to a conversation with a purpose that demands a lot of flexibility. Planning is essential for a successful outcome from the researcher's view point. The researcher may simply jot down a list of topics and a couple of questions to start the talanoa. It is the researcher's responsibility to inform prospective participants of the purpose of the talanoa. It must also be conducted in a natural conversational manner. Audio recording of talanoa and any note taking must be negotiated with the participant. It is advisable to take notes immediately after talanoa to record important points as soon as possible (Cohen, Manion \& Morrison, 2007) and also to maintain the natural flow of the talanoa. 
A main advantage of talanoa is its empowering nature. Participants in this study were empowered when they were invited to participate in the talanoa and throughout this study. Participants were able to be themselves and to freely express their views without fear of being judged. Even if the answer to a question or question to be asked was totally irrelevant, the participants were able to freely share their thoughts. Unlike their classroom experiences, in which participants conveyed a sense of fear of being judged and so they kept quiet or simply agreeing with others as opposed to sharing their views.

Using talanoa in this study empowers all Pasifika peoples: the participants, the researcher, and the Pasifika peoples. In the past, Pasifika peoples have voiced concerns about researchers undertaking research involving Pasifika peoples to satisfy their academic goals (Vaioleti, 2006). Researchers gathered data and disappeared. Pasifika peoples presume that researchers become experts in their fields by exploiting Pasifika peoples' knowledge. Through talanoa life-long relationships were formed. In this study, the researcher was introduced to some participants' families and friends who had issues with their home computers. This was based on the participants' view that the researcher is a "computer man", that is someone who can fix computers.

The researcher's epistemology and the study's objectives were also contributing factors for choosing talanoa as opposed to a semi-structured interview or a focus group. Informed by the interpretive paradigm, the researcher's values were prominent throughout the study. The researcher and participants were engaged in an interactive process (Merten, 1998). Values shared by the researcher and the participants included respect, love, humility, reciprocity, collective responsibility, to name a few. Due to this congruence, the emotional and spiritual states of the participants were satisfied and the participants perceived that the learning experience was enjoyable and meaningful. This contrasted with their learning experiences in the lectures in which the participants perceived that learning in that setting was hard. The mismatching epistemologies of the nonPasifika lecturer and the Pasifika learners resulted in tensions which the students could not manage. The participants' inability to manage this tension may have led the participants to avoid classes resulting in an unsuccessful academic outcome.

Implicit to talanoa is the relaxed atmosphere that permeates the shared space and time. Laughter is acceptable or normal and so participants use it to identify with other participants, ease tension, and even as an avoidance mechanism 
(Murata, 2009). Two participants relayed how they were "told-off" by their lecturer for giggling in class. This made them feel "stressed-out" and they could not wait to get out of the class. According to the participants, whenever they attended that class it sometimes became a stressful event. Whenever the lecturer looked in their general direction, they quickly looked away to avoid another "telling-off". This type of environment lends itself to a culturally unsafe environment for Pasifika students to foster their learning.

Talanoa enables Pasifika peoples to explore their worldviews without any reservation. In other words, talanoa upholds Pasifika peoples' way of knowing and is guided by Pasifika values and protocol. Through these familiar processes, participants feel at ease and are not psychologically burdened to participate. Participants have used expressions such as "it's hard to understand computer terms" in the context of their classroom learning experience. Through talanoa the same computer terms were demystified and participants felt enlightened to discover that it was not that hard after all.

The implications of this experience can be contributed to the congruence between the knowledge making assumptions of the participants and the delivery methods. In the participants' classroom, the materials to be learnt were delivered through a lecture where the participants were passive learners. The assumption by the lecturer was that students should have read the relevant chapters from the prescribed text book and the lecture was aimed at reinforcing the readings. Both these activities, reading and listening, were perceived by the participants as individualistic in nature and participants revealed difficulty in reading and comprehending the text book.

Utilising talanoa in this study validates Pasifika values such as "respect, reciprocity, communalism, collective responsibility, gerontocracy, humility, love, service, and spirituality" (Anae, Coxon, Mara, Wendt-Samu \& Finau, 2001, p.14). Respect for each other between the participants and the researcher is paramount. Reciprocity is practiced in terms of views, ideas, and experiences. In this study, while the participants had contributed to the researcher's study, the researcher has reciprocated in terms of sharing his "computer man" knowledge and expertise to enhance the participants' learning experience. Through talanoa the participants' learning journey was better supported communally and as a collective responsibility. This is in contrast to the participants' lecturer expectation that learning is an individual pursuit. 


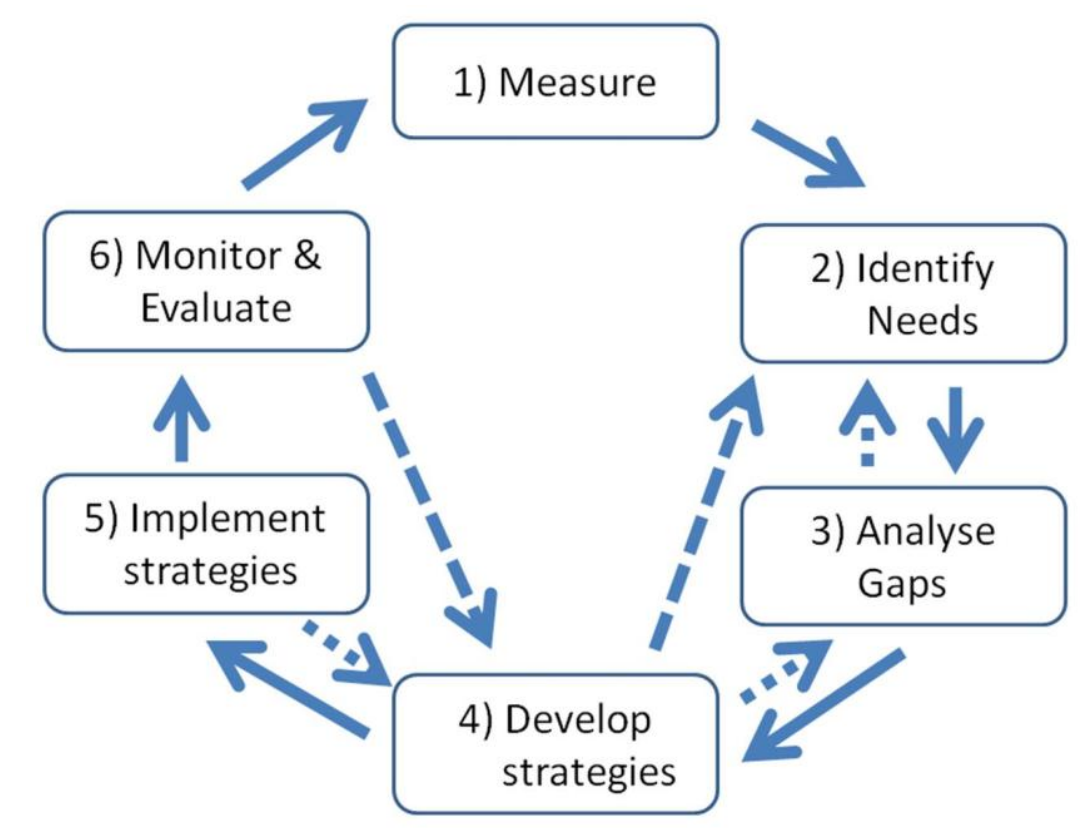

Figure 26: Pasifika Students' ICT Skills Development Framework

\section{Phase 1 - Measure}

Determining the participants' current ICT levels was a crucial step in the PS-ICTSDF. It enabled the researcher to better understand the participants' current ICT skill levels. In this study the National Certificate in Computing (Level 2) on the NZQA framework, operational internet and mobile phones skills were used as the benchmark. The benchmark may be changed to suit the type of participants. For instance, if participants were high school students then a lower level benchmark may be used. The need to measure the participants' current ICT skill levels is crucial given that some international studies confirm that many students have lower ICT skill levels than they claim (Cretchley, 2007; Katz, 2007; Verhoeven, Heerwegh, \& De Wit, 2011). Students tend to perceive they have higher or lower ICT skills then they actually have and so measuring their current skill level offers a clearer picture.

\section{Phase 2 - Identify Needs}

Identifying the learning needs of the participants is the second phase of the PSICT-SDF. Through ICT talanoa, participants are invited to share their learning experience and from this talanoa sessions, the participants perceived learning needs that can be assisted through ICT is identified by the researcher. At the moment, Pasifika tertiary students' educational outcomes require a boost. In this study, ICT is used to deliver the information to be learnt presented in multiple 
media which enhances the information to be learnt through the visual and auditory senses (Lin \& Atkinson, 2011).

\section{Phase 3 - Analyse Gaps}

Analysing the perceived learning gaps is determined by matching the participants measured ICT skills and their study needs. During the study, it was found that in some cases there was a need to revisit Phase 2 to re-evaluate the participants learning needs. This is shown in Figure 26 with a dotted line with an arrow pointing from Phase 3 to Phase 2. This implies that if the need arises then the previous phase can be revisited.

\section{Phase 4-Develop Strategies}

Developing the strategies that will enhance the participants' learning experience demands the fulfilling of participants' immediate needs. Evident from this study is the need to have immediate relevance in using ICT to the Pasifika learners. In the case of the participants' enrolled in the Business Studies diploma, their motivation to improve their ICT skills were influenced by the compulsory Business Computing course. Similarly, the participant enrolled in the Certificate in Patisserie was eager to learn how to use the desktop publishing software in order to complete a home work requirement. Therefore, it is crucial to allow the participants to reveal an area of interest or for the researcher to identify an aspect of the participants' learning requirement to use ICT. For the less enthusiastic participants, it may help identifying their hobbies or issues that they are passionate about.

During the study, it was found that while developing strategies the need to constantly consult with the participant regarding their learning needs is vital. It needs to meet the current learning needs of the participants to ensure that the participant finds the strategy relevant. This is reflected in Figure 26 with a dotted line beginning at Phase 4 and ending at Phase 2. Another dotted line also begins from Phase 4 and ends at Phase 3 . This is to ensure that the developed strategy is relevant to the participant for it to be utilised.

\section{Phase 5 - Implement Strategies}

Implementing the strategies developed to enhance the learning experience of the participants can be the shortest in terms of time spent on all the phases. If the developed strategy does not meet the participants then the strategy is put aside 
and the needs analyses starts once again. This requires the researcher to be innovative in terms of the use of ICT to match the participants learning needs.

\section{Phase 6 - Monitor and Evaluate}

Monitoring and evaluating the developed strategies follows on from a successful strategy. In the event that the participants find the strategy engaging and relevant, the researcher needs to determine if more of the same is required or a higher level is required. For example, the participants enrolled in the Exercise Science programmes indicated that while they found the Youtube videos on respiratory system useful they were unsure how to locate other relevant videos. This offered the opportunity to demonstrate to them the skill of searching within the Youtube website. So while they have had been shown how to search for relevant videos by using keywords, they will still need to practice on their own to improve their searching skills. The benefit of this searching skill is that it can be used on the common search engines such as Google, Bing and Yahoo. 


\section{Summary}

This chapter included a discussion on the study's finding presented in the previous chapter six. The discussion began with the significance of talanoa in this study. This was followed by the discussion of some of the perceived barriers to Pasifika tertiary students acquiring ICT skills. Seven barriers that were identified from this study included: a lack of interest in ICT; limited ICT access; lack of awareness of ICT potentialities; lack of foundation skills for using the computer; fear of the computer; the mature participants reluctance to use the computer; and the past work experiences of participants. The second thread of discussion in this chapter considered some factors that supported Pasifika students in acquiring ICT skills. Four factors that influenced the participants ICT skills included: prior learning experience for younger participants (between 18 and 24 years old); prior work experience for mature students (24 years and older); peers and family members; and self-efficacy. The third thread of discussion in this chapter presented some ICT skills that would enhance Pasifika students' learning experience. This discussion was based on the participants' programme of study. 


\section{CHAPTER 8}

\section{CONCLUSION}

\section{Introduction}

This final chapter will present a summary of each of the preceeding seven chapters of this thesis. This is followed by a summary of findings from the study. Lastly, the implications of this study for practice, institutional policy, and for further research are outlined.

The study aimed to increase the ICT skills of Pasifika tertiary students to counterbalance the rapidly increasing use of ICT by the tertiary institutions. An assumption held by tertiary institutions is that all students embarking on tertiary studies have some basic ICT skills. Students who lack basic ICT skills were required to learn the skills during their spare time. While this study proposes an ICT skills development framework for Pasifika students it can also be utilised for other learners.

The current state of affairs in relation to Pasifika students, tertiary education and ICT is depicted in Figure 1. It depicted a smaller portion of the overlapping spheres of Pasifika students, tertiary education and ICT. Utilising the Pasifika students ICT skills development framework (Figure 26) developed for this study will pave the way for an increased portion of the overlapping spheres as shown in Figure 27. As tertiary institutions increase their ICT adoption for delivering education along with the projected growth of Pasifika students' participation, the Pasifika students' ICT skills development framework aims to increase their ICT skills to better handle the ICT-based demands of tertiary education. A benefit of this approach is the likelihood of more Pasifika peoples employed in ICT related fields. 


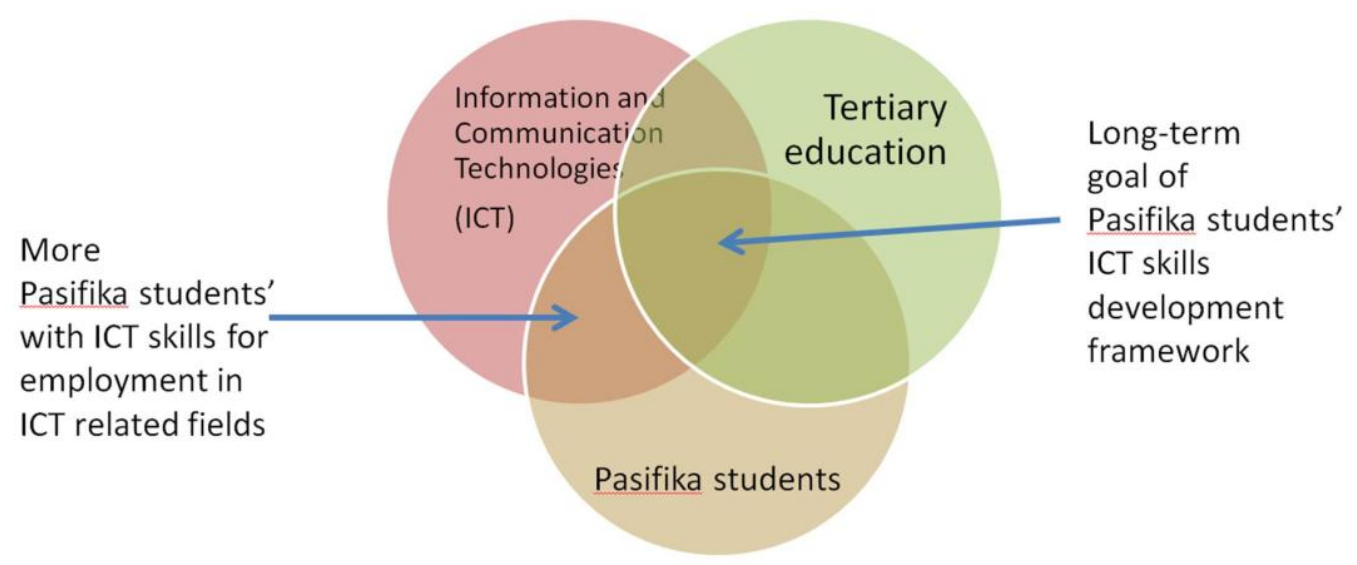

Figure 27: Increased ICT skill levels of Pasifika learners

Chapter two covered the background and the rationale for this study. This study involved Pasifika tertiary students and it was deemed necessary to offer a historical background of Pasifika peoples and their participation in tertiary education. Associated with their tertiary participation was the academic underachievement. Amongst other things, the researcher holds the view that a contributing factor to the academic underachievement was the low literacy and numeracy skills of Pasifika students. This lack of basic skills further influenced Pasifika peoples' employment opportunities.

The literature review was presented in chapters three and four. Chapter three explored the use of ICT in the New Zealand tertiary education sector and the experiences of mainstream students who had been exposed to ICT-assisted learning. Further investigation of the Pasifika students' tertiary use of ICT is necessary as there is a dearth of available literature. The systems development life cycle was adapted to provide a framework for the uplifting of participants ICT skills. ICT skills are vital for the economic growth and necessary for employability. Situated learning theory was used to enable participants to acquire ICT skills through social interactions and informal learning. Using situated learning theory was based on the researcher's view that it was congruent with Pasifika students' learning styles.

Chapter four is part two of the literature review. It explored ICT-supported learning experiences of students at various international tertiary institutions. Included in this chapter were international studies focusing on ICT-supported learning in a number of disciplines. The disciplines were relevant to the participants in this study and included accounting, business marketing, economics, English language (ESOL), physical education (PE), construction 
trades, IT, hospitality, counselling, and engineering. The innovative use of ICT to support international students' learning experiences as presented in this chapter offer many positive opportunities for Pasifika learners.

The research methodology was outlined in chapter five. The theoretical lens through which the study was designed and conducted was described. The study was informed by the interpretivist paradigm. Case study was deemed as the appropriate research methodology for this study while data was gathered through talanoa, participant observation, and researcher's reflective journal. Data analysis relied on the theoretical propositions that led to this study (Yin, 2009) and guided by the analytic manipulations described by Miles and Huberman (1994). The theoretical assertions made prior to this study included Pasifika students' ICT skill levels were not at the level assumed by tertiary institutions; and the uplifting of Pasifika students' ICT skills was best developed socially.

Chapter six discussed the findings of this study. The discussion evolved around the Pasifika students' ICT skills development framework (Figure 10). The framework comprised of six phases namely: measure; identify needs; analyse gaps; develop strategies; and monitor and evaluate strategies. The first phase measured the participants' current ICT skills. Based on three ICT skill levels, the study found that four participants had basic ICT skills, 16 had intermediate ICT skills while eight had ICT skills suitable for their programme of study. Basic level included the ability to use the basic functions of a computer, mobile phone, or the internet. Intermediate level included: the ability to identify some common computer hardware peripherals; use some of the basic functions of generic software applications such as MS Word, Excel, and PowerPoint; use a mobile phone for communication; and use the internet. The third ICT skills level participants were capable of meeting the ICT demands of their studies.

Chapter seven offered a discussion based on the study's research questions. The first sub-question "What are some of the factors that hinder Pasifika students' use of ICT to enhance their learning experiences?" The study identified seven perceived barriers that hindered participants' use of ICT. These included: a lack of interest in ICT; limited ICT access; lack of awareness of ICT potentialities; lack of foundation skills; fear of ICT; reluctance of mature students (30 years and above) to use the computer; and the participants' previous work experience. The second sub-question "What are some factors that support Pasifika students' to acquire ICT skills?" The study found four factors that 
supported the participants in acquiring ICT skills. These included: prior learning experience for the younger participants (less than 25 years old); prior work experience for the participants above 25 years old; peers and family members; and self-efficacy.

The third sub-question "How do Pasifika students use ICT to enhance their learning experience?" While more than half of the participants (16) had intermediate ICT skills, their use of the computer and the internet needed further improvement to ensure that they meet course assessments. Only four participants reported using their mobile phone to assist their learning while nearly half (13) used the internet mainly for entertainment. Without the additional support, most of the participants will struggle to meet their course assignments and other assessments.

\section{Summary of findings}

Twenty-eight participants were involved in this study comprising 15 females and 13 males. Based on the TEC's reporting on age distribution ranges, the participants' age distribution was: four were under the age of 20, 12 were in the 20-24 age group, nine were in the 25-39 age group, and three were in the 40 years and above age group. In this study, more than half the participants (16) were in the under 25 which is classified as younger participants by the Ministry of Education (2010a) which confirms the trend that more younger Pasifika students are pursuing tertiary studies. In terms of the participants' ethnicities: eighteen identified as Samoans, four Fijians, three Tongans, and one each from the Cook Islands, Kiribati, and Papua New Guinea.

Nearly half of the participants (13) were enrolled in Business Studies programmes. This high number of participants in Business Studies is consistent with the national trend of Pasifika tertiary students' high participation in office studies and business and management programmes (Wensvoort, 2011). Four participants were enrolled in ESOL programmes, three participants were in the Exercise Science programmes, two participants were enrolled in each of the following courses: Construction trades, IT, and Hospitality. A participant was enrolled in the Counselling programme and another in the Engineering. Only two participants were pursuing degree qualifications. Eleven were pursuing diploma qualifications while most (15) were completing certificate qualifications. The high number of participants (26) enrolled in lower qualifications (certificate and 
diplomas) was consistent with the national trend of high number of Pasifika tertiary students enrolled in the lower qualifications (Wensvoort, 2011).

The Pasifika students' ICT skills development framework (Figure 10) was utilised to enhance the learning experience of participants through the use of ICT. The framework was adapted from the systems development life cycle, a framework that is used to guide the software development process. The Pasifika students' ICT skills development framework comprised of six phases that includes: measure, identify needs, analyse gaps, develop strategies, implement strategies, and monitor and evaluate strategies.

The first phase of the Pasifika students' ICT skills development framework used the New Zealand's National Certificate in Computing (Level 2) as the benchmark for the participants' ICT skills level. Additional measures for the participants' operational skills in the use of mobile phones and the internet were also included. Three ICT skill levels were determined: basic, intermediate, and suitable for their programme of study. Basic level included the ability to use the basic functions of a computer, mobile phone, or the internet. Intermediate level included: the ability to identify some common computer hardware peripherals; use some of the basic functions of generic software applications such as MS Word, Excel, and PowerPoint; use a mobile phone for communication; and use the internet. The third level, suitable for participants' programme of study included all the skills in levels one and two, and the ability to work on their own. In other words, participants in this level can manage the ICT demands of their studies. In this study, four participants were identified to have basic ICT levels, sixteen participants were in the intermediate level while eight had ICT skills suitable for their chosen programme of study.

The second phase of the Pasifika students' ICT skills development framework was the identification of the participants' learning needs. These were gathered through talanoa. The needs were identified by the participants based on how they perceived their ability to meet course assessments. The needs were presented according to the participants' programme of study which included Business Studies, ESOL, Exercise Science, Construction trades, Hospitality, Counselling, IT, and Engineering.

The third phase of the Pasifika students' ICT skills development phase was the analysis of perceived gaps between the participants ICT skills measure in phase 
one against the learning needs identified in phase two. Seven participants in the Diploma in Business Studies qualification sought assistance for a compulsory course named Business Computing. Four participants in the National Certificate of Business Administration were keen to learn more about the accounting software, MYOB. Four participants in the ESOL programmes were interested in improving their English reading, writing and oral skills. The participants enrolled in the Exercise Science, Construction trades, and Hospitality were convinced that ICT skills were not required in their current learning experience and were not required in their respective work environments. The participants in IT sought assistance in mathematics and programming while the sole participant in the counselling was interested in internet searching.

The fourth phase involved the development of the ICT-based strategies to assist the participants with their learning. Due to the time constraints, the strategies developed for this study had been mainly focussed on the use of resources that are readily available through the internet. All participants were involved in the first strategy named ICT talanoa. The aim of this strategy was to focus the purpose of talanoa on the ICT used in the participants' programme of study. In addition, this enabled the participants to articulate their experiences in the classrooms. It had been found that participants needed a forum where they could articulate their classroom experiences.

Strategies for the participants completing the Business Computing course included experiential learning, and the use of digital visual aids to assist participants to recall the learnt materials. The participants enrolled in the certificate in business administration were introduced to a few MYOB video tutorials. The participants enrolled in ESOL programmes were introduced to a New Zealand based ESL where they could access reading articles with accompanying audio files prepared by the authors of the website. The participants in the Exercise Science, Construction trade, and Hospitality all benefited from internet-based resources. The participants enrolled in IT and counselling programmes were introduced to strategies to improve their internet searching skills.

The fifth phase was the implementation of the strategies. Participants completing the Business Computing course were able to enhance their understanding of the personal computer through first-hand experience of the hardware components inside the system unit. The theory requirements of their course included 
computer components such as the CPU, memory, motherboard, hard drive, and the CD-ROM drive. Participants were introduced to the components inside the system unit and were encouraged to remove and later replace the internal components from their respective locations. In addition to the ESL website, participants enrolled in the ESOL programmes were shown how to download the audio files to their portable MP3 players so that they could use the resources while away from the computer. The accompanying text was printed so they could listen and also read the printed text.

The Exercise Science participants were introduced to some complementary resources available on the internet which included detailed and labelled images for the respiratory system, and Youtube videos on the same topic.

The sixth and final phase was the monitoring and evaluation of the strategies. All participants were excited and in some cases impressed with the strategies. Time was a constant challenge in developing and implementing strategies. In two cases, the developed strategies were found to be irrelevant to the participants' perceived learning needs. In one case, the researcher had made an incorrect assumption due to the lack of information from the participant. When the strategy was implemented, the participant was interested in something else. This affected the intended course of events for that particular meeting.

\section{Implications for practice}

The Pasifika students' ICT development framework can be used to further develop strategies and software applications that are tailor-made for Pasifika learners. This study found that majority of the participants required support in the mastery of English language for tertiary studies. In particular, reading literature and writing for academic purposes. For the mature students who still speak their Pasifika languages, the use of the Pasifika languages offer an alternative support medium for their learning. In this case the use of ICT-based resources with dual language support can be developed to enhance their learning experience. As part of his teaching practice, the researcher had explored the use of computer hardware videos delivered in a non-English language for a few students and this proved to be a valuable resource for the students involved. For example, for Pasifika students learning introductory personal computer hardware can be assisted with a video delivered in a Pasifika language enabling the learner to better understand the purpose of each component or peripheral. This video serves as a supplement to the student's learning experience in the classroom. 
Current Pasifika students can be engaged to develop learning resources for future Pasifika students. Utilising the Pasifika students' ICT development framework will progress the researcher's aspiration for Pasifika peoples to become "the realist [that] adjusts the sails" (Ward, cited in Borysenko, 2009, p.25). It is recommended that this will be an on-going iterative process. Current students would use their acquired knowledge and experience to develop an improved and up-to-date version of the learning resource for the benefit of future students. Over time more ICT-based learning resources will become available for Pasifika tertiary learners. Many Pasifika learners struggle to comprehend learning materials due to a notion of "seeing things for the first time". With the supplementary resources and delivered in Pasifika language, it is hoped that "seeing things for the first time" will become a non-issue.

The use of Web 2.0 tools such as blogs and wikis offer an avenue where Pasifika peoples can participate in this knowledge society. A widely held concern amongst Pasifika peoples is the loss of Pasifika languages and the need to maintain these indigenous languages in a foreign country. The use of blogs and wikis to maintain Pasifika languages has not been explored but the researcher holds the view that these tools offer tremendous opportunities for language maintenance. Both tools are freely available for use but not many Pasifika people are familiar with these tools. The use of blogs to promote community organisations has not been widely utilised. In addition, short language videos can be shared on the Youtube website.

\section{Implications for institutional policy}

Based on this study's findings, tertiary institutions must recognise that not all tertiary students have the ICT skills required to fully utilise the institute's ICT resources. For Pasifika learners in this study, their past experiences prior to tertiary studies influenced their ICT skills. For younger learners (under 24 years of age), there is a high possibility that they have acquired computer skills from high school. Pasifika students who have undertaken computer associated subjects at school will have higher computer skills than those who have learnt computer skills informally. The latter group will most likely be familiar with the entertainment use of the computer as opposed to the educational use of the computer. 
Many Australian universities operate from an assumption that students entering universities were increasingly more computer literate with each passing year (Lim, 2004). While no study was found to confirm that New Zealand tertiary institutions operated from the same assumption, anecdotal evidence suggest that the New Zealand tertiary students were expected to use the ICT available at the institution or to learn how to use it along the way. Tertiary institutions must not assume that all learners have basic ICT skills while those lacking these skills were required to learn them in their own spare time.

To facilitate the learners' varying ICT skill levels, the institutuons must have policies in place to first identify this group of learners and processes in place to ensure that their learning needs are accommodated. For example, a standardised measuring tool for identifying the ICT skill levels of all learners at the earliest point upon enrolling at the institution is essential. This will ensure that the institution recognises the varying ICT skill levels of its learners and therefore refrain from assuming students' ability to use ICT when in fact students lack basic skills to properly utilise ICT. During the course of this study, the researcher had encountered Pasifika postgraduate students at a university who were unfamiliar with the institute's learning management system (Blackboard). Students were unable to access learning resources that were to be accessed and read prior to the organised classes. The students' inability to access the resources caused frustration and anguish for the students involved. This may contribute to the students' non-participation in class which ultimately lead to unsuccessful academic outcomes.

At the institute where this study was undertaken, a student support policy focussed on improving literacy and numeracy skills. Meanwhile, policies for improving ICT skills did not exist. Interestingly, ICT was used in the delivery of the literacy and numeracy assessment tool. This approach confirmed the assumption that learners can use the ICT which includes a computer connected to the internet. A number of Pasifika learners, not participants in this study, who were expected to use this assessment tool, were unfamiliar with the use of a computer, especially locating keys and using the keyboard. They revealed their dissatisfaction with the medium used for the assessment to their tutor who agreed with them but could not offer an alternative form of assessing the students' numeracy and literacy skills. The tutor replied that the online assessment tool was the only available option. 
With this situation in mind, institutional policy needs to address the learning needs of Pasifika learners who not only require support for improving their literacy and numeracy skills but have the additional challenge of using ICT. While the institution has saved money through its investment in the online assessment tool, it has disadvantaged the learners who do not posess the ICT skills required to fully utilise it.

\section{Implications for further research}

This study offered some insights into the potential that ICT can offer to support Pasifika students who are academically underachieving. Further investigation is necessary on the use of ICT to support the learning of Pasifika students in key areas such as English and mathematics. Given the varying academic backgrounds and levels of Pasifika students', ICT when set up correctly is capable of delivering personalised learning assistance but in order for this to be useful a clearer understanding of the students' current abilities is required.

In addition, the need to closely work with tutors involved in the delivery of courses is vital for Pasifika students' acceptance of the developed strategies. In this study, the researcher depended solely on the information delivered by the participants. A complete picture can be obtained from the subject tutors and strategies that are more relevant can be developed and implemented.

The use of ICT to facilitate Pasifika learning communities is another area requiring further investigation. Based on Pasifika peoples enthusiasm to pursue further studies (Anae, Anderson, Benseman, \& Coxon, 2002; Wensvoort, 2011) and the lack of cultural support for those in smaller tertiary institutions, an exploratory study to determine the viability of online learning communities to support Pasifika learners is necessary. Evident in this study was the sole female participant enrolled in the engineering programme. The support of Pasifika people qualified and experienced in the engineering field may be able to support the participant during her studies. 


\section{Summary}

In this final chapter, the contents of the thesis are summarised. An aim of this study was to uplift the ICT skills of Pasifika tertiary students. This was based on the premise that improving ICT skill levels of Pasifika tertiary students will enhance the students' learning experience resulting in improved learning outcomes. Currently, tertiary institutions are increasing their use of ICT for delivering education while Pasifika participation continues to increase. A concern for the researcher was the likelihood of the further disadvantaging of Pasifika students who may lack the required ICT skills to successfully complete tertiary education.

Chapter two discussed the study's background and rationale. Due to the focus of Pasifika students in the study, it was deemed necessary to offer a historical background and participation in tertiary education. Associated with their participation in tertiary education was their record of underachievement. A root cause of this underachievement was the lack of basic skills that included literacy and numeracy.

The literature review was presented in chapters three and four. Chapter three explored the experiences of tertiary students' ICT-supported learning in New Zealand tertiary institutions. The scarcity of New Zealand-based studies on courses relevant to this study's participants led to the exploration of international literature. Chapter four presented the experiences of international tertiary students using ICT-supported learning resources. Subjects relevant to the participants' programmes of study included: accounting, business marketing, economics, ESOL, physical education, construction trades, IT hospitality, counselling, and engineering. The innovative use of ICT to support students in international tertiary institutions offered many positive opportunities for Pasifika learners.

The research orientation of this study was outlined in chapter five. The study was informed by the interpretivist paradigm which employed a case study methodology. Three data gathering methods were utilised to facilitate triangulation. The methods included talanoa, participant observation, and the researcher's reflective journal. Data analysis was based on the theoretical propositions that led to this study (Yin, 2009) and guided by the analytic manipulations described by Miles and Huberman (1994). These manipulations included: the arranging of information into different arrays; use of a matrix of 
categories and inserting of evidence within each category; creation of data displays for examining the data; noting frequency of different events; examining of the data for themes; and the arranging information in chronological order.

Chapter six discussed the findings of this study. The discussion evolved around the Pasifika students' ICT skills development framework (Figure 10). The framework comprised of six phases namely: measure; identify needs; analyse gaps; develop strategies; and monitor and evaluate strategies. The first phase measured the participants' current ICT skills. Based on three ICT skill levels, the study found that four participants had basic ICT skills, 16 had intermediate ICT skills while eight had ICT skills suitable for their programme of study. Younger participants (less than 25 years old) were found to have slightly higher ICT skills than the mature participants (25 years and over). The participants' ICT skill levels and their ethnicities were not measure and therefor no comment can be offered relating to their association.

A discussion on the study's findings was presented in chapter seven. The discussion focused on the research questions. The first sub-question "What are some of the factors that hinder Pasifika students' use of ICT to enhance their learning experiences?" The study found seven perceived barriers that hindered participants' use of ICT. These included: a lack of interest in ICT; limited ICT access; lack of awareness of ICT potentialities; lack of foundation skills; fear of ICT; reluctance of mature students (30 years and above) to use the computer; and the participants' previous work experience. The second sub-question "What are some factors that support Pasifika students' to acquire ICT skills?" The study found four factors that supported the participants in acquiring ICT skills. These included: prior learning experience for the younger participants (less than 25 years old); prior work experience for the participants above 25 years old; peers and family members; and self-efficacy.

The third sub-question "How do Pasifika students use ICT to enhance their learning experience?" While more than half of the participants (16) had intermediate ICT skills, their use of the computer and the internet needed further improvement to ensure that they meet course assessments. Without the additional support, most of the participants will struggle to meet their course assignments and other assessments. 
The main research question "How might Pasifika students at a New Zealand institute of technology use ICT to enhance their learning experience?" The study investigated a number of internet based resources to support the participants' learning experiences. The participants confirmed that the resources assisted their comprehension of the materials to be learnt. In other words, the identified ICT-based learning resources offered further reinforcement of the learning materials received in class.

As a final comment, the researcher is hopeful that this study will influence more Pasifika students to improve their ICT skills and to become the "realist [that] adjusts the sails" (Ward, cited in Borysenko, 2009, p.25). Utilising the Pasifika students' ICT skills development framework or variations of it will offer a roadmap for the uplifting of their ICT skills. ICT are the tools of the $21^{\text {st }}$ century therefore more Pasifika people with advanced ICT skills will enable them to stand in good stead in this ICT driven world. 


\section{REFERENCES}

AARP (2008). Investing in training 50+ workers: A talent management strategy. Washington DC: AARP Knowledge Management Department.

Adler, P.A. \& Alder, P. (2008). Observational techniques. In N.K. Denzin and Y.S. Lincoln (Eds) Collecting and Interpreting Qualitatitive Materials. (3 ${ }^{\text {rd }}$ Ed). London: Sage Publication.

Adler, S.M. (2011). Teacher epistemology and collective narratives: Interrogating teaching and diversity. Teaching and Teacher Education, 27(3), 609618.

Adya, M. \& Kaiser, K.M. (2005). Early determinants of women in the IT workforce: A model of girl's career choices. Information Technology \& People, 18(3), 230-259.

Agarwal, R., \& Day, A. (1998). The impact of the internet on economic education. Journal of Economic Education, 29(2), 99-110.

Agbatogun, A.O. \& Banjo, B.O. (2010). Computer efficacy, use and phobia: Contributions to Nigerian undergraduates' academic performance in a computer graphics course. Retrieved from http://www.ncsu.edu/meridian/winter2010/index.html

Akooje, S., \& Arends, F. (2009). Intermediate-level ICT skills and development in South Africa: Private provision form suited to national purpose! Education and Information Technologies, 14(2), 189-204.

Alabbad, A.M. (2011). Interactive computer/network-based program for teaching English as a foreign language in the elementary levels in Saudi Arabia. Multimedia Computing and Systems (ICMCS), 2011 International Conference on 7-9 April 2011. doi: 10.1109/ICMCS.2011.5945699

Albers, J.T., Li, Y., Lemasters, G., Sprague, S., Stinson, R., \& Bhattacharya, A. (1997). An ergonomic education and evaluation program for apprentice carpenters. American Journal of Industrial Medicine, 32(6), 641-646.

Allan, M.K. (2007). Millennial teachers: Student teachers as users of Information and Communication - A New Zealand case study. Retrieved from http://ir.canterbury.ac.nz/bitstream/10092/575/1/12605417 millenial\%20t eachers\%20final\%20post\%20print.pdf

Alton-Lee, A. (2003). Quality teaching for diverse students in schooling: Best evidence synthesis. Wellington: Ministry of Education. 
Alyousef, H.S., \& Picard, M.Y. (2011). Cooperativ or collaborative literacy practices: mapping metadiscourse in a business students' wiki group project. Australasian Journal of Educational Technology, 27(3), 463-480.

Aman, K., Butson, R., Epere, A., Hussein, R., \& Thomson, C. (2009). Blackboard@Otago: A students' perspective. Dunedin, New Zealand: Otago University.

Amituanai-Toloa, M. (2005). Ua malie toa ua malie toa. Students with silver tongues whip the tail: Enhanced teaching and learning of reading comprehension in Samoan bilingual classes. Unpublished PhD thesis. Auckland, New Zealand: University of Auckland.

Anae, M. (1998). Fofoa-i-vao-'ese: the identity journeys of NZ-born Samoans. Unpublished $\mathrm{PhD}$ thesis. Auckland, New Zealand: University of Auckland.

Anae, M., Coxon, E., Mara, D., Wendt-Samu, T. \& Finau, C. (2001). Pasifika education research guidelines. Wellington, New Zealand: Ministry of Education.

Anae, M., Anderson, H., Benseman, J., and Coxon, E. (2002). Pacific peoples and tertiary education: Issues of particition. Wellington: Ministry of Education.

Anae, M., Mila-Schaaf, K., Coxon, E., Mara, D., \& Sanga, K. (2010). Teu Le VaRelationships across research and policy in Pasifika Education. Wellington, New Zealand: Ministry of Education.

Anderson, E.E., Taraban, R., \& Sharma, M.P. (2005). Implementing and assessing computer-based active learning materials in introductory thermodynamics. International Journal of Engineering Education, 21(6), 1168-1176.

Andrews, J. (2010). A+ Guide to Hardware: Managing, Maintaining and Troubleshooting. Boston, MA: Course Technology.

Assante, D. \& Sepe, R. (2011). An international cooperation experience between the International Telematic University Uninettuno and the Helwan University: the double degree in ICT Engineering. Paper presented at the EUROCON - European International Conference on Computer as a Tool. doi: 10.1109/EDUCON.2011.5773271

Atkinson, R.D. (2007). Boosting European prosperity through the widespread use of ICT. Retrieved from http://www.itif.org/files/EuropeanProductivity.pdf 
Audet, C.T., \& Pare, D.A. (2009). The Collaborative Counselling website: Using video e-learning via Blackboard Vista to enrich counsellor training. In G.R. Waltz, J.C. Bleuer, \& R.K. Yep (Eds), Compelling counselling interventions: VISTA 2009 (pp.305-315). Alexandria, VA: American Counselling Association.

Avison, D.E., \& Fitzgerald, G. (1995). Information systems development: methodologies, techniques, and tools. Berkshire, England: McGraw-Hill.

Avison, D.E. \& Fitzegerald, G. (2003). Where now for development methodologies. Communications of the ACM, 46(1), 79-82.

Bachmann, R., \& Braun, S. (2011). The impact of international outsourcing on labour market dynamics in Germany. Scottish Journal of Political Economy, 58(1), 1-28.

Baggerly, J. (2002). Practical technological applications to promote pedagogical principles and active learning in counsellor education. Journal of Technology in Counselling, 2(2). Retrieved from http://jtc.columbusstate.edu/vol2_2/baggerly/baggerly.htm

Bandura, A. (1977). Self-efficacy: Toward a unifying theory of behavioural change. Psychological Review, 84(2), 191-215.

Bandura, A. (1997). Self-efficacy: The exercise of control. New York: W.H. Freeman.

Barker, L.J., McDowell, C., \& Kalahar, K. (2009). Exploring factors that influence computer science introductory course students to persist in the major. ACM GCSE Bulletin - SIGCSE '09, 41(1), 153-157.

Barlow-Jones, G., \& Van der Westhuizen, D. (2011). Situating the student: factors contributing to success in an information technology course. Educational Studies, 37(3), 303-320.

Barnard, D. (2008). Systems analysis and design. Cape Town, South Africa: Pearson Education South Africa Ltd.

Barnard, J. (2010). Online counselling: A guide for therapists. Adelaide, Australia: MTC Books.

Barrett, R., Knoek van Soest, A.J., \& Neal, R. (2002). A computer-graphics model of muscle activation and contraction dynamics. Sports Biomechanics, 1(1), 105-121.

Basioudis, I.G., \& De Lange, P.A. (2009). An assessment of the learning benefits of using a web-based learning environment when teaching accounting. Advances in Accounting, 25(1), 13-19. 
Baso , E.B., \& Akdemir, O. (2010). A comparison of undergraduate students' English vocabulary learning: Using mobile phones and flash cards. Turkish Online Journal of Educational Technology, 9(3), 1-7.

Basoglu, E.B., \& Akdemir, O. (2010). A comparison of undergraduate students' English vocabulary learning: Using mobile phones and flash cards. The Turkish Online Journal of Educational Technology, 9(3). Retrieved from http://www.tojet.net/articles/931.pdf

Bauer, F., Wenninger, J, Haase, J. \& Fischer, T. (2011). Watching a processor at work: A self-explanatory processor and illustrator for the MC8 processor. Paper presented at the EUROCON - European International Conference on Computer as a Tool.

Bauer, S., Percevic, R., Okon, E., Meermann, R., \& Kordy,H. ( 2003). Use of text messaging in the aftercare of patients with bulimia nervosa. European Eating Disorders Review, 11(3), 279-290.

Baum, B., \& Gray, J. (1992). Expert modelling, self-observation using videotape, and acquisition of basic therapy skills. Professional Psychology: Research and Practice, 23(3), 220-225.

Beashel, P. \& Sibson, A. (2000). ICT - Help or hindrance? British Journal of Teaching Physical Education, 31(2), 6-8.

Beaubouef, T., \& Mason, J. (2005). Why the high attrition rate for computer science students: Some thoughts and observations. ACM SIGCSE Bulletin, 37(2), 103-106.

Beaver, K. (2010). Hacking for Dummies. (3 ${ }^{\text {rd }}$ Edition). Hoboken, NJ: Wiley Publishing.

Begum, M. \& Newman, R. (2009). Evaluation of students' experience of developing transferable skills and business skills using a business simulation game. Retrieved August 28, 2011 from: http://fieconference.org/fie2009/papers/1321.pdf

Bell, A., Crothers, C., Goodwin, I., Kripalani, K., Sherman, K. \& Smith, P. (2008). The Internet in New Zealand Report 2007. Final Report. Auckland: Institute of Culture, Discourse and Communication, Auckland University of Technology.

Bender RBT (2003). Systems development life cycle: Objectives and requirements. Retrieved from http://benderrbt.com/Bender-SDLC.pdf

Bennedsen, J., \& Caspersen, M.E. (2007). Failure rates in introductory programming. ACM SIGCSE Bulletin, 39(2), 32-36.

Bergin, S., \& Reilly, R. (2005). Programming: factors that influence success. ACM SIGCSE Bulletin, 37(1), 411-415. 
Berglund, A., Eckerdal, A., Pears, A., East, P., Kinnunen, P., Malmi, L., McCartney, R., Mostrom, J-E., Murphy, L., Ratcliffe, M., Schulte, C., Simon, B., Stamouli, I., \& Thomas, L. (2009). Learning computer science: perceptions, actions and roles. European Journal of Engineering Education, 34(4), 327-338.

Bernhardt, S. A., Edwards, P. G., \& Wojahn, P. R. (1989). Teaching college composition with computers: a program evaluation study. Written Communication, $6(1), 108-133$.

Bhaskar, K.N., \& Kaye, G.R. (1985). Computers and accountancy courses: a reply to Collins. Accounting and Business Research, 15(59), 239-240.

Bidgoll, H. (2004). The Internet Encyclopedia: Volume 3. Hoboken, NJ: Wiley Publishing.

Biggers, M., Brauer, A., \& Yilmaz, T. (2008). Student perceptions of computer science: A retention study comparing graduating seniors vs CS leavers. ACM GCSE Bulletin - SIGCSE '08, 40(1), 402-406.

Bipp, T., Lepper, A., \& Schmedding, D. (2008). Pair programming in software development team - An empirical study of the benefits. Information and Software Technology, 50(3), 231-240.

Bishop,R. (2008). Freeing ourselves from neo-colonial domination in research. In N.K. Denzin \& Y.S. Lincoln (Eds.) The Landscape of Qualitative Research (pp.145-183). London, UK: Sage.

Blignaut, P., \& Naude, A. (2008). The influence of temperament style on a student's choice of and performance in a computer programming course. Computers in Human Behavious, 24(3), 1010-1020.

Blomme, R.J., van Rheede, A., \& Tromp, D.M. (2010). The use of the psychological contract to explain turnover intentions in hospitality industry: a research study on the impact of gender on the turnover of highly educated employees. The International Journal of Human Resource Management, 21(1), 144-162. doi: 10.1080/09585190903466954

Blunch, N. \& Verner, D. (2000). Is functional literacy a prerequisite for entering the labor market? An analysis of the determinants of adult literacy and earnings in Ghana. Retrieved September 4, 2011 from: http://wwwwds.worldbank.org/servlet/WDSContentServer/WDSP/IB/2000/09/01/00 $009494600082205414569 /$ Rendered/PDF/multi page.pdf

Blurton, C. (1999). New directions of ICT-use in education. Retrieved from: http://www.unesco.org/education/educprog/lwf/dl/edict.pdf 
Bolton, R.E. (2005). Computer simulation of the Alonso household location model in the microeconomics course. Journal of Economic Education, 36(1), 59-76.

Borghans, L. \& Ter Weel, B. (2011). Computers, skills and wages. Applied Economics, 43(29), 4607-4622.

Borthick, A.F., \& Clark, R.L. (1987). Research on computing in accounting education: Opportunities and impediments. Issues in Accounting Education, 2, 173-192.

Borysenko, J.Z. (2009). It's not the end of the world: Developing resilience in times of change. Carlsbad, CA: Hay House Inc.

BottleTree Books. (2007). Bebo Unbound: Secure Your Privacy, Buzz Your Band, and Get Popular on Bebo. Memphis, TN: Author.

Bovee, C., Voogt, J., \& Meelissen, M. (2007). Computer attitudes of primary and secondary school students in South Africa. Computers in Human Behaviour, 23(4), 1762-1776.

Boyce, G. (1999). Computer-assisted teaching and learning in accounting: Pedagogy or product? Journal of Accounting Education, 17(2-3), 191220.

Brady, F., Dyson, L., \& Asela, T. (2008). Indigenous adoption of mobile phones and oral culture. Retrieved August 31, 2011 from: http://wwwstaff.it.uts.edu.au/ laurel/Publications/IndigenousAdoptionOfMobilePhon es\&OralCulture.pdf

Brecht, H.D., \& Ogliby, S.M. (2008). Enabling a comprehensive teaching strategy: video lectures. Journal of Information Technology Education: Innovations in Practice, 7, 71-86.

Bredon, G. (1999). Net news - old wine in a new bottle? Journal of Economic Education, 30(1), 28-32.

Brett, P. (2011). Students' experiences and engagement with SMS for learning in higher education. Innovations in Education and Teaching International, 48(2), 137-147.

Brown, B., \& Liedholm, C. (2002). Can web courses replace the classroom in principles of microeconomics? American Economic Review Papers and Proceedings, 92(2), 444-448.

Brown, J.S., Collins, A., \& Duguid, P. (1989). Situated cognition and the culture of learning. Retrieved August 19, 2011 from:

http://www.jstor.org/stable/1176008

Brown, P.A., Hesketh, A. \& Williams, S. (2003). Employability in the knowledgedriven economy. Journal of Education and Work, 16(2), 107-126. 
Brown, S.P. (2001). Introduction to Exercise Science. Baltimore, Maryland: Lippincott Williams \& Wilkins.

Browne, C., \& Culligan, B. (2008). Combining technology and IRT testing to build student knowledge of high frequency vocabulary. The JALT CALL Journal, 4(2), 3-16.

Bryman, A. (2008). Social research methods. (Third edition). Oxford, UK: Oxford University Press.

Bucciarelli, E., Odoardi, I., \& Muratore, F. (2010). What role for education and training in technology adoption under an advanced socio-economic perspective? Procedia Social and Behavioural Sciences, 9(2010), 573578.

Buechler, J. (2009). Movie Maker 2: Do Amazing Things. Redmond, WA: Microsoft Press.

Buhalis, D., \& Law, R. (2008). Progress in information technology and tourism management: 20 years on and 10 years after the internet - the state of etourism research. International Journal of Contemporary Hospitality Management, 13(3), 144-150.

Bunker, B. (2010). A summary of international reports, research and case studies of digital literacy. Wellington: New Zealand Computer Society.

Buzzard, C., Crittenden, V.L., Crittenden, W.F., \& McCarty, P. (2011). The use of digital technologies and learning perspectives. Journal of Marketing Education, 33(2), 131-139.

Callanan, M., Cervantes, C., and Loomis, M. (2011). Informal learning. Wiley Interdisciplinary Reviews: Cognitive Science, 2(6), 646-655. doi: 10.1002/wcs. 143

Campbell, V., \& Johnstone, M. (2010). The significance of learning style with respect to achievement in first year programming students. Proceedings of Australian Software Engineering Conference (ASWEC 2010). (pp. 165-170). Auckland, New Zealand: IEEE

Cantoni, L., Kalbaska, N. \& Inversini, A. (2009). E-learning in tourism and hospitality: A map. Journal of Hospitality, Leisure, Sport \& Tourism Education, 8(2), 148-156.

Carbone, A., Wond, J. \& Ceddia, J. (2011). A scheme for improving ICT units with critically low student satisfaction.

Carnevale, A.P., Gainer, L.J. \& Meltzer, A.S. (1990). Workplace basics training manual. San Francisco: Jossey-Bass Publishers.

Carpell, A. (1991). The Fijian dictionary. Suva, Fiji: Government Press. 
Carter, L., Jernejcic, L., \& Lim, N. (2007). Success in CS: Is culture a factor? Retrieved from http://fie-conference.org/fie2007/papers/1045.pdf

Carver, J.C., Henderson, L., He, L., Hodges, J., \& Reese, D. (2007). Increased retention of early computer science and software engineering students using pair programming. In CSEET '07: Proceedings of the $20^{\text {th }}$ conference on software engineering education \& training (pp115-122). Washington, DC: IEEE Computer Society.

Cavus, N., \& Ibrahim, D. (2009). M-Learning: An experiment in using SMS to support learning new English language words. British Journal of Educational Technology, 40(1), 78-91.

Chalk, P., Boyle, T., Pickard, P., Bradley, C., Jones, R., \& Fisher, K. (2003). Improving pass rates in introductory programming. Retrieved from http://www.ics.heacademy.ac.uk/Events/conf2003/Pete\%20Chalk.pdf

Chambers, M.L. (2006). PCs All-in-one Desk Reference for Dummies. (3 ${ }^{\text {rd }}$ Edition). Hoboken, NJ: Wiley Publishing.

Chaparro, E.A., Yuksel, A., Romero, P., \& Bryant, S. (2005). Factors affecting the perceived effectiveness of pair programming in higher education. In Proceedings of the $17^{\text {th }}$ workshop of the Psychology of Programming Interest Group (pp 5-18). Brighton, UK: PPIG.

Chappell, J., Taylor, R., \& Woodbury, K. (2008). Introducing Excel based steam table calculations into thermodynamics curriculum. Retrieved from http://soa.asee.org/paper/conference/paper-view.cfm?id=8079

Charette, M.F., \& Meng, R. (1998). The determinants of literacy and numeracy, and the effect of literacy and numeracy on labour market outcomes. The Canadian Journal of Economics, 31(3), 495-517.

Chasen, C. (2009). Safety Manager's Guide to Office Ergonomics. Hoboken, NJ: John Wiley \& Sons.

Chavan, M. (2011). Higher education students' attitude towards experiential learning in international business. Journal of Teaching in International Business, 22(2), 126-143.

Chen, H-J, H. (2011). Developing and evaluating syntolearn, a fully automatic video and transcript synchronization tool for EFL learners. Computer Assisted Learning, 24(2), 117-130.

Chen, W. \& Levinson, D.M. (2006). Effectiveness of learning transportation network growth through simulation. Journal of Professional Issues in Engineering Education and Practice, 132(1), 29-41.

Chesley, N. (2010). Technology use and employment assessment. Information, Communication and Society, 13(4), 323-327. 
Cheung, W., \& Hew, K. (2009). A review of research methodologies used in studies on mobile handheld devices in K-12 and higher education setting. Australasian Journal of Educational Technology, 25(2), 153183.

Chizmar, J.F., \& Walbert, M.S. (1999). Web-based learning environments guided by principles of good teaching practice. The Journal of Economic Education, 30(3), 248-259.

Chu, C.M. (2009). Mentoring for leadership in Pacific education. Unpublished PhD thesis. Wellington, New Zealand: Victoria University of Wellington.

Churchill, D. (2009). Educational applications of Web 2.0: Using blogs to support teaching and learning. British Journal of Educational Technology, 40(1), 179-183.

Churchward, C.M. (1959). Tongan dictionary. London, UK: Oxford University Press.

Cisco Networking Academy. (2011). IT Essentials: PC Hardware and Software Companion Guide. (4 ${ }^{\text {th }}$ Edition). Indianapolis: Cisco Press.

Clair, R. S. (2003). Providing a free internet to an isolated nation. Retrieved from: http://www.nunames.nu/about/Niuepaper1.pdf

Clark, J., Dodd, D., \& Coll, R.K. (2008). Border crossing and enculturation into higher education science and engineering learning communities. Research in Science \& Technological Education, 26(3), 323-334.

Clayton, J.F., Rata-Skudder, N., and Baral, H.,P. (2004). Pasifika communities online: And implications. Retrieved October 4, 2009 from: http://www.col.org/pcf3/Papers/PDFs/Clayton John Skudder.pdf

Clough, G., Jones, A.C., McAndrew, P., \& Scanlon, E. (2007). Informal learning with PDAs and smartphones. Journal of Computer Assisted Learning, 24(5), 359-371.

Coffield, F., Moseley, D., Hall, E., \& Ecclestone, K. (2004). Learning styles and pedagogy in post-16 learning: A systematic and critical review. Wiltshire, UK: Learning and Skills Research Centre.

Coglan, D. \& Brannick, T. (2010). Doing research in your own organization. (3 ${ }^{\text {rd }}$ Edition). London: Sage Publications.

Cohen, L., Manion, L., \& Morrison, K. (2007). Research methods in education. $\left(6^{\text {th }}\right.$ Edition). New York: Routledge.

Colasante, M. (2011). Using video annotation to reflect on and evaluate physical education pre-service teaching practice. Australasian Journal of Educational Technology, 27(1), 66-88. 
Commission of the European Communities. (2010). Communication from the Commission to the Council and the European Parliament: The Elearning action plan - Designing tomorrow's education. Retrieved from http://www.aic.Iv/bolona/Bologna/contrib/EU/e-learn ACPL.pdf

Commonwealth of Australia. (2009). Adolescent overload? Retrieved August 14, 2011 from:

http://www.aph.gov.au/house/committee/edt/schoolandwork/report.htm

Cooke, L., \& Greenwood, H. (2008). “Cleaners don't need computers”: bridging the digital divide in the workplace. Aslib Proceedings, 60(2), 143-157. doi: $10.1108 / 00012530810862473$

Coombs, T., \& DeLeon, R. (2007). Google Power Tool Bible. Indianapolis, NI: Wiley Publishing.

Corney, M., Teague, D., \& Thomas, R.N. (2010). Engaging students in programming. In T. Clear and J. Hamer (Eds.) Proceedings of the $12^{\text {th }}$ Australiasian Computing Education Conference (ACE 2010). (pp.63-72). Brisbane, Australia: ACE.

Cortes, N., Blount, E., Ringleb, S., \& Onate, J.A. (2011). Soccer-specific video simulation for improving movement assessment. Sports Biomecahnics, 10(1), 22-34. doi: 10.1080/14763141.2010.547591

Coughlan, J., \& Swift, S. (2011). Student and tutor perceptions of learning and teaching on a first-year study skills module in a university computing department. Educational Studies, 37(5), 529-539.

Coxon, E. \& Mara, D. (2000). Education policy for Pacific Nations people. In J. Marshall, E. Coxon, K. Jenkins, \& A. Jones (Eds). Politics, policy, pedagogy: education in Aotearoa-New Zealand (pp.157-184). Palmerston North, New Zealand: Dunmore Press.

Coyle, C. \& Vaughn, H. (2008). Social networking: Communication revolution or evolution. Bells Labs Technical Journal, 13(2), 13-18.

Creswell, J. (2008). Educational research: Planning, conducting, and evaluating quantitative and qualitative research. ( $3^{\text {rd }}$ Edition). Upper Saddle River, NJ: Pearson Education.

Cretchley, P. (2007). Does computer confidence relate to levels of achievement in ICT-enriched learning models? Education and Information Technologies, 12(1), 29-39. Doi: 10.1007/210639-006-9004-6

Cronin, J.J. (2009). Upgrading to Web 2.0: An experiential project to build a marketing wiki. Journal of Marketing Education, 31(1), 66-75. 
Crowther, K., Thomson, D., \& Cullingford, C. (1997). Engineering degree students are deficient in mathematical expertise - why? International Journal of Mathematical Education in Science and Technology, 28(6), 785-792.

Cuddy, C. (2010). Mobile video for education and instruction. Journal of Electronic Resources in Medical Libraries, 7, 85-89.

Curland, S.R. \& Fawcett, S.L. (2001). Using simulation and gaming to develop financial skills in undergraduates. International Journal of Contemporary Hospitality Management, 13(3), 116-119.

Darden, G.F., \& Shimon, J.M. (2000). Revisit an old technology: Videotape feedback for motor skill learning and performance. Strategies, 13(4), 1721.

Davidson-Tou'mua, R.J. (2005). The tertiary academic reading experiences: Case studies of first year Pacific students. Unpublished Masters thesis. Wellington: Victoria University of Wellington.

Davies, D., Taylor, R., \& Savery, L. (2001). The role of appraisal, renumeration and training in improving staff relations in the Western Australian accommodation industry: A comparative study. Journal of European Industrial Training, 25(7), 366-373.

Davies, N., Fletcher, J., \& Absalo, I. (2010). E-learning for adult literacy, language and numeracy: a case study of polytechnic. Wellington, New Zealand: Ministry of Education.

Davies, N., Fletcher, J., Brooker, B., Everatt, J., Gillon, G., Mackey, J., \& Morrow, D. (2010). E-learning for adult literacy, language and numeracy: a review of the literature. Wellington, New Zealand: Ministry of Education.

Day, J.M., \& Kumar, M. (2010). Using SMS text messaging to create individualised and interactive experiences in large classes: A beer game example. Decision Sciences Journal of Innovative Education, 8(1), 129136.

De Coulon, A., Marcenaro-Gutierrez, O., \& Vignoles, A. (2007). The value of basic skills in the British labour market. Retrieved from http://www.education.gov.uk/rsgateway/DB/RRP/u015215/index.shtml

De Lange, P., Suwardy, T. \& Mavondo, F. (2003). Integrating a virtual learning environment into an introductory accounting course: determinants of student motivation. Accounting Education, 12(1), 1-14.

Deliktas, B. (2008). Computer technology for enhancing teaching and learning modules of engineering mechanics. Computer Application in Engineering Education, 19(3), 421-432. 
Demouy, V., \& Kukulska-Hulme, A. (2010). On the spot: using mobile devices for listening and speaking practice on a French language programme. Open Learning, 25(3), 217-232.

Dennis, A., Wixom, B., \& Roth, R. (2006). Systems analysis design. Hoboken, NJ: John Wiley \& Sons.

Deo, B., \& Phan, H.P. (2006). Approaches to learning in the South Pacific region: A confirmatory factor analysis study. Retrieved from http://www.aare.edu.au/06pap/deo06050.pdf

Department of Communications, Information Technology and the Arts. (2006). Building Australian ICT skills: Report of the ICT skills foresighting working group. Canberra: Department of Communications, Information Technology and the Arts.

Department of Communications, Information Technology and the Arts. (2005). Productivity growth in service industries: Occasional economic paper. Canberra: Department of Communications, Information Technology and the Arts.

Department of Education, Science and Training. (2002). Employability skills for the future. Retrieved August 14, 2011 from:

http://www.dest.gov.au/archive/ty/publications/employability skills/final $r$ eport.pdf

Department of Labour (2011). Skills Challenge Report. New Zealand's skills challenges over the Next 10 years. Wellington, New Zealand: Author.

Deshpande, A.A., \& Huang, S.H. (2009). Simulation games in engineering education: A state-of-the-art review. Computer Application in Engineering Education, 19(3), 399-410.

De Vos, A., De Hauw, S., \& Der Heijden, B.V. (2011). Competency development and career success: The mediating role of employability. Journal of Vocational Behaviour, 79(2), 438-447.

Dickie, J. (2001). Pacific nations students in primary teacher training. New Zealand Annual Review of Education, 10, 89-107.

Dickie, J. (2008). An Investigation of Sites, Uses and Practices For Literacy in the Lives of Pasifika Students. Unpublished PhD thesis. Wellington, New Zealand: Victoria University of Wellington.

Dickson, A., Esima, R., Gregor, P., Syme, S., \& Milne, S. (2005). Strategies for teaching older people to use the World Wide Web. Universal Access in the Information Society, 4(1), 3-15. 
Dickson, J.K., Woodard, P., Canas, R., Ahamed, S., \& Lockston, D. (2011). Game-based trench safety education: Development and lessons learned. Journal of Information Technology, 16, 118-132. Retrieved from: http://www.itcon.org/2011/8

DiPietro, R.B., Thozhur, S.M., \& Milman, A. (2007). Hourly employee retention factors in the United Kingdom quick service restaurant industry. Journal of Foodservice Business Research, 10(4), 39-61. doi: 10.1300/J369v10n04_04

Divjak, B., Ostroski, M., \& Hains, V.V. (2010). Sustainable student retention and gender issues in mathematics for ICT study. International Journal of Mathematical Education in Science and Technology, 41(3), 293-310.

Dixit, J.B., \& Kumar, R. (2007). Structured system analysis and design. Delhi: Laxmi Publications.

Doherty, J. (1997). A Survey of computer use in the New Zealand Building and Construction Industry. Building Research Association of New Zealand, Study Report SR 80. Judgeford, Wellington, New Zealand.

Domingues, L., Rocha, I., Dourado, F., Alves, M. \& Fereira, E.C. (2010). Virtual laboratories in biochemical engineering education. Education for Chemical Engineers, 5(2), e22-e27.

Dougherty, C. (2003). Numeracy, literacy and earnings: Evidence from the National Longitudinal Survey of Youth. Economics of Education Review, 22(5), 511-521.

Douglas, A., Miller, B., Kwansa, F. \& Cummings, P. (2007). Students' perceptions of the usefulness of a virtual simulation in post-secondary hospitality education. Journal of Teaching in Travel \& Tourism, 7(3), 1-19.

Dray, B., Burke, L., Hurst, H.H., Ferguson, A., \& Marks-Maran, D. (2011). Enhancing the employability of newly qualified nurses: a pilot study. Journal of Further and Higher Education, 35(3), 299-315.

Dryburgh, H. (2002). Learning computer skills. Retrieved from http://www.statcan.gc.ca/kits-trousses/pdf/social/edu04 0099a-eng.pdf

Du, H.S. \& Wagner, H. (2007). Learning with weblogs: Enhancing cognitive and social knowledge construction. IEEE Transactions on Professional Communications, 50(1), 1-15.

Dul, J., \& Weerdmeester, B. (2008). Ergonomics for Beginners: A Quick Reference Guide. (3 ${ }^{\text {rd }}$ Edition). Boca Rotan: CRC Press.

Dunne, A., \& Lawlor, M.A. (2010). Young people's use of online social networking sites - a uses and gratifications perspective. Journal of Research in Interactive Marketing, 4(1), 46-58. 
Earle, D. (2010). Benefits of tertiary certificates and diplomas: Exploring economic and social outcomes. Wellington, New Zealand: Ministry of Education.

Eckler, B. (2002). Thinking in C++. Retrieved from http://www.lib.ru.ac.th/download/e-books/Tic2Vtwo.pdf

EduMission. (2011). Science Form Three: Chapter 1 - Respiration System. Retrieved from http://cikguwong.blogspot.com/2011/01/science-formthree-chapter-1.html

Eisenhardt, K.M. (2002) Building theories from case study research. In A.M. Huberman, \& M.B. Miles (Eds), The qualitative researcher's companion (pp.5-36), Thousand Oaks, CA: Sage.

Eley, R., Fallon, T., Soar, J., Buikstra, E., \& Hegney, D. (2008). Barriers to use of information and computer technology by Australia's nurses: a national survey. Journal of Clinical Nursing, 18(8), 1151-1158.

Elgort, I. (2005). E-learning adoption: Bridging the chasm. Retrieved from http://ascilite.org.au/conferences/brisbane05/blogs/proceedings/20 Elgo rt.pdf

Elgort, I., Smith, A.G., \& Toland, J. (2008). Is wiki and effective platform for group course work? Australasian Journal of Educational Technology, 24(2), 195-210.

El-Omari, A.H. (2011). Strategies of using tape and tape recorders in English lessons of the low basic stage by Jordanian teachers: Supervisors perspective. European Journal of Social Sciences, 21(1), 7-16.

Engler, R., \& Smyth, R. (2011). Doing a bachelors degree: comparing university entrance and NCEA levels. Wellington, New Zealand: Ministry of Education.

Etherington, K. (2004). Becoming reflexive researchers: Using ourselves in research. London, UK: Jessica Kingley.

Etter, E.R., Burmeister, S.L., \& Elder, R.J. (2001). Improving student performance and retention via supplemental instruction. Journal of Accounting Education, 18(4), 355-368.

European Commission. (2010). E-skills for the $21^{\text {st }}$ century. Retrieved from http://ec.europa.eu/enterprise/sectors/ict/files/reports/eskills21 final rep ort en.pdf

Evans, J., \& Schneider, G.P. (2009). New Perspectives on the Internet: Introduction. ( $7^{\text {th }}$ Edition). Boston, MA: Course Technology. 
Fanene, N. (2006). A study of the academic writing skills of New Zealand-born Samoans in tertiary institutions. Unpublished Masters thesis. Auckland: Auckland University of Technology.

Fantz, T.D., Siller, T.J., \& Demiranda, M.A. (2011). Pre-collegiate factors influencing the self-efficacy of engineering students. Journal of Engineering Education, 100(3), 604-623.

Farrelly, T. (2009). Business va'avanua: Indigenous development as cultural hybridity in Boumā National Heritage Park, Fiji. Unpublished PhD thesis, Palmerston North, New Zealand: Massey University.

Ferguson, P.B., Gorinski, R., Samu, T.W., \& Mara, D. (2008). Literature review on the experiences of Pasifika learners in the classroom. Wellington, New Zealand: Ministry of Education.

Ferrell, O.C., and Ferrell, L. (2002). Assessing instructional technology in the classroom. Marketing Educational Review, 12(3), 19-24.

Fouts, J.T. (2000). Research on computers and education: Past, present and future. Retrieved from

http://citeseerx.ist.psu.edu/viewdoc/summary?doi=10.1.1.99.7050

Fox, L. (1999). Foundations: A manual for the beginning student of epistemology. London, UK: University Press of America.

Futrell, R.T., Shafer, D.F. \& Shafer, L.I. (2002). Quality software project management. Upper Saddle River, NJ: Prentice Hall.

Gall, M.D., Gall, J.P. \& Borg, W.R. (2007). Educational research: An introduction. $\left(7^{\text {th }}\right.$ Ed.). Boston: Pearson Education.

Ganem-Gutierrez, G.A. (2009). Repetition, use of L1 and reading aloud as meditational mechanism during collaborative activity at the computer. Computer Assisted Learning, 22(4), 323-348.

Ganguly, S., and Bhatnagar, S. (2008). VOIP: Wireless, P2P and New Enterprise Voice Over IP. West Sussex, England: John Wiley \& Sons.

Gann, D., \& Senker, P. (1998). Construction skills training for the next millennium. Construction Management and Economics, 16(5), 569-580.

Garrido, M., Badshah, A., \& Coward, C. (2009). Deconstructing ICT skills and employability. Retrieved August 5, 2011 from:

http://itidjournal.org/itid/issue/view/20

Garrido, M., Sullivan, J., \& Gordon, A. (2010). Understanding the links between ICT skills training and employability: an analytical framework. Retrieved from

http://www.gg.rhul.ac.uk/ict4d/ictd2010/papers/ICTD2010\%20Garrido\%2 0et\%20al.pdf 
Gee, J.P. (2004). Learning by design: Gaming as learning machines. Retrieved from

http://www.ub.edu/multimedia/iem/down/c8/Games as learning machin es.pdf

Gesthuizen, M., \& Wolbers, M.H.J. (2010). Employment transitions in the Netherlands, 1980-2004: Are low educated men subject to structural or cyclical crowding out? Research in Social Stratification and Mobility, 28(4), 437-451.

Giddings, L.S., Campbell, S., \& Maclare, (2006). Going online to learn health sciences research methods. Australasian Journal of Educational Technology, 22(2), 251-267.

Gipp, J. (2009). Windows Movie Maker: Basics. Boston, MA: Course Technology.

Glesne, C. (2006). Becoming qualitative research. An introduction. (3 ${ }^{\text {rd }}$ Ed.). Boston: Pearson Education.

Gokuladas, V.K. (2011). Predictors of employability of engineering graduates in campus recruitment drives of Indian software services companies.

Gookin, D. (2010). PCs for Dummies. (3 ${ }^{\text {rd }}$ Edition). Hoboken, NJ: Wiley Publishing.

Gosper, M., Green, D., McNeil, M., Phillips, R., Preston, G., \& Woo, K. (2008).

The impact of web-based lecture technologies on current and future practices in learning and teaching. Retrieved from

http://www.mq.edu.au/ltc/resources/wblt/research/report.html

Gough, M. (2006). Skype Me! Rockland, MA: Syngress Publishing.

Govender, I. (2009). The learning context: Influence on learning to program. Computers \& Education, 53(4), 1218-1230.

Graham, A., \& Lambert, C.U. (1998). Effective placement of reflective feedback in computer-aided instruction for maintining dining room standards. Journal of the International Academy of Hospitality Research, 10, 1-8.

Granitz, N., \& Koernig, S.K. (2009). Web 2.0 and marketing education: Explanations and experiential applications. Journal of Marketing Education, 33(1), 57-72.

Grant, D.M., Malloy, A.D., \& Murphy, M.C. (2009). A comparison of student perceptions of their computer skills to their actual abilities. Journal of Information Technology Education, 8, 141-160. Retrieved from http://iite.org/documents/Vol8/JITEv8p141-160Grant428.pdf

Gray, A. (2001). The definition and measurement of ethnicity: A Pacific perspective. Wellington, New Zealand: Statistics New Zealand. 
Gray, D. E. (2009). Doing research in the real world. (2 $2^{\text {nd }}$ Edition) London, UK: Sage.

Greco, J. (1999). Introduction: what is epistemology? In J. Greco and E. Sosa (Eds.), The Blackwell Guide to Epistemology (pp.1-31) Malden, MA: Blackwell.

Green, D.A. \& Riddell, W.C. (2003). Literacy and earnings: An investigation of the interaction of cognitive and unobserved skills in earnings generation. Labour Economics, 10, 165-184.

Green, N. (2002). Using ICT within PE - Its impact on a working department. The British Journal of Teaching Physical Education, 33(2), 25.

Greenlaw, S.A. (1999). Using groupware to enhance teaching and learning in undergraduate economics. Journal of Economic Education, 30(1), 33-42.

Grimes, P.W., Krehbiel, T.L., Nielsen, J.E., \& Niss, J.F. (1989). The effectiveness of Economics U\$A on learning and attitudes. Journal of Economic Education, 20(2), 139-152.

Grimm, J.L., Skinner, S.J., \& Ferrell, O.C. (1979). Computer-assisted instruction for the basic marketing course: A student evaluation. Journal of Marketing Education, 1(1), 63-70. doi: 10.1177/027347537900100112

Grurovic, M., \& Hegelheimer, V. (2007). Help options and multimedia listening: Students' use of subtitles and the transcript. Language Learning \& Technology, 11(1), pp. 45-66.

Guiney, P. (2011). E-learning provision and participation: Trends, patterns and highlights. Wellington, New Zealand: Ministry of Education.

Hager, P. (2004). The competence affair or why vocational education and training urgently needs a new understanding of learning. Journal of Vocational Education and Training, 56(3), 409-433.

Hager, P. \& Holland, S. (2006). Graduate attributes, learning and employability. Dordrecht, Netherland: Springer.

Halapua, S. (2003). Walking the knife-edge pathways to peace. Retrieved from http://166.122.164.43/archive/2003/July/07-08-halapua.htm

Halapua, S. (2004). Fiji talanoa. Retrieved from http://talanoa.org/TDP Fiji Talanoa.html

Halcro, K. \& Smith, A.M.J. (2011). Wikis: building a learning experience between academe and businesses. Reflective Practice, 12(5), 679-693.

Hall, B.C. (2008). Investigating the relationships among computer self-efficacy, professional development, teaching experience, and technology integration of teachers. Unpublished Ed.D thesis. Cincinnati, Ohio: University of Cincinnati. 
Hall, J. (2005). Homer economicus: Using The Simpsons to teach economics. Journal of Private Enterprise, 20, 139-152.

Hallberg, M.C. (1996). POLICY: a computer program for student use in courses on economic policy. Journal of Economic Education, 26(4), 314-323.

Ham, V., \& Wenmoth, D. (2007). Evaluation of the E-Learning Collaborative Development Fund. (Final Report to Tertiary Education Commission). Wellington, New Zealand: Tertiary Education Commission.

Hammersley, M. (1990). Reading ethnographic research: A critical guide. $\left(2^{\text {nd }}\right.$ Ed.) London: Longmans.

Hammersley, M. (1992). What is wrong with ethnography? Methodological explorations. London: Routledge.

Hanks, B., \& Brandt, M. (2009). Successful and unsuccessful problem solving approaches of novice programmers. Proceedings of the $40^{\text {th }} \mathrm{ACM}$ technical symposium on Computer education, (24-28). New York: SIGCSE.

Hanks, B., Fitzgerald, S., McCauley, R., Murphy, L., \& Zander, C. (2011). Pair programming in education: a literature review. Computer Science Education, 21(2), 135-173. doi: 10.1080/08993408.2011.579808

Hanks, B., McDowell, C., Draper, D., \& Krnjajic, M. (2004). Program quality with pair programming in CS1. In ITiCSE '04: Proceedings of the $9^{\text {th }}$ annual SIGCSE conference on innovation and technology in computer science education (pp. 176-180). New York, NY: ACM.

Harb, N., \& El-Shaarawi, A. (2007). Factors affecting business students' performance: The case of students in United Arab Emirates. Journal of Education for Business, 82(5), 282-290.

Harbourne, D. (1995). Sector report: Issues in hospitality and catering. Management Development Review, 8(1), 37-40.

Harkess, C., Murray, S., Parkin, M., \& Dalgety, J. (2005). Pasifika achievement: engagement and choice. Wellington, New Zealand: Ministry of Education.

Harley, D., Slade, R., \& Gattiker, U.E. (2001). Viruses Revealed: Understand and Counter Malicious Software. New York, NY: McGraw-Hill.

Harris, K.J., \& Bonn, M.A. (2000). Training techniques and tools: Evidence from the foodservice industry. Journal of Hospitality and Tourism Research, 24(3), 320-335.

Hart, S.L. (1971). Axiology - Theory of values. Philosophy and Phenomenological Research, 32(1), 29-41. 
Harvey, L. (2001). Defining and measuring employability. Quality in Higher Education, 7(2), 97-109.

Hashim, J. (2008). Learning barriers in adopting ICT among selected working women in Malaysia. Gender in Management: An International Journal, 23(5), 317-336.

Hastie, P.A., Casey, A. \& Tarter, A.M. (2010). A case study of wikis and studentdeisnged games in physical education. Technology, Pedagogy and Education, 19(1), 79-91.

Hawi, N.S. (2010). Causal attributions of success and failure made by undergraduate students in an introductory level computer programming course. Computers \& Education, 54(4), 1127-1136.

Hayes, B.G. (2008). Counsellor education: Integration of teaching strategies. Journal of Technology in Counselling, 5(1). Retrieved from http://jtc.columbusstate.edu/Vol5_1/Hayes.htm

Hegarty, J.A. (2004). Standing the heat: Assuring curriculum quality in culinary arts and gastronomy. New York, NY: Haworth Hospitality Press.

Heley, J. (2011). On the potential of being a village boy: An argument for local rural ethnography. Sociologia Ruralis, 51(3), 220-237.

Helu-Thaman, K. (2001). Towards culturally inclusive teacher education with specific reference to Oceania. Retrieved from http://ehlt.flinders.edu.au/education/iej/articles/v2n5/1Thaman/paper.pdf

Helu-Thaman, K. (2009). Towards cultural democracy in teaching and learning with specific references to Pacific Island Nations. Retrieved from http://academics.georgiasouthern.edu/ijsotl/v3n2/invited essays/PDFs/In vitedEssay Thaman.pdf

Higgins, A., \& Krieg, J. (2008). Staff and Student Views of AUTonline (BlackBoard) after Three Years. Journal of Distance Learning. Retrieved from: http://www.deanz.org.nz/home/journal/JDL\%201201\%202008\%20Higgin s\%20and\%20Krieg.pdf

Hillage, J. \& Pollard, E. (1998). Employability: Developing a framework for policy analysis. Retrieved August 13, 2011 from: https://www.education.gov.uk/publications/eOrderingDownload/RB85.pdf

Hirsch, D., \& Nation, P. (1992). What vocabulary size is needed to read unsimplified texts for pleasure? Reading in a Foreign Language, 8(2), 689-696.

Hitchcock, G. \& Huges, D. (1995). Research and the teacher. A qualitative introduction to school-based research. ( $2^{\text {nd }} \mathrm{Ed}$.) London: Routledge. 
Ho, E., Holmes, P., \& Cooper, J. (2004). Review and evaluation of International literature on managing cultural diversity in the classroom. Wellington: Ministry of Education.

Hock, R. (2010). Search engines. Encyclopedia of Library and Information Sciences. ( $3^{\text {rd }}$ Edition). New York: Taylor and Francis.

Hodgen, E. (2006). Statistical profile of Pacific students in tertiary education and engagement in e-learning. Wellington, New Zealand: New Zealand Council of Educational Research.

Hogan, M. (2009). Age difference in technophobia: An Irish study. In C. Barry, K. Conboy, M. Lang, G. Wojtkowski, \& W. Wojtkowski (eds.), Information Systems Development,Challenges in practice, theory and education, pp.117-130. New York, USA: Springer Science + Business Media.

Holmes, B. \& Gardner, J. (2006). E-learning: Concepts and practice. London: Sage Publication.

Holt, D., Boyce, G., Carnegie, G., \& Bigelow, A. (1995). Intelligent computerassisted learning in accounting education. Melbourne, Australia: Deakin University.

Holzinger, A., Kickmeier-Rust, M.D. \& Ebner, M. (2009). Interactive technology for enhancing distributed learning: A study on weblogs.

Huang, S. (2006). Reading English for academic purposes - What situational factors may motivate learners to read? System, 34(3), 371-383.

Huber, M.M., Hancer, M., \& George, R.T. (2010). A comparative examination of information technology usage in the restaurant industry. Journal of Foodservice Business Research, 13(3), 268-281.

Hucking, T., Haynes, M., \& Coady, J. (1993). Second language reading and vocabulary learning. Norwood, NJ: Ablex Publishing Corporation.

Hughes, J. (2006). The proposed use of EFTPOS data in official statistics. Retrieved from http://www.oecd.org/dataoecd/27/59/36965290.pdf

Huguet, J., Woodbury, K., \& Taylor, R. (2008). Development of Excel add-in modules for use in thermodynamics curriculum: Steam and ideal gas properties. Retrieved from http://soa.asee.org/paper/conference/paperview.cfm?id=8432

Hutchens, M.J. (2010). I think I can: The interaction between self-efficacy and anxiety predicting who we talk to. Unpublished $\mathrm{PhD}$ thesis. Athens, Ohio: Ohio State University.

Ibrahim, N. \& Cavus, D. (2009). M-learning: An experiment in using SMS to support learning new English language words. British Journal of Educational Technology, 40(1), 78-91. 
Imran, A. (2009). Knowledge and attitude, the two major barriers to ICT adoption in LDC are the opposite side of a coin: An empirical evidence from Bangladesh. In Proceedings of the $42^{\text {nd }}$ Hawaii International Conference on System Sciences 2009. Waikoloa, Hawaii: HICSS. Retrieved from http://ieeexplore.ieee.org/stamp/stamp.jsp?arnumber=04755751

Ip, C., Leung, R., \& Law, R. (2011). Progress and development of information and communication technologies in hospitality. International Journal of Contemporary Hospitality Management, 23(4), 533-551.

lqbal, Z. (2010). Gender differences in mobile phone use: what communications motives does it satisfy? European Journal of Scientific Research, 46(4) 510-522.

Jarvis, P. (1987). Adult learning in the social context. London, UK: Croom Helm. Jebeile, S., \& Abeysekera, I. (2010). The spread of ICT innovation in accounting education. International Journal of Teaching and Learning in Higher Education, 22(2), 158-168.

Jeffrey, L.M., Atkins, C., Laurs, A., \& Mann, S. (2006). E-learner profiles: Diversity in learners. Wellington, New Zealand: Ministry of Education.

Jeurissen, M.J. (2007). Silence speaks volumes. Unpublished Masters thesis. Auckland, New Zealand: Auckland University of Technology.

Joerding, W. (2010). Teaching and learning with individually unique exercises. Journal of Economic Education, 41(2), 125-135. doi: $10.1080 / 0020481003613813$

Johnson, E. M., Cowie, B., De Lange, W., \& Hight, C. (2009). Leveling the playing field: Exploiting technology to enhance tertiary learning. In Same places, different spaces. Proceedings Ascilite Auckland 2009. http://www.ascilite.org.au/conferences/auckland09/procs/johnson.pdf

Johnson, E. M., Cowie, B., De Lange, W.P., Falloon, G., Hight, C. \& Khoo, E. (2011). Adoption of innovative e-learning support for teaching: A multiple case study at the University of Waikato. Australasian Journal of Educational Technology, 27(3), 499-513.

Johnson, R.D. (2005). An empirical investigation of sources of applicationspecific computer-self-efficacy and mediators of the efficacyperformance relationship. International Journal of Human Computer Studies,62(6), 737-758.

Jones, R.H. (2011). Sport and re/creation: what skateboarders can teach us about learning. Sport, Education and Society, 16(5), 593-611. 
Joshi, M. \& Chugh, R. (2009). New paradigms in the teaching and learning of accounting: Use of educational blogs for reflective thinking. International Journal of Education and Development using Information and Communication Technology, 5(3), 6-18.

Juan, J.R., Hung, W.H., \& Kang, S.C. (2010). Using game engines for physicsbased simulations - A forklift. Journal of Information Technology, 16, 322. Retrieved from: http://www.itcon.org/2011/2

Junco, R., Merson, D., \& Salter, D.W. (2010). The effect of gender, ethnicity, and income on college students' use of communication technologies. Cyberpsychology, Behaviour, and Social Networking, 13(6), 619-627.

Kaplan, M.D., Piskin, B., \& Bol, B. (2010). Educational blogging: Integrating technology into marketing education. Journal of Marketing Education, 32(1), 50-63. doi: 10/1177/0273475309335652

Kareem, H.I.A., \& Bakar, A.H.A. (2011). Identifying IT benefits for Malaysian construction companies. Journal of Information Technology in Construction, 16, 477-492.

Karim, N.S.A., Darus, S.H., \& Hussin, R. (2006). Mobile phone applications in academic library services: A students' feedback survey. Campus-Wide Information Systems, 23(1), 35-51.

Karmakar, S., Roy, N.K., Kumbhakar, P. \& Nafalski, A. (2009). ICT enabled high voltage laboratory: Cost effective tool for Engineering education. Paper presented at the 2009 Third International Conference on Power Systems, Kharagpur, India. December 27-29.

Karmen, G. (2001). Foundations of Exercise Science. Philadelphia: Lippincott Williams \& Wilkins.

Karper, C.M., Robinson, E.H., \& Casado, M. (2005). Computer-aided instructions and academic achievement in counsellor education. Journal of Technology in Counselling, 4,(1). Retrieved from http://jtc.columbusstate.edu/Vol4_1/Karper/Karper.htm

Kathryn Hall Research and Evaluation (2005). Computer access among Māori and Pacific students of The Open Polytechnic in South Auckland. Report prepared for the Learning Support Group of the Open Polytechnic of New Zealand, Wellington: The Open Polytechnic of New Zealand.

Katz, A. (1999). A computer-aided exercise for checking novices' understanding of market equilibrium changes. Journal of Economic Education, 30(2), 148-162.

Katz, I.R. (2007). Testing information literacy in digital environments: ETS's iskills assessment. Information Technology and Libraries, 26(3), 3-12. 
Keats, P.A. (2008). Buying into the profession: looking at the impact of expert videotape demonstrations in counsellor education. British Journal of Guidance and Counselling, 36(3), 219-235.

Kennedy, C., \& Levy, M. (2008). L'italiano al telefonino: Using SMS to support beginners' language learning. ReCALL, 20(3), 315-330.

Kenny, M. (2008) Graduate Counseling Students Success Counseling Undergraduate Students as Clients: A Model For Training. In J. Patterson \& I. Lipschitz (Eds.) Psychological Counseling Research Focus (pp. 59-70). Hauppauge, NY: Nova Science Publishers.

Kent, P.F. \& Linnegar, G.H. (1988). Integrating computers into accounting education: A survey of Australian universities and colleges. Accounting and Finance, 28(2), 81-91.

Kim, T.G., Lee, J.H., \& Law, R. (2008). An empirical examination of the acceptance behaviour of hotel front office systems: An extended technology acceptance model. Tourism Management, 29, 500-513.

King, S.A., Engi, S., \& Poulos, S.T. (1998). Using the internet to assist family therapy. British Journal of Guidance \& Counselling, 26(1), 43-52.

Kinnunen, P., \& Malmi, L. (2006). Why students drop out of CS1 course? Retrieved from

http://www.cgl.uwaterloo.ca/ lank/FemaleRecruitment/p97-kinnunen.pdf

Kirszner, L.J., \& Mandell, S.R. (2009). The Concise Wadsworth Handbook. $\left(6^{\mathrm{TH}}\right.$ Edition). Belmont, CA: Wadsworth Publishing.

Kizito, B.J. (2011). Gender-based analysis of information technology skills development among business computing students. Journal of Emerging Trends in Computing and Information Sciences, 2(8), 355-366.

Klein, B., \& Richards, C. (2001). A brief internet-based treatment for panic disorder. Behaviour \& Cognitive Psychotherapy, 29(1), 536-542.

Klimova, B. F. (2010). Making academic writing real with ICT. Procedia Computer Science, 3(2011), 133-137.

Koh, J.H.L., Chai, C.S., \& Tsai, C.C. (2010). Examining the technological pedagocial content knowledge of Singapore pre-service teachers with a large-scale survey. Journal of Computer Assisted Learning, 26(6), 563573.

Kolone-Collins, S. (2010). Fagogo: "Ua molimea manusina” A qualitative study of the pedagogical significance of Fagogo - Samoan stories at night - for the education of Samoan children. Unpublished Master of Education thesis. Auckland: Auckland University of Technology. 
Koloto, A., Katoanga, A., \& Tatila L. (2006). Critical success factors for effective use of e-learning by Pacific learners. Final report. Wellington: Institutes of Technology and Polytechnics of New Zealand.

Kossiakoff, A., Sweet, W.N., Seymour, S.J., \& Biemer, S.M. (2011). Systems engineering: principles and practice. Hoboken, NJ: John Wiley \& Sons.

Krishnan, V., Schoeffel, O., \& Warren, J. (1994). The challenge of change: Pacific Island communities in New Zealand, 1986-1993. Wellington, New Zealand: New Zealand Institute for Social Research and Development Limited.

Krishnaveni, R., \& Meenakumari, J. (2010). Usage of ICT for information administration in higher education institutions - A study. International Journal of Environmental Science and Development, 1(3), 282-286.

Laguna, K., \& Babcock, R.L. (1997). Computer anxiety in young and older adults: Implications for human-computer interactions in older populations. Computers in Human Behaviour, 13(3), 317-326.

Lai, M.L. (2008). Technology readindess, internet self-efficacy and computing experience of professional accounting students. Campus-Wide Information Systems, 25(1), 18-29.

Lane, C. (2011). Literacy skills of young adult New Zealanders: An analysis from the adult literacy and life skills survey. Wellington, New Zealand: Ministry of Education.

Lanvin, B. (2008). E-skills, competitiveness and employability. Retrieved from http://www.insead.fr/facultyresearch/centres/elab/documents/ESkillsWhitepaperv4.32oct08 000.pdf

Larkin, T.L., \& Quinn, C.M. (2011). The feminine side of engineering: It's way more than just "girl talk!" Proceedings - Frontiers in Education Conference FIE, article number 5673124, pp. F4E1-F4E5.

Lashley, C., \& Rowson, B. (2008). Getting IT right: Exploring information technology in the hospitality curriculum. International Journal of Contemporary Hospitality Management, 17(1), 94-105.

Latu, S., \& Young, A. (2003). Teaching ICT to Pacific Island Background Students. Retrieved August 22, 2011 from:

http://www.acs.org.au/documents/public/crpit/CRPITV30Latu.pdf

Laufer, B. (1992). How much lexis is necessary for reading comprehension? In $\mathrm{H}$. Bejoint \& P. Arnauds (Eds.), Vocabulary and applied linguistics (pp.126132). London: Macmillan.

Lave, J. \& Wenger, E. (1991). Situated Learning. Legitimate Peripheral Participation. New York: Cambridge University Press. 
Law, D., Shaffer, R.J., \& Stout, D.E. (2009). Bridging the education-profession gap: The accounting student-practitioner day (ASPD) program. Journal of Accounting Education, 27(3), 133-146.

Lawes, E. (2009). Literacy and life skills for Pasifika adults: Further results. Results from the adult literacy and life skills (ALL) survey. Wellington, New Zealand: Ministry of Education.

Lee, J.A. (2004). History of computing in education. In J. Impagliazzo \& J.A. Lee (Eds). History of computing in education (pp.1-16). Boston: Kluwer Academic Publishers.

Lee, S.A. (2008). Increasing student learning: A comparison of students' perception of learning in the classroom environment and their industrybased experiential learning assignments. Journal of Teaching in Travelling and Tourism, 7(4), 37-54.

Le Gallais, T. (2001). Innovative construction training: introducing information communication technology into the curriculum. Research in PostCompulsory Education, 6(3), 285-304.

Lengwiler, Y. (2004). A monetary policy simulation game. Journal of Economic Education, 35(2), 175-183.

Leveson, L. (2004). Encouraging better learning through better teaching: A study of approach to teaching in accounting. Accounting Education, 13(4), 529-548

Levin, T., \& Gordon, C. (1989). Effect of gender and computer experiences on attitudes towards computers. Journal of Educational Computing, 5(1), 69-88.

Lew, K. (2009). The Amazing Human Body: Respiratory System. Tarrytown, NY: Marshall Covendish Benchmark.

Lewis, J. (2008). SDLC 100 Success secrets. Raleigh, NC: Lulu

Lewis, C.M. (2011). Is pair programming more effective than other forms of collaboration for young students? Computer Science Education, 21(2), 105-134. doi: 10.108/08993408.2011.579805

Li, C., Dong, Z., Untch, R.H., \& Jagadeesh, D. (2011). Preparation station: a practical tool for CS1 and CS2 students in peerspace. Paper presented in ACME-SE '11 49th Annual Southeast Regional Conference. doi: 10.1145/2016039.2016128

Liberatore, M.W. (2010). Youtube Fridays: Engaging the net generation in 5 minutes a week. CAChe Newsletter, 44(3), 215-221.

Lichtman, M. (2006). Qualitative research in education: A user's guide. London, UK: Sage. 
Liebermann, D.G., Katz, L., Hughes, M.D., Bartlett, R.M., McClements, J., \& Franks, I.M. (2002). Advances in the applications of information technology to sports performance. Journal of Sports Sciences, 20(10), 755-769.

Lin, L., \& Atkinson, R.K. (2011). Using animations and visual cueing to support learning of scientific concepts and processes. Computers \& Education, 56(3), 650-658.

Lincoln, Y.S., \& Guba, E.G. (1985). Naturalistic inquiry. Newbury Park, CA: Sage.

Lindsay, C. (2005). Employability, services for unemployed job seekers and the digital divide. Urban Studies, 42(2), 325-339.

Lipka, O., \& Siegel, L.S. (2011). The development of reading comprehension skills in children learning English as a second language. Reading and Writing, (), 1-26.

Lockyer, B., Johnson, J. \& Dyer, J. (2009). Concepts content requirements for a mobile online learning community for marginalised youth. Proceedings of the International Multiconference on Computer Science and Information Technology. Retrieved September 1, 2011 from: http://ieeexplore.ieee.org/xpls/abs all.jsp?arnumber=5352701\&tag=1

Lodico, M.C., Spaulding, D.T., \& Voegtle, K.H. (2006). Methods in educational research: From theory to practice. San Francisco: Jossey-Bass.

Lopez-Bassols, V. (2002). ICT skills and employment, OECD Science, Technology and Industry Working Papers, 2002/10, OECD Publishing. Retrieved August 13, 2011 from:

http://dx.doi.org/10.1787/110542373678

Lu, M. (2008). Effectiveness of vocabulary learning via mobile phone. Journal of Computer Assisted Learning, 24(6), 515-525. doi: 10.1111/j.13652729.2008.00289.x

Luccase, R.A., \& Thomas, M.K. (2010). Simpsonomics: teaching economics using episodes of the Simpsons. Journal of Economic Education, 41(2), 136-149.

Lumsden, K., \& Scott, A. (1988). A characteristic approach to the evaluation of economics software packages. Journal of Economic Education, 19(4), 352-360.

Lundetrae, K., Gabrielsen, E., \& Mykletun, R. (2010). Do basic skills predict youth unemployment (16- to 24-year-olds) also when controlled for accomplished upper-secondary school? A cross-country comparison. Journal of Education and Work, 23(3), 233-254. 
Luu, K., \& Freeman, J.G. (2011). An analysis of the relationship between information and communication technology (ICT) and scientific literacy in Canada and Australia. Computers \& Education, 56(2011), 1072-1082.

Lysonki, S., \& Durvasula, S. (2008). Digital piracy of MP3: Consumer and ethical predispositions. Journal of Consumer Marketing, 25(3), 167-178.

MacDonald, Z., \& Shields, M.A. (1998). WinEco: an evaluation. Journal of Economic Surveys, 12(2), 221-231.

Maclntyre, L. (2008). Tongan mothers' contributions to their young children's education in New Zealand: Lukuluku 'a e kau fa'É Tonga' ki he ako 'enau fānau iiki' 'i nu'u sila. Unpublished PhD thesis, Palmerston North, New Zealand: MasseyUniversity.

Macpherson, C., Spoonley, P., \& Anae, M. (Eds.) (2001). Tangata o te moana nui: The evolving identities of Pafici peoples in Aotearoa/New Zealand. Palmerston North, New Zealand: Dunmore Press.

Madigan, E.M., Goodfellow, M., \& Stone, J.A. (2007). Gender, perceptions, and reality: Technological literacy among first-year students. ACM SIGC SE Bulletin, 39(1), 410-414.

Majid, R.A., Noor, N.L.M., Adnan, W.A.W., \& Mansor, S. (2010). A survey on user involvement in software development life cycle from practitioner's perspectives. Proceeding $-5^{\text {th }}$ International Conference on Computer Sciences and Convergence in Information Technology, ICCIT 2010, article no. 5711064, 240-243.

Manning, L.M. (1996). Economics on the internet: electronic mail in the classroom. Journal of Economic Education, 27(3), 201-204.

Manning, L.M., \& Riordan, C.A. (2000). Using groupware software to support collaborative learning in economics. Journal of Economic Education, 31(3), 244-252.

Manowaluilou, N. (2008). The importance of undergraduate's computer competency and information literacy skills: marketing faculty's perspectives in Thailand. Retrieved from https://mospace.umsystem.edu/xmlui/bitstream/handle/10355/5588/rese arch.pdf?sequence $=3$

Manueli, K., Save, L., \& Koh, D. (2008). Enhancing Pasifika businesses success with ICT. Proceedings - International Conference on Computer Science and Software Engineering, CSSE 2008 3, Article Number 4722401, pp. 540-545.

Mara, D.L. (2007). Theories and narratives: Pacific women in tertiary education and the social construction of ethnic identities in Aotearoa New Zealand. 
Unpublished PhD thesis. Wellington, New Zealand: Victoria University of Wellington.

Marshall, S. (2005). Determination of New Zealand tertiary institution of elearning capability: An application of an e-learning maturity model (eMM). Wellington, New Zealand: Ministry of Education.

Martin, F., \& Dunsworth, Q. (2007). A methodical formative evaluation of computer literacy course: What and how to teach. Journal of Information Technology Education, 6, 123-134. Retrieved from: http://jite.org/documents/Vol6/JITEv6p123-134Martin217.pdf

Matsumoto, J. (2000). Point-and-click training. Restaurants \& Institutions, 110(7), 61.

Matthews, B. \& Ross, L. (2010). Research methods. A practical guide for the social sciences. Essex, England: Pearson Education Limited.

Mayer, R.E. (2009). Multimedia Learning. (2 ${ }^{\text {nd }}$ Edition) New York: Cambridge University Press.

McAllister, C., \& Louth, R. (1988). The effect of word processing on the quality of basic writers' revision. Research in the Teaching of English, 22(4), 417427.

McCoy, C. (2010). Perceived self-efficacy and technology proficiency in undergraduate college students. Computers \& Education, 55(4), 16141617. doi: 10.1016/j.compedu.2010.07.003

McDonald, M., Dorn, B. \& McDonald, G. (2004). A statistical analysis of student performance in online computer science courses. SIGCSE'04

McDowall, S. (2010). Literacy teaching and learning in e-learning context. Wellington, New Zealand: Ministry of Education.

McDowell, C., Werner, L., Bullock, H.E., \& Fernald, J. (2006). Pair programming improves student retention, confidence, and program quality. Communications of the ACM, 49(8), 90-95.

Mcilroy, D., Sadler, C., \& Boojawon, N. (2007). Computer phobia and computer self-efficacy: their association with undergraduates' use of university computer facilities. Computers in Human Behaviour, 23(3), 1285-1299.

McLoughlin, C., \& Oliver, R. (1999). Designing learning environments for cultural inclusivity: A case study of the indigenous online learning in tertiary level. Australian Journal of Educational Technology, 16(1), 58-72.

Meelissen, M.R.M., \& Drent, M. (2008). Gender differences in computer attitudes: Does the school matter? Computers in Human Behaviour, 24(3), 969985. 
Mentzer, J.T., Cox, J.E., \& Meadow, H.L. (1983). The use of computer-based marketing cases in introductory and advanced marketing management courses. Journal of Marketing Education, 5(2), 2-12. doi: 10/1177/02347538300500202

Merriam, S.B. (2001). Qualitative research and case study applications in education. San Francisco: Jossey-Bass.

Merriam, S.B. (2009). Qualitative research: $A$ guide to design and implementation. San Francisco, CA: Jossey-Bass.

Mertens, D.M. (1998). Research methods in education and psychology. Integrating diversity with qualitative approaches. Thousand Oaks, CA: Sage.

Merten, S.M. (2005). Research and evaluation in education and psychology. Integrating diversity with quantitative, qualitative, and mixed methods. $\left(2^{\text {nd }} E d.\right)$. Thousand Oaks: Sage Publications.

Messineo, M., \& DeOllos, I.Y. (2005). Are we assuming too much? Exploring students' perceptions of their computer competence. College Teaching, 53(2), 50-56.

Meyers, K.L., Silliman, S.E., Gede, N.L., \& Ohland, M.W. (2010). A comparison of engineering students' reflections on their first year experiences. Journal of Engineering Education. Retrieved from http://www.jee.org/2010/april/8.pdf

Michaloski, A.O., \& Costa, A.P. (2010). A survey of IT use by small and mediumsized construction companies in a city in Brazil. Journal of Information Technology in Construction, 15, 369-390.

Mila-Schaaf, K. (2010). Polycultural capital and the Pasifika second generation: Negotiating identities in diasporic spaces. Unpublished PhD thesis. Auckland, New Zealand: Massey University.

Miles, M.B., \& Huberman, A.M. (1994). Qualitative data analysis: An expanded source book. Thousand Oaks, CA: Sage.

Miller, G. A., \& Gildea, P. M. (1987). How children learn words. Scientific American, 257(3), 94-99.

Miller, M. (2007). Absolute Beginner's Guide to Computer Basics. (4 ${ }^{\text {th }}$ Edition). Indianapolis: Que Publishing.

Ministry of Economic Development. (2008). New Zealand's Digital Strategy 2.0.

Wellington, New Zealand: Author.

Ministry of Education. (1998). New Zealand's tertiary education sector: Profile and Trends 1998. Wellington, New Zealand: Author. 
Ministry of Education. (2000). New Zealand's tertiary education sector. Wellington, New Zealand: Author.

Ministry of Education. (2006). ICT Strategic Framework for Education. Wellington, New Zealand: Author.

Ministry of Education. (2010a). Pasifika in tertiary education in New Zealand in 2009. Wellington, New Zealand: Author.

Ministry of Education. (2010b). Pasifika Education Plan: Monitoring Report 2009.

Wellington, New Zealand: Author.

Ministry of Education. (2011). Statistics. Retrieved

http://www.educationcounts.govt.nz/statistics/tertiary education/participa $\underline{\text { tion }}$

Ministry of Pacific Island Affairs. (2010). Career futures for Pacific peoples: A report on future labour market opportunities and education pathways for Pacific peoples. Wellington, New Zealand: Author.

Ministry of Pacific Island Affairs and Statistics New Zealand (2002). Pacific progress: A report on the economic status of Pacific peoples in New Zealand. Wellington, New Zealand: Author.

Mitchell, C. (2009). ICT industry skills saps and ultra fast broadband roll-out skill requirements. Wellington: Ministry of Economic Development.

Mitchell, D., Clayton, J., Gower, B., Barr, H., \& Bright, S. (2005). E-learning in New Zealand Institute of Technology or Polyechnics: Final Report. Wellington, New Zealand: Ministry of Education.

Miyazoe, T. \& Anderson, T. (2009). Learning outcomes and students' perception of online writing: Simultaneous implementation of a forum, blog, and wiki in EFL blended learning setting.

Mohammad, M. (2010). The implementation of government information systems and computer education within Aboriginal community in Australia. Paper presented at the 2010 International Conference on Educational and Information Technology. doi: 10.1109/ICEIT.2010.5607641

Mohsin, A. (2007). Human resource concerns: As assessment of motels in Hamilton, New Zealand. Journal of Human Resources in Hospitality \& Tourism, 6(2), 27-41.

Mompean, A.R. (2010). The development of meaningful interactions on a blog used for the learning of English as a foreign language. European Association for Computer Assisted Language Learning, 22(3), 376-395.

Morris, L.J., \& Byers, C.R. (1988). The impact of computerized test banks as a study aid in an introductory marketing course. Journal of Marketing Education, 10(2), 46-51. doi: 10/1177/027347538801000209 
Moses, K. (2010). Key factors affecting learner motivation to successfully complete qualifications through workplace learning. Wellington, New Zealand: Industry Training Federation.

Moy, M. (2011). Efficient and playful tools to teach Unix to new students. Paper presented at the $16^{\text {th }}$ Annual Joint Conference on Innovation and Technology in Computer Science (ITiCSE '11). doi: 10.1145/1999747.1999776

Muir, N.C. (2010). Computers for Seniors for Dummies. (2 ${ }^{\text {nd }}$ Edition). Hoboken, $\mathrm{NJ}$ : Wiley Publishing.

Muller, S. (2010). Upgrading and Repairing PCs. (19 ${ }^{\text {th }}$ Edition). Upper Saddle River, NJ: Pearson Education.

Munter, M. (1986). Using the computer in business communication courses. The Journal of Business Communication, 23(1), 31-42.

Murata, K. (2009) Laughter for diffusing tension: examples from business meetings in Japanese and in English. In R. Goebel, J. Siekmann, \& W. Wahlster (Eds.), New Frontiers in Artificial Intelligence, pp.294-305. New York: Springer.

Muratet, M., Torguet, P., Jessel, J.P., \& Viallet, F. (2009). Towards a serious game to help students learn computer programming. International Journal of Computer Games Technology, 2009, Article ID 470590. doi: $10.1155 / 2009 / 470590$

Murphy, L. J. \& Mitchell, D. L. (1998). When writing helps to heal: e-mail as therapy. British Journal of Guidance and Counselling, 26(1), 21-32.

Nabobo-Baba, U. (2005). Vugalei : voices and silences of what and how we know: indigenous Fijian epistemology and implications for education. Unpublished $\mathrm{PhD}$ thesis, Auckland, New Zealand: University of Auckland.

Nakhid, C. (2002). "Intercultural" Perceptions and Institutional Responses: Explaining Pasifika Students' Achievement in New Zealand Secondary School. Unpublished PhD thesis, Auckland, New Zealand: University of Auckland.

Nassar, K. (2002). Simulation gaming in construction: ER, The Equipment Replacement Game. Journal of Construction Education, 7(1), 16-30.

Nawawi, N.H.A., \& Ling, L.M. (2010). Undergraduate tax education in the new millennium: Technical vs conceptual. 2010 International Conference in Science and Social Research, (pp 602-606). Kuala Lumpur, Malaysia: CSSR. 
Neish, B. (2009). Computer Accounting Using MYOB Business Software. New York: McGraw-Hill.

Newby, P. (2010). Research methods for education. Harlow, England: Pearson Education.

Newhouse, C.P. (2002). Literature review: The impact of ICT on learning and teaching. Retrieved from

http://www.det.wa.edu.au/education/cmis/eval/downloads/pd/impactrevie w.pdf

New Zealand Computer Society (2011). Exploring SFIA (1 of 3): ICT skills and recruitment. Retrieved from http://www.nzcs.org.nz/newsletter/49

New Zealand Trade and Enterprise. (2011). Information and communication technology. Retrieved August 5, 2001 from:

http://www.nzte.govt.nz/access-international-networks/Exploreopportunities-in-growth-industries/growth-industries/Pages/Informationand-communication-technologies.aspx

New Zealand Qualification Authority (2011). National Certificate in Computing (Level 2). Retrieved from http://www.nzqa.govt.nz/ngfdocs/quals/pdf/0010.pdf

Nieto, S. (2008). Affirming diversity: The socio-political context of multicultural education. White Plains, NY: Longman.

Norris, P. (2001). Digital divide: civic engagement, information poverty and the internet. Cambridge, UK: Cambridge University Press.

Obermayer, J.L., Riley, W.T., Asif, O., \& Jean-Mary, J. (2004). College smokingcessation using cell phone text messaging. Journal of American College of Health, 53(2), 71-80.

O'Leary, T. J., \& O'Leary, L. I. (2008). Computing Essentials. New York: McGraw-Hill.

Opie, C. (2004). What is educational research? In C. Opie (Ed.), Doing educational research: a guide to first time researchers, (pp.1-14) London, UK: Sage Publication.

Oraegbunam, N.M. (2009). Applying information and communication technology in counselling practice. Procedia Social and Behavioural Sciences, 1(1), 1749-1752.

Organisation for Economic Co-operation and development. (2005). New perspectives on ICT skills and employment. Retrievedfrom: http://www.oecd.org/dataoecd/26/35/34769393.pdf

Ortlipp,M. (2008). Keeping and using reflective journals in the qualitative research process. The Qualitative Report, 13(4), pp. 697-705. 
Otsuka, S. (2005). Cultural influences on academic performance in Fiji: a case study in the Nadroga/Navosa province. Unpublished $\mathrm{PhD}$ thesis. Sydney, Australia: The University of Sydney.

Otsuka, S. (2006). Talanoa research: culturally appropriate research design in Fiji. Retrieved from http://www.aare.edu.au/05pap/ots05506.pdf

Otunuku, M., \& Brown, G.T.L. (2007). Tongan students' attitudes towards their subjects in New Zealand relative to their academic achievement. Asia Pacific Education Review, 8(1), 117-128.

Ozer, T., \& Cravalho, E.G. (2004). On developments in interactive web-based learning modules in a thermal-fluids engineering course: Part II. International Journal of Engineering Education, 20(5), 849-860.

Ozer, T., Kenworthy, M., Brisson, J.G., Cravalho, E.G., \& McKinley, G.H. (2003). On developments in interactive web-based learning modules in a thermal-fluids engineering course. International Journal of Engineering Education, 19(2), 305-315.

Pacific Economic Development Agency Ltd. (2007). Pacific People in NZ.

Retrieved from

http://www.pacificeda.org/index.php?option=com content\&view=article\&i $\underline{d=30 \& \text { Itemid }=36}$

Painter, J. (2000). Teaching garnishing and napkin folding to hospitality students, comparing the effectiveness of written diagrams versus multimedia computer videos. Foodservice Research International, 12(3), 175-183.

Pajares, M.F. (1992). Teacher's belief and education research: cleaning up a messy construct. Review of Education Research, 62(3), 307-332.

Palmer, J. (2006). Negotiating the indistinct: reflections of a Korean adopted American working with Korean born, Korean Americans. Qualitative Research. 6 (4), 473-495. London: Sage Publications.

Pan, S.C. (2010). The relationship between teachers' self-efficacy and the integration of Web 2.0 tools. Unpublished PhD thesis. Athens, Ohio: Ohio University.

Papastergiou, M. (2010). Physical education and sport science undergraduate students as multimedia and web developers: Moving from the user's to the creator's perspective. Education and Information Technology, 16(3), 281-299.

Papastergiou, M., Gerodimos, V., \& Antoniou, P. (2011). Multimedia blogging in physical education: Effects on students' knowledge and ICT selfefficacy. Computers \& Education, 57(3), 1998-2010. 
Park, M., Chan, S.L., \& Ingawale-Verma, Y. (2003). Three success factors for simulation based construction education. Journal of Construction Education, 8(2), 101-114.

Parr, J.M., \& Fung, I. (2000). A review of the literature on computer-assisted learning, a particularly integrated learning systems, and outcomes with respect to literacy and numeracy. Final Report. Wellington, New Zealand: Ministry of Education.

Pasikale, A. \& Yaw, W. (1998). Weaving the way: Pacific Islands peoples' participation in the provision of learning pathways for Pacific Islands learners. Wellington: Education \& Training Support Agency.

Pasikale, A. (1996). Seen, but not heard: voices of Pacific Islands' learners: a qualitative study of Pacific Islands' learners in second-chance education, and the cultural differences impacting on their aspirations, opportunities and participation. Wellington: Education \& Training Support Agency.

Patterson, Jr., F.G. (2004). Life cycles for system acquisition. In A.P. Sage (Ed.), Systems Engineering and Management for System Development, pp. 82-110. Oxford, UK: EOLSS Publishers. Retrieved from http://www.eolss.net/ebooks/Sample\%20Chapters/C15/E1-28-01-02.pdf

Patton, M.Q. (2002). Qualitative research \& evaluation methods ( $3^{\text {rd }}$ ed.). London, UK: Sage.

Paul, P., \& Mukhopadhyay, K. (2005). Experiential learning in international business education. Journal of Teaching in International Business, 16(2), 7-25.

Pelgrum, W.J. and Law, N. (2003). ICT in education around the world: Trends, problems and prospects. Retrieved from http://unesdoc.unesco.org/images/0013/001362/136281e.pdf

Penetito, W. and Sanga, K. (2003). A conversation of the philosophy of and practice of teaching research in Maori and Pacific education. New Zealand Annual Review of Education, 21, 21-37.

Peng, G., \& Eunni, R.V. (2011). Computer skills, non-rountine tasks, and wages premium: A longitudinal study. Journal of Strategic Information Systems, 20(4). doi: 10.1016/j.jsis.2011.09.002

Petelo, L.M. (2003). Fa'alogo i leo o le fanau : a qualitative study of the ways in which students of Samoan background experience their education within the University of Canterbury. Unpublished PhD thesis. Canterbury, New Zealand: University of Canterbury.

Petrova, K. (2001). Teaching differently. Retrieved from http://aut.researchgateway.ac.nz/handle/10292/847 
Petrova, K. \& Sinclair, R. (2005). Business Undergraduates Learning Online: A One Semester Snapshot. International Journal of Education and Development Using Information and Communication Technology, 1(4), pp. 69-88, December 2005. ISSN 1814-0556.

Ping, L.C. (2003) Information and Communication Technologies (ICT) addressing the challenges of economics education: to be or not to be? International Review of Economics Education, 2(1), 25-54.

Pogue, D., \& Goldstein, A. (2005). Switching to the Mac: The Missing Manual, Tiger edition. Sebastopol, CA: O'Reilly Media.

Porter, L., Lee, C.B., Simon, B., \& Zingaro, D. (2011). Peer instruction: Do students really learn from peer discussions in computing? Proceedings of the seventh international workshop on Computing education research. Providence, RI: ACM.

Potter B \& Johnston C. (2006). The effect of interactive on-line learning systems on student learning outcomes in accounting. Journal of Accounting Education, 24(1), 16-34.

Prescott, S.M. (2009). Pacific business sustainability in New Zealand: a study of Tongan experiences. Unpublished PhD thesis, Auckland, New Zealand: Auckland University of Technology.

Preziosa, A., Grassi, A., Gaggioli, A., \& Riva, G. (2009). Therapeutic applications of the mobile phone. British Journal of Guidance \& Counselling, 37(3), 313-325.

Pritchard, R.M.O., \& Nasr, A. (2004). Improving reading performance among Egyptian engineering students: principles and practice. English for Specific Purpose, 23(4), 425-445.

Quennerstedt, M. (2011). Practical epistemologies in physical education practice. Sport, Education and Society. doi: 10.1080/13573322.2011.582245

Quinn, A.C., Hohenshill, T., \& Fortune, J. (2002). Utilization of technology in CACREP approved counsellor programs. Journal of Technology in Counselling, 2(2). Retrieved from:

http://itc.columbusstate.edu/vol2 2/quinn/quinn.htm

Raina, R. (2007). ICT human resource development in Asia and the Pacific: Current status, emerging trends, policies and strategies. Retrieved August 5, 2011 from: http://www.unapcict.org/ecohub/resources/icthuman-resource-development-in-asia-and-the 
Rambo-lgney, B.C., \& Brinthaupt, T.M. (2008). Best practices of college teaching connect with hybrid online instruction. Journal of Technology in Counselling, 5(1). Retrieved from http://jtc.columbusstate.edu/Vol5_1/RamboBrinthaupt.htm

Rapisarda, C., \& Jencius, M. (2005). Using high bandwidth videoconferencing to enhance technology attitudes in students. Journal of Technology in Counselling, 4(1). Retrieved from http://jtc.columbusstate.edu/Vol4_1/Rapisarda/Rapisarda.htm

Raturi, S., Hogan, R., \& Helu-Thaman, K. (2011). Learners' access to tools and experience with technology at the University of the South Pacific: readiness for e-learning. Australasian Journal of Educational Technology, 27(3), 411-427.

Rawlinson, D.R., \& Lupton, R.A. (2007). Cross-national attitudes and perception concerning software piracy: A comparative study of students from the United States and China. Journal of Education for Business, 83(2), 8794.

Richards, D. (2009). Features and benefits of online counselling: Trinity College online mental health community. British Journal of Guidance \& Counselling, 37(3), 231-242.

Richards, K. (2006). 'Being the teacher': Identity and classroom conversations. Applied Linguistics, 27(1), 51-77.

Ridwan, m., Yap, C., \& Mannan, A. (2001). A WWW-based course structure for teaching athermodynamics and heat transfer course. International Journal of Engineering Education, 17(2), 176-188.

Robinson, D., \& Robinson, K. (2005). Pacific ways of talk - hui and talanoa. Retrieved from http://scpi.org.nz/scpi docs/Pacific Ways of Talk.pdf

Robinson, L. (2006). Moving beyond adoption: Exploring the determinants of student intention to use technology. Marketing Education Review, 16(2), 79-88.

Robinson, S., Perkins, S., Bauer, S., Hammond, N., Treasure, J., \& Schmidt, U. (2006). Aftercare intervention through text messaging in the treatment of bulimia nervosa - Feasibility pilot. International Journal of Eating Disorders, 39(8), 633-638.

Rochford, K. (2010). Those who stayed loyal: An empirical examination of New Zealand manufacturers surviving in a global market. Journal of Enterprising Communities: People and Places in the Global Economy, 4(4), 346-371. 
Rockman et al. (1999). A more complex picture: laptop use and impact in the context of changing home and school access. Retrieved from http://www.rockman.com/projects/126. micro.aal/yr3 report.pdf

Rodgers, A., Corbett, T., Bramley, D., Riddell, T., Wills, M., Lin, R.B., \& Jones, M. (2005). Do u smoke after txt? Retrieved from http://www.ncbi.nlm.nih.gov/pmc/articles/PMC1748056/pdf/v014p00255. $\underline{\mathrm{pdf}}$

Rosen, L.D., \& Weil, M.M. (1992). Measuring technophobia. A manual for the administration and scoring of the computer anxiety rating scale, the computer thoughts survey and the general attitude toward computer scale. Orange, CA: Chapman University.

Royce, W.W. (1970). Managing the development of large software systems. Proceedings of IEEE WESCON, August 1970, 1-9.

Ruru, D. (2010). Strengthening the effectiveness of aid delivery in teacher education: a Fiji case study. Unpublished PhD thesis, Wellington, New Zealand: Victoria University of Wellington.

Ryan, P.K. (2011). Social Networking. New York: The Rosen Publishing Group.

Saeed, N., Yang, Y., \& Sinnappan, S. (2009). Emerging web technologies in higher education: a case of incorporating blogs, podcasts and social bookmarks in a web programming course based on students' learning styles and technology preferences. Educational Technology \& Society, 12(4), 98-109.

Safko, L. (2010). The Social Media Bible. Hoboken, NJ: John Wiley \& Sons.

Samuelsson, U. (2010). ICT use among 13-year-old Swedish children. Learning, Media and Technology, 35(1), 15-30.

Sancho, P.G. (1986). Mathematics and computers in teaching engineering, European Journal of Engineering Education, 11(2), 161-164.

Santos, I.M., and Ali, N. (2011). Exploring the use of mobile phones to support informal learning. Education and Information Technologies. doi: 10.1007/s10639-011-9151-2

Santos, J. (2002). Developing and implementing an internet-based financial system simulation game. The Journal of Economic Education, 33(1), 3140.

Satherley, P., \& Lawes, E. (2007). The adult literacy and life skills (ALL) survey: An introduction. Wellington, New Zealand: Ministry of Education.

Saunders, P. (1964). The effectiveness of The American Economy in training secondary school teachers. American Economic Review, 54(4), 396403. 
Savage, S.J. (2009). The effect of information technology on economic education. Journal of Economic Education, 40(4), 337-353. doi: $10.1080 / 00220480903237901$

Savage, T.M., \& Vogel, K.E. (2009). An introduction to digital multimedia. London: Jones and Bartlett Publishers.

Sayago, S. \& Blat, J. (2011). An ethnographical study of the accessibility barriers in the everyday interactions of older people with the web. Universal Access to the Information Society, 10(4), 359-371.

Scheraga, J.D. (1986). Instruction in economics through simulated computer programming. Journal of Economic Education, 17(2), 129-139.

Schmidt, R.A., \& Lee, T. (1999). Motor control and learning. Champaign, IL: Human Kinetics.

Schmidt, S.J. (2003). Active and cooperative learning using web-based simulations. Journal of Economic Education, 34(4), 151-167.

Schoeffel, P. \& Meleisea, M. (1994). Pacific Islands Polynesian attitudes to child training and discipline in New Zealand: some policy implications for social welfare and education. Social Policy Journal of New Zealand, 6.

Schraw, G.J., \& Olafson, L.J. (2008). Assessing teachers' epistemological and ontological worldviews. In M.S. Khine (ed.), Knowing, knowledge and beliefs: Epistemological studies across diverse cultures (pp. 25-44). Perth, Australia: Springer.

Schreuders, P.D., Mannon, S.E., \& Rutherford, B. (2009). Pipeline or personal preferences: women in engineering. European Journal in Engineering Education, 34(1), 97-112.

Scott, C., \& Rockwell, S.C. (1997). The effect of communication, writing, and technology apprehension on likelihood to use new communications technologies. Communication Education, 46(1), 44-62.

Scott, D, and Lane, C. (2010). Non-formal and formal learning: adults in education. Wellington, New Zealand: Ministry of Education.

Scott, D. \& Morrison, M. (2006). Key ideas in educational research. London, UK: Continuum International Publication.

Selwyn, N. (2009). Faceworking: exploring students' education-related use of Facebook. Learning, Media and Technology, 34(2), 157-174.

Selwyn, N., Marriott, N. \& Marriott, P. (2000). 'Getting a Tick in the Box': exploring accountancy undergraduates' use of information and communications technology. Research in Post-Compulsory Education, 5(2), 193-209. 
Shashaani, L. (1994). Socioeconomic status, parents' sex role stereotypes, and the gender gap in computing. Journal of Research on Computing in Education, 26(4), 433-451.

Sheets, R.H. (2005). Diversity pedagogy: Examining the role of culture in the teaching-learning process. Boston, MA: Allyn \& Bacon.

Sheets, R.H. (2009). What is diversity pedagogy theory? Multicultural Education, 16(3), 11-17.

Shepherd, C. (2004). E-learning has more fans than we thought. IT Training, 5(7), 29.

Sheriffdeen, S. (2007). Challenges faced by staff and students at tertiary level in flexible learning environment: An institutional study. Retrieved from http://unitec.researchbank.ac.nz/handle/10652/1278

Sherman, C. (2005). Google Power: Unleash the Full Power of Google. New York, NY: McGraw-Hill.

Shieh, R.S., Chang, S.L. \& Liu, E.Z.F. (2011). A case study of low-status women's attitudes towards computers. Educational Studies, 37(2), 233243.

Sigala, M. (2007). RFID applications for integrating and informationalizing the supply chain of foodservice operators. Journal of Foodservice Business Research, 10(1), 7-29.

Sigala, M. (2011). Integrating and exploiting information and communication technologies (ICT) in restaurants. Journal of Foodservice Business Research, 6(3), 55-76.

Siguaw, J., Enz, C., \& Namasivayan, K. (2000). The adoption of information technology in US hotels: Strategically driven objectives. Journal of Travel Research, 39(2), 192-201.

Simkins, S.P. (1999). Promoting active student learning using the world wide web in economics courses. Journal of Economic Education, 30(3), 278-286.

Singh, D., Kim, Y-S., \& Feinstein, A.H. (2011). Internet utilization as a medium for training employees in multi-unit restaurants. Journal of Foodservice Business Research, 14(2), 122-145.

Skills2Learn (2010). Skills2Learn News: Launch of the gas \& plumbing e-learning programme. Retrieved from: http://www.skills2learn.com/news-gasplumbing-launch.htm

Skoudis, E., \& Zeltser, L. (2004). Malware: Fighting Malicious Code. Upper saddle River, NJ: Pearson Education. 
Smith, L.M., \& Smith Jr, L.C. (1989). Microcomputer applications for teaching economic concepts: some old and new approaches. Journal of Economic Education, 20(1), 73-92.

Smith, L.T. (2008). On tricky ground: Researching the native in the age of uncertainty. In N.K. Denzin \& Y.S. Lincoln (Eds.) The Landscape of Qualitative Research (pp.145-183). London, UK: Sage.

Smith, P., Smith, N., Sherman, K., Goodwin, I., Crothers, C., Billot, J., Bell, A. (2010). The Internet in New Zealand 2009. Auckland, New Zealand: Institute of Culture, Discourse and Communications, AUT University.

Sneed, J. \& Kresse, K.H. (1988). Understanding foodservice financial management. Salem, MA: Aspen Publishers.

Sommerville, J. \& Craig, N. (2006). Implementing IT in Construction. New York: Routledge, Taylor \& Francis Group.

Sorrentino, R.S.M. (2000). A simulation of Internet enhanced motor learning. Unpublished PhD thesis. Calgary, Alberta: University of Calgary.

Spiezia, V. (2011). Does computer use increase educational achievements? Student-level evidence from PISA. OECD Economic Studies, 7(1), 1-22.

Sprague, D., \& Pixley, C. (2008). Podcasts in education: let their voice be heard. Computers in the Schools, 25(3-4), 226-234.

Stair, R., and Reynolds, G. (2010). Principles of Information Systems. Boston, MA: Course Technology.

Stanley, T., \& Edwards, P. (2005). Interactive multimedia teaching of accounting information systems (AIS) cycles: student perceptions and views. Journal of Accounting Education, 23(1), 21-46.

Stare, M., Jaklic, A., \& Kotnik, P. (2006). Exploiting ICT potential in service firms in transition economies. The Service Industries Journal, 26(3), 287-302.

Statistics New Zealand. (2007a). Information and Communication Technology in New Zealand: 2006. Wellington, New Zealand: Author.

Statistics New Zealand. (2007b). Samoan people in New Zealand: 2006. Wellington, New Zealand: Author.

Statistics New Zealand. (2007c). Regional Summary Tables. Retrieved from http://www.stats.govt.nz/Census/about-2006-census/regional-summarytables.aspx

Statistics New Zealand (2009). Household Use of Information and Communication Technologies: 2009. Retrieved from http://www.stats.govt.nz/browse for stats/industry sectors/information t echnology and communications/HouseholdUseofICT HOTP2009.aspx 
Statistics New Zealand \& Ministry of Pacific Island Affairs. (2010). Demographics of New Zealand's Pacific population. Wellington, New Zealand: Author.

Statistics New Zealand (2011a). Household use of information communication technology: 2009 Additional tables. Retrieved from: http://www.stats.govt.nz/browse for stats/industry sectors/information t echnology and communications/hhold-use-of-ict/household-ict-2009$\underline{\text { tables.aspx }}$

Statistics New Zealand (2011b). Subnational ethnic population projections. Retrieved from: http://www.statistics.govt.nz/browse for stats/population/estimates and projections/subnational-ethnic-population-projections.aspx

Stefanovic, M., Matijevic, M., Cvijetkovic, V., \& Simic, V. (2007). Web-based laboratory for engineering education. Computer Application in Engineering Education, 18(3), 526-536.

Stein, S.J., Shephard, K., \& Harris, I. (2011). Conceptions of e-learning and professional development for e-learning held by tertiary educators in New Zealand. British Journal of Educational Technology, 42(1), 145165.

Stockwell, G. (2010). Using mobile phones for vocabulary activities: Examining the effect of the platform. Language Learning \& Technology, 14(2), 95110.

Stoilescu, D., \& Egodawatte, G. (2010). Gender differences in the use of computers, programming, and peer interactions in computer science classrooms. Computer Science Education, 20(4), 283-300.

Stoner, G. (2009). Accounting students' IT application skills over a 10-year period. Accounting Education: An International Journal, 18(1), 7-31

Sugahara, S., \& Borland, G. (2006). The effectiveness of PowerPoint in the accounting classroom. Accounting Education: An International Journal, 15(4), 391-403.

Sun, Y. (2010). Extensive writing in foreign-language classrooms: a blogging approach. Innovations in Education and Teaching International, 47(3), 327-339.

Surdam, D.G. (2009). A sports franchise simulation game. The Journal of Economic Education, 40(2), 138-149.

Sustelo, F., \& Guerreiro, P. (2010). Analysing self-reflection by computer science students to identify bad study habits. Paper presented at the IEEE EDUCON Education Engineering 2010 - The Future of Global Learning Engineering Education. Madrid, Spain: IEEE 
Suter, W.N. (2006). Introduction to educational research. A critical thinking approach. Thousand Oaks: Sage Publications.

Sydorenko, T. (2010). Modality of input and vocabulary acquisition. Language Learning \& Technology, 14(2), 50-73.

Taplin, R.H., Low, L.H., \& Brown, A.M. (2011). Students' satisfaction and valuation of web-based lecture recording technologies. Australasian Journal of Educational Technology, 27(2), 175-191.

Taylor, H.G., \& Mounfield, L.C. (1994). Exploration of the relationship between prior computer experience and gender success in college computer science. Journal of Educational Computing Research, 11(4), 291-306.

Taylor, M., \& Pountney, D. (2009). Animation as an aid for higher education computer teaching. Transactions on Edutainment III, Book Series Title: Lecture Notes in Computer Science, 203-218. Doi: 10.1007/978-3-64211245-4_18

Tearle, P. \& Golden, G. (2008). The use of ICT in the teaching and learning of physical education in compulsory education: how do we prepare the workforce of the future? European Journal of Teacher Education, 31(1), 55-72.

Tertiary Education Commission. (2008). Literacy, language and numeracy action plan 2008-2012. Wellington, New Zealand: Tertiary Education Commission.

Thatcher, A. (2008). Web search strategies: The influence of web experience and task type. Information Processing and Management, 44(3), 1308-1329.

Theunissen, P., \& Theunissen, C.A. (2007). New Zealand-based students' perception and use of the internet as a communication tool and source of information. Communication Journal of New Zealand, 10(1), 28-45.

The Virginia Adult Learning Resource Centre (2010). General Construction Lesson One: Measurement and Dimensions. Retrieved from http://www.valrc.org/publications/buildingbasics/index.html

The World Bank. (2009). 2009 Information and communications for development: Extending reach and extending impact. Washington: Author.

Thomas, A. \& Stratton, G. (2006). What are we really doing with ICT in physical education: a national audit of equipment, use, teacher attitudes, support, and training. British Journal of Educational Technology, 37(4), 617-632.

Thomson, L., \& Lamshed, R. (2006). E-learning within the building and construction and allied trades. Canberra, Australia: Department of Education, Science and Training. 
Thornton, P., \& Houser, C. (2005). Using mobile phones in English education in Japan. Journal of Computer Assisted Learning, 21(3), 217-228.

Todman, J., \& Dick, G. (1993). Primary children and teacher's attitudes to computers. Computers and Education, 20(2), 199-203.

Tuten, T. (2009). Real world experience, virtual world environment: The design and execution of marketing plans in Second Life. Marketing Education Review, 19(1), 1-5.

Underground Skater. (2008). Skateboarding. Retrieved from http://freepdfhosting.com/0cb384d4d4.pdf

Vaioleti, T. (2006). Talanoa research methodology: A developing position on Pacific research. Waikato Journal of Education, 12, 21-35.

Varsavsky, C. (2010). Chances of success in and engagement with mathematics for students who enter university with a weak mathematics background. International Journal of Mathematical Education, 41(8), 1037-1049.

Van Braak, J.P. (2004). Domains and determinants of university students' selfperceived computer competence. Computers and Education, 43(3), 299312.

Veen, W. (2009). How technologies change our schools, companies and governments. Proceedings of the International Workshop on Enterprises \& Organisational Modelling and Simulation 2009. New York: ACM

Veletsianos, G. (2011). Higher education scholars' participation and practices on Twitter. Retrieved from http://www.veletsianos.com/wpcontent/uploads/2011/10/scholars on twitter veletsianos.pdf

Verezub, E., Grossi, V., Howard, K., \& Watkins, P. (2008). Building e-based literacy for vocational education and training students. Australasian Journal of Educational Technology, 24(3), 326-338.

Verhoeven, J.C., Heerwegh, D., \& de Wit, K. (2011). First year university students' self-perception of ICT skills: Do learning styles matter? Journal of Education and Information Technologies. doi: 10.1007/s10639-0109149-1

Von Haenisch, C. (2011). How did compulsory personal therapy during counselling training influence personal and professional development? Counselling and Psychotherapy Research, 11(2), 148-155.

Vryzas, K., \& Tsitouridou, M. (2002). The home computer in children's everyday life: The case of Greece. Journal of Educational Media, 27(1-2), 9-17.

Vygotsky, L. (1978). Mind in society: The development of higher psychological processes. M. Cole, V. John-Steiner, S. Scribner, \& E. Souberman (Eds. \& Trans.). Cambridge, MA: Harvard University Press. 
Walczyk, T. (2008). Google video - just another video sharing site? Journal of Library Administration, 47(1-2), 175-181.

Waldron, V.R., \& Yungbluth, S.C. (2007). Assessing student outcomes in communication-intensive learning communities: A two-year longitudinal study of academic performance and retention. Southern Communication Journal, 72(3), 285-302.

Wallace, P., \& Clariana, R. (2005). Perception versus reality - determining business students' computer literacy skills and need for instruction in information concepts and technology. Journal of Information Technology Education, 4, 141-151. Retrieved from http://www.jite.org/documents/Vol4/v4p141-151Wallace59.pdf

Waller, V., \& Waller, G. (2000). The Internet Companion: The Easy Australian Guide. Sydney, Australia: UNSW Press.

Walsh, B., \& Johnson, G.A. (2001). Validation: Never an endpoint: A systems development life cycle approach to good clinical practice. Drug Information Journal, 35(3), 809-817.

Walter, M. (2010). The nature of social science research. In Social Research Methods (2 $2^{\text {nd }}$ ed., pp. 3-30). Melbourne, Australia: Oxford University Press.

Wang, Q. (2006). Transforming learning with emerging technologies. In M. S. Khine (Eds.), Teaching with technology: Strategies for engaging learners (pp. 281-294). Jurong, Singapore: Prentice Hall.

Ward, M.J., Kester, D., \& Kouzekanani, K. (2009). Using preservice teachers to improve computer skills of at-risk alternative high school students. Journal of Education for Students Placed at Risk, 14(2), 189-200.

Watson, H.J. (1981). Computer simulation in business. New York: John Wiley and Sons.

Watson, W.R., \& Watson, S.L. (2007). An argument for clarity: What are learning management systems, what are they not, and what should they become? TechTrends, 51(2), 28-34.

Watty, K., Jackson, M., \& Yu, X. (2010). Students' approaches to assessment in accounting education: The unique student perspective. Accounting Education: An International Journal, 19(3), 219-234.

Webb, S. (2006). Can ICT reduce social exclusion? The case of an adults' English language learning programme. British Educational Research Journal, 32(3), 481-507. 
Weil, M.M., \& Rosen, L.D. (1995). The psychological impact of technology from a global perspective: A study of technological sophistication and technophobia in university students from twenty three countries. Computers in Human Behaviour, 11(1), 95-133.

Weir, T., \& Connor, S. (2009). The use of digital video in physical education. Technology and Education, 18(2), 155-171.

Wellington, W.J., \& Faria, A.J. (1996). The use of simulation games in marketing classes: Is simulation performance due to luck or skill? Journal of Marketing Education, 18(2), 50-61. doi: 10/1177/027347539601800206

Wellington Institute of Technology. (2009a). Business Management. Wellington, New Zealand: Author.

Wellington Institute of Technology. (2009b). ESOL. Wellington, New Zealand: Author.

Wellington Institute of Technology. (2009c). Exercise Science and Recreation. Wellington, New Zealand: Author.

Wellington Institute of Technology. (2009d). Construction Trades. Wellington, New Zealand: Author.

Wellington Institute of Technology. (2009e). Hospitality and Tourism. Wellington, New Zealand: Author.

Wellington Institute of Technology. (2009f). Addictions, Counselling and Health Studies. Wellington, New Zealand: Author.

Wellington Institute of Technology. (2009g). Annual Report 2008. Wellington, New Zealand: Author.

Wellington Institute of Technology. (2011). Annual Report 2010. Wellington, New Zealand: Author.

Wells, P., De Lange, P. \& Fieger, P. (2008). Integrating a virtual learning environment into a second-year accounting course: determinants of overall student perception. Accounting and Finance, 48(3), 94-97.

Wenger, E. (1998). Communities of practice: learning, meaning and identity. New York: Cambridge University Press.

Wensvoort, M. (2011). Pasifika in tertiary education in 2009. Wellington, New Zealand: Ministry of Education.

Wexler, S.S., Drury, L.J., Coppola, J., F., Tschinkel, B.J., \& Thomas, B.A. (2011). Service-learning computing courses assist with technology needs in community based organizations serving older adults. doi: $\underline{10.1109 / \text { LISAT.2011.5784226 }}$ 
Whitton, N. \& Hynes, N. (2006). Evaluating the effectiveness of an online simulation to teach business skills. Retrieved September 3, 2011 from: http://www.ascilite.org.au/ajet/eiist/docs/vol9 no1/papers/current practice/whitton hynes.htm

Wikan, G., \& Molester, T. (2011). Norwegian secondary school teachers and ICT. European Journal of Teacher Education, 34(2), 209-218.

Wilkinson, D., \& Birmingham, P. (2003). Using research instruments. A guide for researchers. London, UK: RoutledgeFarmer.

Wilson, A. (2011). Effective professional development for e-learning: What do the managers think? British Journal of Educationbal Technology. DOI: $10.1111 / \mathrm{j} .1467-8535.2011 .01248 . x$

Wilson, B. (1999). Redressing the anxiety imbalance: computerphobia and educators. Behaviour \& Information Technology, 18(6), 445-453.

Winke, P., Gass, S.M., \& Sydorenko, T. (2010). The effects of captioning videos used for foreign language listening activities. Language Learning \& Technology, 14(1), 66-87.

Wolf, C. (2007). Construction of an adaptive e-learning environment to address learning styles and an investigation of the effect of media choice. Unpublished PhD thesis. Melbourne, Australia: Royal Melbourne Institute of Technology University.

Wongyu, L. (2005). A model curriculum for integrating computer science and ICT curriculum. Seoul, Korea: Korea Education and Research Information Service.

Woo, K., Gosper, M., McNeill, M., Preston, G., Green, D., \& Phillips, R. (2008). Web-based lecture technologies: Blurring the boundaries between faceto-face and distance learning. ALT-J: Research in Learning Technology, 16(2), 81-93. Retrieved from http://repository.alt.ac.uk/742/

Wood, J. (1968). Using the tape recorder in teaching adults to read. Journal of Reading, 11(7), 528-531.

Woodward, A.T., Freddoloni, P.F., Blaschke-Thompson, C.M., Wishart, D.J., Bakk, J., Kobayashi, R., \& Tupper, C. (2011). Technology and aging project: Training outcomes and efficacy from a randomised field trial. Ageing International, 36(1), 46-65.

Wozniak, P.A. (1990). Optimization of learning. Retrieved from http://www.supermemo.com/english/ol.htm

Woolcock, C. (2011). To what extent does studying to become an Australian trade-qualified cook prepare culinary students for further education? Journal of Culinary Science \& Technology, 9(4), 228-246. 
Workman, J.P. (2008). Wikis in the classroom: Opportunities and challenges. Marketing Education Review, 18(1), 19-24.

Workforce Development Council of Seattle-King County. (2007). State of the workforce: Information technology and the workforce. Retrieved August 5, 2011 from: http://www.seakingwdc.org/pdf/state-of-the-workforce/sow$\underline{\text { IT.pdf }}$

Wright, B.L. (2011). I know who I am, do you?: Identity and academic achievement of successful black African American male adolescent in an urban pilot high school in the United. Urban Education, 46(4), 611638.

Wright, J. (2002). Online counselling: learning from writing therapy. British Journal of Guidance \& Counselling, 30(3), 285-298.

Xie, I. \& Joo, S. (2010). Transitions in search tactics during the web-based search process. Journal of the American Society for Information Science and Technology, 61(11), 2188-2205.

Yin, R.K. (2009). Case study research: design and methods. (4 ${ }^{\text {th }}$ Edition). Thousand Oaks, CA: Sage Publications.

Yu, C.W.M., \& Boulton-Lewis, G.M. (2008). Hong Kong secondary business teachers' conceptions of student competence and ways of teaching. Journal of Vocational Education and Training, 60(3), 257-272.

Yunus, M.M., Hashim, H., Embi, M.A., \& Lubis, M.A. (2010). The utilization of ICT in the teaching and learning of English: 'Tell Me More'. Procedia Social and Behavioral Sciences, 9(2010), 685-691.

Yusop, F.D., Sulaiman, H., \& Abdullah, S.S. (2008). Information Communication Technology (ICT) competencies for counsellors. Journal of Technology in Counselling, 5(1). Retrieved from http://jtc.columbusstate.edu/Vol5 1/Yusop.htm

Zahay, D., \& Fredricks, E. (2009). Podcasting to improve delivery of a projectbased internet marketing course. Marketing Education Review, 19(1), 57-63.

Zhang, L.J. (2008). Constructivist pedagogy in strategic reading instruction: exploring pathways to learner development in the English as a second language classroom. Instructional Science, 36(2), 89-116. 


\section{APPENDICES}

\section{Appendix I - Ethics Approval}

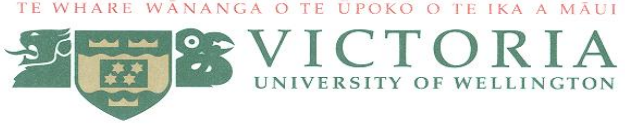

23 February 2009

Kerese Manueli

238 Major Drive

Kelson

Lower Hutt

Dear Kerese

RE: Ethics application TKM/2008/46, RM 6163

I am pleased to advise you that your ethics application 'Pasifika students in information Technology programmes: Retention and completion at Wellington regional polytechnics' with the requested amendments, has been approved by the Victoria University of Wellington College of Education Ethics Committee. Please note that the approval for your research to commence is from the date of this letter.

Good luck with your research.

Yours Sincerely

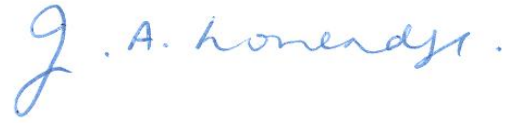

Dr Judith Loveridge

Co-Convener

Victoria University of Wellington College of Education Ethics Committee 


\author{
Introductory Letter to Polytechnics
}

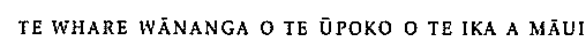

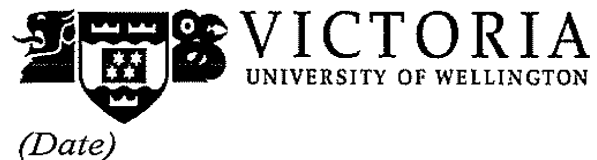

COLLEGE OF EDUCATION

(Date)

(........................

Dear Sir/Madam,

My name is Kerese Manueli and I am a PhD student at the Victoria University of Wellington's (VUW) School of Education. I am employed as an academic staff member at the Wellington Institute of Technology (WelTec).

This letter is to request your approval and support to carry out my $\mathrm{PhD}$ research to investigate factors that enhance/impede Pasifika students' performance in the IT course at polytechnics in the Wellington region.

Your permission is sought to contact Pasifika students enrolled in your IT programmes and to invite them to participate. Students' participation is voluntary. I plan to meet your Pacific students' co-ordinator who can identify Pasifika IT students. The students that $I$ am interested in are those enrolled in programme that are Level 5 or above.

The outcome of this study will offer a better understanding of Pasifika students' performance in IT courses in a polytechnic and the development of a framework for improving Pasifika IT successful completion of their studies. Students' responses will not be attributed to a particular polytechnic but will be towards all polytechnics in the Wellington region.

Ethics approval has been granted by the VUW College of Education Ethics Committee for this research. All data gathered (questionnaires, interview notes, etc.) will be kept in a locked cabinet and all electronic data will be kept in a password protected file and access will be restricted to the investigator. All questionnaires, interview notes and other materials will be destroyed at the conclusion of the research.

The research will be conducted in two phases: the first will be through a questionnaire (attached) and the second phase will involve interviews.

If you have any questions, please do not hesitate to contact me on 9202285 or email me kerese.manueli@,weltec.ac.nz. Alternatively, you can contact my research supervisors: Associate Professor Kabini Sanga on 463 6894; email kabini.sanga@vuw.ac.nz or Cherie Chu on cherie.chu@vuw.ac.nz

Vinaka vakalevu and I look forward to your assistance.

\title{
Kerese Manueli
}


(Date)

Bula vinaka (student's first name),

My name is Kerese Manueli and I am a $\mathrm{PhD}$ student at the Victoria University of Wellington's (VUW) School of Education. I am employed as an academic staff member at the Wellington Institute of Technology (WelTec).

This letter is an invitation for you to participate in a research project that $I$ am required to undertake. Ethics approval has been granted by the VUW College of Education Ethics Committee for this research. Please note that your participation is voluntary.

The purpose of the research is to investigate factors that enhance/impede your performance in the IT course that you have enrolled in. The outcome of this study will offer a better understanding of Pasifika students' performance in IT courses in polytechnics and the development of a framework for improving Pasifika IT successful completion of their studies.

The research will attempt to capture your views from the beginning till the completion of your course. It is envisaged that there will be 2 phases: the first will be through a questionnaire (attached) and the second phase will involve interviews. All recipients of this letter are invited to participate in the first phase. For the second phase, only some of you will be invited to be involved. There will be 2 interviews during the period of your studies and you will be informed well in advance.

Ethics approval has been granted by the VUW College of Education Ethics Committee for this research. All data gathered (questionnaires, interview notes, etc.) will be kept in a locked cabinet and all electronic data will be kept in a password protected file and access will be restricted to the investigator. All questionnaires, interview notes and other materials will be destroyed at the conclusion of the research. Data gathered from the interview will not be attributed to individual participants but rather to a chosen pseudonym and all data will be kept confidential to the researcher.

If you have any questions, please do not hesitate to contact me on 9202285 or email mekerese.manueli@weltec.ac.nz.

Alternatively, you can contact my research supervisors: Associate Professor Kabini Sanga on 4636894 or email kabini.sanga@vuw.ac.nz or Cherie Chu on cherie.chu@vuw.ac.nz

Vinaka vakalevu and I look forward to your assistance.

Kerese Manueli 


\section{Appendix III - Consent Form}

\section{Pasifika IT students' interview questions}

\section{CONSENT FORM}

Thank you for accepting the invitation to participate in the interviews.

Please read the following list; place a tick next to each item if you agree with it and sign on the space provided if you agree to participate in the interview:

$\square$ I have been given a thorough explanation and have understood the nature and objectives of this study.

$\square$ I have been given an opportunity to ask questions and am satisfied with the given answers.

$\square$ I am aware that as a participant, my name will remain confidential to the researcher and will not be disclosed but a pseudonym of my choice will be used to refer to my comments or contributions.

$\square$ I consent to the interview being audio taped and that the tape will be destroyed at the end of the research.

$\square$ I have the right to withdraw at any stage of the research, and all data that $I$ have supplied will be returned to me or be destroyed if requested.

$\square$ I understand that the interview data will be used by the researcher for the purpose of his $\mathrm{PhD}$ thesis and that may also be used for publications in journals and/or conference presentations.

Signature:

Date :

If you wish to receive a summary of the study, please supply an emailpostal address. 
Appendix IV - Participant Observation Template

Participant Observation Form

Date:

Time:

Venue:

Participants :

\begin{tabular}{|l|l|}
\hline Observations & Notes \\
\hline . & \\
\hline & \\
& \\
& \\
& \\
& \\
\end{tabular}


Appendix V - Template for Reflective Journal

Reflective Journal Template

Date:

Time:

Remarks: 